\title{
The beliefs and practices of Indonesian high-school \\ EFL teachers regarding the teaching and learning of culture and interculturality
}

\section{MUHAMMAD IWAN MUNANDAR}

A thesis submitted to Victoria University of Wellington in fulfilment of

the requirements for the degree of Doctor of Philosophy in Applied Linguistics

VICTORIA UNIVERSITY OF WELLINGTON

2019 
This page is intentionally left blank. 


\begin{abstract}
This study examined the pedagogic beliefs and practices of Indonesian teachers of English as a foreign language (EFL) regarding the teaching and learning of culture and interculturality in the local high-school English classrooms. I took an intercultural stance on language education and viewed language and culture as socially constructed practices that have fluid and negotiable boundaries and are interrelated in multiple and complex ways (Holliday, 2011, 2016; Kramsch, 1998; Liddicoat, 2002). An interculturally-oriented language education recognises an inextricable language-culture connection and links home $^{1}$ with target language-and-cultures (Byram, 1997; Kramsch, 1993; Liddicoat \& Scarino, 2013; Newton, Yates, Shearn, \& Nowitzki, 2010).

I conducted a qualitative case study to gain in-depth understandings of the phenomenon in question. I illuminate how the Indonesian EFL teachers addressed culture and interculturality in the EFL classrooms, what beliefs informed the teachers' instructional judgement and decisions, and what immediate and wider contextual factors shaped their understandings and presentations of culture and interculturality in the classrooms.

Five teachers working in general, vocational and Islamic high schools participated in this study. I made classroom observations, conducted stimulated recall and in-depth interviews, and administered narrative frames to glean the teachers' insights. I also used document analysis and students' focus group discussion to corroborate the teachers' practices and illuminate the situatedness of Indonesia's EFL pedagogy. Triangulations within the data set occurred throughout the iterative research process. In addition, I paid close attention to the sociolinguistic, cultural, educational, political and religious factors that were simultaneously at play and likely to impact on the teachers' beliefs and practices.

The cases of the EFL teachers reveal some significant evidence. First, the ways the teachers worked with culture and interculturality was to a certain extent influenced by Indonesia's policies on language, general education, and EFL pedagogy. The policies and underlying ideology shaped the teachers' beliefs and attitudes towards English and the NSs of English as well as towards values and behaviours associated with Western culture.
\end{abstract} Second, the teachers' conceptions of culture had an important bearing on how they

\footnotetext{
1 'Home languages' in the Indonesia's sociolinguistic setting can refer to both the national and local languages. The prominence of Indonesian as the sole national language allows for its widespread use in tandem with or in place of local vernaculars. The 'national' language may be localised and thus seen as 'local' depending on varied sociolinguistic contexts and purposes of communication.
} 
represented culture in the classrooms. The teachers" "large culture" (Holliday, 1999;

Holliday, Hide, \& Kullman, 2010) approach to culture and interculturality intersected with the expected role of the teachers and influenced their instructional decisions.

Third, despite the hegemonic State policies, the fact remains that the teachers demonstrated an active agency in dealing with the complexities of culture and interculturality. A variety of linguistic, cultural and political factors present in the immediate classroom and school contexts as well as in the wider socio-educational setting contributed to their agency. The teachers negotiated and mediated between home and target language-and-cultures. Fourth, the paths of EFL pedagogy and Islamic worldview ineluctably cross in predominantly-Muslim Indonesia. Both the teachers and learners came to terms with sometimes conflicting cultural beliefs and behaviours embodied in English and perceived to be incompatible with-or even threatening to-cultural values, meanings, and practices ingrained in the local societies.

In the light of the findings, I explore some wider pedagogic implications for various stakeholders in Indonesia's educational setting in particular and in other similar EFL contexts. An intercultural EFL pedagogy could and ought to go beyond equipping learners with a mere English skill to providing them with opportunities to develop critical openness, informed understanding, and constructive engagement with the "foreign, culturally different others". 


\section{Acknowledgement}

Alhamdulillahirabbil'alamin; praise is due to the Lord of the Universe. To me, not only is this $\mathrm{PhD}$ journey academically challenging, but also spiritually enriching.

Firstly, I should like to thank the Indonesia's Ministry of Research, Technology, and Higher Education for awarding me the BPPLN and Victoria University of Wellington for giving me the 4th-year and doctoral submission scholarship. Without the financial assistance, this thesis would never come to fruition.

I would like to extend profound gratitude to my supervisors Jonathan Newton and John Macalister for their unflagging commitment, insightful feedback, encouraging advice, and much-appreciated patience at every stage of this $\mathrm{PhD}$.

I should also like to gratefully acknowledge everyone at IKIP PGRI Jember, especially pak Andri for 'introducing' me to the institution; pak Arifin, pak Fadil, and pak Syamsul for providing ample opportunity for academic development; mbak Ria, Firna and Rina as well as $b u$ Erni and $b u$ Win for their administrative assistance during my time overseas.

I feel much indebted to all the participants who had generously shared their valuable experiences and insights. Unbeknown to themselves, they are the stars of this thesis.

Barry Lewis at the FGR as well as Janet, Matthew and Bernie at the LALS deserve special mention for their administrative support. Similarly, my appreciation goes to late Tony Quinn for his help with study resources.

Very special thanks go to pak Budi and $b u$ Wiwin, Ghifary and Syva, mbak Nunki and pak Bismo, Hadi and PPI Wellington as well as everyone at the Embassy of Indonesia (KBRI) and UMI for their help and kindness extended to me during $\mathrm{PhD}$ time.

I owe a deep debt of gratitude to my wife Koesriyana and children Dipa and Ozza for their patience, understanding, encouragement, and unfailing love. I dedicate this thesis to you! My heartfelt thanks go to Yang Ti Siti Komariyah. May Allah pour His rewards on you abundantly.

Above all, I can never thank enough my father Abdul Kohar Dihardjo and late mother Masmaimunah for their unconditional love, endless prayer, and unswerving support. You are a constant source of inspiration and I am proud to say I am following in your footsteps. May Allah pour out His mercy upon you. I am most grateful to the Mojokerto family for their support and encouragement. Blood is thicker than water. 
This page is intentionally left blank. 
Table of contents

Abstract

Acknowledgement

Table of contents

$\mathrm{V}$

List of figures

List of tables

List of abbreviations

viii

ix

ix

\section{Chapter I: Introduction}

1.1 Rationale

1.2 Interculturality: a self-account

1.3 Research questions

1.4 The significance of the study

1.5 Organisation of the thesis

1.6 Summary

\section{Chapter II: Literature Review}

2.1 Introduction

2.2 Language

2.2.1 Expanded view on language 12

2.3 Culture 16

2.3.1 Concepts of culture 17

2.3.2 Language-culture nexus 25

2.4 The theoretical framework of ILTL 28

2.4.1 Language, culture and learning $\quad 29$

2.4.2 Principles for ILTL 31

2.4.2.1 L1 in foreign language classrooms 37

2.4.2.2 Authenticity in EFL pedagogy 43

2.4.3 NNEST and interculturality 47

2.4.3.1 NNEST in Indonesia's EFL context 49

2.4.4 Teacher pedagogic belief $\quad 52$

2.4.5 NNEST belief about culture teaching $\quad 56$

2.5 Summary $\quad 60$

Chapter III: Research Methodology

3.1 Introduction 63

3.2 Research paradigm 63

3.3 Research strategy: qualitative case study 65

3.4 Data collection 69

3.4.1 Research participants $\quad 69$

3.4.2 Research setting $\quad 72$

3.4.2.1 Research site $\quad 72$

3.4.2.2 Language and education policies $\quad 74$

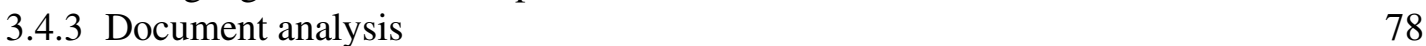

$\begin{array}{lr}3.4 .4 \text { Pilot study } & 80\end{array}$

$\begin{array}{ll}3.4 .5 \text { Classroom observation } & 81\end{array}$

3.4.6 Stimulated Recall 83 
$\begin{array}{ll}\text { 3.4.7 Narrative Frame } & 84\end{array}$

3.4.8 In-depth interview 86

3.4.9 Focus group discussion 88

3.5 Data analysis $\quad 89$

3.5.1 Transcription and translation 90

3.5.2 Framework and procedure $\quad 91$

3.6 Ethics and trustworthiness 97

3.6.1 Ethics 97

$\begin{array}{ll}3.6 .2 \text { Trustworthiness } & 98\end{array}$

$\begin{array}{ll}3.7 \text { Summary } & 99\end{array}$

Chapter IV: The EFL Teachers' Cases

4.1 Introduction 103

4.2 Ambar's case 104

4.2.1 Policy-oriented actions 105

4.2.2 Personalising classroom materials 110

4.2.3 Belief-practice gap 112

4.2.4 Recap and remarks on Ambar's case 114

4.3 Ana's case 117

4.3.1 Acting on policy 117

4.3.2 Teaching English, negotiating values 121

4.3.3 Authentic user $\quad 126$

$\begin{array}{ll}\text { 4.3.4 Recap and remarks on Ana's case } & 128\end{array}$

4.4 Aris' case 131

4.4.1 Setting EFL contextually 131

4.4.2 Instilling values implicitly 135

4.4.3 Recap and remarks on Aris' case 137

4.5 Wati's case 141

4.5.1 Authenticity is crucial 142

4.5.2 Native-speakerness does matter 144

4.5.3 English as a globalising tool 147

4.5.4 Recap and remarks on Wati's case 152

4.6 Yanti's case 155

4.6.1 Different Western culture 156

4.6.2 EFL teachers as cultural guards 158

4.6.3 Home cultures as classroom resources 161

4.6.4 NSs as resource persons 166

4.6.5 Recap and remarks on Yanti's case 167

4.7 Summary 171

\section{Chapter V: Cross-case Discussion}

5.1 Introduction 175

5.2 Teaching culture, enacting policy 175

5.3 Culture in the EFL classrooms 182

5.4 EFL teachers as intercultural mediators 193

5.5 EFL, Islam and interculturality 206

$\begin{array}{ll}5.6 \text { Summary } & 215\end{array}$ 


\section{Chapter VI: Conclusion}

6.1 Summary and concluding remarks 217

6.2 Areas for further research 222

Reference $\quad 227$

Appendix $1 \quad$ : Victoria University's Ethics Approval 244

Appendix 2 : Application for field-work permission from the Office of National 245 Education (DIKNAS)

Appendix 3 : Application for field-work permission from the Ministry of 246 Religious Affairs (KEMENAG)

Appendix $4 \quad$ : Application for field-work permission from the principal 247

Appendix 5 : Primary supervisor's support letter for DIKNAS permission $\quad 248$

Appendix $6 \quad$ : Primary supervisor's support letter for principal permission $\quad 249$

Appendix $7 \quad$ : Teacher information sheet (English) 250

Appendix 8 : Teacher information sheet (Indonesian) 251

Appendix 9 : Teacher consent form 252

Appendix 10 : Student information sheet (English) 253

Appendix 11 : Student information sheet (Indonesian) 254

Appendix 12 : Student consent form (English) 255

Appendix 13 : Student consent form (Indonesian) 256

Appendix 14 : DIKNAS field-work permission 257

Appendix 15 : KEMENAG field-work permission 258

Appendix 16 : Transcription confidentiality form $\quad 259$

$\begin{array}{lll}\text { Appendix } 17: \text { Translation confidentiality form } & 260\end{array}$

Appendix 18 : Observation protocol 261

Appendix 19 : Interview protocol 262

Appendix 20 : Narrative Frame (English) 265

Appendix 21 : Narrative Frame (Indonesian) 266

Appendix 22 : Interview transcript (Indonesian) 267 


\section{List of figures}

Figure $1 \quad$ : Iceberg of culture 18

$\begin{array}{lll}\text { Figure } 2 & \text { : A model of culture } & 19\end{array}$

Figure $3 \quad$ : Iterative processes of intercultural learning 33

Figure $4 \quad$ : Principles of iCLT 34

Figure 5 : Renewed principles of iCLT 41

Figure $6 \quad:$ An authenticity continuum 46

Figure $7 \quad:$ A framework of language teacher cognition $\quad 54$

$\begin{array}{lll}\text { Figure } 8 & \text { : Pendalungan on the world map } & 74\end{array}$

Figure $9 \quad$ : English NF 86

Figure $10 \quad$ : Indonesian NF 86

Figure 11 : GHS Jawa students stand up singing Indonesia Raya 107

$\begin{array}{lll}\text { Figure } 12 & 108\end{array}$

Figure $13 \quad$ : Ambar's English RPP 109

Figure $14 \quad$ : Ambar supervises students 110

Figure 15 : A vacancy with a Kathmandu's address 111

Figure 16 : An audio-visual passage on polar bears 112

$\begin{array}{lll}\text { Figure } 17 \quad \text { : Ana supervises students } & 120\end{array}$

$\begin{array}{lll}\text { Figure } 18 & \text { : A student performs a speaking task } & 123\end{array}$

$\begin{array}{lll}\text { Figure } 19 & \text { : Aris discusses students' work } & 133\end{array}$

Figure $20 \quad$ : Students in Aris' class complete tasks 137

Figure $21 \quad$ : Wati explains English news report 144

$\begin{array}{lll}\text { Figure } 22 & \text { : VHS Agri students watch a video featuring English NSs } & 147\end{array}$

Figure $23 \quad$ : VHS Agri students practice in pair 149

Figure $24 \quad$ : Wati's syllabus on descriptive text 150

Figure 25 : Wati's RPP 148

Figure 26 : Yanti writes on "making appointment and reservation by phone" 155

Figure $27 \quad$ : IHS Negeri students work in groups 161

Figure 28 : Male students practice making appointment by phone 163

Figure 29 : Female students practice making appointment by phone 164

$\begin{array}{lll}\text { Figure } 30 & \text { : Yanti's syllabus } & 165\end{array}$

Figure $31 \quad$ : Yanti's RPP/lesson plan 166

$\begin{array}{lll}\text { Figure } 32 & \text { : Students stand up singing patriotic songs } & 178\end{array}$

$\begin{array}{lll}\text { Figure } 33 & \text { : Aris' RPP } & 179\end{array}$

Figure 34 : Core competency in Wati's RPP 180

Figure $35 \quad$ : Ana explains phrases for complimenting 184

Figure $36 \quad$ : Yanti discusses expressions for making invitation 184

Figure 37 : Students in Aris' class perform task on "procedure text" 188

Figure 38 : Anglo-Link materials used in Yanti's class 198

Figure 39 : A video in Chinese shown in Ana's class 199

Figure 40 : Local and foreign foods shown in Wati's class 200

Figure $41 \quad$ : Students practice writing "procedure text" in Aris' class 200

Figure 42 : A video features English NSs in Ana's class 204

Figure 43 : Students watch a video featuring senior students 206 


\section{List of tables}

Table $1 \quad$ : Teacher participants $\quad 71$

Table $2 \quad$ : Student participants

Table $3 \quad$ : Classroom observation $\quad 83$

Table $4 \quad$ : Phases of thematic analysis $\quad 95$

Table 5 : Participants and data collection methods 104

\section{List of abbreviations}

$\begin{array}{ll}\text { BSNP } & \text { Badan Standar Nasional Pendidikan (National Education Standards Board) } \\ \text { ELT } & \text { English Language Teaching } \\ \text { EFL } & \text { English as a Foreign Language } \\ \text { EIL } & \text { English as an International Language } \\ \text { FGD } & \text { Focus Group Discussion } \\ \text { GHS } & \text { General High School (Sekolah Menengah Umum) } \\ \text { ICC } & \text { Intercultural Communicative Competence } \\ \text { iCLT } & \text { Intercultural Communicative Language Teaching } \\ \text { IHS } & \text { Islamic High School (Madrasah Aliyah) } \\ \text { ILTL } & \text { Intercultural Language Teaching and Learning } \\ \text { K13 } & \text { Kurikulum 2013 (2013 Curriculum) } \\ \text { KTSP } & \text { Kurikulum Tingkat Satuan Pendidikan (School-based Curriculum) } \\ \text { L1 } & \text { First language } \\ \text { L2 } & \text { Second language } \\ \text { MGMP } & \text { Musyawarah Guru Mata Pelajaran (Subject Teacher Forum) } \\ \text { MoEC } & \text { Ministry of Education and Culture (Kementerian Pendidikan dan } \\ & \text { Kebudayaan) } \\ \text { MoRA } & \text { Ministry of Religious Affairs (Kementerian Agama) } \\ \text { NEST } & \text { Native speaker English teacher } \\ \text { NNEST } & \text { NNEST } \\ \text { NF } & \text { Narrative Frame } \\ \text { NS } & \text { Native speaker [of English] } \\ \text { NNS } & \text { Non-native speaker [of English] } \\ \text { RPP } & \text { Rencana Pelaksanaan Pembelajaran (lesson plan) } \\ \text { SR } & \text { Stimulated Recall } \\ \text { VHS } & \text { Vocational High School (Sekolah Menengah Kejuruan) } \\ & \\ \end{array}$


This page is intentionally left blank. 


\section{Chapter I}

\section{Introduction}

\subsection{Rationale}

This study examines the pedagogic beliefs and practices of Indonesian EFL teachers in the local high-school English classrooms regarding the teaching and learning of culture and interculturality. In the classrooms, teachers have a key role in preparing learners to participate in culturally diverse societies (Kohler, 2015). These learners are typically familiar with the Internet and global social media, being engaged in their everyday lives with the multiplicity of codes, ways of meaning-making, and semiotic activities (Kramsch, 2014d). English teachers are perhaps faced with unique challenges and opportunities in view of the role of English as a world language and the use of English in varied local settings. In this respect, Widodo, Wood, and Gupta (2017) point to the need to design and implement English language teaching (ELT) that is socially grounded in local traditions in which people may have sociolinguistic norms perceived to be different from those of English-speaking countries.

In Indonesia, which is home to over 240 million people, 400 ethnic and cultural groups, and 700 living languages (BPS-Statistics, 2018; Simons \& Fennig, 2018), English is a de facto and de jure foreign language ("Constitution of Indonesia," 2016; Undang-Undang Republik Indonesia No. 24 Tahun 2009 tentang Bendera, Bahasa, dan Lambang Negara, serta Lagu Kebangsaan [Law No. 24/2009 on the National Flag, Language, Symbol, and Anthem], 2009). Law number 24/2009 ("Language law”) decrees that a "foreign language" is a 'language other than Indonesian and local vernaculars'. In this world's most populous Muslim nation, Indonesian serves as the sole national language and takes a pivotal role in constructing a national and cultural identity. As Quinn (2001) notes, what defines and unites Indonesia as a nation amid the extraordinary sociolinguistic diversity chiefly comes from its national language. For the vast majority of learners, there is no immediate need to use English in daily social interactions. These sociolinguistic and political factors create a backdrop against which the local EFL teachers address culture and interculturality in their EFL teaching practices.

EFL education in Indonesia formally starts at junior high school (Year 7). In senior high school (Year 10-12), EFL is aimed at developing in learners: 1) oral and written communication skills at the level of "informational" literacy; 2) awareness of the very fact and importance of the English language as part of Indonesia's efforts to improve its 
competitiveness at a global level; 3) understanding of the relationship between language and culture (Badan Standar Nasional Pendidikan, 2006). At the level of informational literacy, pupils are expected to have access to knowledge by means of their language skills. It is further stated that:

Setiap lulusan satuan pendidikan dasar dan menengah memiliki kompetensi pada tiga dimensi, yaitu sikap, pengetahuan, dan keterampilan. Lulusan ... SMA/MA/SMALB/Paket C memiliki kompetensi pada dimensi pengetahuan sebagai berikut. Dimensi pengetahuan: Memiliki pengetahuan faktual, konseptual, prosedural, dan metakognitif pada tingkat teknis, spesifik, detil, dan kompleks berkenaan dengan: 1. ilmu pengetahuan, 2. teknologi, 3. seni, 4. budaya, dan 5. humaniora. Mampu mengaitkan pengetahuan di atas dalam konteks diri sendiri, keluarga, sekolah, masyarakat dan lingkungan alam sekitar, bangsa, negara, serta kawasan regional dan internasional. (Kementerian Pendidikan dan Kebudayaan, 2016b) Every primary and secondary school graduate is required to develop competencies in three dimensions, that is attitude, knowledge, and skills. ... Concerning the knowledge dimension, secondary school graduates are expected to: Gain factual, conceptual, procedural, and metacognitive knowledge at a technical, specific, detailed, and complex level relative to: 1. science, 2. technology, 3. art, 4. culture, and 5. humanities. They should have the abilities to relate the acquired knowledge to personal, family, school, local community and environment, national as well as regional and international contexts. [my translation]

The national policies specifically mention culture, language-culture connections, and contexts in which learners may apply cultural knowledge and skills. Recognising the importance of culture is generally in line with the principles for intercultural language teaching and learning (ILTL). Broadly speaking, ILTL adopts an integrative approach to language and culture in language education. Language and culture are conceived of as inextricably intertwined in that language reflects cultural preoccupations, and understanding of the larger pragmatic context is essential for language learners to make sense of cultural meanings offered by language (Kramsch, 1998). For Kramsch (1993), cultural awareness should both enable and reflect language proficiency, and in language learning, culture 'is always in the background, right from day one' (p. 1) rather than an expandable fifth skill added to the teaching of speaking, listening, reading, and writing.

Language learners need to develop awareness of and sensitivity to their own and other culture(s) and skills to communicate in the target language in socially appropriate ways across different cultural contexts (Byram, 2012; Byram, Gribkova, \& Starkey, 2002). No longer is language skill alone or native speaker (NS) proficiency seen as a realistic goal of foreign language education (Moloney \& Harbon, 2010). In line with this view, language teachers need attend to the language-culture nexus from the beginning of the language learning processes not only to draw learners' attention to the connectedness of language 
and culture, but also to prevent uninformed cultural learning raising the risk of stereotyping and prejudice (Newton, 2016; Newton et al., 2010).

Sociolinguistic norms may further complicate how the cultural dimension is perceived. English is now spoken with a wider dispersion than any other language (Finegan, 2009), involving people from diverse national, linguistic and cultural backgrounds. It is increasingly used in non-Anglo-American cultural settings and de-linked from the socalled inner circle countries (Honna, 2005; McKay, 2003). The fact remains that English teachers are prone to fall into the trap of the "NS fallacy", assuming that a NS is the ideal teacher of English and that sociolinguistic values of the NSs should be the norm (Braine, 2013; Phillipson, 1992). In Indonesia's EFL classrooms, for instance, English continues to be viewed as a Western language and associated with the culture of English-speaking countries (Widodo, 2016; Zacharias, 2014b).

The pervasiveness of culture and the context-bound nature of pedagogic beliefs and practices, coupled with teachers' lived experiences of multilingualism and cultural diversity, can provide fertile ground for research into the teaching of culture and interculturality in Indonesia's high-school EFL classrooms. Among the recent studies into this area of which I am aware are ones conducted by Manara (2014), Gandana (2014), and Siregar (2016). Manara (2014) examined how Indonesian English teacher educators conceive of their profession and professional selves. Gandana (2014) investigated the ways English lecturers' beliefs and understandings of the English language, culture, interculturality and pedagogy intersect with classroom discourses and professional identity. Siregar (2016) looked into the challenges and opportunities for adopting an intercultural stance in university English classrooms. However, little has been done to show how Indonesian high-school EFL teachers approach and represent culture in the classrooms, what beliefs inform their instructional decisions, the correspondence between their beliefs and classroom teaching, or the extent to which the immediate and wider contexts influence their beliefs and practices.

Regardless of the different foci, what the above studies have in common are discussions on the cognitions and the agency of teachers. The issues raised concern teachers' beliefs, understandings or views about self, teaching approach, language, culture, professional learning, and identity construction. Teacher belief, which is commonly seen as a subset of cognitions, is a driving force behind instructional decisions teachers make (Kumaravadivelu, 2012). Teachers have cognitions about many aspects of their work that shape and are shaped by their actions (Borg, 2006). Teachers' professional knowledge and 
beliefs are in-context, in-content, and in-person (Kagan, 1992). That is, teachers' knowledge bases and beliefs structures are related to specific groups of student and academic materials to teach, and are embedded within their unique belief systems. Teacher beliefs can be deep-seated and difficult to change (Pajares, 1992; Phipps \& Borg, 2009).

In view of all that has been mentioned so far, this study seeks to explore the local EFL teachers' experiences of working-or otherwise-with culture and interculturality, what beliefs shape their practices, and the role that the contextual factors play in mediating the teachers' beliefs and classroom decisions. Echoing Burns' (1992) idea, the study was conducted in the hope of presenting a critical exploration of "what is" and "what might be" regarding the teaching of culture and interculturality as well as facilitating the examination, challenging and questioning of the teachers' pedagogic beliefs and behaviours.

\subsection{Interculturality: a self-account}

This study is a naturalistic inquiry and as such is influenced by the values of the researcher, the assumptions underlying the substantive theory and the methodological paradigm that guide the research, and the values that characterise the context in which the research is conducted (Lincoln \& Guba, 1985). In what follows, I briefly describe how I become personally interested and professionally involved in intercultural issues in the field of EFL. By describing personal and professional experiences, not only do I become aware of personal values and assumptions and spot potential biases, but I may also be able to reflect on and recount the multiple realities of local EFL teachers' personal and professional lives.

I was born to parents of different ethnic groups, i.e. Javanese and Malay, and have Javanese as a mother tongue. I grew up in a town in the province of Jawa Timur and Javanese society has most of the time been my immediate environment. In my formal education, I studied Javanese as a school subject until Year 9. Under these circumstances, I develop my ethnic, personal and social identity. I was exposed to Indonesian during my first years of education, and since then I have used it extensively, especially for educational and official purposes. Javanese and Indonesian then seem to take turns to serve as first language(s) as I achieve a 'native proficiency' in the two languages. Both languages have jointly forged my cultural and national identity in a dynamic and complex manner.

As a Javanese, I have since childhood been familiarised with speech levels of Javanese language, that is ngoko, madya and krama (low-, middle- and high-style). These stylistic variations are indicative of social status which is assessed by such a bewildering variety of factors as the nature of the social relationship between interlocutors, social distance or 
solidarity, age, wealth, descent, education or occupation (J. Holmes, 2013; G.

Poedjosoedarmo, 2006). When speaking Javanese, I am expected to make an appraisal of my social status relative to that of the addressee. Using proper speech style is an integral part of the Javanese politeness strategies and respectful behaviours towards others. In this sense, language is both personal and communal, and knowing a language means engaging in social practices by means of that system rather than merely knowing a linguistic system or communicating information (Liddicoat \& Scarino, 2013). The features also point to what Heryanto (2006) says is the inextricable connection between language and social life.

The majority of Javanese people are Muslim, and so are Indonesians. Java and Indonesia are bound up with each other. It is argued that 'Indonesia and Java are overlapping social, linguistic, cultural, conceptual and religious as well as geographic spaces and political entities. Indonesia has acquired, willingly or unwillingly, much from Java' (Woodward, 2011, p. 14). Being a Javanese and Muslim can thus be a source of personal and cultural biases. On a wider scope, societal norms can loom large in the implementation of the national education policy which shows traces of western values. Philosophical outlooks and cultural realities, especially those of the Javanese as the numerically and sociopolitically dominant ethnic group, leave their mark on teacherstudent interactions and are likely to hinder efforts to put western theories into practice (Dardjowidjojo, 2001; Kuswandono, Gandana, \& Rohani, 2015; Sugiharto, 2014). As Dardjowidjojo (2006) argues, local values that cherish obedience as a yardstick of good behaviour and at the same time discourage teachers from relinquishing their dominant roles have seemed to hamper the effectiveness of the student-centred and teacher-as-facilitator approaches in Indonesia's EFL classrooms.

Being brought up surrounded by other Javanese, I share their beliefs and behaviours. Entrenched Javanese and Indonesian ideals and attitudes have indelibly affected the way I learn and use an additional language, i.e. English. More often than not, when learning and using English in particular, I feel that I have to navigate through a different set of values ingrained in the languages. I started to study English in junior high school. Listening to English teaching programmes broadcast by a number of foreign radio stations, such as British Broadcasting Corporation (BBC), Australian Broadcasting Corporation (ABC), and Voice of America (VOA) was among my favourites during high school years. At that time, I thought learning English was about achieving a NS proficiency and listening to the stations was part of my learning strategies. I found this activity very useful, but I tended to overlook the fact that I could better understand explanations in English offered by 
Indonesian presenters than those given by English-speaking ones. It was perhaps because I felt 'familiar' with the 'non-native' pronunciation, accent or ways of thinking of the Indonesians although they were speaking English.

Then, in my undergraduate study, the personal interest in intercultural issues led me to take a course in "Cross-Cultural Understanding". If I recall correctly, the course was generally oriented towards gaining some greater understanding of the cultural values and behaviours of the NSs of English. An assumed situation of communication was more between native and non-native than among non-natives. After obtaining an undergraduate degree, my job was mostly as an English-Indonesian translator and copy writer. The positions required me to grapple with different language practices and shuttle between linguistic repertoire and embedded cultural values.

Later in the late 1990s, I made a career turn, became an academic and undertook further study for a Masters in an Australian university. It happened that in my study programme there were more NNS students than the NS ones. Again, I felt I had to navigate through values shared by the Javanese, Indonesian and other NNSs of English, and to also consider values held by fellow students from different nationalities and cultures. It was an eye-opener for me. This may suggest the idea that knowledge and awareness are multidirectional in the sense that 'knowing contributes to expanded awareness and awareness contributes to expanded knowing' (Liddicoat, 2011, pp. 838-839).

As an English language learner and an academic, I have faced up to the intercultural dimensions of ELT/EFL inside and outside the classroom in Indonesia and overseas. I often feel the need to make sense of the mental and social processes occurring in intercultural communication that involves the use of the local vernacular, the national language, and English. As Barnard and Burns (2012, p. 3) suggest, '[T]eaching and learning occur within certain physical and temporal boundaries, which will tend to affect the teacher's ability or willingness to act in accordance with his or her beliefs'. Therefore, in addition to making subjectivities visible and detecting personal biases, the personal history depicted above may capture the complexity of the person-, context- and time-bound experiences of Indonesian EFL teachers (Croker, 2009), and to a certain degree illustrate how social, cultural, and situational factors mediate between the pedagogic beliefs and classroom behaviours of the local teachers. 


\subsection{Research questions}

As a local EFL practitioner, I find Indonesia's cultural diversity and multilingualism inside and outside the English classrooms intriguing. Indonesian EFL teachers and learners have generally acquired a local vernacular or two (or more) plus Indonesian prior to studying English in the formal education. Issues relating to the role of home language-and-cultures in the teaching, learning and use of English in the Indonesia's particular socio-educational setting have occupied my curious mind. I was therefore keenly interested in looking into the Indonesian EFL teachers' beliefs about the teaching and learning of culture and interculturality in the local high-school EFL classrooms, what the EFL teachers' actual teaching practices are, and how a variety of linguistic, cultural, political and religious factors contribute to their judgement and decisions in the classrooms.

This study involved an exploration into the beliefs and practices regarding the construction and classroom representations of culture and interculturality of the Indonesian EFL teachers working in the local general, vocational, and Islamic high schools. The following questions formed the basis of this inquiry:

i. How do the Indonesian EFL teachers address culture and interculturality in their highschool EFL classroom practice?

ii. What beliefs inform the EFL teachers' observed classroom practice?

iii. What broader cultural and intercultural understandings and experiences do the EFL teachers identify as shaping their representations of culture and interculturality?

iv. In what ways do sociolinguistic, cultural, political and religious factors present in the immediate and wider socio-educational settings affect the EFL teachers' instructional judgment and decisions?

To that end, I observed the EFL teachers' classes to get first-hand experience of their intercultural representations. I distributed narrative frame (hereafter NF) questionnaire and conducted stimulated recall (SR) and in-depth interviews to delve into the teachers' pedagogic beliefs and their personal and professional experiences feeding into their classroom behaviours. Also, I analysed policy and classroom documents and carried out students' focus group discussion in order to identify broader and immediate contextual factors that affected the EFL teachers' beliefs as well as illuminating the situatedness of their judgments and decisions. 


\subsection{The significance of the study}

This study seeks to make the following theoretical, methodological and practical contributions to ELT in general and to strengthening of interculturally-oriented EFL in Indonesia:

i. It offers classroom-based evidence on what the Indonesian EFL teachers' pedagogic beliefs about culture and interculturality are, the extent to which these beliefs are evident in their classroom practice.

ii. It identifies linguistic, cultural, political, economic and religious factors present in the immediate and wider socio-educational settings that shape the teachers' instructional judgment and decisions;

iii. It highlights the benefits and feasibility of an intercultural EFL pedagogy within the context of Indonesia's sociolinguistic and cultural diversity;

iv. It provides information to help improve in-service EFL teachers' awareness of the importance of integrating culture into the teaching materials and practices and of mining the linguistic repertoire and cultural conceptions of both the EFL teachers and learners;

v. It may be used as a baseline to review and redefine the current objectives, curriculum and materials of EFL education in Indonesia and align them with the goals of intercultural language pedagogy;

vi. It provides policy makers and relevant educational stakeholders with an empirical basis for introducing interculturally-informed teacher education and continuing professional development programmes; and,

vii. It expands existing literature on an intercultural EFL pedagogy, especially with respect to the role of religious beliefs and identities as well as of the broader context of religion in teachers' understandings of and willingness to adopt an intercultural approach to EFL pedagogy.

\subsection{Organisation of the thesis}

This study is organized into six chapters. Chapter 1 introduces the thesis and Chapter 2 provides a review of existing literature on language, culture, language-culture connection and principles for ILTL which serve as the theoretical and analytical frameworks of the study. Concepts on and findings of studies into ESL/EFL teachers' beliefs and practices regarding culture teaching and learning, authenticity and native-speakerness are also examined here. Chapter 3 explains methods for data collection and analysis. This includes 
paradigmatic approach, research design, selection of participants, and procedures for gathering and interpreting data. Chapter 4 reports the case of each teacher participant. A recap on the individual cases highlights and key themes that emerged. Chapter 5 consists of a cross-case discussion arranged according to salient emerging themes within and across the data set. Chapter 6 presents summary and concluding remarks as well as areas for further research.

\subsection{Summary}

In chapter 1 , I offered a rationale for conducting the present study. This chapter briefly discusses the principles of ILTL that serve as my theoretical frameworks to explore Indonesian EFL teachers' pedagogic beliefs and practices regarding the teaching and learning of culture and interculturality in the local high-school EFL classrooms. I provided a broad overview of Indonesia's sociolinguistic and educational context within which the teachers' instructional judgments and decisions are situated. Multilingualism is the norm inside and outside the classrooms. This predominantly Muslim country has a population of more than 240 million, 400 cultural groups, and 700 living languages. I carried out this study by taking account of the complexity and pervasiveness of culture, the context-bound nature of the EFL teachers' beliefs and classroom practices, and a variety of factors that are present in the immediate and wider socio-educational setting feeding into the teachers' pedagogic beliefs and classroom behaviours. I gave a short description of personal and professional backgrounds that shape my values and assumptions and specified research goals, which further clarify my positionality. A number of potential contributions that the research report can make highlight the significance of the study. Also, I presented research problems that form the basis of this inquiry and a section on the thesis organisation that gives information about what to expect from each chapter. 
This page is intentionally left blank. 


\section{Chapter II \\ Literature review}

\subsection{Introduction}

This chapter sets out the theoretical underpinnings of the present study. Principles for intercultural language teaching and learning (ILTL) guided this inquiry. The central tenets concern ways of integrating language and culture in language education and of establishing links between home and target language-and-cultures. Teachers' knowledge of and beliefs about language, culture and the relationship between the two affect the their instructional decisions (Liddicoat \& Scarino, 2013; Scarino \& Liddicoat, 2009). As such, I present discussions on concepts of language, culture and the language-culture nexus in relation to the intercultural principles and particularly to what is important and relevant to the research purposes. Important issues here also relate to the role of first or home languageand-cultures and the notion of authenticity and native-speakerness in ELT and especially EFL pedagogy. In order to narrow the focus of this study, I discuss ideas and research on ESL/EFL teachers' pedagogic beliefs and classroom practices regarding the teaching and learning of culture and interculturality. Explicit references are made to the local EFL teachers in the context of Indonesia's EFL education.

\subsection{Language}

Language fills the spaces between us with sound; culture forges the human connection through them. Culture is in language, and language is loaded with culture.

Agar (1996, p. 28)

Agar (1996) posits that learning language is more than learning about grammar and the dictionary. Meanings that tie language inside the "circle" (emphasis in original)-grammar and dictionary-to the world outside go well beyond what it is in the grammar and the dictionary. Meanings that tell us who we are and how the world works are culture-laden and arbitrary, offering an almost infinite number of possibilities. Different meanings reflect different points of view and mentalities, that is the "natural" or "right" ways of seeing and doing things. These differences happen inside the same language as well as between different ones. For Agar, the circle some people draw around language-which makes it 
deceptively self-contained, fixed and closed-needs to be erased and ideas about "language" have to change.

Theories about language may not only be incorporated into language and education policies, but also imprinted on the minds of the teachers and enacted in language classrooms (Scarino \& Liddicoat, 2009). That is, what the teachers know and believe about language informs the ways they teach and how students learn about language. As Liddicoat and Scarino (2013, p. 11) assert, '[T]he theories of language that a teacher holds affect the process and practice of language teaching and what is understood as process in language development and the assessment of achievement'. Central to these understandings are that language teachers recognize the complex and multifaceted phenomena of language and language use, treat students as aspiring bi/multilinguals, and move from constraining and reductive constructs of language (Dailey-O'Cain \& Liebscher, 2009; Liddicoat, 2011). In this line of reasoning, in the following I discuss an 'expanded view' on language which embodies the basic principles for ILTL and thus undergirds this inquiry.

\subsubsection{Expanded view on language}

Liddicoat and Kohler (2012) contend that an intercultural endeavour begins with an enlarged theory of language dispelling the notion of unproblematic and unproblematised language-as-code. Views on language deal primarily with fundamental questions about the nature of language. In this study, language is seen from a wider perspective and detached from widespread and commonly held assumptions, where it is narrowly conceived of as a closed, finite and static entity. Rather, language is understood as 'open, dynamic, energetic, constantly evolving and personal' (Shohamy, 2006, p. 5). Sharing Agar's idea on a great many possibilities of meanings that language is likely to offer, Shohamy's conception of language underlines blurred and flexible boundaries of language as well as the hybrids, mixes, fusions and infinite varieties of language, whether it serves as a personal mental functioning and the expression of self or a context-bound social process of communication, adaptation, negotiation, and mediation. In Shohamy's (2006, p. 5) opinion, the fact that language is on both the personal and social planes results from its 'being creative, expressive, interactive, contact- and dialogue-based, debated, mediated and negotiated'. Moreover, according to Shohamy, present-day English can be a case in point given that the use of English as a world language has often crossed so-called fixed boundaries of language and constantly created new varieties, providing evidence of the fluidity and flexibility of languages. 
Generally speaking, language has been defined as either a structural system, a communicative system or a social practice (Liddicoat \& Scarino, 2013). First, that language is traditionally seen as a system of structures is, for instance, implied in the following definition, i.e. a set of shared symbols that a cultural group has mutually agreed to use to create meaning in which its relationship with the symbols is often arbitrary (Samovar, Porter \& McDaniel, 2009). That is, language is a code made up of symbols (vocabulary) that conveys uniform meanings among the speakers of the language and rules (grammar) that enable the speakers to manipulate the symbols in order to communicate (DeCapua \& Wintergerst, 2016).

However, if language is understood simply in terms of linguistic structure, it could well be that language is seen as fixed and finite. Language education will then emphasise memorising words and rules for constructing sentences. Teachers who consider language merely as code can be inclined to make acquiring grammar and vocabulary their primary goal (Liddicoat, Papademetre, Scarino, \& Kohler, 2003; Scarino \& Liddicoat, 2009). For Bennett (1997, p. 16), if language is perceived merely as a set of words and structures, this will not only make language learning a 'simple (but tedious) process of substituting words and rules to get the same meaning with a different tool', but also put learners at the risk of becoming "fluent fools". That is, they may speak a foreign language well but lack the knowledge of cultural values and beliefs intrinsic to that language necessary to interact in a contextually appropriate manner.

Second, language is conceived as a communicative system, which moves from taking language as structures to understanding its purposes. It is then important to realize the nature of communication and the role that language plays in communicative events. However, as Liddicoat and Scarino observe (2013), in linguistics and language education the issues tend to escape serious critical attention. Under the influence of the grammaroriented focus of modern linguistics, communication is often reduced to the use of combinations of linguistic structures to express the speaker's thought. Communication is seen as an unproblematic exchange of meanings through language, overlooking speaker's voice, constant negotiation and co-construction of meaning, and the enactment of self. In the word of Phipps and Gonzalez (2007, p. 2), seeing languages as "skills" or "technical adjuncts" defies principled reasons for making languages 'an intellectual discipline full of possibilities, a source of understandings and insights that can empower and enrich human life'. Echoing this view, Liddicoat and Scarino (2013) argue that under simplistic theories of communication, what is communicated and communicable in the language classroom is 
trivialized and the agency of the language learner as an active meaning-maker in communication can be marginalized, too.

What is needed is a more interactionally grounded concept of communication, which takes account of foreign language situations and intercultural interactions. In Jackson's (2014) view, attention should be drawn to the complex connection between language, culture and identities that serve as core elements in intercultural communication. Jackson adds that our sense of self, cultural socialization, and the language we use have a profound impact on how we position ourselves in the world and communicate with people from a different linguistic, cultural or religious background.

Third, language can be viewed as a social practice, which goes beyond the traditional boundaries of language as a structural or communicative system (Liddicoat \& Kohler, 2012). This approach largely concurs with the expanded view of language and conceptualises language as constitutive, symbolic, open, interactive, and communal. Language is constitutive of the whole human world, that is part of one's being and acting in the world (Liddicoat \& Scarino, 2013). The inseparability of language from the human world makes it personal. As Shohamy (2006, p. 5) puts it, language is so personal that 'the choice of words and forms of expression differ among individuals, as they are used in different ways by different individuals at different points in time, in different contexts and domains, and on different topics'. That is, language is a unique phenomenon of personal meaning-making by which individuals attach own values and meanings to describe realities and have a freedom of expression regarding choices they make, be it relating to word choices, structures, topics, or contents.

Language is symbolic as it represents something other than itself. For Kramsch (2009), language use holds symbolic power because it mediates our existence through symbolic forms that are conventional and represent objective realities, and symbolic forms construct our subjective realities. Exploring the symbolic power of language can make language education experiences more dynamic and engaging since language is not seen simply as a thing to be studied, but rather as a way of knowing and communicating about the world and participating in social life (Scarino \& Liddicoat, 2009).

As a manifestation of human's dialectic relationship with the ever-changing circumstances, language is open and constantly evolving. Languages change over time and reflect the dynamic process of human interaction resulting from contact among people, in relation to historical, political, and economic factors (Shohamy, 2006). Symbols and 
meanings are continuously and creatively created, used, and exchanged to make meaningful new connections and interactions.

Language is interactive and varies with context. Fantini (2012) claims that speakers specify their experience in varying ways according to whatever is of interest and importance to them. People categorise, segment and classify events and experiences into different structures and hierarchies. It is the variability within language and the diversity of context of language use that make language creative and a living expression of self (Shohamy, 2006). Knowledge of the variability and of the contexts in which language varies is constitutive of an individual's communicative repertoire which enables language users to encode not only linguistic meanings, but also social meanings and identities (Liddicoat \& Scarino, 2013).

In addition, language is communal in that it emerges from social interactions and becomes an integral part of cultural membership. Language use renders its speakers intelligible and acceptable to those around them, allowing membership of a culture (Fantini, 2012). Similarly, Kramsch (1998, p. 65-66) maintains that language is indispensable for a cultural membership and is important for political allegiances from which speakers 'draw personal strength and pride, as well as a sense of social importance and historical continuity from using the same language as the group they belong to'.

To conclude this section, an expanded view of language presents language as an integrated whole in that such a conception captures the very nature of language, i.e. constitutive, symbolic, open, interactive and communal, and to encompass the rich and dynamic complexities of language use in the act of communication (Liddicoat \& Kohler, 2012; Liddicoat \& Scarino, 2013). Understood in this way, language goes beyond merely a closed, fixed and finite structural code or a self-evident, unproblematic tool of communication. For Skutnabb-Kangas (1981), language can reflect the cultural knowledge and experiences of its speakers and become an overt manifestation of their ethnic, cultural, national or religious identities. All languages are of equal worth and valid for everything because they are equally capable of functioning as instruments for cognition and communication. Language too can be harnessed as a liberating vehicle for its speakers to learn about and express themselves, as well as constructing and exploring their worlds. The enlarged theory of language forms the theoretical basis of this study.

In the next section, I look at some basic concepts of culture as well as how it is generally defined and treated in the language classroom. 


\subsection{Culture}

As with language, what teachers think of culture can affect how they teach and the ways students learn language. Culture is, however, one of the notoriously slippery concepts to define, let alone to operationalize in the language classroom. Problems with defining culture seem to lie so much in making sense of its 'exact' nature. As Agar (1996) observes, people have known that culture is so basic and important, yet it is so elusive that no one can quite figure out what culture really is.

Culture has long been an object of academic study. In the 1950s, Kroeber and Kluckhohn (1952) reviewed more than 160 descriptions of culture and argued that cultural systems condition historically contingent ideas, values and actions of human groups as well as shaping their behaviours, achievements and products of action. More recently, Baldwin et al. (2006) examine over 300 definitions of culture from various disciplines, including education, anthropology, psychology, linguistics and political science. Baldwin et al.'s report highlighted how people's understandings of culture have changed considerably over time. Theorists bring their own perspectives to the definitions of culture and are unable to reach consensus on its basic qualities or structures. It is never easy, for example, to identify which element is in the centre or periphery of culture due to its subtlety, fluidity and variability.

In the broader field of intercultural communication, this study subscribes to Holliday, Hyde and Kullman's (2010, p. 2) view of culture, that is:

a fluid, creative social force which binds different groupings and aspects of behaviour in different ways, both constructing and constructed by people in a piecemeal fashion to produce myriad combinations and configurations.

Under a postmodern paradigm, culture is presented in a dynamic, non-essentialist way as a moveable concept with blurred and negotiable boundaries (Holliday, 2011, 2016; Liddicoat, 2002). Culture is deemed to be an uncertain, subjective, socially constructed entity, which is politically and ideologically charged. Culture is no longer described in relation to separate geographical blocks or national structures. Being a social force that is evident where it is significant, culture is bound up with values and can relate equally to social groups of any type or size for any period of time, and can be typified by a discourse as much as by a language. Cultures flow, mix together, change, cut across and through each other, irrespective of national territories and attributes. A dynamic, non-essentialist conception of culture then moves the language classrooms away from "large culture" framings that rigidly define culture in terms of a set of such externally-ascribed, large 
entities as ethnicity, nationality or international society (Holliday, 1999, 2009). Such a view of culture also avoids falling into an essentialist trap, that is, one which explains 'people's behaviour as the essence of their culture, and that all people from that culture will behave in that way' (Holliday, 2013, p. 172).

While struggling with the complex phenomenon and manifestation of culture and avoiding the simplicity of its conception, as Moran (2001) says, the challenge in the language classroom is twofold: first, finding simple approaches to the complexities and mysteries of culture; second, presenting notions of culture that are based on the realities and potential of the classroom. The following discussion on the concepts of culture is thus by no means devised to provide a definitive interpretation of culture, but rather to offer views that explore some fundamental assumptions of culture, especially as they may intertwine with language and communication in the context of language education and form a sound basis for developing an intercultural awareness and understanding.

\subsubsection{Concepts of culture}

Attempts to understand culture are often made by breaking it down into components and invoking metaphors. Kramsch (1998) approaches culture by working out its original meaning. Kramsch states that the word "culture" is derived from the Latin verb colere, which means "to cultivate" and denotes what has been grown and groomed. Kramsch contrasts culture with "nature", which h is from the Latin nascere, meaning "to be born" and signifying what is born and grows organically. For Kramsch, this illuminates the opinion that culture is 'always the result of human intervention in the biological processes of nature' (p. 10). Similarly, Liu, Volčič \& Gallois (2015) write that culture in its original meaning concerns a process of tending something and shares its etymology with such modern English words as agriculture, cultivate and colony. Its meaning is then extended to include ideas related to the human mind and a state of being "cultivated". Thus, as Kumaravadivelu (2008) notes, culture may be viewed more appropriately as a verb than a noun since it is more a process (what culture does) than a thing (what it is).

Moran (2001) uses the common iceberg metaphor to illustrate explicit and tacit cultural dimensions. Persons, practices, products and communities make up visible phenomena, and perspectives constitute the invisible one (Figure 1). In the cultural process, tangible products that persons as members of a given culture use in varied practices under given circumstances in some ways reflect their values, attitudes, and beliefs. In this view, members of the culture are believed to be in the constant process of actively creating and 
changing products, practices, perspectives and communities that are manifested in large, amorphous social units (e.g. national culture, race, religion, or socioeconomic class) and more narrowly defined groupings (e.g. political party, a charity organization, or family).

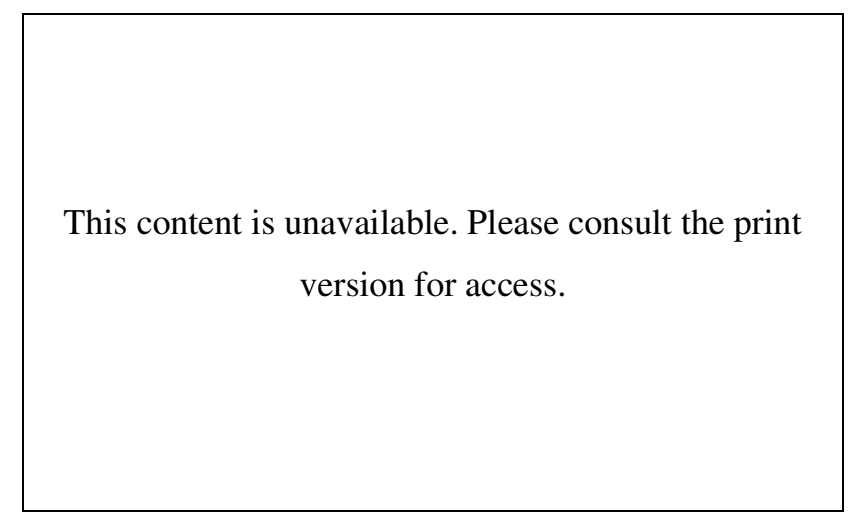

Figure 1: Iceberg of culture adapted from Moran (2001, p. 28)

Similarly, Dodd (1998) describes culture in terms of inner, intermediate and outer layers (Figure 2). History, identity, beliefs, values, and worldview make up the inner layer. These aspects are of cosmic significance and serve as a cultural window through which members of a culture perceive themselves, reality, and other people. The cultural manifestations fall into the intermediate level of culture that may include artistic expressions, social roles, rules, customs and communication patterns. Cultural beliefs inform how people undertake cultural activities, perform roles or have communication. Then, larger formalised systems such as religion, economy, politics, education, kinship, and healthcare constitute the outer cultural layer. These are, Dodd argues, the products of culture. All the religions a social group follows, the festivals people celebrate, the educational system, the political ideology, and the healthcare practices say something about the culture of a society or nation. 


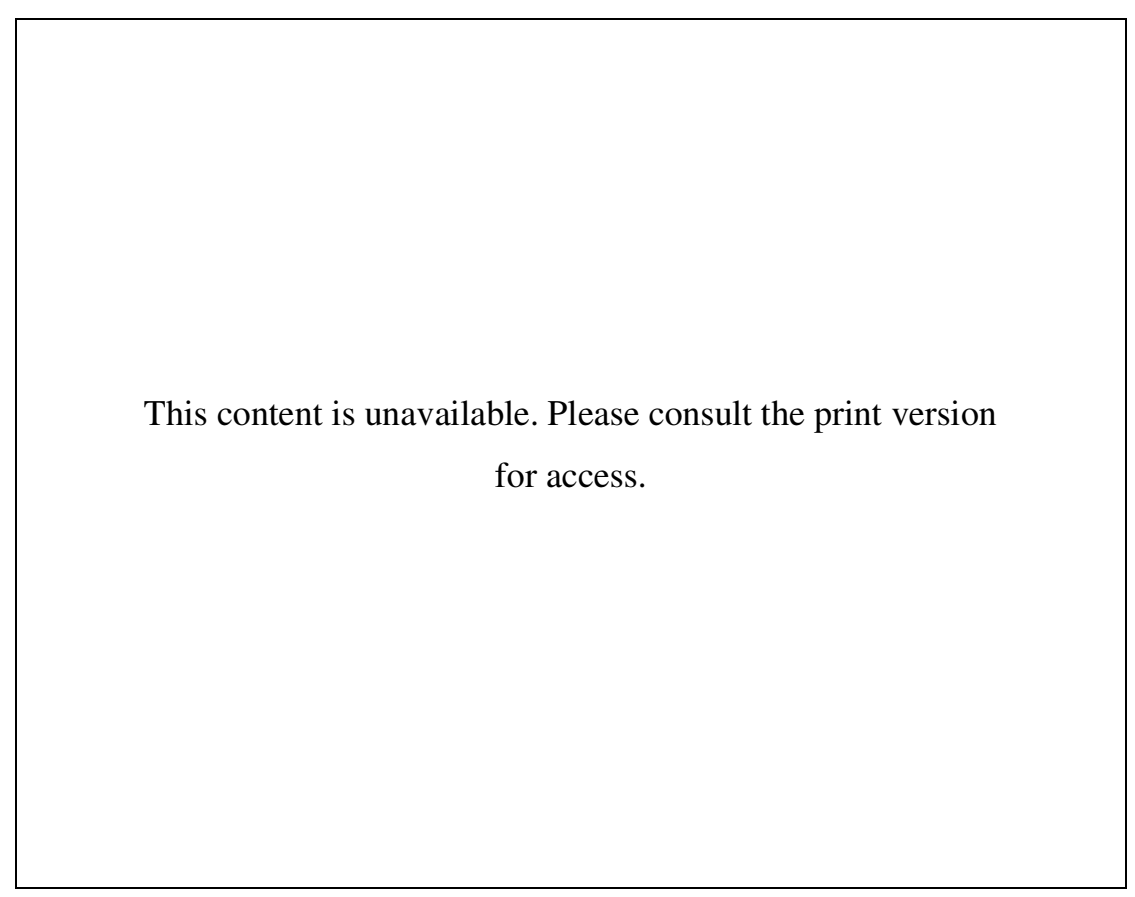

Figure 2: A model of culture adapted from Dodd (1998, p. 38)

The above models can be useful for describing cultural elements and manifestations as well as the permeation of culture through our everyday lives and interactions. However, using layers as a metaphor can risk presenting culture as having discrete units and clear-cut boundaries and overlooking the holistic nature of culture. It can be challenging to explore and explicate, for instance, how cultural values within the inner layer shape and are shaped by religious beliefs residing in the outer layer, and the extent to which religious values and identities may impact on communication. As an illustration of this, Kirkpatrick and Sussex (2012) note that the widespread adoption of In Shaa Allah (If God wills) by English speaking Muslims raises questions concerning its proper use by non-Muslims when talking to Muslims or how cultural accommodation and negotiation may take place when the communication is either between NSs and NNSs or between NNSs. The phrase is used in expressions referring to a future or hypothetical predicate as a recognition of the power of the Deity over human plans and their realizations. This might be radically different from the standard Anglo interpretation of the future in relation to conceptions like the Divine intervention in human intentions and free will (Sussex, 2012). In other words, the use of such a religiously-inspired term as In Shaa Allah may portray not only how fluid cultural 
components and how porous cultural boundaries-if any-can be, but also how influential religious or cultural beliefs are in shaping language use and meaning-making.

Like Dodd, Kramsch (2015) conceptualises culture in terms of layers, i.e. the social (synchronic), the historical (diachronic), and the imaginings. The social layer entertains two standpoints, i.e. "culture as membership" and "culture as standards". The former refers to the idea that members of a social group share one linguistic code and are bounded by social, historical and imagined realities; the latter suggests common collective ways of viewing the world, beliefs, attitudes and values that are both liberating and constraining. The historical dimension is constitutive of a society's cultural identity, allowing members of a social group to have a place in that society through shared history and traditions. The third layer is characterised by "common dreams, fulfilled and unfulfilled imaginings". Here, language plays an integral part in the creation of socially and historically situated discourse communities, that are to a large extent imagined communities, and their cultural realities and imaginings.

Apart from the definitions of culture, scholars have sought to identify its basic characteristics. Some of the salient features are that culture is learned, relative, shared, holistic, dynamic and fragmentary, as sketched in below:

i. Culture is learned

We define the world and learn how to create and give meanings throughout our life. In Jackson's (2014) view, we become accustomed to particular ways of thinking and doing as we grow and learn our first language(s). Children learn sociocultural content through language-mediated interactions, acquiring language and culture in an integrated process. This refers to enculturation by which members of a social group incorporate within the selves the conventions, values, motives, patterns of culture, etc. imposed by a social group through learning and socialization (Kramsch, 1998). Culture learning can be conscious or otherwise, but for Samovar et al. (2009) much of it is transmitted unconsciously through observation, interaction and imitation.

ii. Culture is relative

Since much of culture is acquired below the level of awareness, we are largely unaware of our own cultural perceptions. These may remain invisible until we encounter other ways of being. Culture is relative in the sense that only when a culture is made reference to another and cultural differences arise can it become apparent and really be understood (Jackson, 2014). That is, societal systems of value, ethical standards and social norms can only be judged when compared with other cultural 
systems and must be understood as inevitably related to their specific cultural context of historical development. In the language classroom, these draw attention to the need to make teachers' and students' evaluative responses to other cultures explicit and conscious so that they become aware of the culturally-determined beliefs and the basis for judgements about others (Byram et al., 2002).

iii. Culture is shared

People live as members of particular groups and group members share a set of values, ideas and patterns of behaviour that make them and their group's traditions distinct from other people and other traditions. This resonates with Jackson's (2014, p. 70) notion that culture 'involves membership in a community or group that shares a common history, traditions, norms and imaginings in a particular cultural space (e.g. a neighbourhood, region, virtual space)'. Sharing a common set of perceptions and behaviours enables members to identify with people who are like them and make their actions intelligible to other members (Haviland, Prins, Walrath \& McBride, 2005). Culture serves as a common denominator that allows its members to predict how other members are more likely to behave in a certain circumstance and to react accordingly.

iv. Culture is holistic

Rather than working separately as discrete units, various pieces of culture are related to each other and function as integrated systems. A set of beliefs about a specific cultural event is in some ways interconnected with values toward another event. Because all aspects of the event relate to one another, it may not make sense on its own and hence must be interpreted as an integral part of the whole system. There are no such things as fixed, clear-cut boundaries of culture. Instead, they are fluid, blurred and overlapping. A seemingly simple act might therefore make symbolic statements about what are valued in or important to a culture, offering a complex example of the holistic aspects of the culture (S. Liu, Volčič \& Gallois, 2015; Samovar et al., 2009).

v. Culture is dynamic

Culture is a never-ending 'process of reinvention' and change is inevitable (Ethington, cited in Samovar et al., 2009). The paradox may be that culture seeks to endure and give stability, but it is never static. Emphasising the dynamic and plural nature of culture, Kumaravadivelu (2008) notes that cultures are subject to change because they do not exist in a vacuum, allowing for contact with each other. Cultures thrive partly because of the connections they establish with one another. Cross-fertilization and interconnectedness are between components of the same culture and between cultures 
themselves. Cultural homogeneity is illusory since "no culture can exist in its purest form, every culture is, willy-nilly, a hybrid culture' (Kumaravadivelu, 2008, p. 12).

vi. Culture is fragmentary

That culture is about membership is not to say that all members of a culture possess similar cultural traits. How members perceive elements of culture, display cultural membership, or live up to cultural beliefs is fragmentary and subject to individual interpretation, which is necessarily subjective, personal and partial (Jackson, 2014). In other words, our understanding of norms, beliefs and behaviours associated with any cultural group to which we belong is never complete and at the same time always dependent on personal experience, breadth of cultural knowledge, and point of view. In this way, we will not lose sight of the reality of subcultural and individual differences in any culture (DeCapua \& Wintergerst, 2016).

In addition to the features of culture described above, a variety of definitions of culture have been offered by scholars in various fields. These definitions throw light on the fluidity, hybridity and variability of culture, pointing to its pervasive yet elusive quality. In applied linguistics and language education, how culture is understood draws largely on the conceptualisations in other disciplines, especially anthropology and sociology.

Nevertheless, the ways in which culture is operationalised in the language classroom have often been limited, and as such there is a need to develop more nuanced understandings of the nature of culture and of how the study of cultures can inform an intercultural language pedagogy (Liddicoat \& Scarino, 2013). Accordingly, Liddicoat and Scarino (2013) identify four ways in which culture has been conceptualised in language education:

i. Cultures as national attributes

Culture is understood in relation the particular attributes of a national group. Understandings of what constitutes a culture are framed in terms of labels derived from recognizable, often stereotypical, representations of national attributes. Cultures are presented as a closed and finished product that tends to overlook the internal diversity of any culture. In culture teaching, this view is closely related to treating cultures as high culture and area of study. What is common in these approaches is the idea that culture resides in the essentialized attributes located in a given territory. Culture thus seems to be more where it is found than what it is. 
ii. Cultures as societal norms

Culture is defined in terms of the norms, values and practices that characterize a given social group. These may concern with values placed on certain ways of speaking or behaving, level of politeness or appropriateness associated with some culturally favoured utterances or otherwise, etc. In the classroom context, this approach can be problematic because, first, the focus of understanding culture is likely to be placed on knowing about cultural values and practices rather than knowing how to engage with the culture, and second, cultures tend to be seen as homogeneous and static instead of varying with individuals and contexts (Liddicoat, 2002, 2011; Liddicoat \& Scarino, 2013). The ways people participate within cultures can vary according to a range of contexts and thus cultural possibilities that exists within a society.

iii. Cultures as systems of symbols Culture is thought of as 'the imposition of symbolic meaning upon reality' and is concerned with understandings of social practices in context (Sarangi, 2009). Seen as symbolic systems, cultures allow interactants to construct and share meanings and make it possible for a collective sense of experience to be communicated and interpreted as being meaningful. Thus, rather than merely giving learners exposure to information about a culture, culture learning can be more productively aimed at developing the interpretive resources necessary for understanding actions structured in symbols as contextualized, negotiated, and variable (Liddicoat \& Scarino, 2013).

iv. Cultures as practices

Culture is a dynamic set of practices which represent actions and understandings that are created and constantly co-constructed by individuals as they live their lives and engage in the process of dealing with the problems of social life (Liddicoat, 2002; Liddicoat \& Scarino, 2013). These practices create interpretive frameworks for people to make sense of and structure their social world as well as communicating with other people. Within this paradigm, culture is seen as situated, emergent, dynamic and highly variable whose elements are intermingled and boundaries are fluid. The situatedness of culture typifies the context-sensitive and dialectic nature of meaningmaking in which social behaviours, events, institutions or processes can be causally attributed and intelligibly described (Sarangi, 2009).

In the language classroom, culture teaching and learning with direct reference to national attributes or societal norms is likely to pose some risk of defining culture as something 
geographically-confined, invariable and unitary, and as such orientating learners towards acquiring information about a country and its 'culture', what 'appropriate' language is, what established or accepted social customs are, and so forth (Byram et al., 2002; Liddicoat, 2002). That is, cultural knowledge is equated with facts or artefacts and cultural competence is chiefly concerned with knowing and recalling information about the culture. Not only can information about one's own culture and that of other people be simplified and reductionist, but it can be stereotypical as well (Tomlinson \& Masuhara, 2004). It is thus important, as Liddicoat $(2002$, p. 7) underscores, that in language pedagogy a dynamic view of culture is adopted, that is, culture is seen as 'a set of practices in which people engage in order to live their lives'. People's way of living and their linguistic and nonlinguistic practices vary according to individual differences and particular cultural contexts. Viewed from this perspective, culture is not about things and static pieces of information, but rather about actions and understandings that are open to variation, mutually-informing and constantly-changing.

To sum up, the present study takes a non-essentialist, dynamic approach to culture. This view presents culture as a 'fluid, creative social force' that binds any type and any size of groupings-wherever there is cohesive behaviour-and their dynamic set of practices in different ways, constructing and constructed by members of the group in a piecemeal fashion, resulting in manifold dimensions and configurations (Holliday, 1999; Holliday et al., 2010; Liddicoat, 2002). Such a theoretical stance allows the language classroom to define and treat culture as socially-constructed, historically-contingent and politicallycharged human values, ideas and behaviours, bringing the pervasiveness, subtlety, fluidity, and variability of culture to the fore. Moreover, the conception of culture may grasp the realities and potential of language teaching and learning both inside and outside the classroom where cultures are believed not only to flow, intermingle and change, but also to permeate language and language use.

The nature of culture and how it may be addressed in the language classroom have been the subject of much debate. Equally problematic are issues concerning languageculture relationship. I will then explore such a connection in the following section. 


\subsubsection{Language-culture nexus}

Language is that proverbial two-edged sword-it arises from culture and, conversely, it influences and affects culture.

Fantini (2012, p. 264)

The language-culture connection is one of the main tenets of ILTL. Byram (1991, p. 18) posits that ' $[I] n$ engaging in language, speakers are enacting sociocultural phenomena; in acquiring language, children acquire culture'. For Kramsch (2013, p. 62), '[W]ithout language and other symbolic systems, the habits, beliefs, institutions, and monuments that we call culture would be just observable realities, not cultural phenomena'. Culture is semantically encoded in the linguistic sign and its use and language is constitutive of cultural perceptions, beliefs, and values (Kramsch, 2014a). Yet, the relation of language, thought and culture has long been a matter for intellectual speculation. The debate revolves around how or to what extent language influences human thought and cultural disposition, and is generally described in terms of "linguistic determinism" and "linguistic relativity".

Under the former term, it is believed that language determines human thought. The particular language people use filters how they perceive external realities, interpret events, and categorise experiences (S. Liu et al., 2015). This "linguistic determinism" theory has, however, frequently met with heavy criticism since it implies that we are prisoners of our language in the sense that we cannot think in a certain way because the language we speak prevents us from doing so (Ahearn, 2017; Kramsch, 1998). In Kramsch's view, we have our own culturally-shaped ways of interpreting events and specifying objects. We attach different meanings to the concepts underlying the words and structures. People's shared understandings are more largely attributed to common conceptual systems arising from the larger context of experiences than to structural equivalences. Also, that linguistic structures constrain one's perception of reality in an inescapable manner has been considered too strong a claim, one that could easily slip into prejudice and racism (Kramsch, 1998; Kumaravadivelu, 2008). It would be absurd to assume, for instance, that just because the particular language people speak, they could not have access to scientific knowledge.

Conversely, the "linguistic relativity" theory states that the relationship between language and thought is predispositional (Ahearn, 2017; DeCapua \& Wintergerst, 2016). It is held, Ahearn (2017) stresses, that language shapes our thought and predisposes us to think and behave with respect to it, but it does not prevent us from challenging our own thinking and predispositions. The relation of language, thought and culture is neither 
deterministic nor unidirectional. They influence one another in a flexible and mutually constitutive way. Similarly, DeCapua and Wintergerst (2016) emphasize that speakers of different languages may actually perceive the world differently as their perspectives are also different. Languages people speak oblige them to convey certain information in certain ways, which in turn develop particular "habits of the mind". Yet, the speakers are not necessarily inextricably bound by the confines of the language and the culture it represents. For example, some languages have lexical and syntactical choices that reflect the relationship between interactants and relative social position. However, that does not prevent speakers of the languages from recognizing and favouring egalitarianism and equality. On the other, speakers of languages lacking in such linguistic properties have various other ways to indicate rapport, respect other's position in social hierarchy, or convey differing levels of formality.

How language is in some ways interrelated to culture may be more readily apparent when language is conceived as a meaning-making system rather than simply as code and the symbolic power of language is highlighted (Agar, 1996; Fantini, 2012; Kramsch, 2009, 2013a). In Agar's (1996) opinion, words and sentences-that he calls 'language inside the circle' (emphasis in original)-are often not enough for communication. Communication can occur without grammar. It is the meaning that allows communication to happen. Not only does meaning tie parts of speech, the grammar and the dictionary to the world outside, but it also tells us who we are, whom we are dealing with, the kind of situation which we are in, how life works, and what is valued or deemed important in life.

Likewise, as Kramsch $(2009,2013 a)$ points out, how linguistic signs function as symbolic form is quite arbitrary but it is used in motivated or non-arbitrary ways. Language in contexts of communication is viewed as a coherent symbolic system for meaning-making. Symbol derives meaning from the force of social convention. Its symbolic power is created through the language user's engagement with and manipulation of various symbols of such concrete, material kinds as vowels, verbs, sounds and accents. Language use is symbolic not just because it mediates human existence through symbolic forms and refers to the representation of objective realities, but also because it constructs subjective realities such as perceptions, beliefs, values, emotions and aspirations.

Kramsch (1998, p. 3) explores three ways in which language is closely tied to culture, particularly in the context of communication. First, 'language expresses cultural reality' in that words are used to describe events or facts and to share ideas and experiences. Speakers' beliefs, attitudes and worldview are expressed through the actual use of the 
language. Second, 'language embodies cultural reality' in that the language that members of a culture use not only expresses a common experience but creates experience as well. People generate and give meanings to experiences through their use of language, whether it is spoken, written, or visual. Third, 'language symbolizes cultural reality' in that language has in itself cultural values with which speakers of the language identify their cultural identity and membership. Language is not a culture-free code that is separable from the way its users think and behave. The prohibition of language use can thus be taken by its speakers as a rejection of their group or culture.

How inseparable language from culture remains a moot point, too. Kumaravadivelu (2008) argues that language is to a certain extent linked to culture, but they are not irrevocably bound. Supporting the ideas on how valiant, nimble, and successful people are in dealing with language-and-communication problems, Kumaravadivelu cites the emergence, spread and functionality of Worlds Englishes as an example. That the Western language, i.e. English, is effectively and elegantly used in the creative literature written by non-English speaking authors proves that-if any proof is needed-it has become a powerful vehicle for expressing local sociocultural nuances that are alien to the Western societies. In other words, English is exploited, adapted, and manipulated in such a manner that it can be "detached" from supposedly entrenched cultural values and is at the same time creatively used to carry the weight of new cultural baggage.

Despite the extensively debated relationship, Kumaravadivelu (2008) adds, the language-culture connection has immense implications for language education in that students can have opportunities to learn about cultures that have informed their views of themselves and the world. It is important that they understand how culture underlies many different facets of life, that cultural differences exist, and how it feels to see and experience the world differently through actual language use. Likewise, Scarino and Liddicoat (2009) suggest that understanding the nature of the language-culture relationship is central to interculturally-oriented language classrooms. Key ideas are that, first, teachers and learners adopt a balanced view of language as code and as social practice; second, in actual language use the meaning of language forms is created and understood within a cultural framework; and third, the context of meaning-making relates to lived realities of both home and target language and culture. This approach will allow both teachers and learners to enrich their understandings of the ways in which cultural framework affects what is communicated, or what is not, and how. The language classrooms can also work towards a 
deeper awareness of how their own language-and-culture and that of the target society are simultaneously present in intercultural communication.

Elsewhere, Kramsch (2014b, p. 414) reminds language teachers who have to teach both the standard language and its variations in discourse as well as introducing culture, even in its stereotypical forms, that:

[T] he challenge is how to seize the moment to move students from the security of the stereotype to its exhilarating but risky variations, and how to engage them with the differences in world-views indexed by these variations.

In brief, the above discussion casts light on the debate on the language-culture connection. This study clings to the idea that language and culture are inevitably interrelated. Thus, the challenge that confronts the language classroom may lie in teasing out how language and language use are inseparable from culture as well as the extent to which first language-andculture influences the teaching, learning, acquisition, and use of additional one(s).

I have so far examined the notions of language, culture and the interrelationship between the two, which serve as the fundamentals of intercultural language pedagogy. In what follows, I will more fully discuss a theoretical framework for interculturally-oriented language teaching and learning, one that concerns the link between language, culture and learning, general principles for ILTL, the role of first language-and-culture in foreign language classrooms, and the concept of authenticity in EFL pedagogy.

\subsection{The theoretical framework of ILTL}

ILTL can be generally understood as overarching alternative ideas on the nature of language and culture and on how they may be best taught and learned (the approach), ways of teaching language-and-culture and interculturality (the method), and different kinds of classroom material and activity (the technique) to achieve intercultural goals (Liddicoat, 2011; J. C. Richards \& Schmidt, 2010). It is more a personal and professional stance than a set of teaching methods (Liddicoat \& Scarino, 2013; Newton et al., 2010). Metaphorically, teachers' stance, as Cochran-Smith (2003) notes, signifies teachers' orientational and positional ideas, the physical placing of the body as well as their intellectual activities and perspectives. It may capture the ways teachers stand and see and the complexity of teaching that occurs within webs of sociocultural, historical and political significance.

For Liddicoat (2011, p. 840), ILTL is best taken as 'a set of shared assumptions about the nature of language, culture, and learning that shapes an overall understanding of what it means to teach language and to do this in an intercultural way'. Liddicoat thinks of ILTL 
as theoretical orientations that frame pedagogic principles and choices to be adapted by language teachers to their location-specific situations. ILTL offers a broader perspective from which teachers construct knowledge and practices to fit into their socio-educational contexts. It can also be construed as an open, adaptive sensitizing construct, considering that an intercultural state is 'an unfinishable work in progress of action in response to new experiences and reflection of the action' (Liddicoat, 2011, p. 839). ILTL thus confronts us with context-boundedness, multidimensionality and dynamism of teaching and learning language-and-culture.

The core areas of ILTL, i.e. language, culture, and intercultural communication, are viewed through dynamic, non-essentialist lenses and conceived as open, interactive, and fundamentally-changing concepts with fluid and negotiable boundaries (Holliday, 2016; Liddicoat, 2002). Language teachers' understanding of the nature and impact of languageand-culture affect their instructional judgements and classroom decisions. Their views of language-and-culture are inherent in an intercultural orientation and have implications within and beyond classroom teaching (Bianco, Liddicoat, \& Crozet, 1999).

In the following section, I will expand on how language, culture and education are conceptualised from the perspective of intercultural pedagogy and ILTL principles.

\subsubsection{Language, culture and learning}

The main tenets of an interculturally-framed pedagogy are grounded in the belief that language, culture and education are interdependent at the theoretical and practical level (Liddicoat et al., 2003; Liddicoat \& Scarino, 2013; Scarino \& Liddicoat, 2009). Scarino and Liddicoat (2009, p. 25) stress that 'there is an important relationship between the two [theory and practice]: a good theory can be immensely practical, just as excellent practice informs theory-making'. Learning is seen as both a cognitive constructive (intrapersonally) and a socioculturally constructive process (interpersonally) of knowledge-construction. As a cognitive process, learning takes place within the individual and represents an internal process of interpreting, reorganizing, and restructuring information in the mind of the individual learner. As a socioculturally constructive process, learning is developed through and accomplished in the social process of interaction with more knowledgeable others. Individuals build up the knowledge structure that is congruent with the cultural system in which the individuals and learning are located. The wider social setting is constitutive of learning. Rather than being dichotomized, the mental and the social are seen as dialectical 
at the core in which the two domains affect each other and marked by a dynamic tension and interconnectedness between its parts and processes. In Lantolf's (2000, p. 79) words:

... human forms of mental activity arise in the interactions we enter into with other members of our culture and with the specific experiences we have with the artifacts produced by our ancestors and by our contemporaries. ... not only does our mental activity determine the nature of our social world, but this world of human relationships and artifacts also determines to a large extent how we regulate our mental processes.

Learning, then, is understood as 'socially constructed, mediated through language and other tools that are congruent with the culture in which the learner and learning are situated, and develops over time' (Scarino \& Liddicoat, 2009, p. 28). Within this view of learning, language is instrumental in mediating knowledge-creation. Learning occurs in social interactions within which language is the primary means that learners use to make and share meanings with themselves and with others and to negotiate social values and relationships. Language is essential to the process of creating and exchanging meanings. That is, language mediates the construction of knowledge and the development of the individual's framework of reference necessary for interpreting objects and experiences. In this sense, learning, language, meaning-making and thought processes are interdependent.

Liddicoat and Scarino $(2009,2013)$ maintain that learning occurs firstly on a social, interpersonal plane through the process of interaction and then on an individual, intrapersonal plane in which one makes the learning his/her own through internalization. Interaction, context, prior knowledge and linguistic background are seen as determining language learning and use and developmental outcomes. It is in and through social interactions that learning and cognitive development occur. Supportive interactions with more proficient others and assistance that is provided in various ways (scaffolding) mediate student's learning and achievement. Apart from becoming a source of input for the receiving learner, the social context that is negotiated and jointly constructed by the participants of interaction creates the condition for active meaning-making together with interlocutors who are more or less competent in terms of language.

The dynamic and developmental nature of language learning is primarily concerned with the mediation and realisation of pupil's learning potentials over time through scaffolding. This involves using a variety of instructional techniques, conceptual tools as well as material and linguistic resources and technologies with the aim of moving students toward a higher level of comprehension and greater independence in the learning process. As Liddicoat and Scarino (2013, p. 35) put it: 
... the act of learning a second language as an act of mutual interpretation and exchange of meanings in interaction, that is, that students learn what it means to interpret the world and others in the world and to be interpreted by others through the horizon of the linguistic and cultural system that is their own while gradually and increasingly coming to understand the linguist and cultural system that they are learning.

The notion of "development" suggests that learners develop language by adding new ways of making and negotiating meanings rather than acquiring something that is different from what they already have, as implied in the term "acquisition" (Mahboob \& Lin, 2016). What is also of central importance is preconceptions that students bring to learning as they engage with learning a new language and culture. New learning builds on prior knowledge that is already shaped by students' experiences of first language and culture. Learner's linguistic and cultural background can be seen as providing a prestructured position that foregrounds subsequent learning. Learning and using additional language then necessarily involves students comparing their own languages and cultures with those of the target language community and coming to understand how they themselves see the world through their distinctive linguistic and cultural frames of reference.

\subsubsection{Principles for ILTL}

ILTL views student's linguistic and cultural background from a positive light, that is as a pedagogic resource rather than an interference. Home and target language-and-culture are 'equally valid representations of human life' (Liddicoat, 2011, p. 843). Initial conceptions serve as the point from which students compare with other values and the bases around which they build own conceptual systems. Elsewhere, Buttjes (1991) explains that language acquisition is embedded in socialisation into first native culture and that language has from early childhood on played a crucial role in the development and transmission of sociocultural knowledge. However, later stages of formal language education generally see a shift from oral to literate representations of knowledge and from spoken to written discourse, presenting language as a decontextualized, abstract system of symbols. These notions overlook the sociocultural context of language use and learning and do justice to neither the formal language teaching nor the objectives of intercultural communication in foreign language education.

Scholars in applied linguistics arguing for an integration of learning, language and culture offer frameworks for language education from an intercultural perspective. Liddicoat et al. (2003) and Liddicoat and Scarino (2013) put forward five principles that can be preconditions for the design and implementation of ILTL as follows: 


\section{Active construction}

Learning evolves from purposefully and actively engaging in the construction and interpretation of meaning as well as from continuous reflection on oneselves and others in the act of communication. In language teaching and learning, students are afforded with opportunities to explore language and culture through active engagement and to develop a personal, intercultural space with different dimensions. Teachers need to support students in their efforts to understand the culturally-conditioned nature of human behaviours, to develop and explore personal ways of interpreting, and to recognize the cultural embeddedness of one's responses.

2. Constant connections

Learning occurs when students' prior knowledge is challenged and connections between their existing and new framework of knowledge are drawn. Students need to compare and build bridges between local and target language-and-cultures as well as between initial conceptions and new understandings. In this way, new insights can be gleaned which then allow students to reorganise and extend their existing knowledge and gain a fuller understanding of language, culture, values and their interrelationship. Teachers may draw upon the diversity of students, identify similarities and differences between the known and the new, and show how interrelationships between the similarities and differences can be established.

3. Social interaction

As learners engage with new conceptual systems and communicate across linguistic and cultural boundaries, they need to recognize the boundaries and work towards reciprocal relationships between their own linguistically and culturally contexted ways of interacting and other such ways. Understandings that social interaction is the overriding aim of language use and that participants of interaction con-construct and continuously negotiate meaning across variable perspectives may also imply that language classrooms should explore multiple beliefs, values and practices.

4. Conscious reflection

Learning involves becoming aware of what and how one thinks, knows and learns through conscious reflection. This process may emerge from reflecting critically and constructively about first and additional language, culture, learning, knowing, understanding and the interrelationship between these. A willingness to reflect on the difference and engage with diverse others is essential to the ability to decentre, that is to step out from one's own culturally constructed framework of understanding, value 
multiple interpretations, and see the world from alternate perspectives without students renouncing their primary culture (Byram et al., 2002; Liddicoat \& Scarino, 2013).

\section{Responsibility}

Learning is dependent on the attitudes, dispositions and values that learners hold and develop over time. Attempts to implement this ethical commitment not just require that learners take responsibility for their own process of learning and raise awareness of the ethical uses of knowledge. Rather, in the act of communication this is manifested in their readiness to accept responsibility for having certain ways of communicating and interacting with others within and across languages and cultures, continuously seeking a better understanding of self and others, and constantly developing an intercultural sensitivity and understanding.

How to put the five principles into practice and engage students with the intercultural inside and outside the classroom may consist in four interconnected processes, i.e. noticing, comparing, reflecting and interacting (Liddicoat, 2011; Liddicoat \& Scarino, 2013). As Figure 3 may suggest, the processes comprise a set of activities that are copresent and iterative. Noticing involves recognizing cultural similarities and differences embedded and made manifest in language. It is, however, not a naturally occurring phenomenon in the classroom. This can happen when teachers bring to the students the kinds of exposure they need and students examine new inputs in their own terms and gain a more comprehensive understanding of new experiences they have.

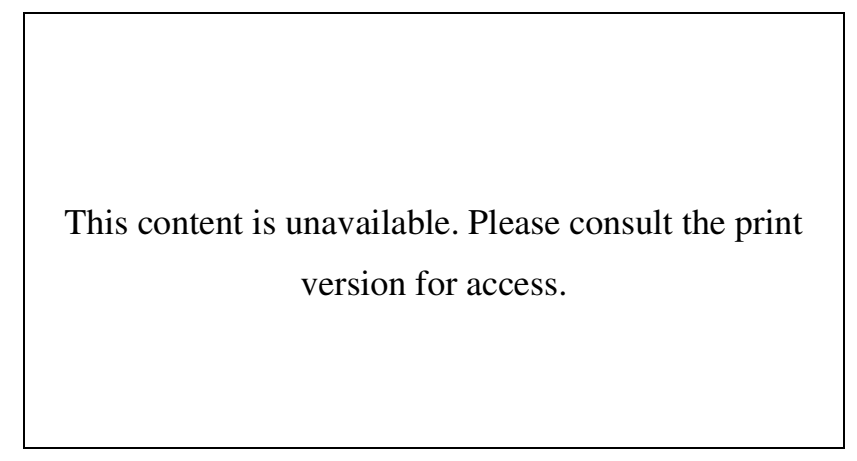

Figure 3: Iterative processes of intercultural learning (Liddicoat, 2011, p. 841)

What students notice lays the basis for other processes. The act of comparison enables students not only to identify cultural similarities and differences but also to compare between their background culture and the target culture as well as between what they 
already know and new inputs they have noticed. Reflection is seen as a process of interpreting experiences by which students make a personal sense of lived realities and construct an evolving understanding of what linguistic and cultural diversity mean for themselves. It is essential that students continuously think about the importance of what has been discovered and critically reflect on their thoughts about diversity and possible ways of engaging constructively with diversity.

Reflection ultimately relates to interaction because reflection cannot be done in a vacuum. It cannot be isolated from students' learning and experiences of diversity and personal meanings of such experiences that they create. Interculturality necessitates an active engagement with diversity rather than a passive knowing. Understood as experiences of language and culture, interactions in turn offer "renewed opportunities for noticing, comparing, and so on, and form part of an ongoing cycle of developing increasingly complex understandings" (Liddicoat \& Scarino, 2013, p. 61).

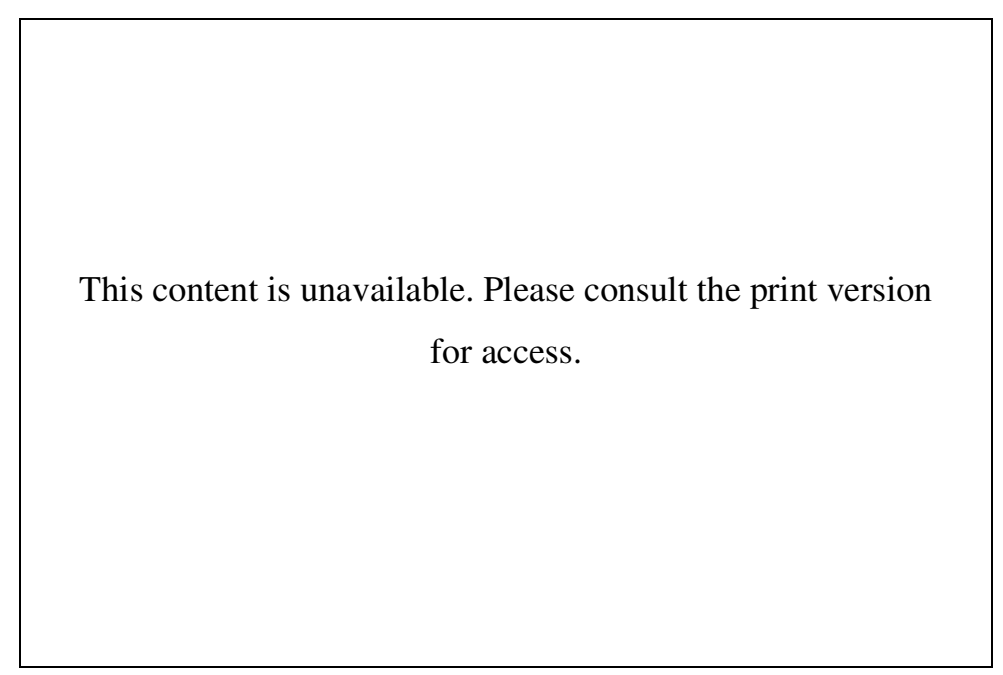

Figure 4: Principles of iCLT (Newton et al., 2010, p. 63)

In a similar vein, Newton et al. (2010, pp. 64-74) propose six principles for intercultural communicative language teaching and learning ("iCLT"):

1) integrates language and culture from the beginning;

2) engages learners in genuine social interaction;

3 ) encourages an exploratory and reflective approach to culture and culture-in-language;

4) fosters explicit comparisons and connections between languages and cultures;

5) acknowledges and responds appropriately to diverse learners and learning contexts;

6) emphasises intercultural communicative competence rather than NS competence. 
iCLT first and foremost views culture as dynamic and in a complex interplay with language. It entertains the notion of culture-in-language, that is language and culture interrelate. This stance implies that, among other things, language and culture are to be integrated into the teaching of language macro skills (listening, speaking, reading, writing) from early on, which may prevent from uninformed culture learning. Second, iCLT is aimed at involving students in genuine social interaction and providing them with experiential and interactive learning opportunities. Social interaction, either direct or mediated, should enable students to explore linguistic and cultural boundaries, confront own values so as to learn more about themselves, and delve into the cultural worlds of others. Third, iCLT advocates an exploratory, discovery-based approach to language and culture learning. The focus of learning needs to shift from transmission of "facts" or a static body of knowledge about culture to exploration of visible and less visible culture allowing students for a wealth of cultural experience.

Fourth, iCLT draws explicit comparisons and connections between languages and cultures. Guided open comparisons can yield useful insights into one's own and other people's culture and foster awareness of how cultures both connect and differ. Like Kramsch (1993), Newton et al. assert that these cultural comparisons and connections are oriented towards a "third place" or an intercultural position in which learners can negotiate differences, communicate effectively, and interact comfortably across cultures. Fifth, iCLT adopts culturally responsive and contextually appropriate practices. It values and embraces the diversity of students' sociocultural backgrounds and learning environments. Sixth, iCLT proposes that intercultural communicative competence (ICC) is a more realistic goal of second/foreign language learning than the NS competence.

Intercultural language classrooms, as Newton's iCLT framework indicates, seek to develop in language learners ICC, which principally refers to the abilities to use a foreign language and communicate across languages and cultures (Byram, 1997, 2009). Byram's highly influential, elaborated model of ICC moves away from the NS-based notion of communicative competence and gives greater emphasis on the pedagogic purposes of foreign language education. In order to face the challenges of communicating across linguistic and cultural boundaries, intercultural speakers serve as pedagogic models rather than the largely monolingual, monocultural NNSs.

As with Liddicoat and Scarino's model, what is immediately apparent in Newton et al.'s framework above is that it does not represent a linear progression in that one principle comes after and replaces the other. Rather, the principles are nested within which at each 
stage in development prior principles remain available and are mutually influencing (Liddicoat, 2011). This concurs with Byram et al.'s (2002) idea that multidirectional relationship and the iterative process suggest that the intercultural knowledge that students have or need to have is never complete and perfect. Teaching interculturally, Newton (2016) argues, requires no new method or approach. What is required from teachers is to build an explicit focus on interculturality into the classroom opportunities and communicative experiences available to students. Taking an intercultural stance allows teachers to approach factual cultural knowledge interculturally as it affects how and what they teach as well as what learning outcomes are valued. The stance may help classes gain insights from apparently simple language-such as forms of greeting, terms of address or expressions of politeness and respect-because early attention to culture and interculturality is encouraged (Newton et al., 2010). Likewise, Liddicoat (2011) highlights how an intercultural orientation may facilitate a transformational engagement of students in language learning. In an interculturally-oriented language education, culture will no longer remain external to students as their worldviews, identities and practices are confronted or transformed. The borders between self and others are explored, problematised and redrawn as students decentre from their existing cultural positionings and form an intercultural identity as a result of engagement with other languages and cultures.

In short, the intercultural can be a never completed process because people's social values and identities develop throughout their life. New ones are acquired as people become a member of new social groups. The values, beliefs, and identities they hold and represent are deeply embedded in one's self. Thus, however open, tolerant and flexible people wish to be, when they are faced with new experience or unexpected beliefs and behaviours, they might still feel shocked or disturbed. What is then essential is that the language classrooms become consciously and constantly aware of the need to respect, value, adjust, and understand other people as well as other languages and cultures.

As noted earlier, in an intercultural language pedagogy, learners' linguistic and cultural conceptions are put in a favourable light as learning and communicative resources. In what follows, I will discuss issues relating to the position of learners' first language in foreign language classrooms, especially in the Indonesia's EFL context. 


\subsubsection{L1 in foreign language classrooms}

Je te parle dans ta langue et c'est dans mon langage que je te comprends. I speak to you in your tongue, but it is in my language that I understand you.

Edouard Glissant (cited in Kramsch 1993, p. 177)

From an intercultural perspective, first language (L1) and practices serve as the foundations for raising learners' awareness of their own values and the resources for comparing and making connections with additional or target language-and-culture. Fantini (1997), for example, highlights how primary languages embody personal cultural experiences, shape people's communicative behaviour and actual language use, and permeate various aspects of their lives. As Fantini puts it:

Why is it then that we take language for granted, unaware that our native tongue is not merely "neutral" communication system, but a pervasive medium that directly influences every aspect of our lives? It may be because we seldom need to reflect on our use of language; it has been there for as long as we can remember. And therein lies the power of a different cultural experience (p. 8).

Nonetheless, mainstream second language acquisition (SLA) theories and practices have generally been in favour of exclusivity of the target language (Mahboob \& Lin, 2016; Moore, 2013). ELT classrooms, as Cenoz and Gorter (2013) note, are traditionally linked to instructional practices isolating English from other languages in learners' repertoire and the curriculum. These may stem from common yet tenuous arguments as follows:

i. Language is discrete and stable

Language is perceived as a stable, fixed and discrete entity with clear-cut boundaries which are detached from other languages, meaning-making systems, and modalities (Mahboob \& Lin, 2016). Static models of and boundaries between languages often lead to the prescription and standardization of linguistic systems and to the production of education resources. Not only does this position portray the static, reductive look at language, but it may also be circumscribed by the myth of native-speakership, the superiority of NS, and the imposition of unrealistic views of language correctness and monolingualism (Alptekin, 2002; McKay \& Brown, 2016; Shohamy, 2006).

ii. L2 teaching is best modelled on L1 acquisition

How monolingual children acquire L1 is often conceived as the only successful way of acquiring language (Cook, 2001). Children acquire their L1 in the absence of other language and they do not rely on another language to attain the NS competence. These conceptions have in turn generated ideas about the negative influence of existing language on additional language acquisition. Already acquired languages are believed 
to be a hindrance rather than an asset and hence should be minimized or even banned in foreign language classrooms (Phillipson, 1992).

iii. L1 and L2 are separate in L2 mind

Some hold that L1 and L2 form two distinct systems in the L2 user's mind and the success of L2 acquisition lies in making languages separate from one another (Cook, 2001). Cook emphasises that L2 meanings cannot exist separately from L1 as the two languages are interwoven in the learner's mind in several aspects: vocabulary, syntax, phonology, and pragmatics. Code-switching/mixing is typically mentioned as evidence for cognitive processes in which two or more languages are active and interconnected in L2 user's mind (Cook, 2001; Velasco \& García, 2014). Multilingual learners perform translanguaging to make meaning by drawing on whatever linguistic features from different languages at their disposal that are believed to work as a single linguistic resource (Creese \& Blackledge, 2015; Hornberger \& Link, 2012).

iv. The more exposure to target language, the better the results It is assumed that the more exposure to target language, the better the results that learners get (Phillipson, 1992). There is clearly a sense that the amount of exposure to target language inside and outside the language classroom is most important factor of success in L2 learning, which ends up with avoidance or prohibition of L1 use. Although seemingly commonsensical, the view that the length of time determines the success of L2 learning overlooks various contextual conditions that need to be fulfilled for the desired outcomes to appear. The erroneous ideas, Phillipson adds, fail to notice such essential aspects as better qualified teachers, well-written learning materials, and improved methods of teaching.

v. Use of other languages lowers standards of target language Popular beliefs hold that standards of target language are bound to drop if other languages are used much (Phillipson, 1992). Mahboob and Lin (2016, p. 30) argue that this zero-sum equation is derived from a belief that 'the limited cognitive processing capacity of the individual will be thinly spread over too many linguistic systems if more than one language is allowed into the classroom'. The tenet ignores the enormous human cognitive capacity for capitalizing on available linguistic resources such as by code-switching/mixing and translanguaging. At a wider level, Phillipson (1992) adds that such beliefs originate in a monolingual culture which contrasts with the realities of multilingual societies where the spread of literacy can lead to high levels of proficiency in more than one language. 
Multilingual speakers mix linguistic features of different languages or language varieties to serve various social and communication purposes. Kirkpatrick and Sussex (2012), for instance, observe that Asian multilingual users of English commonly code-mix English with local languages and use such a sociolinguistic act as both a creative strategy and an identity marker. In classroom interactions, multilingual teachers and learners often seek support from L1 in the L2 acquisition. As Cook (2001) states, this happens when teachers convey and check meaning, explain grammar, and organize the class. Personal contact with students can also be maintained through L1 use. L1 is a valuable part of student's collaborative and individual learning strategies. In Pendalungan, Indonesia where this study was conducted, for instance, students usually have an ability to speak at least a local vernacular (i.e. Javanese, Madurese or Osing) plus Indonesian before learning English. Those who attend Islamic schools learn and may have some knowledge of Arabic as well. Multilingualism is the norm. Code-switching or mixing is prevalent inside and outside the EFL classrooms.

Cahyani et al.'s (2016) study into the pedagogical and sociocultural functions of teacher and student code-switching in Indonesia's university bilingual classrooms can be a case in point. The findings show that the code-switching involved not only English and Indonesian but also Javanese in which each language demonstrated its own strategic roles in the context of the target language discourse. The teachers used English to give praise or reprimanded students, switched to Indonesian to reinforce students' understanding, and alternated with Javanese to make humorous comments. In general, teacher and student code-switching fit into four functional categories, i.e. knowledge construction, classroom management, interpersonal relations, and personal meanings. The study concluded that the local teachers intentionally shuttled between languages to construct and transfer knowledge, managed students' behaviour, and engaged in affective interactions. Student use of code-switching was concerned with interpersonal relations and sociocultural necessity and a way to polish their language.

Similarly, Macaro's (2009) study on the impact of teacher code-switching on vocabulary acquisition in EFL classrooms in China is based on the "optimal use" theory, that is 'codeswitching in broadly communicative classrooms can enhance second language acquisition and/or proficiency better than second language exclusivity' (p. 38). It explores the extent to which code-switches improved the comprehension of the meaning of potentially difficult words. There was no conclusive evidence that the code-switching led 
to a better comprehension than remaining in the L2. However, there was an increasing possibility that an exclusion of L1 from L2 classrooms may reduce the cognitive and metacognitive opportunities available to learners. Also, Moore's (2013) study focuses on contextual features and influences surrounding the emergence of L1 use in Japanese university EFL classrooms. It is found that variability in the amount or consistency of L1 production can be attributed to differences in students' English proficiency, task engagement, familiarity with interlocutor as well as task control and pedagogic roles within peer interactions. The above studies point to various sociolinguistic and pedagogic functions of the classroom code-switching, and particularly to the role of learner's first language(s) as a cognitive, learning and communicative resource.

Understood as a way of knowing and being in the world, first language plays a crucial role in making sense of additional language as well as new and likely different ideas and practices associated with it (Scarino \& Liddicoat, 2009; Skutnabb-Kangas, 1981). It could be argued that learner's first language is indispensable for understanding and forging links with additional languages. For Liddicoat and Scarino (2013), in the interpersonal process of mapping new information onto the existing knowledge framework, learners' prior knowledge is challenged and new insights are created. Students learn and extend their understanding by relating new knowledge and experiences to existing knowledge and prior experiences and what they have already known and familiar with, actively making connections between preconceptions and new understandings as well as between first language and additional ones. Also, for Liddicoat and Scarino, language and culture are fundamentally interconnected and equally play a part in learners' language repertoire and cultural lens. Existing linguistic and cultural background is especially important because learners can only take in new knowledge when it is connected to knowledge structures which have been shaped by their experiences of the first language-and-culture.

In that regard, in the field of ELT, Newton's (2016) re-visioned model of iCLT (Figure 5) expressly pinpoints the need to respond favourably to the socio-educational diversity of the language classroom and to use effectively learners' primary linguistic and cultural conceptions as pedagogic resources. iCLT is conceived of as a socially-sensitive, culturally-responsive pedagogy oriented towards making the most of the linguistic and cultural diversity inside and outside the classroom. This idea highlights the situatedness of classroom events and interactions as well as instructional judgment and decisions. Interculturally-informed English classrooms thus strategically draw upon home knowledge, languages and practices, as these may especially relate to target language-and- 
culture, and at the same time are mindful of the cultural beliefs, values and identities of the teachers and learners.

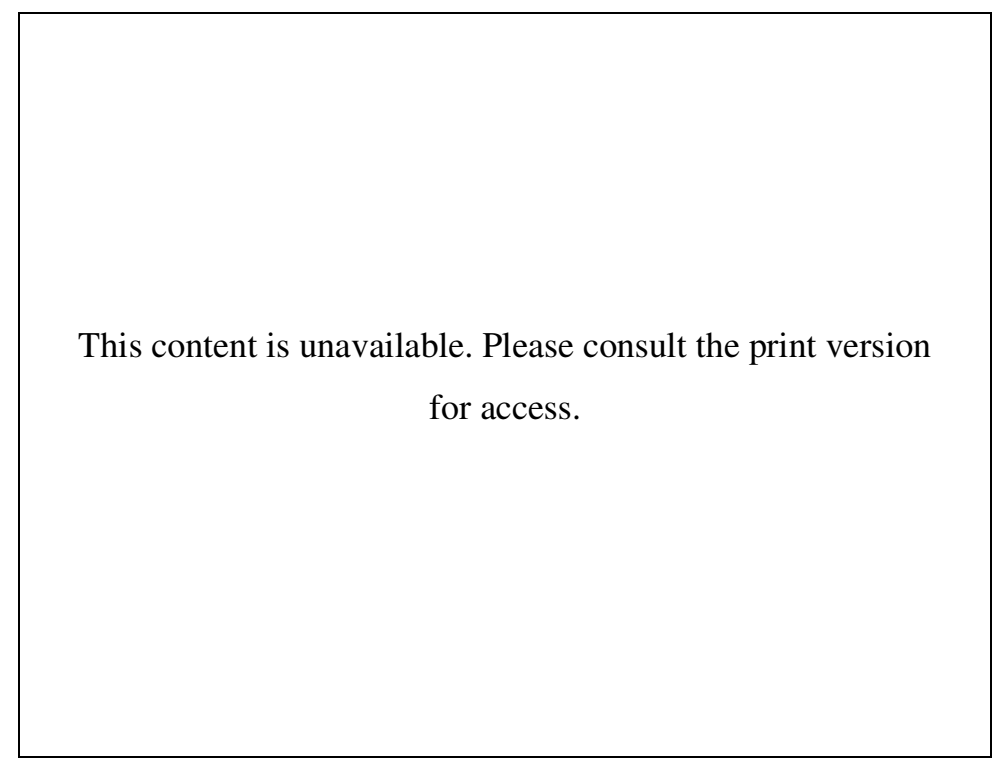

Figure 5: Renewed principles of iCLT (adapted from Newton, 2016)

While recognising the linguistic and cultural knowledge, meanings and experiences that the teachers and learners bring into the classrooms as cognitive and communicative resources, Newton's construct of iCLT pays special attention to the variety of world Englishes. Present-day English is deemed to be a global lingua franca delinked from particular English-speaking countries and the sociolinguistic norms of the NSs of English (McKay, 2012; McKay \& Brown, 2016). A greater understanding of the varieties of English and of the diverse national, linguistic and cultural backgrounds of today's English learners and users may provide a natural link to an adoption of an intercultural approach to the teaching and learning of English.

Intercultural language pedagogy challenges the NS-based notions of learner progress and proficiency, and instead models learners on intercultural speakers rather than 'NSs' and works towards developing in learners ICC in preference of "native-speaker competence'. Moreover, the iCLT model underlines the idea that the development of learners' ICC is an iterative, multidimensional process (Byram et al., 2002; Liddicoat, 2011) and that culture teaching and learning is a lifelong pursuit (Damen, 2003). That is, the intercultural values, understandings and competencies that learners develop in 
interculturally-oriented English classrooms shape and are shaped by what they put into practice beyond the classrooms in interculturally-framed ways.

In the light of the multilingualism and internal cultural diversity of Indonesia, Newton's renewed principles of iCLT described above were used in this study as an a priori framework to capture and evaluate general reference to cultural norms made by the multilingual EFL teachers and learners as well as instances of culture in and around host and target languages. The existing linguistic repertoire and cultural conceptions of the teachers and learners provides a starting point for making sense of new ideas and practices that come with English and for building their own conceptual systems. It is therefore likely, if not inevitable, that local EFL teachers and learners are harnessing their familiarity with linguistic features, cultural meanings or religious significance that come with Indonesian, Javanese, Madurese and/or Arabic during the classroom events and interactions.

The iCLT principles also served as a theoretical lens through which I discerned the EFL teachers' engagement or otherwise with culture in their classroom practices. In theory, following these principles, the EFL teachers should be guiding learners' conceptions of culture and bringing the language-culture nexus into explicit focus during their teaching practice from the beginning of the language instruction. EFL classroom materials and activities should not only allow learners to develop fluency in the target language, but also give them opportunities to explore linguistic and cultural boundaries, confront their own cultural assumptions so as to learn more about themselves, and navigate through the cultural worlds, attitudes, behaviours, norms, and values of culturally different others.

I have now discussed the role of L1 in the foreign language and particularly EFL education as well as the conceptual frameworks to identify how L1 is drawn on in the teaching and learning process. Isolation or avoidance of L1 use in the foreign language classroom is often linked with an exclusivity of the target language and NS's sociolinguistic norms, overlooking the cognitive, communicative and pedagogic potential of primary language-and-cultures of both the teachers and learners. In this respect, the NSbased concept of authenticity has been fraught with problems, too. The position of English as a foreign or international language may further complicate the classroom application of authenticity. Hence, I will next discuss issues concerning authenticity in EFL pedagogy. 


\subsubsection{Authenticity in EFL pedagogy}

In ELT, authenticity is a thorny issue due in part to its link to native speakerness. For Byram (1997), the use of NS as pedagogic model not only ignores the social identities and cultural competence of the learner in any intercultural interaction as well as different socioeducational conditions under which NSs and learners acquire and learn a language, but also presents learners with an unrealistic target and leads to inevitable failure. Likewise, Alptekin (2002) writes that NS-based authenticity is restrictive to both learner and teacher and circumscribes their autonomy since 'real' language use for NSs is not likely to be real for NNSs and because language teaching becomes inseparable from teaching NS culture, at the risk of marginalizing student's native language and culture. Alptekin adds that the ideal NS-listener is a nonexistent abstraction and that it is more or less about a proficient user of language. This can be more perplexing when it is concerned with such a global lingua franca as English. As a language of wider communication, English is now used by more NNSs than NSs in increasingly NNS-NNS interactions. In many of these situations, Anglo-American sociolinguistic norms may no longer be relevant.

According to Liddicoat and Scarino (2013), authenticity is especially important when language is seen as representing genuine instances of culture and language education as the negotiation of language-and-culture relationship. In the EFL context, it cannot be assumed that English is a social or living language. Its use in the wider society is often practically limited. EFL learners will also have developed some linguistic competence and cultural frames of reference prior to learning English. That authenticity remains contentious is partly because of its association with "native-speakerism". Holliday (2006, p. 385) stresses that native-speakerism is a pervasive ideology in ELT that is "characterized by the belief that "native-speaker" teachers represent a "Western culture" from which spring the ideals both of the English language and of English language teaching methodology'. ELT can be unavoidably problematic when the genuineness of pedagogic resources, classroom activities or teacher's autonomy is benchmarked against "real" communicative behaviours of the NSs (Badger \& MacDonald, 2010; Gilmore, 2007).

Richards and Schmidt (2010, p. 41-42) define "authentic materials" as ones originating from magazines, newspapers, speeches in radio or television, etc., which 'have been taken from real-world sources' and 'were not originally developed for pedagogical purposes'. Initially, authenticity had to do with the instructional text but it is expanded to relate to student, task and classroom context (Buendgens-Kosten, 2013; MacDonald, Badger, \& Dasli, 2009). It is also linked to teacher legitimacy. And yet, that the main criterion of 
authenticity is whether teaching materials are used in non-pedagogic natural communication so as to represent "real" communication between NSs brings the issues of the identity and authority of the NS into question. Kramsch (1998) argues that some may be under the impression that there are people who speak only a standardised native tongue and live by one national culture, whereas in reality most people partake of various languages or language varieties and hold memberships in different cultures and subcultures. The many combinations of language use and cultural membership, the dynamics of social roles, and different contextual factors are evidence of the communicative patterns of the NSs inevitably vary. What may be regarded as representative, real or authentic usages of the NSs are neither single nor static.

Today, the vast extent of English use on a global scale may mean that the language can no longer be seen as a property of a certain culture or speech community and that in places where no NS may be present the sociolinguistic norms of the NS are of limited relevance (Baker, 2009; Widdowson, 1994). The number of NNSs of English is three to four times higher than the NS, and the ratio tends to keep increasing due to the ongoing international prominence of English (Crystal, 2003, 2008; Graddol, 1999). Communication between the NNSs exceeds that between the NSs and NNSs. For McKay (2002), EIL is typically characterised by the current users of English, the changes resulting from its global spread, and the cultural basis of EIL. English is now used in more NNS-NNS interactions taking place in multilingual contexts than in NS-NNS exchanges in English-speaking countries (McKay \& Bokhorst-Heng, 2008). In this respect, McKay and Brown (2016) and McKay (2018) emphasize that the use and the teaching and learning of EIL needs to be "culturally neutral" on the grounds that English is not associated with a particular sociocultural context in the same way that some other languages such as French, Japanese or Korean are linked to a certain culture.

The global spread of English has also allowed for many a new non-native variety of English that brings with it different sociolinguistic standards or norms. Different cultural contexts for the use of English lead to different sociolinguistic standards or norms for the use of the language (McKay, 2012). As Graddol (1997, p. 6) predicted 22 years ago, English 'will continue to evolve, reflecting and constructing the changing roles and identities of its speakers'.

Scholars have revisited the concept of authenticity against a backdrop of the everchanging social and learning environments. Kramsch $(1993,1998)$ considers the following factors in reconceptualising (in)authenticity: 


\section{i. Diverse authenticity}

Within any given society, authenticity naturally varies and depends on such a wide variety of contextual variables as age, gender, race, ethnicity, occupation, social status, etc. What is deemed authentic in one context can be inauthentic in another.

ii. Relational authenticity Authenticity does not reside in the text but as a quality assigned to it, created by the response of the text receiver and the interaction between the receiver and the text which incorporates the intentions of the text producer.

iii. Stereotyped appropriateness

Language learners often have a desire to think or behave like speakers of the language in order to be recognized and validated by them. Plagiarizing behavioural patterns of others is 'no guarantee that one will be more easily accepted by the group who speaks the language, nor that mutual understanding will emerge' (Kramsch, 1993, p. 181).

iv. Appropriated selves

An appropriation of authentic selves as learners lies in the learners' effort to redefine texts against their own priorities, precisely because they are learners, as well as in the ability 'to make a foreign language and culture their own by adopting and adapting it to their own needs and interests' (Kramsch, 1998).

In more recent works, Pinner (2016b, 2016a) explores the notion of authenticity of English as a global language, arguing that it matters not only to the process of language education but also to learners as individuals and their position within society. Authenticity is defined as 'a complex dynamic construct that can only be understood by examining it from social, individual and contextual dimensions, in relation to actual people' (Pinner, 2016a, p. 4). This concept seeks to fit in with today's era of super-diversity when cultures are in constant interaction and it is difficult to pinpoint where one language or culture ends and another begins, with the English language becoming a binding agent for many crosscultural exchanges. A renewed understanding of authenticity needs to be sensitive and more inclusive to the diversity of English varieties and the majority stakeholders of English for whom it is taught and learned as a "disembodied" foreign language (Lowe \& Pinner, 2016; Pinner, 2016b).

As Figure 6 shows, overlapping circulating arrows are meant to suggest dynamic changes in the nature of authenticity and stress that it is more an interrelated, multidimensional process than a fixed state. The horizontal axis represents the social dimension 
of authenticity: at one end, individual learners/teachers and their educational needs, linguistic ability, and personal motivation to learn/teach; at the other end, the target language use community. The individual dimension is a recognition of the importance of Self and of other important factors such as identity, affect and agency. The community represents what Anderson (1998) calls imagined communities. These might be a community within an L1 country, an international community where English is used in intercultural communication, or a workplace where it is spoken in multilingual contexts.

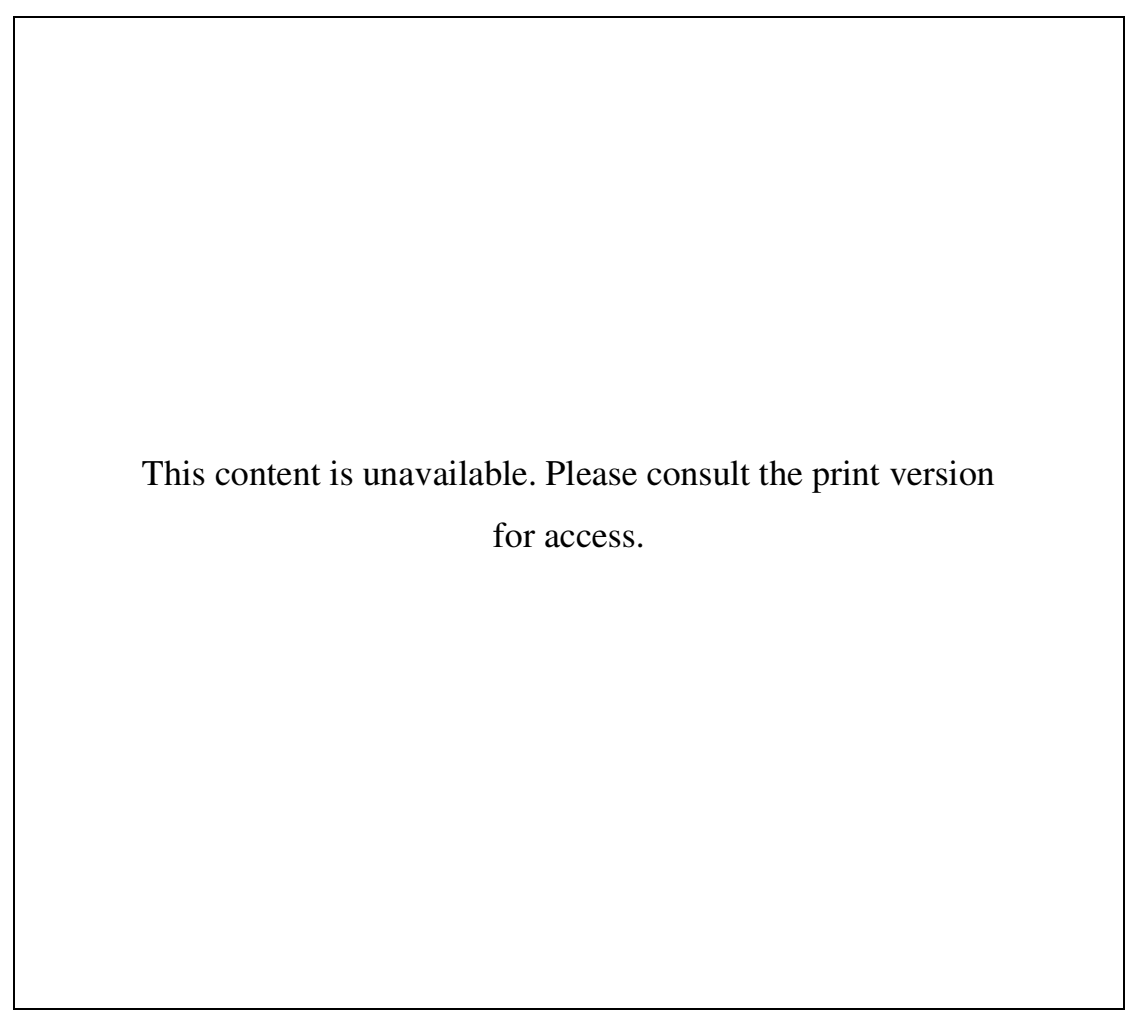

Figure 6: An authenticity continuum (Pinner, 2016a, p. 103)

The vertical axis signifies relevant contexts of language learning and use, that is learning contexts, i.e. the classroom, and the use domain. The use domain refers to situations in which learners will be using the language for "real" communication. Classroom materials would be particularly useful as they invite learners/teachers to question their relationship to the contents being used and how such learning/teaching resources may relate to their educational goals. While seeking to incorporate both social and contextual dimensions and 
"real" language use, the continuum validates variously situated individuals and interactions in localised language classrooms. In this sense, the continuum offers a broader and balanced perspective which acknowledges dynamic hybrid culture and the myriads of influences on how languages are actually taught, learned and used around the world.

English teachers may find the above model useful given that it presents authenticity as a kind of continuum and offers a flexible framework for interpretation and application. The onus rests on the teachers to articulate the dynamic, fluidity and hybrid of English and today's English use as global lingua franca. Non-native ESL/EFL teachers warrant special attention given that they constitute a vast majority of English language teachers worldwide, i.e. over $80 \%$ (Braine, 2010), and that their professional pedagogic authority is often benchmarked against so-called NS competence and authenticity. In what follows, I will then write about EFL teachers in the Indonesia's EFL context.

\subsubsection{NNEST and interculturality}

Among the wide implications of the global spread of English is the demand for teachers of English around the globe, which is met largely by local EFL teachers. In interculturallyoriented language and in particular English classrooms, the teachers-irrespective of whether they are NESTs or NNESTs-serve as intercultural speakers and mediators who are primarily responsible for developing in learners ICC (Byram, 1997, 2009). Discussions revolving around the NEST/NNEST divide, however, seem to part of the wider issue concerning native speakerness. In this regard, Phillipson (1992) and Medgyes (1994) have made significant contributions to the debate. Both address ingrained assumptions about the identity and authority of NEST/NNEST in ELT. Two of the key tenets of Phillipson's (1992, p. 185) "native speaker fallacy" directly concern the role, competence and legitimacy of NEST, i.e. the monolingual fallacy and the native-speaker fallacy; the former assumes that "English is best taught monolingually", the latter claims that "the ideal teacher of English is a native speaker".

Phillipson (2016) challenges the belief that the monolingual, monocultural NS of English is the legitimate owner of English, the best pedagogic model, and intuitively the most effective teacher, simply disregarding the sociolinguistic differences of NSs, the diversity of students' socio-educational backgrounds, and the complexity of the teaching and learning process. Not only is such a monolithic view, as Phillipson (2016, p. 86) further underlines, narrowly focused on the target language and thus cognitively, linguistically and pedagogically invalid, but its effects are also far-reaching, adding that: 
Adherence to this fallacious pedagogical canon has major structural and economic consequences in educational investment and priorities, training, and testing, as well as for 'international' publishers and the testing business. In education worldwide it serves to establish inequalities between NSs of English and speakers of other languages, and teachers from different backgrounds, irrespective of their qualifications (p. 86).

Medgyes $(1992,2001)$ observes that most of the NEST/NNEST gaps are language-related. NESTs may achieve their potential superiority through their ability to use the language spontaneously and in the most diverse communicative situations. Conversely, NNESTs are in some cases handicapped by their lack of proficiency in English. Yet, it remains debatable whether more proficient teachers are more efficient in teaching. While recognising the importance of developing high English proficiency, Medgyes argues that language deficiency applies to both non-native and NESTs to varying degrees and is not the single most important factor in their professional success. Effective teaching hinges on many variables. Some relative pedagogic competencies of NNESTs may redress the balance. For Medgyes, NNESTs are more likely to serve as imitable models of successful learner, teach language-learning strategies more effectively, provide more information about the English language, better anticipate language difficulties, be more sensitive to students' needs and problems, and benefit from sharing students' mother tongue.

In a similar vein, Byram (2015) questions whether NSs or NNSs are a priori more competent teachers of ICC. Byram argues that NSs may have some knowledge of the culture of social groups of the target language. However, such pre-existing knowledge is usually limited to one country, to only some social groups in that country, or to the "banal" culture of the groups they know. In ELT, the diversity of international Englishes entails knowledge of various social groups in many different countries rather than of only English-speaking countries, that are in fact culturally diverse, too. NNESTs, on the other hand, may well gain insights into local cultural beliefs and practices and as such NESTs' privileged cultural knowledge of the target community would be counterbalanced (Byram et al., 2002). NNESTs' pedagogical competences and cultural awareness and sensitivity more than compensate their perceived lack of language proficiency. Hence, Byram (2015) emphasises that NNESTs are just as important as NESTs and that there are no a priori reasons why NESTs or NNESTs are better qualified to teach such components of ICC as savoir (knowledge) or savoir être (attitudes).

Among some of NNESTs' potential advantages are that they share native language(s) with learners' and show a deeper cultural sensitivity to their learning needs and exigencies. In general, NNESTs also display greater familiarity with local sociolinguistic, economic, 
religious, and political milieu. They may find such an understanding of particular factors and situations useful since language teachers, as Byram et al. (2002) suggest, need to make learners' cultural perception and stereotypes explicit. The primary purpose of bringing buried frames of reference to the surface is to make learners conscious and more aware of their own cultural predispositions and evaluative responses to others. Here, Byram et al. contend that criticising learners' basis for making judgements is not expected from teachers, although they may not take neutral position on bias, racism and unfounded generalizations. Thus, the EFL teachers' sensitivity to and familiarity with the society's worldview can help them navigate the local value systems and strike a balance between challenging stereotypes and prejudices and changing own and learners' cultural values.

In addition, the awareness and understandings of the various local factors and wider socio-educational environment resonates with a culturally responsive pedagogy. Teaching, as Gay (2010) notes, can be more relevant and effective when such ecological factors as life experiences, cultural knowledge, frames of reference, and ethnic identities of teachers and pupils are integrated into school practices. Culturally responsive teaching and learning can be validating as it values culturally different individuals and acknowledges the legitimacy of student's cultural heritages.

Apart from the comparative knowledge of language and pedagogical (dis)advantages, it is worth stressing again that in an interculturally-oriented pedagogy language teachers are expected to be intercultural speakers or mediators and to demonstrate the following abilities (Byram, 1997; Byram et al., 2002; Liddicoat, 2011; Liddicoat \& Scarino, 2013):

i) spark learner's interest in and curiosity about their own and other's cultural beliefs, meanings and behaviours;

ii) encourage critical reflections on cultural differences, diversity and otherness;

iii) withhold judgment about others and decentre from pre-existing assumptions;

iv) compare learner's language-and-cultures with those of others;

v) shuttle and mediate between home and target cultures;

vi) foster a greater intercultural awareness and understanding; and, vii) allow for active engagement and further cultural exploration.

It could be summed up that regarding NNEST and interculturality the question is not whether one is native or NNEST, but rather whether the teacher adopts the principles for interculturally-framed language pedagogy and possesses the abilities to facilitate the realisation of intercultural goals in the classroom practices. Also, interculturally-oriented 
English teachers mine the social context of teaching and learning and benefit from the diversity of the classroom, school, and community by drawing on as much home knowledge, languages and practices as possible (Newton, 2016). The next section will then look briefly at the dynamic complexity of Indonesia's EFL classrooms.

\subsubsection{NNEST in Indonesia's EFL context}

Applying the principles for ILTL to Indonesia's EFL context presents both challenges and opportunities to the local EFL teachers, particularly in view of the nation's extraordinary sociolinguistic and cultural diversity. As previously mentioned, there are more than 400 ethnic groups and 700 living languages in Indonesia, with Bahasa Indonesia (Indonesian language) being the sole national language and constituting a fundamental part of the national unity and identity. In this predominantly Muslim country, more than $90 \%$ of its people affirms the importance of religion in their lives ("Chapter 2. Religiosity," 2008; Theodorou, 2015). The existing education and language policies, general perception and actual usages of the local vernaculars, Indonesian and English create a dynamic interplay. Tensions that arise from such a relationship affect the ways English and associated cultures are perceived and presented in EFL classrooms.

The policies on EFL education and pertinent curricula cannot be considered in isolation from the national policies on language and general education. English in Indonesia is sanctioned as a "foreign language", and the teaching and learning of English in formal education is linked to the nation's competitive edge (Undang-Undang Republik Indonesia No. 20 Tahun 2003 tentang Sistem Pendidikan Nasional [Law No. 20/2003 on National Education System], 2003; Undang-Undang Republik Indonesia No. 24 Tahun 2009 tentang Bendera, Bahasa, dan Lambang Negara, serta Lagu Kebangsaan [Law No. 24/2009 on the National Flag, Language, Symbol, and Anthem], 2009). Teachers of any subject in Indonesia's schools are required to integrate a particular set of cultural, moral and religious values into their syllabus, RPP (lesson plan), and teaching practices (Kementerian Pendidikan Nasional, 2010, 2011). Under these policies, EFL teachers are not exempted from inculcating character traits within the framework of the nationally mandated character education. The 18 proposed traits are rooted in the State ideology Pancasila, Indonesian culture, religions, and the objectives of the national education, i.e. religious, honest, tolerant, disciplined, hardworking, creative, independent, democratic, curious, patriotic, nationalistic, achievement oriented, friendly/communicative, peace-making, well-read, 
environmentally conscious, socially aware, and responsible. That is, English classrooms have always been on the nation's cultural, economic, and political agenda.

Morality, religiosity, and spirituality are integral parts of the formal education and permeate English classes. Qoyyimah's $(2015,2016)$ studies, for example, demonstrate that high school EFL teachers in Indonesia incorporated both "secular" and "religious" moralities in their EFL classes. Secular moralities were selected mainly on the basis of their alignment with particular English teaching materials. These were evident in the teachers' RPPs and their implicit and explicit pedagogies. However, more diffuse religious moralities were largely grounded in the teachers' preferred values of religiosity that resonate with school communities' religious premises. Both secular and religious values were also manifested in the regulative and instructional discourses.

Mambu's $(2014,2016,2017)$ findings shed light on the place of spirituality, especially Christianity, in Indonesia's EFL context, and on how teachers and students exploit religious issues and negotiate their sense of spirituality. Integrating religious issues in language classes can be a delicate matter, due partly to fear of interference with personal belief or proselytization and avoidance of sensitive topics. Mambu suggests, however, religious values that are salient features in Indonesia's education can be seen as an opportunity for EFL teachers to encourage reflections on religious views and identities and foster willingness to engage in interfaith dialogues. Therefore, teachers need to decentre their religious beliefs and mainstream a sense of self-reflexivity, humanity and community. At the same time, they might ground their pedagogy in local concerns over interreligious relations, allow students to raise sociopolitical awareness, and envision social transformation dialogically.

In the context of Islamic boarding school (pesantren), Palmer and Chodidjah's (2011) Intercultural English Pesantren project was aimed at developing teachers' languageteaching skills as well as teachers' and students' English and intercultural competence. In general, the pesantrens have quite limited access to outside influences and are run with a strong religious ethic. The materials for this project were designed to prepare students for interaction with people from other cultures, consider intercultural interaction as an enriching experience, and encourage them to understand different worldviews and behaviours of others. Central to the project was that materials raise intercultural awareness of global issues by exploring topics through a variety of perspectives and classroom activities and that unit topics would be presented in a way that enables both teachers and students to actively engage with issues appropriately within the restrictions of Islamic 
schooling. Popular topics such as sport, music or hobby have the potential to be controversial in terms of what is religiously and contextually appropriate, especially for female students. Leading students through different aspects of a main topic incorporating first personal experience and local issues then wider international topics seeks to help students engage personally rather than abstractly with the themes.

The above discussion serves to illustrate Indonesia's education context as well as the challenges and opportunities the local EFL teachers have to deal with in adopting ILTL principles. In the light of the diversity of this EFL setting and the very nature of interculturality as 'an unfinishable work in progress of action in response to new experiences and reflection on the action' (Liddicoat, 2011, p. 839), an investigation into the pedagogic beliefs and practices of English teachers in Indonesia's high school EFL classrooms is therefore potentially valuable for broadening the theoretical base and drawing out practical implications for an interculturally-framed EFL pedagogy.

I wil next discuss concepts of teacher pedagogic beliefs and in particular EFL teachers' beliefs and classroom practices regarding culture as well as the teaching and learning of culture and interculturality.

\subsubsection{Teacher pedagogic belief}

Teacher's pedagogic belief can be understood as a subset of cognitions (Borg, 2003; Woods, 1996). Borg (2006, p. 1) posits that "cognition" is used as an inclusive term to describe 'what language teachers think, know and believe'. That is, cognition encompasses such psychological constructs as beliefs, knowledge, theories, attitudes, images, assumptions, metaphors, conceptions and perspectives. In language education, pedagogic beliefs can be conceptualized as 'personal theories the teachers held regarding the nature of the broader educational process, the nature of language, how it is learned, and how it may be best taught' (Breen, Hird, Milton, Oliver, \& Thwaite, 2001, p. 472). Pajares (1992) notes that the potent affective, evaluative and episodic nature of belief serves as a filter through which teachers view new information. He adds that '[T]hought processes may well be precursors to and creators of belief, but the filtering effect of belief structures ultimately screens, redefines, distorts, or reshapes subsequent thinking and information processing' (Pajares, 1992, p. 325). Similarly, Kumaravadivelu (2012) argues that so influential is belief in shaping thinking and action that teachers use it as a filtering mechanism with which they screen, interpret, comprehend, and absorb new phenomena and experiences. 
People can hold beliefs which represent alternate situations and contrast with everyday realities. Nespor (1987, p. 318) contends that 'beliefs serve as means of defining goals and tasks, whereas knowledge systems come into play where goals and the paths to their attainment are well-defined'. A lack of knowledge or direct experience of the envisioned world, or even failures to translate the ideal into reality, does not diminish the value of beliefs. Beliefs, Nespor asserts, are imbued with affective and evaluative components based on personal preferences. They can operate more or less independently of the cognition closely associated with knowledge.

Because attempts to define "knowledge", "assumptions" and "belief" as distinct concepts are always fraught with difficulties, Woods (1996) maintains that the terms may be taken to represent points on a spectrum of meaning ranging from knowledge to belief. Here, as Woods suggests, "knowledge" refers to "things we "know" - conventionally accepted facts'; "assumptions" signifies 'the (temporary) acceptance of a "fact" ... which we are taking as true for the time being'; and "belief" denotes 'an acceptance of a proposition for which there is no conventional knowledge, one that is not demonstrable, and for which there is no accepted agreement' (p. 195). The interwoven nature of teachers' beliefs, assumptions, and knowledge (BAK) means that there is an interrelationship among the BAK networks and that the concepts in their use may overlap with one another. Teachers' background knowledge, assumptions and beliefs 'are not composed of independent elements, but rather structured, with certain aspects implying or presupposing others' (p. 200). That is, classroom interactions, curricular decisions, and interpretations of pedagogic theories are filtered through and shaped by these mental constructs.

Individual beliefs coexist with and relate to each other and thus work as a "system" (Pajares, 1992; Richardson, 1996). Seeing beliefs as a system can be useful for discussing belief's effects on and interface with classroom decision-making, and especially for making sense of "mismatches" between beliefs and practices. For Pajares (1992), one's belief system houses all the beliefs acquired through the process of cultural transmission. Its adaptive function allows individuals to define and understand the world and themselves. As a system, it is 'composed of beliefs connected to one another and to other cognitive/affective structures, complex and intricate though these connections may be, that form beliefs about constructs-beliefs about politics, about abortion, about art, about the nature of knowledge' (Pajares, 1992, p. 315-316).

It is also generally accepted that beliefs and actions are mutually informing and that a number of factors mediate between beliefs and behaviours. The term "relationship", 
although useful for research and analysis, is usually viewed with disfavour as it implies separation between otherwise fundamentally interconnected beliefs and practices (Richardson, 1996). As for mediating factors in the formation of pedagogic beliefs, scholars offer different conceptualizations but four aspects are frequently mentioned in studies on teacher cognition, i.e. schooling, professional education, classroom practice, and teaching contexts (Basturkmen, 2012; Borg, 2006; Phipps \& Borg, 2007).

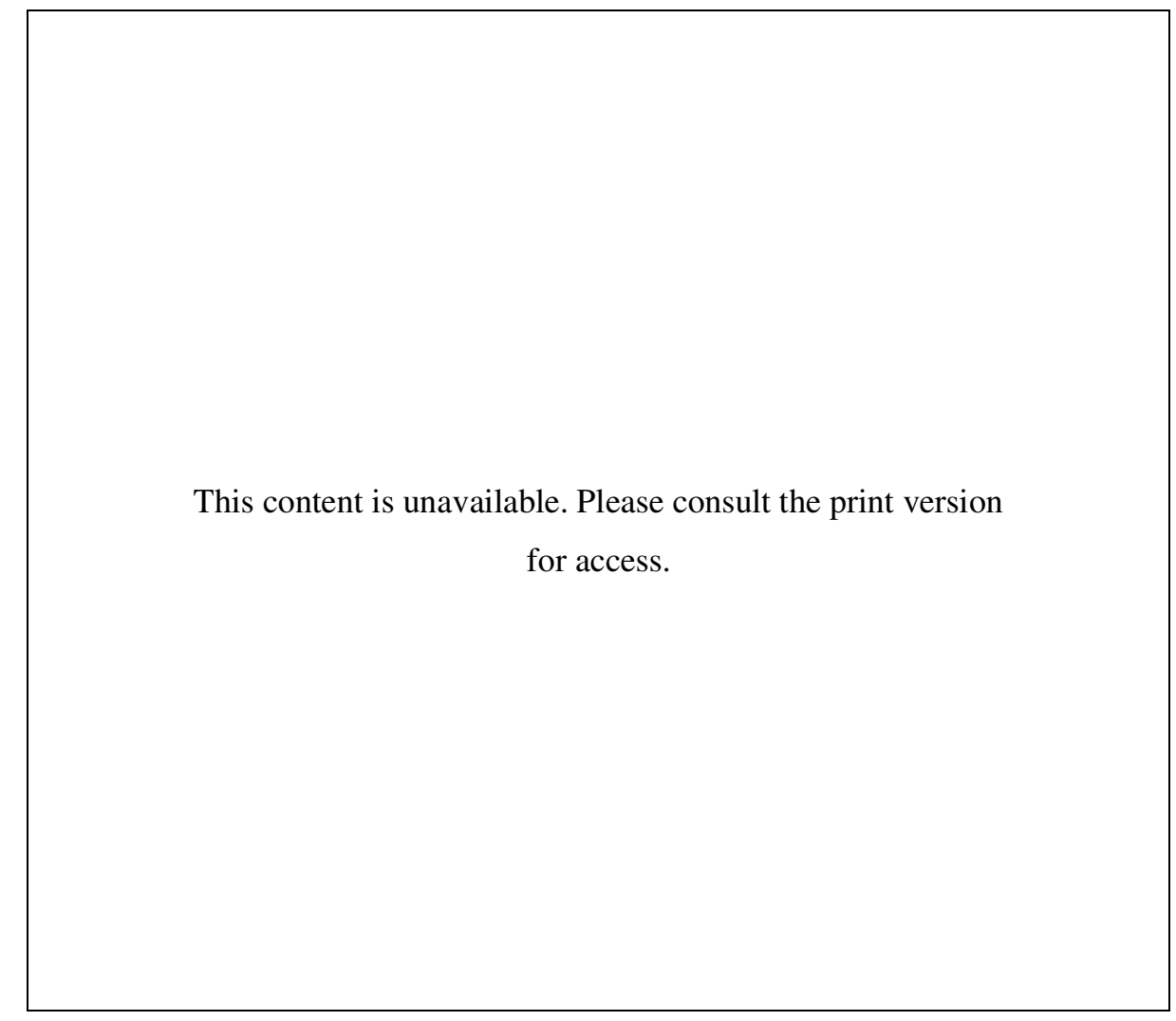

Figure 7: A framework of language teacher cognition, schooling, professional education, and classroom practice (Borg, 2006, p. 283)

Borg's (2006) framework of teacher cognition (Figure 7) perhaps best describes the relationships between cognition, teacher learning (schooling and continuing professional education), classroom practice, and the wider context. The model works on the fundamental assumptions that 'teachers are active, thinking decision-makers' and that 'knowledge and beliefs exert a strong influence on human action' (p. 1). Borg argues that teachers have cognitions about all aspects of their work. Experiences as learners continue 
to affect cognitions about teaching and learning throughout teachers' career and professional lives. Teacher cognitions and practices are in fact interactive. That is, the broader teaching contexts play an important role in mediating the extent to which teachers' instructional decisions are congruent or otherwise with their cognitions.

Teacher cognition is contextualized in that the immediate classroom and school contexts and the larger socio-educational factors mediate between stated beliefs and actual practices. Holliday (1994) distinguishes the micro from the macro social context: the former is the socio-psychological aspect of group dynamics within the classroom; the latter concerns the wider societal and institutional influences on classroom events. What happens in the classroom, Holliday argues, can only be fully understood from the wider, macro picture which displays 'the attitudes derived from relationships of status, role and authority brought by students and teachers from outside the classroom that influence those aspects of classroom interaction' (p. 14). Borg (2003, p. 106) also notes that understandings of what teachers think should not be in isolation of what they do, and the study of cognition and practice overlooking the socio-psychological contexts in which these take place 'will inevitably provide partial, if not flawed, characterisations of teachers and teaching'.

According to Phipps and Borg (2007), such contextual factors as prescribed curricula, a lack of time, and student preparations for examinations may in practice hinder teachers' attempts to teach in line with their beliefs. Basturkmen's (2012, p. 286) review of research into the correspondence between language teachers' beliefs and practices confirm some findings of previous studies regarding the context-bound nature and situational constraints of teacher's beliefs and practice, suggesting that:

... there was evidence across situations of the role of contextual factors in mediating the relationship between teachers' stated beliefs and practices. The review showed how teachers under pressure from situational constraints felt unable to put their beliefs into practice ... and that the relationship between the teachers' beliefs and practices could vary in different schools and classrooms.

Teachers' beliefs may not be reflected in or incongruent with classroom behaviours for several possible reasons, some of which are directly related to the teaching context. For instance, in Farrell and Lim's (2005) study of English teachers' conceptions of grammar teaching in a Singapore's primary school, the divergences between stated beliefs and actual practices were partly attributed to time constraints and reverence for traditional grammar approach. Time constraints the teachers perceived as required in the syllabus came not only from the syllabus demands and the school administration but from the parents as well. The attitude attached to traditional grammar instructions was another significant reason why the 
teachers continued to employ the traditional approach despite express enthusiasm and preference for a communicative approach. Likewise, Farrell and Bennis'(2013) study in the context of a private language academy in Canada shows that in addition to time factors, the beliefs and instructional decisions of both experienced and novice ESL teachers were for the most part based on their perceptions of students' learning and influenced by efforts to maintain a good rapport with the group. That is, the mismatches between teachers' beliefs and practices may be explained in terms of a broad range of contextual factors that make it problematic or constraining to teachers to put their beliefs in place.

In order to restrict the focus of the present discussion and to get a fuller picture of issues concerning EFL teachers' beliefs and practices regarding culture and interculturality, I will in the next section sketch some recent studies into the pedagogic beliefs and classroom behaviours of NNESTs in a number of EFL educational settings.

\subsubsection{NNEST belief about culture teaching}

A cultural turn in applied linguistics has since the 1990s provided fertile ground for an interculturally-informed language pedagogy. The paradigm shift is characterised by a renewed look at the nature of language and culture and at the complex interplay between the two, a revisit of the importance and place of culture in language pedagogy, and an introduction of intercultural (communicative) competence as an instructional goal (Buttjes \& Byram, 1991; Byram, 1997; P. Holmes, 2014; Kramsch, 1995, 2013a). At the macro level, a broad variety of issues relating to the teaching and learning of culture and interculturality in language pedagogy covered in existing studies may reflect the sheer diversity of ELT/EFL socio-educational settings in which English is used, taught and learned around the world. At the micro classroom level, as Kramsch (2014d) puts it, local EFL teachers are interacting in their daily professional lives with learners who are mostly youngsters being familiar with the Internet and with different platforms of global social media and communication technologies. In these, Kramsch adds, we are witnessing:

a proliferation of semiotic activity, a healthy disrespect of academic authority ... hybridities and code-switchings, and multimodal bursts of creativity and innovation. ... The Internet and electronic forms of communication have exploded the conventional, predictable forms of communication offered by print literacy, grammars, and dictionaries, opened the way for creativity, agency and innovation, but they have also increased semiotic uncertainty and ambiguity. ... they have changed what we mean by communication, language and culture (p. 250).

Take, for example, Canh's (2015) study into Vietnamese English teachers' beliefs about the cultural dimensions of ELT. It reveals that the teachers generally believed the 
inseparability of culture teaching from language education. While acknowledging that good cultural knowledge helped learners to communicate more effectively in English, the teachers differed widely on their cultural orientations, that is whether the cultural content concerns only Anglo-American cultures or the cultures of any countries with which Vietnam has relations, including the cultures of ASEAN countries. Apart from time constraints, students' English skills and learning motivation, and examination-oriented education, a perceived lack of cultural knowledge created tensions between the teachers' instructional beliefs and practices. Sharing some of Canh's findings, Vo's (2017) research into EFL lecturer's views and practices regarding ICC in the Vietnam's context indicates that the majority of the lecturers reported their awareness of and showed support for ICCbased teaching practices. Yet, nearly $50 \%$ and $30 \%$ of the lecturers "rarely" and "sometimes" carried out relevant ICC-oriented classroom activities respectively. Vo identified five main culprits for such a belief-practice discrepancy, i.e. limited teaching time, meagre ICC resources, little opportunities to use English, lack of ICC knowledge, and inadequate ICC training.

Canh's and Vo's studies share some causes of the belief-action gap such as time constraints and a lack of cultural training and competence. What differentiates the two is, among other things, that the lecturers in Vo's study were less preoccupied with a NS-based model of communicative competence. The lecturers were more inclined to help learners 'get acquainted with other cultures' and 'see that the interactions with other cultures in English can enrich their experiences' (Vo, 2017, p. 24). Canh's mention of the cultures of South-East Asian countries draws attention to the differing cultural orientations which carry potential pedagogic implications. Kirkpatrick $(2006,2014)$ points out that the use of English as the sole working language and a lingua franca in the ASEAN community has created a situation in which no one is necessarily advantaged by speaking English as a mother tongue. It is thus only fair that EFL materials and classroom activities familiarise students with the cultures of the people with whom they are most likely to communicate in English. For Kirkpatrick, learners need to be able to present their own culture while at the same time understand how it relates to and differs from other cultures.

Some of the results of Canh's and Vo's mixed-method research are consistent with the findings of Nguyen et al.'s (2016) ethnographic study into Vietnamese EFL teachers' beliefs about the role of culture in language instruction. Nguyen et al. noted that 'opportunities for culture to find its way into EFL classroom activities were still limited. Priority was given to teaching language knowledge and skills' (p. 165). Nguyen et al. 
indicated that the teachers tended to give only a minor supporting rather than fundamental role to culture, depend largely on the prescribed materials, and focus mostly on developing learners' cultural knowledge of English-speaking countries. Also, in the light of the inservice teachers' relative lack of knowledge of IC, a sufficient support within the framework of continuing professional development is thus necessary.

In the context of mainland China, Tian's (2013) study into Chinese English teachers' beliefs about and approaches to IC in university EFL classrooms offers evidence on the teachers' perceptions and actual practices and examines IC through the lens of Eastern (Confucian) philosophy. Key findings of the study showed that Chinese traditional values shaped IC development in the EFL classrooms. That is, the classroom instruction carried with it a sense of Chineseness and put special emphasis on raising Chinese consciousness. The teachers perceived IC to comprise not only aspects of attitude, knowledge and skills but also moral values. IC principles too should aim to develop learner into a "whole human being" under Confucianism. Despite recognising the importance of IC, most of the teachers still encouraged the acquisition of a body of cultural knowledge and thus failed to make the intercultural dimensions a regular focus. The teachers rarely engaged students in exploratory activities. Some expressed concerns about their 'being challenged by students who were heavily influenced by abundant information from the media and Internet' ( $p$. 148). In addition, the effectiveness of IC development in EFL classroom practices was generally hampered by the teachers' limited cultural knowledge, the exam-oriented system, curriculum requirements, and students' lack of English proficiency.

Other studies involving Chinese teachers of English highlighted some similar issues as those arising from Tian's investigation. Ding (2013) and Gu (2016) identified a number of major barriers to effective intercultural EFL classrooms in China. It was argued that illprepared teachers and poorly-articulated intercultural curriculum have made the focus of EFL teaching and assessment remain on language skill and an acquisition of NS-based sociopragmatic norms. A shortage of interculturally-informed assessment materials and lack of administrative support was largely responsible for adding to the teachers' confusion over what aspect to evaluate and how to assess it, causing a deficiency in their attempts to evaluate students' ICC in the classroom (Gu, 2016). Zheng and Gao's (2017) action research on Chinese EFL learners' development towards interculturally-shaped productive bilingualism offers a somewhat different emphasis. Three cycles of planning, acting, observing and reflecting were geared to guiding learners to become open to their own and others' cultural assumptions and to incorporate multiple perspectives. Critical reflection on 
the complexity of the multilingual, multidialectical Chinese society was also encouraged. Zheng and Gao suggested that the revised teaching steps and techniques were generally effective in helping learners develop productive bilingualism which is characterized by transcendence of polarities and critical openness toward both self and others. Students too became more aware of their own biases and prejudices and had an increased ability to find creative solutions to conflicting situations.

Furthermore, in the context of a university preparatory programme in the Kingdom of Saudi Arabia (KSA), Osman (2015) identified EFL teachers' perception of ICC objectives, which are adapted from the work of Byram (1997) and Fantini and Tirmizi (2006), and its relevance to teaching practices. The findings indicate the fact that ICC objectives were not explicitly articulated in the EFL curriculum and materials limited their systematic integration and created a gap between the teachers' perception of ICC objectives and their classroom implementation. The teachers specified three most important attitude, knowledge, and skill areas of the objectives, i.e. the ability to suspend judgment and appreciate the complexities of cross-cultural interactions, knowledge of the levels of formality in language and behaviour, and the ability to identify and explain intercultural misunderstandings to overcome conflicting perspectives. This view might reflect local demand where direct intercultural contacts between Saudis and foreign workers, including the locally expanding Indian and Philippine communities, are increasing (Moskovsky \& Picard, 2019; Osman, 2015). In this regard, Osman reiterated the importance of acquainting learners with different varieties of today's English in order that they can communicate more effectively and appropriately across linguistic and cultural boundaries.

As with many other Arabs, the Saudis see the supremacy of Arabic and Islam as central to their cultural, national, and religious identity. One of the Saudi's educational goals is to furnish learners with at least one additional living language, apart from their native language, in order for them to acquire knowledge and sciences, contribute to the spread and service of Islam, and benefit humanity (Elyas \& Badawood, 2016). Despite the dominance of Arabic language in the KSA and Middle East in general, there are still concerns over adverse effects of the "hegemony" of English on Arabic, a fear of erosion of traditional culture and religion as well as confusion among some educators and the public at large as to the value of English and when and how English teaching and learning should be introduced and conducted (Alqahtani, 2019; R. Kirkpatrick \& Barnawi, 2017). Regarding the tension and paradox, Alrahaili (2019, p. 96) contends that: 
While Saudi EFL learners do not appear to regard English as a linguistic or cultural threat and are ambivalent in relation to actual political and/or military threats presented by the English-speaking communities, they do see Anglophone culture as a potentially serious threat to traditional Saudi and Islamic values, and such perceptions have the capacity to generate negative attitudes.

Alrahaili further suggests that a favourable attitude towards English and its speakers or openness to other cultures does not necessarily mean being influenced by or accepting cultural and religious values of Western, English-speaking, secular communities. Rather, perceiving English as a threat to the Muslim culture and opposing its teaching and learning reflects a myopic view amid the benefits of keeping abreast of developments in modern science and technology that can be made possible in part by English proficiency.

Moreover, English skills can be positively used to affirm Muslim identity, disseminate Islamic teachings, and help dissipate negative stereotypes about Muslims.

Issues relating to the teaching and learning of culture that have arisen in the EFL contexts described above may not be exclusive to the educational settings in that local EFL teachers in Indonesia's EFL classrooms are also faced with some similar problems.

\subsection{Summary}

In Chapter 2, I examined from an intercultural perspective the concepts of language, culture and language-culture nexus. Understandings of language, culture and their connectedness affect how these are treated in the language classrooms. The expanded view on language goes beyond the conventional notion of language as a fixed and finite structural code or an unproblematic tool of communication. Rather, language is understood as open, energetic, constantly evolving and both personal and communal, offering a good many possibilities of hybrids, mixes and meanings.

This inquiry adopts a dynamic, non-essentialist approach to culture. Culture is conceived of as a moveable concept with negotiable boundaries. As a fluid and creative social force, culture binds groupings of any type and size and aspects of behaviour in different ways, producing a vast array of configurations. The dynamic, non-essentialist view dissociates culture from the idea of a static and monolithic entity, delinking culture from geographic blocks and particular communities. Today's English as a world language may illustrate such a holistic nature of language and porous boundaries of culture in which new features, versions and varieties are continually created by people from diverse national, linguistic and cultural backgrounds. This phenomenon can also be indictive of how language and culture are inextricably interrelated in multiple and complex ways. 
An intercultural language pedagogy develops in learners ICC and sees intercultural speakers as pedagogic models, moving away from the NS-based notions of instructional goal and teaching ability. The primary linguistic and cultural conceptions of the teachers and learners are seen in a positive light as cognitive and communicative resources. What learners bring with them into the classroom becomes a point of departure for building their own conceptual systems as they are exposed to new and likely different cultural meanings made manifest in the target language. In Newton's (2016) words, incorporating learners' home knowledge, languages and experiences into the EFL classroom not only makes the most of the classroom diversity but also shows appreciation of the linguistic backgrounds and cultural worlds, belief, values and identities of both the teachers and learners.

In interculturall EFL classrooms, the question is whether or not the teachers have the abilities to encourage learners' critical reflections on otherness and diversity, make preconceptions explicit, and decentre from one's own perspectives. They need to be able to draw connections and mediate between home and target languages, develop greater intercultural understandings, and allow for further cultural exploration. Also, the diverse socio-educational settings of EFL worldwide have brought the idea of the NS-based authenticity into question. For Pinner (2016b, 2016a), authenticity is a continuum and is sensitive to individual, social and other contextual dimensions of the use, teaching and learning of English around the globe. It should no longer be benchmarked against the sociolinguistic norms of members of Western culture. The problems with associating EFL pedagogy exclusively with NS cultures lie not only in the static, reductionist view of culture and the fact that English-speaking communities are culturally diverse, but also in the relevance or otherwise of NS cultures to the students' learning goals and potential conflicts with local cultures (Alptekin, 2010; McKay, 2009). In the light of the problematic NS-based notions including the "NEST/NNEST", in the following the term "EFL teacher"-as, for example, in "local" or "Indonesian EFL teacher"-is generally used in preference to "NNEST", except where a special mention is necessary.

Furthermore, teacher pedagogic beliefs and practices are mutually informing and situated (Borg, 2006; Kumaravadivelu, 2012; Pajares, 1992). Language teachers' theories of culture influence how they approach and represent culture in their teaching (Liddicoat \& Scarino, 2013; Scarino \& Liddicoat, 2009; Song, 2014). Studies indicate that various educational, sociocultural, political and religious dimensions intersected with English teachers' representation of culture and interculturality in local EFL classrooms (Alrahaili, 2019; Osman, 2015; Siregar, 2016; Tian, 2013; Vo, 2017; Zheng \& Gao, 2017). Confucian 
values in China and Islamic principles in Saudi Arabia, for example, shaped the EFL teachers' perspective on and students' development of ICC in the respective countries. A range of immediate and wider contextual factors could feed into the EFL teachers' beliefs and help the teachers put espoused beliefs into practice or otherwise. 
This page is intentionally left blank. 


\section{Chapter III \\ Research methodology}

\subsection{Introduction}

In this chapter, I describe the methods and processes of gathering, analysing, and interpreting data. I will first explicate the research paradigm that constitutes ontological and epistemological assumptions underpinning this study. Then, I explain the research strategy, i.e. qualitative case study, that derives from the philosophical point of view. The data collection section elaborates the research participants and setting and methods of data collection. In particular, the research setting outlines the sites where I gathered the data and accounts for language and education policies that govern, either directly or indirectly, the EFL pedagogy in Indonesia. This allows a fuller picture of the present, wider educational and sociocultural context of Indonesia and the situatedness of the phenomenon being studied. The final sections illuminate the analytical frameworks and procedures as well as issues relating to the ethical stances and trustworthiness of this investigation.

\subsection{Research paradigm}

I subscribe to the view that research paradigm, strategy, and method are interrelated.

Research paradigm guided me in ontological and epistemological assumptions as well as in choices of strategy and method for data collection and analysis (Lincoln, Lynham, \& Guba, 2011). In its widest sense, a paradigm is a worldview referring to 'a way of thinking about and making sense of the complexities of the real world' (Patton, 2002, p. 69). So essential is the paradigm that not only does it embody the core beliefs and attitudes about the world, but it also offers an interpretive framework within which the world can be understood and studied (Guba \& Lincoln, 1994).

I took a constructivist perspective because it resonates with the dynamic, nonessentialist approach to language and culture (Holliday, 2016; Hua, 2016; Liddicoat, 2002). Constructivists opine that knowledge and truth are not discovered; they are created by mind (Schwandt, 1994). Proponents of constructivism commonly assume that a singular, stable, and fully-knowable external reality is not directly accessible to human beings, that people interpret and construct reality of the human world, and that 'the world of human perception is not real in absolute sense' (Patton, 2002, p. 96). Any notion of truth is construed as informed and sophisticated constructions coalescing around consensus, 
which is always open to change and reconstruction (Guba \& Lincoln, 2005; Lincoln et al., 2011). Constructivism can also be used to mean internal, cognitive processes of individuals and the joint activities and their impact on the social construction of meaning (Hua, 2016).

Under constructivism, it is not possible to separate researcher from personal values and experiences, nor from the local and specific (Guba \& Lincoln, 2005). What creates data is the interactive link between the researcher, the object, and context of the research. The fundamentals of constructivism that concern human agency and subjectivity concur with the basics of a qualitative study. This study too was conducted according to qualitative research principles, i.e. naturalistic setting, insider's meaning, emergent design, multiple methods, and interpretive analysis. First, the research setting under study is the natural, everyday world where people live, work or study. I collected data ${ }^{2}$ at the sites where participants actually experienced the problem being studied. I did not make any attempt to control or intervene in the real-world settings (Croker, 2009; Merriam \& Tisdell, 2016).

Second, the focus of inquiry is on understanding the meanings that the participants bring to the situations. Subjective opinions and significance of the participants' actions can be revealed only by the actual individuals themselves (Dörnyei, 2007). As Guba and Lincoln (1994, p. 106) write:

Human behaviour, unlike that of physical objects, cannot be understood without reference to the meanings and purposes attached by human actors to their activities. Qualitative data, it is asserted, can provide rich insight into human behaviour.

Third, the nature of the present study is emergent and evolving in that no aspect of the research design is tightly prefigured. This investigation went through an iterative process in which data collection, analysis and interpretation shifted among the stages of an investigation (Dörnyei, 2007). The process kept this study open to respond flexibly to emerging new details, to avoid being prescribed by my personal agenda, and to allow for inductive-deductive logic in lieu of a purely inductive approach. Fourth, I used multiple methods to collect and analyse various types of data that derived from different sources. This offered different perspectives and helped minimise the danger of a one-sided representation of the situation (K. Richards, 2003). In the light of the strengths and weaknesses of each type and source of data, a combination of data collection methods

\footnotetext{
${ }^{2}$ I used the term "data" in an uncountable form after Holliday (2007) to signify "a body of experience" rather than "a number of items."
} 
made it possible for me to use different forms of data to validate and cross-check findings, patterns, and conclusions (Patton, 2002).

Fifth, the interpretive nature of qualitative inquiry allows going beyond the descriptive data and giving subjective meaning to data arrays (Patton, 2002; Yin, 2011). I was the primary "research instrument" that made findings "speak for themselves" by giving interpretations. As Patton (2002, p. 480) notes, this process involves:

attaching significance to what was found, making sense of findings, offering explanations, drawing conclusions, extrapolating lessons, making inferences, considering meanings, and otherwise imposing order on an unruly patterned world.

In this section, I addressed issues concerning the nature of reality (ontology) and knowledge (epistemology) by virtue of constructivist paradigm. I worked on the assumption that realities are mental constructions of phenomena that are socially created by individuals in interaction with their world (Guba \& Lincoln, 1994; Holliday, 2007). In what follows, I discuss the conceptual framework of qualitative case study as a research stragey undergirding the present study and its application to this inquiry.

\subsection{Research strategy: qualitative case study}

A research strategy puts paradigms into motion and guides researchers as they move from paradigm to the empirical world, and relates the researchers to specific empirical sites and methodological practices (Denzin \& Lincoln, 2011). I opted for case study as a research strategy given that my study was faced with three general situations as follows, i.e. "how" and "why" questions were the main research questions, my control over actual behavioural events was absent, the focus of this study was a contemporary phenomenon rather than a historical event (Yin, 2014). I conducted a qualitative case study since it appreciates the possibility of multiple realities constructed by people, substantiates inquiry into the implications of the constructions for people's lives and interactions with others, helps render participant's distinctive meanings more accurately, and enables me to examine the case in question more thoroughly (Patton, 2002; Stake, 2010; Yin, 2014).

Case study means different things to different people. It may be seen as a unit of analysis, a research methodology, an end result, or a comprehensive strategy. Stake (1994) assumes that case study is more a choice of object to be studied than a methodological choice. An object can be viewed through a qualitative or quantitative lens. No method of data collection is inherently associated with a case study. Stake has a different emphasis 
from that of Yin $(2014$, p. 16) who defines case study as 'an empirical inquiry that investigates a contemporary phenomenon (the "case") in depth and within its real-world context, especially when the boundaries between phenomenon and context may not be clearly evident.' Merriam and Tisdell (2016, p. 37) define case study as 'an in-depth description and analysis of a bounded system,' which shares Gerring's (2007) view that case study research presupposes a single, relatively bounded phenomenon. Creswell (2013, p. 97) views case study as a methodology and offers a broad definition as follows:

Case study is a qualitative approach in which the investigator explores a real-life, contemporary bounded system (a case) or multiple bounded systems (cases) over time, through detailed, in-depth data collection involving multiple sources of information (e.g. observation, interviews, audiovisual material, and documents, and reports), and reports a case description and case themes.

Qualitative case study researchers enjoy the considerable flexibility of qualitative inquiry, and so did I. There is neither fixed agreed-upon structure nor a single right way of conducting a qualitative case study (Creswell, 2013). A research design can be very much influenced by the purposes and problems of research and differ in its emphases (Yin, 2011). It can also be implicit or explicit, as Yin (2014) suggests, but no study is ever conducted without a research design, whether or not it is planned.

Scholars point to a sensible interconnection between various parts and stages of research. A research design gives a flexible set of guidelines and positions researchers in the empirical world (Lincoln et al., 2011). In addition to linking a theoretical paradigm to a research strategy and method for gathering and analysing findings, a research design connects the researcher to specific places, people, groups, institutions, and a range of relevant information. Creswell $(2013$, p. 50) argues that a research design makes a qualitative project appear 'as a cohesive whole rather than as fragmented, isolated parts.'

Researchers need to ensure that the parts of the research process, e.g. the purposes, the data collection, the findings, and the discussion, are in a way interrelated.

Specifically, Yin (2014) identifies five key components of case study design, i.e. questions, propositions, the unit of analysis, the link between data and propositions, and the criteria for interpreting findings. Research questions provide a valuable clue as to the most relevant method of research to use and propositions constitute theoretical frameworks that direct attention to issues to be examined and guide the researcher on how and where to look relevant data. The unit of analysis refers to a specific, real-life phenomenon that serves as a case to be studied. The logic linking the data to the propositions represents the 
likely analytic techniques that may suit the case study. Setting the criteria for interpreting findings involves deploying relevant theories to interpret and present findings. The last two components suggest what researchers need to do after data collection and anticipate the overall analytic process.

In the light of the theoretical accounts, I was during all the research stages constantly seeking to establish links between the purposes and focus of the present study, research questions, methodological approaches, and analytic framework. For example, I made naturalistic classroom observations in order that I might gather direct empirical evidence of teachers' classroom practices and answer pertinent research questions while keeping the research setting natural. I drew heavily on the theories of intercultural language education given that the focus of this study is the teaching and learning of culture and interculturality in the EFL classrooms. Also, apart from the policies on ELT, I saw the State policies on language and general education relevant to the case being studied and thus included in the discussion and analysis. These examples may in some ways reflect the flexibility of the research design and sensible links between parts and stages of this qualitative case study.

Moreover, a qualitative case study is characterised as bounded, particularistic, and holistic. Boundedness makes an entity qualify as a case. The case that is within a bounded system is bounded by time and space (Creswell, 2013). For Merriam (2009), boundedness forms boundaries of a single unit and "fences in" what researchers are going to study. It can be a single person, programme, group, institution, community, or specific policy that is a case example of some phenomenon. The boundaries of a single case have a common sense of obviousness, and the scope of the researcher's intent or interest may determine the boundaries (Hood, 2009). The selected case to study in this inquiry was bounded by a number of spatial, temporal, and other concrete qualities. The focus of the study, i.e. pedagogic beliefs and practices, the central topic examined, i.e. the teaching and learning of culture and interculturality, and the participants involved, i.e. Indonesian high-school EFL teachers and learners, help define boundaries of the case. Indonesia's current policies on language, general education, and EFL education have some concrete manifestation and form a bounded system as well.

A second distinct feature of case study, being particularistic, may arise from an indepth study of unique, context-bound cases. The problems that case researchers strive to address are highly individualised and contextualised (Hood, 2009). Stake (1995, 2005) asserts that case researchers should aim to examine the particularity and complexity of a case and to arrive at a greater understanding of its patterned activity. Case researchers are 
interested in the uncommon stemming from the nature of the case rather than in the ordinary. This includes its activity and functioning; its historical significance; the physical environment; other contexts relative to economy, politics, law, and aesthetic; other cases which bring out the case; and informants who provide empirical evidence about the case.

The physical environment, activities, and functioning of EFL classrooms in the different types of high-school in Indonesia, i.e. general, Islamic and vocational highschool, foregrounded the investigation into the ways the local EFL teachers' worked with culture and interculturality in the classrooms. The unique sociolinguistic situation of the research site Pendalungan, which is home to predominantly Javanese and Madurese ethnic groups, could allow for uncommon classroom interactions. The EFL teachers took account of learners' sociolinguistic backgrounds while working towards mandated educational goals, needs, and priorities of the learners, and this might add to the complexity and particularity of the case being studied.

A case study is holistic as it imparts detailed information, facilitates a fuller understanding, and offers a rich description of a particular case by drawing on multiple forms and sources of evidence (Creswell, 2013; K. Richards, 2003, 2011). A holistic perspective, as Patton (2002) observes, is part of the analytic approaches by which the whole phenomenon is conceived more as a complex system than merely the sum of its parts. Case researchers highlight complex interdependencies and system dynamics whose meanings may not be reduced to some discrete units and straightforward, cause-effect relationships. Overall understandings of what has been obtained from observations or interviews relate to the unifying nature of people's social environment or of an organisation's external context (gestalt).

In order that this study becomes a holistic one, I employed different methods of data collection and sought to obtain a variety of forms and sources of evidence, allowing data cross-checks and strengthening the trustworthiness of an inquiry as well (Creswell, 2013). I made classroom observations, gave teachers SR and in-depth interviews, and administered NFs alongside document analysis and student's focus group discussion. Using a combination of different types of data redresses the balance as the strengths of one method can minimise the weaknesses of another method (Patton, 2002). By embracing the concept of triangulation, I made use of different forms of data, sources of information, methods of data collection, and theoretical perspectives in order to offer corroborating evidence, as well as providing detailed accounts and a holistic picture of the socioeducational phenomenon under investigation (Creswell, 2013; Yin, 2011). 
In the next section, I will expand on each method and procedure for collecting data, that begin with an explanation of the research participants and setting.

\subsection{Data collection}

This study was aimed at understanding the EFL teachers' pedagogic beliefs and classroom practices regarding the teaching and learning of culture and interculturality. It was also devised to explore the extent to which contextual factors impact on the EFL teachers' understandings and representations of language-and-culture in the EFL classrooms. The subtlety of teacher pedagogic belief as a mental construct, the elusive nature of culture, and the complexity of cultural representations in the language classroom reasonably entail multiple forms of evidence. Various types of data generated from several methods might be especially useful in capturing the participants' subjective meanings and getting information about pedagogic beliefs and cultural values that are neither directly observable nor readily measurable. I relished the challenge of illuminating the complex interplay of local and national socio-educational factors amid global cultural and political forces.

I collected data by using a combination of classroom observations, an NF, SR and indepth interview as the primary methods of data collection. Document analysis and focus group discussion ("FGD") served as secondary methods. I involved both teachers and students as participants, eliciting as detailed information as possible by analysing policy and classroom documents, studying the EFL teachers' actual classroom behaviour, doing interviews, and seeing the teachers do activities in their natural settings. In particular, I made classroom observations prior to applying other direct, face-to-face data collection procedures to keep the research sites as naturalistic as possible. What follows is a more detailed information about the research participants and setting of this study.

\subsubsection{Research participants}

The research participant is epistemologically an integral part of knowledge creation in which the researcher and the researched interact, shape one another, and co-construct understandings and knowledge (Denzin \& Lincoln, 2011). Findings are created through the interaction between inquirer and the targeted phenomenon (Guba \& Lincoln, 1994). In this study, the participants were Indonesian teachers of English and pupils in Indonesia's senior high schools located in Pendalungan district (pseudonym), East Java, Indonesia.

In order to find and select intended teacher participants, I benefited from my personal and professional network as a lecturer in Pendalungan. I sent invitations in the first 
instance to a number of teachers from general, vocational and Islamic high schools, henceforth "GHS", "VHS" and "IHS" respectively, who might be willing to voluntarily participate in the proposed study. I attached Information sheets that were written in English and Indonesian. Initially, there were nine teachers who responded to the invitations and expressed their interest to take part. I arranged meetings with the interested teachers to explicate the study and especially the data collection procedures as well as to ensure that they had at least two years' experience of teaching in high schools and some experience of using English in communication with people from different national background. I applied these broad criteria to ensure that the participant's personal and professional experiences suited the research purposes.

The teachers were given information that the process of data collection that would include two to three classroom observations, a 4-page narrative frame completion, and two interviews. These procedures were planned to take up to a maximum of ten weeks to comply with the conditions of the Indonesia's Ministry of Higher Education on which was funding my studies. By the end of the allocated time for data collection, five teachers managed to complete all the procedures whereas the remaining four could not due to conflicting schedules and the time constraints.

All the participants were certified teachers working in four different state high schools presented under the pseudonyms "GHS Jawa", "GHS Pari”, "VHS Agri”, and "IHS Negeri'. Being a 'certified teacher' means, among other things, that the teacher is deemed to have acquired the necessary academic qualifications, have passed the Teacher Competency Test as well as being required to be teaching a minimum of 24 hours per week and entitled to professional allowance (Iskandar, Ree, \& Al-Samarrai, 2012; Suryahadi \& Sambodho, 2013). The teachers are henceforth presented under the pseudonyms "Ambar", “Ana", "Aris", "Wati”, and "Yanti”.

\begin{tabular}{l|l|l|l}
\hline $\begin{array}{l}\text { NNEST } \\
\text { (pseudonym) }\end{array}$ & $\begin{array}{l}\text { High school } \\
\text { (pseudonym) }\end{array}$ & Education & $\begin{array}{l}\text { Teaching } \\
\text { experience }\end{array}$ \\
\hline Ambar & GHS Jawa & BA in English Education & $15+\mathrm{yr}$. \\
\hline Ana & GHS Jawa & BA in English Education & $20+\mathrm{yr}$. \\
\hline Aris & GHS Pari & $\begin{array}{l}- \text { BA in English Education } \\
- \text { Master's in Education Design }\end{array}$ & $20+\mathrm{yr}$. \\
\hline Wati & VHS Agri & $\begin{array}{l}- \text { BA in English Education } \\
- \text { Master's in Education Design }\end{array}$ & $20+\mathrm{yr}$. \\
\hline Yanti & IHS Negeri & BA in English Education & $10+\mathrm{yr}$. \\
\hline
\end{tabular}

Table 1: Teacher participants 
Ambar completed a BA in English education and by the time of data collection had around 17 years' teaching experience. At GHS Jawa, she taught students of Year 10, 11 and 12 and thus played an active role in preparing Year 12 students for the high-stake national examination. Ana taught at the same school as Ambar. She had a BA in English education and over 20 years' teaching experience. Before teaching at GHS Jawa, Ana had taught for around 14 years in junior high schools. Ana was awarded the Pendalungan's "High Achiever Teacher" in 2009 by the MoNE local office. In 2015, Ana was assigned by the MoNE to write and review the modules for the pre- and post-UKG held as part of the national teacher certification programme.

Aris received a BA in English Education from a Pendalungan-based university and a master's degree in Instructional Design from a Surabaya-based university. He had taught English in GHS Pari for more than 10 years. Prior to teaching in the senior high school, Aris had had a teaching position in a junior high school for about 15 years. Aris maintained an active membership in several professional bodies and had from 2011 to 2013 chaired the all-Pendalungan GHS MGMP.

Wati, a VHS teacher, gained a BA in English Education and a Master's in English education. She had around 25 years' teaching experience. Prior to teaching at VHS Agri, she had taught English in junior high schools for almost 18 years. Like Ana, Wati's extensive teaching experience and active involvement in various English education and professional development programs have allowed her to perform different roles, including being a trainer, instructor and mentor. From 2013 to 2016 Wati had become Chairwoman of the Association of Vocational High School English Teacher of Pendalungan. In 2016, she was appointed School Accreditation Assessor for Secondary Education by the BNSP.

Yanti, an IHS teacher, had 12 years' teaching experience. She got a BA in English education. Before teaching at "IHS Negeri", Yanti had taught English in a primary school for around three years. At IHS Negeri, she taught English to Year 10, 11 and 12 students, and one of her duties was to prepare Year 12 students for the national examination. She has been involved in continuing professional developments programmes organised by the MoRA and the MoNE.

Concerning focus group discussion, seven Year 12 students from the three different types of high school, presented under pseudonyms "Sdt 1" to "Sdt 7", participated. Three students were from GHS, the other three were from VHS, and the other one was from IHS. The method of recruitment of the student participants was slightly different from that of teacher participants. At first, I did not have any 
contact with the students. The teacher participants helped give Information sheets to their respective students and asked whether any of their students might be willing to voluntarily participate in this study. Initially, nine students expressed their interest. I arranged meetings with the students to go through the Information sheet and answer questions about the study in person.

After the meetings, seven students proceeded with their intended participation by signing the Consent form. All of them were over the age of 16 . Of the seven students, five are female and two are male. Six students identified themselves as Javanese, one as Madurese and one as half-Javanese half-Madurese due to intermarriage. Like many other Indonesians, the student participants are multilingual. They speak Javanese or Madurese, or both, as their home language(s) plus Indonesian. Five of the students had started learning English from junior high school (Year 7), and two of them had learned the language from Year 4.

\begin{tabular}{|l|l|l|l|}
\hline $\begin{array}{l}\text { FGD } \\
\text { Student }\end{array}$ & School & Grade & Gender \\
\hline Sdt 1 & GHS Jawa & Year 12 & Female \\
\hline Sdt 2 & GHS Jawa & Year 12 & Female \\
\hline Sdt 3 & GHS Jawa & Year 12 & Female \\
\hline Sdt 4 & VHS Agri & Year 12 & Male \\
\hline Sdt 5 & VHS Agri & Year 12 & Male \\
\hline Sdt 6 & VHS Agri & Year 12 & Female \\
\hline Sdt 7 & IHS Negeri & Year 12 & Female \\
\hline
\end{tabular}

Table 2: Student participants

\subsubsection{Research setting}

The research setting refers to the school site where I collected the data and its immediate socio-educational environment as well as prevailing policies that govern language, general education and EFL pedagogy in Indonesia. These policies may cast some light on the wider social, cultural, economic, politic and religious context within which the local EFL teachers' pedagogic beliefs and classroom practices regarding culture and interculturality were situated.

\subsubsection{Research site}

The schools where I gathered data are located in Pendalungan, Indonesia (Figure 8). With a total area of around 3,000 $\mathrm{km}^{2}$, an estimated population of 2,5 million people, and about 350,000 inhabitants in its urban area ("Pendalungan Regency," 2016; "Kabupaten Pendalungan,” 2016), Pendalungan is among one of the five largest cities in East Java 
province. It is a Muslim-majority district. Two major ethnic and cultural groups are Javanese and Madurese.

I collected data from IHS Negeri, VHS Agri, and one GHS Pari that are situated on the outskirts of the city. GHS Jawa is the only school that is in the urban area. GHS Pari is the farthest school from the city centre, but even so the schools have easy access as they are located along the main street.

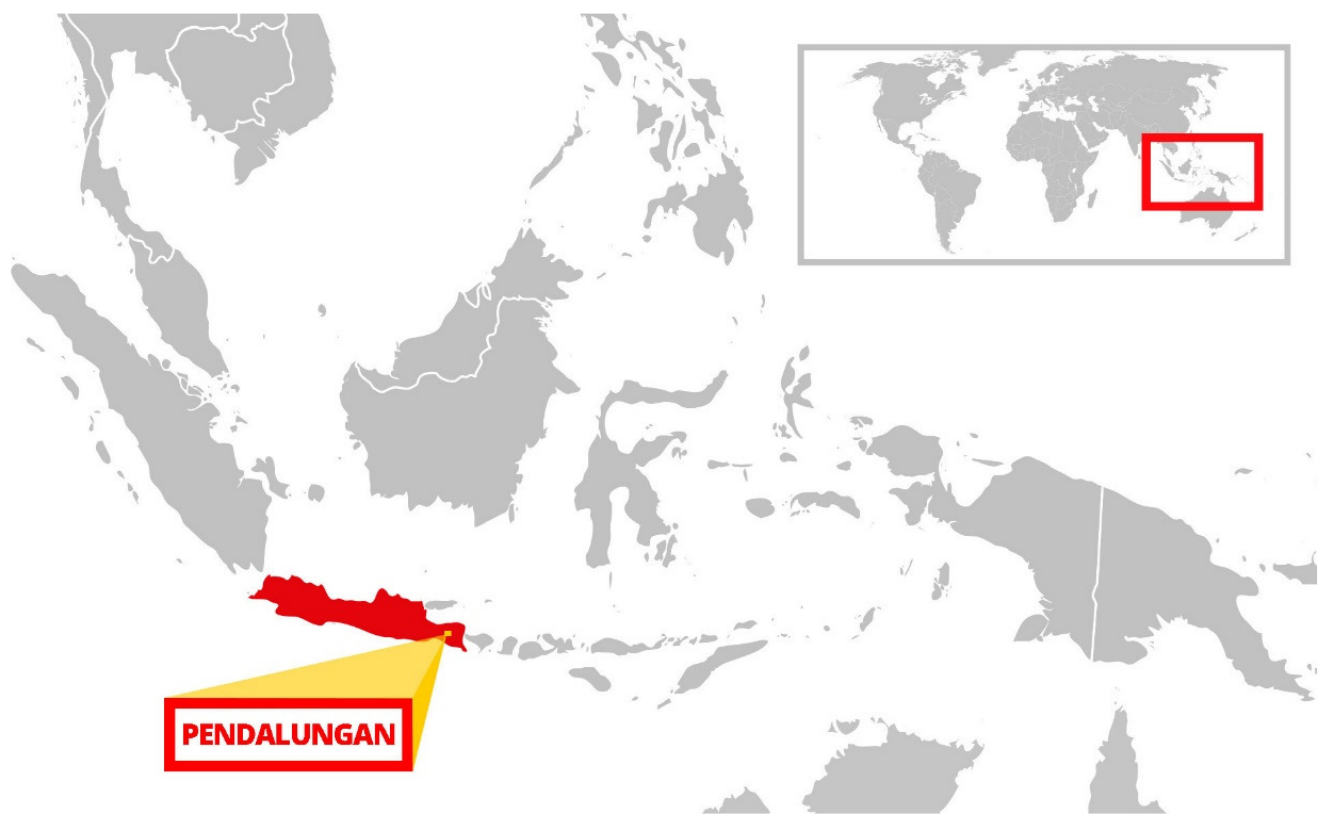

Figure 8: Pendalungan on the world map

All the schools are mixed or co-educational schools. GHS Pari has more than 800 students in total. Both GHS Jawa and IHS Negeri have over 1,000 students. VHS Agri is the biggest school in terms of the number of students and the width of the school area. It has around 2,800 students and is said to be the Indonesia's biggest agricultural high school. All the four schools have had intercultural encounters within their school environment with people from both English and non-English speaking countries. These occurred, for example, when the schools had international students from a local university or from the International Association of Students in Economic and Commercial Sciences (AIESEC) conducting a community outreach programme, representatives of partner institution, and guests from international organisations. 
The unique characteristic of IHS Negeri is partly influenced by its position as an Islamic high school. For example, announcements that are made by the school office over the loudspeaker intended for students and teachers within the school area are in three languages, that is Indonesian, English and Arabic. In other schools, announcements are usually in Indonesian and English only. VHS Agri is largely characterised by its vocational and technical orientation. The compulsory internship for Year 11 students, for instance, is in Indonesia as well as in Malaysia and Thailand.

\subsubsection{Language and education policies}

An overview of Indonesia's language and education policies helps create a fuller understanding of the interplay of language and non-language factors as well as the contemporary, wider socio-educational settings within which the EFL teachers' beliefs and practices regarding the teaching and learning of culture and interculturality are situated. As with other school subjects, the English teaching and learning in Indonesia is subject to the general objectives of the national education. Under Article 3, Law 20/2003 on National Education System (Undang-Undang Republik Indonesia No. 20 Tahun 2003 tentang Sistem Pendidikan Nasional [Law No. 20/2003 on National Education System], 2003), education in Indonesia:

... berfungsi mengembangkan kemampuan dan membentuk watak serta peradaban bangsa yang bermartabat dalam rangka mencerdaskan kehidupan bangsa, bertujuan untuk berkembangnya potensi peserta didik agar menjadi manusia yang beriman dan bertakwa kepada Tuhan Yang Maha Esa, berakhlak mulia, sehat, berilmu, cakap, kreatif, mandiri, dan menjadi warga negara yang demokratis serta bertanggung jawab.

... functions to improve the capability and shape the character of the nation and to build a great civilization so as to enhance its people's intellectual capacity and strives to realise learners' potentials in order that they become ones who believe in and are faithful to one and only God; who are of good character, healthy, knowledgeable, competent, creative, independent; and as citizens, are democratic and responsible.

The "Core Competency" (Kompetensi Inti) that Indonesian primary and secondary school students should develop are concerned with attitude (spiritual and social), knowledge and skills (Kementerian Pendidikan dan Kebudayaan, 2016a, 2016b). In line with the policy, character education serves as an integral part of the national education. Personal and social morality that is rooted in the State ideology Pancasila, local cultural and religious values, and the national education goals should be integrated into the national curriculum, school's syllabus, and teacher's lesson plans and instructional practices (Kementerian Pendidikan dan Kebudayaan, 2013a, 2013b; Kementerian Pendidikan Nasional, 2010, 2011). 
One of the key issues surrounding EFL education in is the status of English. Under Article 1 of Language law, English is legally sanctioned as a "foreign language," that is "language other than Indonesian and local language". This means that the official position of English is similar to other "foreign" languages such as Arabic, Mandarin, or Dutch. The legal standing of English has some impact on how it might be perceived by the society at large and positioned in the education sector. The fact that the formal instruction of English is started in secondary education, that it has remained a school subject rather than a medium of instruction (MoI), or that the teaching hours have been relatively limited and fluctuate over the curricula can be related to some extent to the legal status of EFL in Indonesia (Lauder, 2008; Lowenberg, 1991).

In spite of the absence of an explicit status, English has from the 1950s been included in the national curriculum as a compulsory foreign language to be taught in high schools as well as a core subject in the final national examination of secondary education and the university admission test (Mistar, 2005; Nababan, 1991). Indonesia has implemented several national curricula with the latest being Curriculum 2013. Prior to Curriculum 1994, English was introduced in Year 7. Curriculum 1994 allowed English lesson to be offered in Year 4 as an optional subject.

Under the current K13, the decision was again reversed. Formal English teaching is to be provided in secondary schools. One teaching hour for English class in senior high school is 45 minutes and the number of teaching hour is a minimum of $2 \times 45$ minutes per week (90 minutes), depending on student grades and programmes (Kementerian Pendidikan dan Kebudayaan, 2013a, 2013b). There has been a significant reduction of the teaching hours when compared to the preceding curriculum. In Curriculum 2006, Year 10 and 11 students took a minimum of 4 x 45-minute (180 minutes) English lessons and Year 12 students might have up to 5 x 45-minute (225 minutes) English lessons per week (Kementerian Pendidikan dan Kebudayaan, 2006).

Grammar-translation, oral and audio-lingual approaches had been used respectively until Curriculum 1975 (Dardjowidjojo, 2000). From Curriculum 1984 onwards, Indonesia's ELT has adopted CA and sought to develop in student's communicative competence (Lie, 2007; Sukyadi, 2015). However, since the 2000s Indonesia's EFL curricula have seen significant reforms although the changes are still driven more by ideological and political purposes than educational benefits (Widodo, 2016). All too often there have been conflicting needs and interests of policy makers, education authorities, teachers, and students. According to Widodo, Curriculum 2013 does not elaborate on such 
key elements as curriculum materials, pedagogy, and assessments from relevant theories of language and language education. This may have caused confusion for school administrators and teachers as to how to enact curriculum materials at the school and classroom levels.

Before 2005, in general, Indonesian teachers had relatively low educational qualifications and a significant proportion of in-serve teachers were under qualified. It was estimated that more than 60 percent of kindergarten, primary and secondary school teachers (excluding Islamic schools) did not hold a four-year degree (Al-Samarrai et al., 2013). In response partly to the situation, Law 14/2005 on Teacher and Lecturer (Teacher law) was passed. It is aimed at improving the quality of teachers and teaching at all levels of education. The Teacher law prescribes the followings: (i) a minimum academic qualification, i.e. a four-year degree; (ii) the required competencies in four domains, i.e. pedagogical, personal, professional, and social; (iii) an incorporation into national teacher standards; (iv) the teacher certification programme; and, (v) the conditions under which teachers are entitled to receive special and professional allowances (Undang-Undang Republik Indonesia No. 14 Tahun 2005 tentang Guru dan Dosen [Law No. 14/2005 on Teacher and Lecturer], 2005). The law specifies the academic qualification, competency standards and certification processes, and introduces a set of new professional allowances to address the issue of teacher welfare. These efforts have been made possible largely by the allocation of $20 \%$ of the national and regional budget to education as mandated by the Education law (Undang-Undang Republik Indonesia No. 20 Tahun 2003 tentang Sistem Pendidikan Nasional, 2003).

Furthermore, as regards the contemporary socio-educational and political landscape of Indonesia, some recent policies shed light on Indonesia's official language ideology permeating the EFL pedagogy. These include removing English from primary school curriculum, reducing English teaching hours in secondary school, and dissolving the international-standard school (SBI) (de Lotbinière, 2012; International-standard school unconstitutional, 2013; Sagita, 2013). The current K13 curriculum dropped mandatory English from primary school and instead offers the language as an elective only. English teaching hours in secondary school have been reduced from a minimum of $4 \times 45$ minutes to 2x45 minutes per week (Kementerian Pendidikan dan Kebudayaan, 2013a, 2013b; Sukyadi, 2015). The drop and reduction of English were conducted in favour of Indonesian, nationalism, and religion. 
Take RSBI/SBI, for instance. After around seven years of existence, in 2013 it was ruled to be unconstitutional on the grounds that the school gave unequal education access to the public in terms of the extra funds and facilities, that it introduced discriminatory practices against students from disadvantaged families, and that the use of English as a medium of instruction in several subjects dissuaded students from using Indonesian and posed a threat to the maintenance of Indonesian and local languages (Mahkamah Konstitusi, 2013; Parlina \& Aritonang, 2013). Some of the considerations set forth in the Constitutional Court (MK) decision against the SBI expressly relate the use and the teaching and learning of English to the use and prominence of the local and national language (Bahasa Indonesia), Englishization, Indonesianness, and national identity:

... bahasa pengantar RSBI yang umumnya berorientasi pada bahasa Inggris, cepat atau lambat, akan semakin menggerus bahasa lokal dan bahasa nasional kita, yang akan berujung pada memudarnya kepribadian dan karakter lokal dan nasional manusia Indonesia. "Inggrisisasi" di berbagai lembaga ... sepertinya menjadi semakin nyata pada era kekinian. ... Ketidakberdayaan bahasa lokal dan "kagagapan" bahasa nasional menjadi penanda (signifier) dari ketidakmampuan sebuah bangsa mempertahankan jati dirinya. ... ... Bahasa pengantar dan karakter lulusan yang hendak dibangun dari sekolah bertaraf internasional dinilai tidak melahirkan manusia berkepribadian Indonesia; ... Bahwa penekanan bahasa Inggris bagi siswa di sekolah RSBI atau SBI merupakan penghianatan terhadap Sumpah Pemuda tahun 1928 yang menyatakan berbahasa satu yaitu bahasa Indonesia. ... bahwa Bahasa Indonesia hanya dipergunakan sebagai pengantar untuk beberapa mata pelajaran ..., maka sesungguhnya keberadaan RSBI/SBI secara sengaja mengabaikan peranan Bahasa Indonesia dan bertentangan dengan Pasal 36 UUD 1945 yang menyebutkan bahasa negara adalah bahasa Indonesia;

... that the MoI in RSBI is oriented towards English, sooner or later, erodes our local vernaculars and national language, which will lead to the weakening of the personality as well as the local and national character of the people of Indonesia. 'Englishization' that occurs in many institutions ... appears to be more noticeable. ... The powerlessness of local vernaculars and the "stutter" of the national language signify a nation's inability to maintain its core identity. ... The MoI and the character of graduate that SBI aims to develop are considered to be contradictory to the development of the character of Indonesians; ... That the emphasis is put on RSBI or SBI students' ability to use English is an act of treachery against the 1928 Youth Pledge that vows to recognise one national language of Indonesian. ... that Bahasa Indonesia is used as a MoI in only some subjects ..., then in principle, the existence of RSBI/SBI deliberately ignores the role of Bahasa Indonesia and violates Article 36 of the 1945 Constitution that stipulates that the State language is Bahasa Indonesia; ... (Mahkamah Konstitusi, 2013, pp. 40, 50).

The MK decision captures the spirit of Article 32 of the 1945 Constitution stipulating that '[T]he State develops Indonesian national culture amid world civilisation by ensuring the society's freedom to maintain and develop their own cultural values' and '[T]he State respects and maintains local languages as part of national cultural wealth.' In the same vein, the preamble to Language law states that 'the Indonesian national flag, language, symbol, and anthem constitute a unifying force, an identity, and the very existence of the 
nation.' These basic laws stipulate that Indonesian is the sole state and official language and serves as the primary medium of instruction for all levels of education. It has become an integral part of the country's political unity and an important source of the national culture and identity amidst the extraordinary ethnolinguistic and cultural diversity (Alisjahbana, 1976; Quinn, 2001). Under Article 1 of Language law, English falls into the category of "foreign language," that is "language other than Indonesian and local language". There is no such term as "second", "third" or "additional" language in the current laws. Furthermore, Article 43 of Language law decrees that foreign language ability is for the nation merely to gain a competitive edge.

To sum up, the design, content and implementation of language and education policies in Indonesia are influenced by interrelated linguistic, cultural, educational, economic, socio-political and religious factors. In particular, the EFL policy and its application are affected by such influences. What happens in the EFL classrooms is inevitably subject to the interaction between competing values and forces at the local, national, and international levels. Hence, within school contexts, the local EFL teachers' pedagogic beliefs, instructional decisions, and classroom behaviours might be best viewed against the backdrop of the rich complexities as well as ongoing tensions and contestations.

\subsubsection{Document analysis}

I collected and analysed different types of pre-existing policy and classroom document in order to get a sense of the "whole picture" and better understand the immediate and wider educational and sociolinguistic context within which the EFL teachers made their instructional judgments and decisions. The documentary materials were developed for reasons other than this study and served as "auxiliary documents" which "can supplement a research project ... but are neither the main focus of investigation nor the primary source of data for understanding the topic' (Altheide \& Schneider, 2013, p. 7). The document analysis plays a supportive role in making sense of findings and explicating the case in question (Roller \& Lavrakas, 2015). That is, in addition to data obtained by the primary data collection methods, i.e. classroom observation, SR, NF, and in-depth interview, I drew on the policy and classroom documents to shed light on the situatedness and multidimensionality of the EFL teachers' beliefs and practices regarding the teaching and learning of culture and interculturality in their EFL classrooms.

My awareness of and familiarity with Indonesia's general socio-educational context, informed hunches as an insider, the topic of the study, and the research problems helped 
guide me on what documents to collect, what information to look for and focus on, and how to interpret information emerging from the documents in relation to one gleaned from the primary methods (Holliday, 2007; Merriam \& Tisdell, 2016). It is important, first, to be mindful that matters pertaining to language and general education including EFL pedagogy in Indonesia are subject to national legislation. The policies on EFL pedagogy cannot be looked at in isolation from policies on language and general education. Therefore, I gathered a number of state laws and regulations that govern issues relating to language and general education. In this respect, relevant documents comprised: 1) the 1945 Constitution as supreme law; 2) law number 20/2003 on national education system; 3) law number 24/2009 on national flag, language, symbol, and anthem; and, 4) Indonesia's Supreme Court decision. These official rules and regulations could in some way inform how the Indonesian EFL teachers conceptualised language, culture and interculturality and the ways they represented their pedagogic beliefs and attitudes in the classrooms.

I also collected decrees of the Minister of Education that contained the national EFL curriculum and stated policies on EFL pedagogy. At the school and classroom level, these documents consisted of school's approved syllabus and RPPs. For many schools, a common practice is that a team of EFL teachers jointly develop syllabus, whereas the writing of RPP is individual teachers' responsibility. The content of both the syllabus and RPP should be in agreement with various aspects contained in the national curriculum that include, for instance, the education objectives, core and standard competencies, character traits within the framework of the character education, and allocated teaching hours.

Second, specific information to elicit from the policy and classroom documents was concerned with the conceptions of language, culture and interculturality. The documentary materials may either expressly incorporate or implicitly acknowledge certain definitions, understandings or attitudes towards language, culture and interculturality. These conceptions and approaches reflect the State explicit or implicit ideology that feeds into language and education policies and permeates EFL resources and materials (Ferguson, 2006, 2012; Spolsky, 2004). What might be especially tricky was to identify the "latent content" of the documents signifying "the "hidden" meaning of content that lies beneath the surface and is contextually based' as well as the "manifest content" referring to the more readily apparent, literal meaning (Roller \& Lavrakas, 2015, p. 230). The ILTL principles became my sensitising and analytical lens through which I captured and categorised pertinent constructs, identifying emergent patterns, themes and meanings. The 
context-boundedness of the content laid a basis for the next stage, i.e. making meaningful interpretations of the information in terms of the primary data.

Third, not only were themes emerging from the document analysis useful when I was conducting field work and collecting the primary data, but they had also been especially important throughout the analytical processes. During the data collection, the emergent themes gave me further insights into the multifarious factors contributing to EFL education in Indonesia as well as into the dynamic complexities of the EFL teachers' pedagogic beliefs and classroom practices regarding culture teaching and learning. In addition, the emergent themes helped me to become more sensitised to what information to seek or classroom interactions to notice in classroom observations or what questions to ask in the interviews that follow. Furthermore, during the data analysis I used the emergent themes to corroborate or refute what I observed in the EFL teachers' classroom teaching or what they reported in the NFs and interviews. The use of the information extracted from the policy and classroom documents in the data analytical and interpretation processes allowed for both a methodological triangulation and a "thick description" of the case being studied.

\subsubsection{Pilot study}

I did a pilot study in advance of the main study. It involved two participants and took the first three weeks of my field work to pilot classroom observations, SR interview, and NF. The participants were English teachers in a GHS and IHS. Doing a pilot study allowed me to test and refine one or more aspects of the main study, including its design, data collection instruments, or analysis plans (Yin, 2011). A pilot study might also alert me to potential problems that could be sorted out by making some adjustments before the actual investigation (McKay, 2006; Murray, 2009).

The first procedure to pilot was naturalistic classroom observation. Logistical and practical matters that arose out of the observations included what recording equipment to bring to the classroom and how to best capture the teacher's behaviour and the classroom situation. I used a tripod and handycam to video classroom events and a notebook to make handwritten observation notes. More substantive issues might be connected with things to observe and focus on. I had to strike a balance between what was prescribed in the research agenda and what might emerge from the naturalistic observations.

A pilot SR was a continuation of the classroom observations. This procedure is concerned with retrospective verbal commentaries and interactive decision-makings with the use of video recordings as stimuli (Borg, 2006). Since cognition and action are 
mutually informing, teachers' pedagogic beliefs must be inferred not only from belief statements but also from their intentionality to behave in a particular manner and the behaviour relative to the belief in question (Borg, 2003, 2006; Pajares, 1992; Richardson, 1996; Rokeach, 1968).

The next pilot procedure was an NF completion to collect self-narrative data. An NF is a story template that is comprised of sentence starters and empty spaces for participants to complete and write their stories (Barkhuizen \& Wette, 2008). Narratives attach importance to lived and told life experiences, storyteller's perspective of the experiences, and contexts in which series of events or actions take place (Barkhuizen, 2008, 2014a; Benson, 2014; Creswell, 2013). Individual stories are situated and reported within participants' personal experiences, culture (race or ethnicity), and historical contexts (time and place).

The final procedure was an in-depth interview. This was necessary as we cannot directly observe participants' thoughts or how they interpret the world (Merriam \& Tisdell, 2016). Owing to the unobservable nature of belief, indirect questions are usually best to elicit beliefs (Kagan, 1990, 1992). As such, most questions were open-ended, indirect ones. Although there were a set of pre-prepared guiding questions, participants were encouraged to elaborate on the issues raised in an exploratory manner (Dörnyei, 2007). Thus, I had identified key topics to be covered with each interviewee and be prepared to allow the interview to develop naturally in unexpected directions and open up new areas to probe in depth (Heigham \& Croker, 2009; K. Richards, 2009).

The way I handled logistical and practical matters had given me more concrete ideas, for example, of what to use and to bring to the classrooms, or how I should behave in a formal but friendly way during observations and interviews. More substantive issues were evident in the addition or modification of interview questions and NF wording. A range of issues had also afforded some insight into developing topics and relevant theories, brought about a likely shift in emphasis of the study, and showed the need to keep an open mind on real-life situations and new developments.

The findings and subsequent refinements provided a basis for the main study that I conducted immediately after the pilot study.

\subsubsection{Classroom observation}

I made a number of naturalistic classroom observations before doing interviews and distributing NFs. Observations provide direct evidence of behaviour from which individual's mental states and reasoning processes may be inferred (Borg, 2003). The 
settings under the observations were naturally occurring. I watched the participants teaching on site and made video recordings of their practices. I took observation notes, too. The observation was largely open as it had no preset analytic categories, allowed additional categories to be added, and developed categories from the data (Borg, 2006).

\begin{tabular}{l|c|c|l}
\hline \multicolumn{1}{c|}{ NNEST } & High school & $\begin{array}{l}\text { Number of } \\
\text { observation }\end{array}$ & Length \\
\hline Ambar & GHS Jawa & 3 & $270 \mathrm{~min}$. \\
\hline Ana & GHS Jawa & 3 & $270 \mathrm{~min}$. \\
\hline Aris & GHS Pari & 2 & $180 \mathrm{~min}$. \\
\hline Wati & VHS Agri & 2 & $180 \mathrm{~min}$. \\
\hline Yanti & IHS Negeri & 3 & $270 \mathrm{~min}$. \\
\hline
\end{tabular}

Table 3: Classroom observation

People may behave differently when they know they are being observed (Patton, 2002). That is, the teacher participants might have changed their usual teaching practices or behaviours due to my presence in their classrooms. In this respect, it was important that the teachers would not come up with the idea of being assessed or feel the need to conduct their teaching so as to meet perceived research expectations or purposes. Hence, I arranged a meeting or two with each teacher participant ahead of the observations in order not only to build up a good rapport and give general information about the study and the procedures for data collection, but also to once again guarantee the confidentiality of the data collection and presentation and to stress the importance of the naturalistic classroom events and interactions to this study. I asserted that no attempt would be made to control, intervene in or manipulate the 'real-world' settings. In this way, I was primarily seeking to prevent the teacher participants from feeling obliged to behave in an "expected way" and to keep the classroom settings as naturalistic as possible.

I made a total of 13 classroom observations involving five teachers from four different schools. These excluded four teachers who were unable to complete all the data collection procedures within the possible timeframe and accordingly not included in the data analysis and report. Pursuant to the K13, one teaching hour in senior high school lasts for 45 minutes. Each observation I made lasted for around 90 minutes. As a result, there were over 1,170 minutes of video recordings and several pages of observation notes on the participants' observed teaching practices and classroom situations.

Observation recognises the contemporaneity as well as the complex realities of the subjects and their sociocultural milieu (Lincoln \& Guba, 1985). However, as Patton (2002) asserts, equally important is reporting what did not occur. Patton goes on to say that 
making informed judgements about the significance of non-occurrence can be among the most substantial contributions an inquirer can make because such views may give new insights into something that ought to or is expected to happen.

Further exploration by means of other procedures that followed the observations, i.e. NF and SR and in-depth interviews, helped me to give some more details about the classroom events I directly observed and explore some factors contributing to the absence or non-occurrence of activity.

\subsubsection{Stimulated recall}

I held video Stimulated Recall (SR) with five teacher participants whose English classes I had previously observed and video-recorded. On the final classroom observation, I jointly arranged the time and place of the interview with the teachers. Then, I watched the video recordings of the observations and checked against the observation notes. These enabled me to identify segments for the participants to reflect on, note the exact times of the segments, and make draft questions. The teachers themselves chose the place since they were more familiar and felt comfortable with the location at the school complex. The video recordings of teachers' classroom behaviours became the stimulus. I used a 12.6-inch laptop with touchscreen technology to play the video recordings during interviews. Each interview lasted for around 40-50 minutes and was tape-recorded, so there was a total of over 200 minutes SR data.

A SR is part of verbal commentaries which provide access to teacher thinking processes. Teachers are presented with a stimulus and asked to talk about their beliefs, thoughts, and reasoning processes retrospectively (Borg, 2006; Gass \& Mackey, 2000). In naturalistic classroom research where it is not possible for teachers to verbalise their thought processes while they are teaching, SR facilitates an investigation of aspects of cognition that lie behind teachers' decisions and actions (Ryan \& Gass, 2012).

I managed to conduct SRs with five teachers on day one and day two after the classroom observation. It was not possible to have interviews on the same day of the final observation was mainly because of the availability of the teachers. Generally, they had a number of teaching hours on a single day and would be at school until around $02.00 \mathrm{pm}$ as school hours normally ended at $01.30 \mathrm{pm}$. What made it possible for me to have two SR interviews on day one, i.e. with Aris and Yanti, and three on day two, i.e. with Ambar, Ana and Wati, was that the teachers had different schedules of observation and accordingly their final observations were on different days, too. 
The EFL teachers preferred speaking Indonesian in the SR. Using the first language had enabled them to reveal beliefs more freely. Ensuring that participants refer to the original situation and their actual thinking at the recorded behaviours was also critical. As Ryan and Gass (2012) point out, the formulation of recall questions might be especially useful. Past tense verbs or adverbial markers signifying past experiences should be used to reflect the thought processes at the time of the original task.

Such questions in Indonesian as "Apa yang saat itu Anda pikirkan ketika melakukan/mengatakan ini?" (What were [at that time] you thinking about when you did/said this?) or "Ketika melakukan/mengatakan ini, apa yang saat itu terpikir oleh Anda?" (When you did/said this, what was in your mind?) would be quite specific and lead teachers into recalling their thoughts. In Indonesian, verbs do not conjugate. Different tenses do not change the form of verb. Here, adverbial phrases of time played a central role in the recall questions as they differentiated present from past activities.

\subsubsection{Narrative frame}

I used a Narrative Frame (NF) to capture the complex nature of the EFL teachers' mental lives and find evidence of their pedagogic belief. The NF was devised as a written story template that is comprised of incomplete sentences as starters and a number of spaces for respondents to reflect on and depict their lived experiences (Barkhuizen, 2014a; Barkhuizen \& Wette, 2008). That is, an NF is a partly-controlled, self-reflective instrument which combines a predetermined set of unfinished sentences with the opportunity for respondents to explore and make evaluations of their experiences relevant to the given topic in their own words. It is a sort of "guided composition" (Viet \& Bygate, 2012) in which participants could seek guidance and support on the structure and content of the story from sentence starters.

I applied the procedure to the five teacher participants following the SR interviews. The teachers were provided with an explanation as to what NF was for, how to complete the NF, and when to hand it back to me. Participants were free to ask questions about the procedure. The NF was made available in printed and digital forms. Participants might choose to complete either a printed or digital form and by handwriting or computer typing.

NF was available in English and Indonesian (Figure 9 and 10). It was practicable to use a common language if the participants and the researcher knew the language (Barkhuizen, 2014b). I gave participants both versions so that they would arrive at a better understanding of the NF and find it easier to recount their teaching experiences. They were 


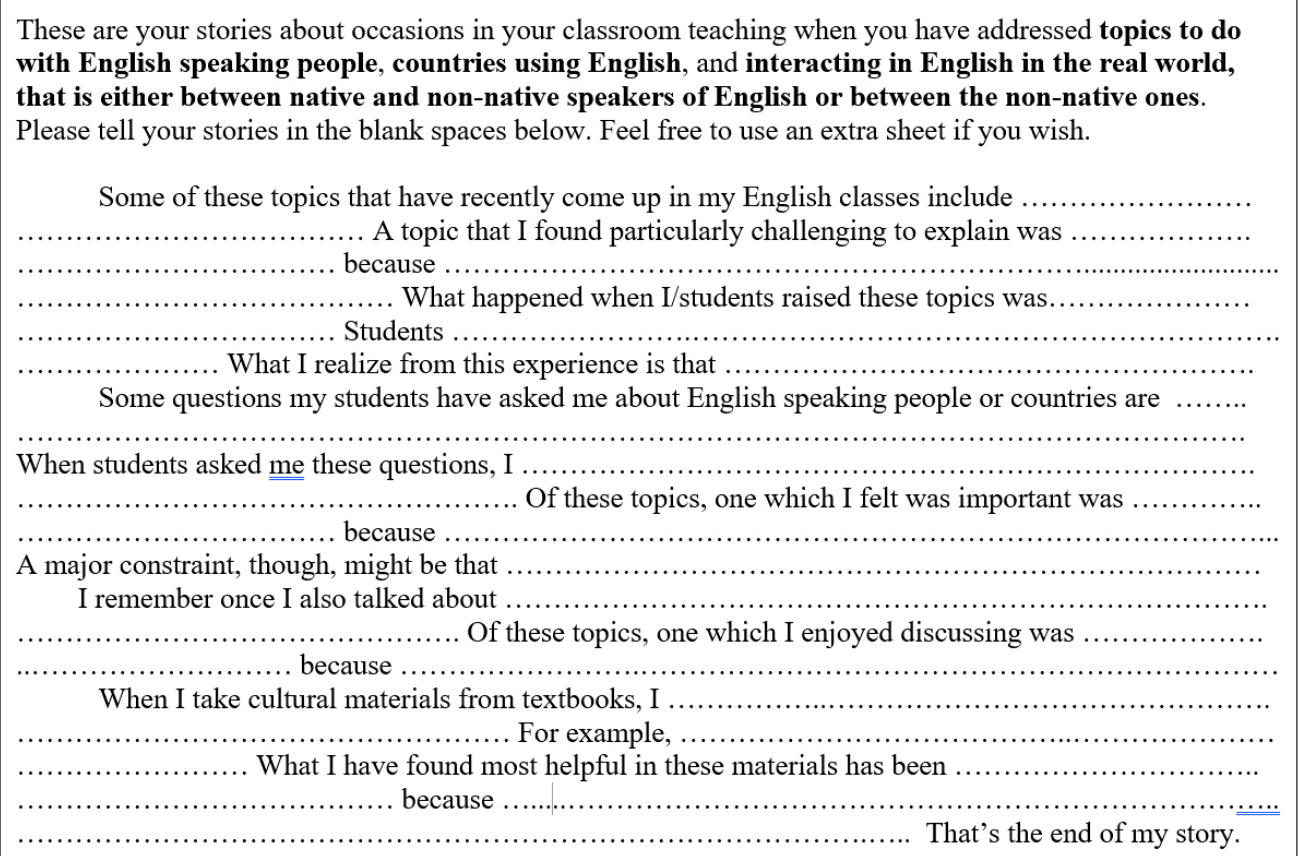

Figure 9: English NF

Berikut adalah cerita ringkas tentang peristiwa atau kejadian dalam kelas ketika Anda membahas tema yang berkaitan dengan penutur asli bahasa Inggris (native speaker of English), negara-negara berpenutur bahasa Inggris, dan interaksi di luar kelas menggunakan bahasa Inggris, baik antara non-penutur asli dengan penutur asli maupun antara non-penutur asli. Tuliskan cerita Anda di bagian kosong di bawah ini. Silakan gunakan lembar tambahan jika perlu.

Sejumlah topik tentang tema di atas yang akhir-akhir ini muncul dalam kelas bahasa Inggris saya antara

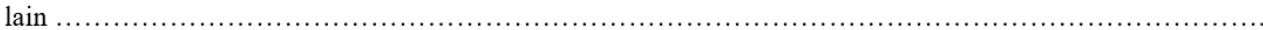

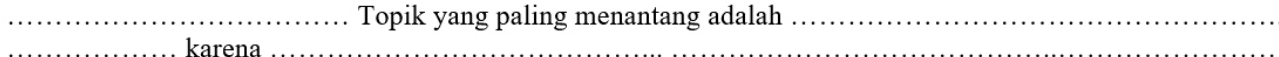

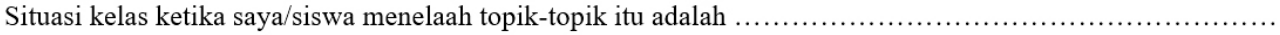

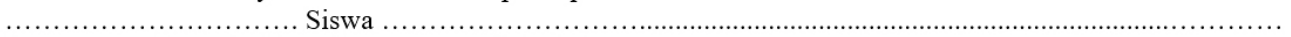
Yang saya pahami dari kejadian tersebut adalah bahwa

Beberapa pertanyaan yang pernah siswa ajukan tentang penutur atau negara-negara berpenutur bahasa Inggris termasuk

Ketika siswa menanyakan tentang hal itu, saya

$\ldots \ldots \ldots \ldots \ldots \ldots \ldots \ldots \ldots \ldots \ldots \ldots \ldots \ldots$ Berkaitan dengan topik-topik tersebut, salah satu yang saya anggap penting adalah

karena

Namun demikian, hambatan utamanya mungkin adalah

Saya juga pernah mengulas tentang

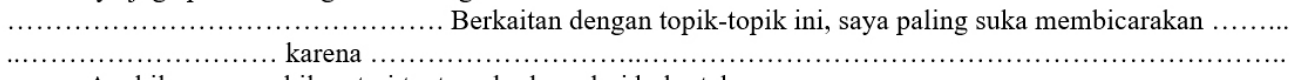

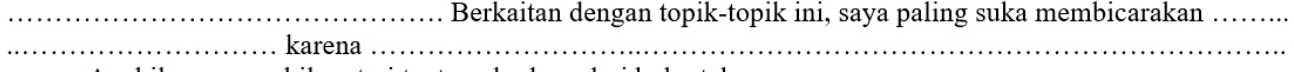
Apabila mengambil materi tentang budaya dari buku teks, saya Misalnya,

Menurut saya, tema atau materi budaya yang paling bermanfaat adalah

karena

Sekian cerita ringkas saya

Figure 10: Indonesian NF 
As can be seen from the Figures, the NF contained two main parts, i.e. instruction and content comprising three indented paragraphs. The instruction was so critical that in addition to giving information on how to complete the instrument and raising some issues being studied, it introduced topics relevant to the focus of the study. These had something to do with English speaking people, countries using English, and interacting in English in the real world, that is either between the NSs and NNSs of English or between the NNS ones. It is worth mentioning that the instruction mentions "occasions in classroom teaching" to mean actual classroom practices and "interactions in the real world" to refer to the real-life situation outside the classroom. Possible issues were printed in bold type to quickly draw the participants' attention to the phenomenon under investigation.

The content of the instruction consists of two main parts that prompt participants, first, to look at their classroom practices in relation to the predetermined issues and, second, to reflect on such experiences and talk about them in their own words. Such phrases in the sentence starters as 'a topic ... was', 'what happened ... was', 'when ..., I ...', 'some questions ... are', 'I also talked about ...' or 'For example, ...' gave teachers an opportunity to explore their actual teaching behaviours and link them with the issues. The NFs record the storied experiences of EFL teachers in Indonesian high schools and capture their theoretical knowledge of and beliefs about culture teaching. Other expressions such as '(found) particularly challenging', 'because', 'What I realise ...', '(was) important', 'major constraint', '[I] enjoyed', and 'most helpful' allowed teachers to reflect on their classroom activities and interactions.

Reflections also dealt with how the teachers interacted with students and the ways they made use of the textbooks, particularly in relation to the use of materials on culture. What was then particularly relevant to and potentially useful for this study is that the NF procedure would allow teachers to reflect on and make sense of the lives they have lived or they imagine living, demonstrate understandings of their teaching knowledge and practices, and articulate interpretations of these practices (Barkhuizen, Benson, \& Chik, 2014; Barkhuizen \& Wette, 2008).

\subsubsection{In-depth interview}

The last procedure I employed was a semi-structured interview. I held the in-depth interviews with all the five teachers within seven days after each of the participants submitted the NFs. Each interview lasted for 60-70 minutes. It was audio-taped so there was a total of more than 300 minutes' audio recording. 
What made it different from the SR interview was that this in-depth interview was devised to explore the teachers' views at a depth and glean insights into their beliefs, perceptions, and motivations (K. Richards, 2009), without being confined to the recorded teaching behaviours and classroom interactions. Despite being a single, one-shot interview, this in-depth interview was principally concerned with the previous procedures in that developing issues and emerging themes formed a basis for the interview guide. The guide was, however, in the form of a list of intended topics and key questions about the topics or subtopics to be covered in lieu of rigidly preformatted questions. The key questions dealt mainly with the teachers' ideas about language and culture, language and culture connection, the use of English in intercultural communication, culture in Indonesia's EFL classrooms, and the role of local EFL teachers in the teaching and learning of culture and interculturality.

I also raised questions about some 'unexpected' issues and themes that emerged from the previously conducted policy document analysis, classroom observations, SRs, and NFs. These included the State language ideology, nationally-imposed character education, home languages and practices, implicit culture teaching, NS-based competence and authenticity, and the influence of religious and especially Islamic perspectives. As with the pilot study, my questions were mostly open-ended, such as "Mengapa kelas bahasa Inggris diawali doa bersama dan menyanyikan lagu patriotik? [Why were the English classes started by offering a prayer and singing patriotic songs?]" or "Apa alasan Anda memilih materi yang menampilkan penutur asli atau non-penutur asli bahasa Inggris? [What were your reasons for using classroom materials that feature NSs or NNSs of English?]". That the interview was in Indonesian was also a definite plus. The language barrier was lowered and a possibility of misunderstanding was averted. Then, I transcribed the Indonesian interview and translated the transcription into English.

In the application of the procedure, a number of issues that I dealt with included rapport, neutrality, bias, and preconceptions, which overlap with each other. First, I built an easy rapport with the teachers to help them feel comfortable to express themselves in the interview. I reassured the teachers that the confidentiality of identity and information would be strictly preserved and that the recorded data had nothing whatsoever to do with any professional evaluation. Second, I took a non-judgemental approach to the teachers' pedagogic beliefs and classroom behaviours and affirmed neutrality on what they were going to tell me. I stressed that there would be neither right nor wrong answer and let the 
interviewees to tell anything without engendering either favour or disfavour on what is being said (Patton, 2002).

Third, I strived to detect and reduce bias, which is often manifested in 'a personal preference, like or dislike, which can interfere with our ability to be objective, impartial and without prejudice' (Jackson, 2014, p. 165). Unfortunately, bias is an inherent quality of human beings. All people have biases, and so do all reports (Stake, 2010). What is then of vital importance is to acknowledge and be honest about our own biases, explain them, consider how they might come into research, and account for them during the research (Hood, 2009). In practice, I refrained from using expressions that might lead the teachers to think that their perspective was compared to that of mine. Also, I held back from picking evaluative words or phrases that could be regarded as judging how good or bad the teachers' ideas were against private beliefs and thoughts.

Fourth, I had made myself constantly aware of the basic nature of this study, that is emergent and evolving, and ensured preconceptions would not be counterproductive. Preconceived ideas were for clarifying my philosophical position and offering guidelines on the purpose and focus of the study. Interview questions that I asked were aimed at absorbing almost any relevant information that might be useful for working out the teachers' cultural meanings and interpretations. I raised questions in order to explore new, uncharted areas of the problem under investigation. Moreover, I put open-ended questions and kept the interview open for unusual or unanticipated responses.

I also used in-depth interviews as a "member checking". That is, I presented to the teachers the SR interview transcripts and completed NFs, asked for correction and comment, as well as seeking (in)accuracy, insensitivity, and new meanings (Stake, 2010).

\subsubsection{Focus group discussion}

I held a student FGD as the final, complementary method of data collection. Students were purposely selected as a group of people 'associated with the cultural scene who have some things in common as well as several key differences' (Jackson, 2016, p. 246), or as individuals who have some knowledge of the topic being studied (Merriam \& Tisdell, 2016). The group interview was primarily aimed at gathering information about students' experiences in and their perspectives on cultural representations in English classes. There were seven student participants. Five are female and two others are male. All of the participants were Year 12 students. Although people of heterogeneous groups could in 
theory produce varied data, the dynamics of the group session works better with participants of similar backgrounds (Dörnyei, 2007).

I conducted the discussion in a room of a university where I worked in order to create a sense of "neutrality", that is the location was not part of any student's school and allow them to share feelings and opinions at their ease. The interview was done in Indonesian and audiotaped, resulting in an over 60 minutes' recording. I made a verbatim transcription and then translated it into English.

I created as friendly and relaxed atmosphere as possible to make the students feel comfortable and more willing to exchange views. I underlined the anonymity and confidentiality, emphasized that there would be no correct or incorrect answers, and reiterated the point that this study was not part of any academic assessment. The interview was conducted in a semi-circle seating arrangement. Also, I put an audio recorder behind the students so as to further reduce their anxiety, if any.

The fact that the students were enrolled in different schools and programmes and that they had been taught by several teachers other than the teacher participants might allow them to provide a wide range of information about classroom cultural representations or intercultural encounters they had that involved the use of English within and/or outside school. I functioned as a moderator and made sure that nobody was more dominant than others and that even the shyer participant would have a chance to offer views and contribute positively to the discussion. Only one participant spoke at one time was attempted. Yet, it was also much the same as a semi-structured interview that mostly consisted of broad, open-ended questions accompanied.

\subsection{Data analysis}

The analytic framework and procedure I employed exhibits three basic characteristics, i.e. interconnected, exploratory, and pragmatic. The interconnectedness of research paradigm, strategy, and method is manifested in the way I analysed and interpreted data. The paradigmatic stance was anchored in constructivist perspective that laid the basis for understanding reality and constructing knowledge. The research strategy, qualitative case study, helped set reasonable boundaries of the issue in question and maintained the research focus. It delved into a range of contextual factors and drew on multiple sources of evidence. The exploratory orientation was necessary because the research explored a relatively under-researched setting, namely, high-school EFL classrooms in Indonesia. 
The pragmatic approach allowed the use of the research method and particularly analytic strategy that would work best in the present study. That is, this study was neither rigidly inductive (data-driven) nor purely deductive (theory-driven), but rather practically drawing on inductive-deductive strategies in which background knowledge and theories fed into the data and emergent findings were somehow linked to the propositions. Theoretical interests and prior research informed the research topic and at the same time the research focus was shaped by new details. In this way, this study recognised the complexities of the social world-like education in general or language teaching in particular-that is never straightforward and left open to any possible lines of analysis and interpretation (Patton, 2002; K. Richards, 2003).

\subsubsection{Transcription and translation}

I made more than 500 minutes' audio recordings of SR, in-depth and focus group interviews. I had transcribers make verbatim transcription of the recordings as the raw data for further analysis. Transcribers, and later translators, were students of an English department in a Pendalungan-based university. Before giving the audio files to transcribers, I listened to the recordings and made a list of technical words with which transcribers might be unfamiliar. I discussed the terminology with the transcribers and helped them understand the basic ideas. Once the transcription was done, I checked its completeness and accuracy against the source audio files. I made minor editing regarding spelling and punctuation with the aim of increasing its readability for the next step, i.e. translation of the Indonesian transcript into English.

Translation would normally involve a more complex task than transcription. The challenges included gaining a proper understanding of the message in the source language (i.e. Indonesian) and presenting the information in the target language (i.e. English) in a grammatically, contextually and culturally acceptable form. This undoubtedly requires a broad knowledge of linguistic and sociolinguistic aspects of the two languages and some familiarity of the subject matter, particularly its discipline-specific vocabulary.

The transcription tasks allowed translators to become more familiar with the research topic and key terms, for example, "native English speaker", "English speaking people", "English speaking country", "native/non-native speaker English teachers", "stimulated recall", etc. I had discussions with the translator during the translation process and did final edit in efforts to make the translation of good quality. Both the original Indonesian and the 
English versions are displayed in the analysis and discussion section in order that readers have access to the raw information and a chance to check the accuracy of translations.

\subsubsection{Framework and procedure}

The analytic framework I adopted was based largely on the model of qualitative thematic analysis developed by Braun and Clarke (2006, 2012) and Clarke and Braun (2014). In Braun and Clarke's opinion, a qualitative thematic analysis is more an analytic tool or technique than a methodology. A thematic analysis is unbounded to any paradigmatic or theoretical assumptions, whereas methodology is commonly seen as a more comprehensive, theoretically informed framework for research. It does not owe allegiance to some theoretical positions. This is not to say that the thematic analysis is atheoretical or suited to any and all research designs. It can be used in a wide range of applications. A thematic analysis offers flexibility not only in conceptual bases, but also in other aspects of research such as the type of research question, the data collection method, the type and size of data set, and approaches to the construction of meaning.

A qualitative thematic analysis is thought of as a procedure for systematically identifying, analysing, and interpreting patterned meanings or themes within and across data sets. Revealed patterns may pertain to participants' lived experience, views and perspectives, or their behaviour and practices. A thematic analysis can aid in the report of the semantic (surface) and latent (underlying) meanings in the data, that is the assumptions and ideas that lie behind what is explicitly stated. It is further argued that a thematic analysis can be applied to recognise what is common to the way a topic is talked or written about and make sense of commonalities that become important to addressing a specific topic. While legitimately retaining the focus on meaning across data sets, the thematic analysis allows researchers to organise and describe data in rich detail and afford insights into shared experiences and meanings.

\section{Codes and theme}

I identified key features of the data set and generated codes and themes to provide substantial evidence and support my analytic claims. A code is defined as "a word or short phrase that symbolically assigns a summative, salient, essence-capturing, and/or evocative attribute for a portion of language-based or visual data" (Saldaña, 2012). Good thematic codes express the qualitative richness of a phenomenon (Boyatzis, 1998). They are usable in the analysis, interpretation, and presentation of the five teachers' cases. 
Coding is not simply attaching an informative label to a chunk of text intended to reduce or simplify data, but it highlights 'special features of certain data segments in order to link them to broader topics or concepts' (Dörnyei, 2007, p. 250). Coding goes beyond a mere descriptive labelling. In the coding processes, I found it essential to notice patterns that emerged across the individual accounts and capture abstract commonalities. In some respects, tentative interpreting had begun in the coding stage, as its link to the theory and the research topic was very much in the foreground. Coffey and Atkinson (1996) note that coding reflects analytic ideas. It generates concepts from data. Attaching codes to data and generating concepts enable researchers to review what data is saying. Codes, data categories, and concepts are brought together and related closely to one another.

Codes are the building blocks for themes and show broader patterns of meaning underpinned by a shared core idea (Clarke \& Braun, 2017). In the thematic analysis, themes are very crucial because they not only provide a framework for organising and reporting the analytic observations, but also address the research question. That is, themes capture something meaningful or important about the data in terms of the specific research topic or problem and represent patterned meanings across the full data sets (Braun \& Clarke, 2006). Themes are used to both offer compelling evidence and structure the presentation of findings. It is worth stressing that themes are analytically constructed out of coding and that researchers themselves attach 'importance' to data items so that they qualify as a theme. Researchers determine what a theme is by making active, reflexive and interpretive choices in developing codes and themes (Clarke \& Braun, 2014).

\section{Inductive-deductive strategy}

A qualitative thematic analysis flexibility allowed me to straddle analysis between inductive and deductive logic. I subscribed to the view that atheoretical inquiry is next to impossible. Merriam and Tisdell (2016), for example, maintain that theory underlies all research. Theories serve as the underlying structure, the scaffolding or frame that informs study. Supporting this view, Dörnyei (2007, p. 39) emphasizes that researchers' prior knowledge 'helps them to see and decipher details, complexities and subtleties, as well as to decide what kind of questions to ask or which incidents to attend to closely'.

The inductive reasoning enabled me to combine and order bits and pieces of information from the documents, observations, and interviews into larger themes (Merriam $\&$ Tisdell, 2016). As I worked from the particular to the general, I sought to construct categories, patterns and themes. Simultaneously, the deductive approach allowed the 
analysis of the data according to an existing theoretical framework (Patton, 2002). Rather than drawing on the framework for testing or confirming categories, I used it as a sensitizing lens through which I gleaned the most relevant information, figured out potential codes and themes, and explored the case in question.

In practice, I brought the theoretical frameworks to the data in the coding and analytic process. As Braun and Clarke (2006) conclude, data is never coded in an epistemological or theoretical vacuum. Although the development of codes and themes was driven by my theoretical and analytic interests, the codes and themes not devised to fit in into prefigured frames or preconceptions. In a nutshell, the bottom-up, inductive logic allowed for the development of codes and themes from the content of the data itself, and the top-down, deductive reasoning let me bring to the data a series of background knowledge, concepts, and ideas to generate codes and themes and interpret the data.

\section{Analytic procedure}

Following are the steps I took to implement the thematic analysis. These were primarily based on the six-phase process proposed by Braun and Clarke (2006, 2012) and Clarke and Braun (2014). Some of the phases are similar to those of other qualitative studies and not necessarily exclusive or unique to a thematic analysis. Coding and theme derivation that serve as the backbone of thematic analysis seem common in qualitative research. The theoretically flexible approach draws its strength from the iterative nature of qualitative analytic process. There were no clear-cut boundaries between the phases of analysis. It also involved a constant back-and-forth movement within the data set and the analytic stages and throughout the overall research processes.

The six phases basically consist of four main stages, i.e. data familiarization, coding, theme development, and write-up. The central concept, that is theme development, is divided into more detailed steps comprising searching for and reviewing potential themes as well as defining and naming themes. In what follows, I describe the basics and step-bystep guide of the analysis and then what I did in the relevant phases. 


\begin{tabular}{c|l|l}
\hline \multicolumn{1}{c|}{ Phase } & \multicolumn{1}{c}{ Process } \\
\hline 1 & Data familiarization & $\begin{array}{l}\text { Transcribing data, reading and re-reading the data, noting } \\
\text { down initial ideas. }\end{array}$ \\
\hline 2 & $\begin{array}{l}\text { Initial codes } \\
\text { development }\end{array}$ & $\begin{array}{l}\text { Coding interesting features of the data in a systematic fashion } \\
\text { across the entire data set, collating data relevant to each code. }\end{array}$ \\
\hline 3 & Search for themes & $\begin{array}{l}\text { Collating codes into potential themes, gathering all data } \\
\text { relevant to each potential theme. }\end{array}$ \\
\hline 5 & $\begin{array}{l}\text { Review of potential } \\
\text { themes }\end{array}$ & $\begin{array}{l}\text { Checking if the themes work in relation to the coded extracts } \\
\text { and the entire data set, generating a thematic 'map' of the } \\
\text { analysis. }\end{array}$ \\
\hline 6 & nefining and & $\begin{array}{l}\text { Ongoing analysis to refine the specifics of each theme, and the } \\
\text { overall story the analysis tells, generating clear definitions and } \\
\text { names for each theme. }\end{array}$ \\
\hline
\end{tabular}

Table 4: General phases of thematic analysis (Braun \& Clarke, 2006, 2012; Clarke \& Braun, 2014)

Phase one involves familiarization with the data. This enabled me to immerse myself in all aspects of the data set and become intimately familiar with the depth and breadth of the content. Repeated reading in an active and critical manner was necessary. Listening to or transcribing audio data or watching video helped me search for meanings and form some ideas of developing patterns.

At this stage, I noticed features that might be relevant to the research topic more carefully and became increasingly familiar with the data. Choosing what to look for or focus on during the classroom observations and deciding what observed practices to explore in the interviews in one way or another familiarized me with the data set. I checked Emergent issues against the research topic and questions. Theories, preconceptions, and prior research became lenses that influenced my comprehension or evaluation during the close reading. Transcribing the audio files and translating the transcript into English were parts of the interpretive and creative processes that would assist in the data analysis.

Phase two aims for the development of initial codes from the data set. Essentially, codes should capture key features of the data that are of potential relevance to the research question. I sought to give each data item equal attention. What might be relevant was perhaps not quite clear so that inclusive, thorough, and systematic coding was vital. Codes could be developed at the manifest and latent levels, incorporating both obvious and underlying meanings. They could go beyond the surface meanings and offer conceptual interpretations. In Stake's (2010, p. 151) words, coding is 'for interpretation and storage more than for organizing the final report'.

I applied descriptive and in vivo coding approaches to the initial codes development. According to Saldaña (2012), the use of a combination of the basic coding methods may 
serve as a generic approach to data and analysis as they remain open to changing in case they are not generating substantive items. Descriptive coding is especially appropriate for observation notes and documents by providing a detailed inventory of their contents. I found the method especially useful because the topics of the written materials that I analysed (i.e. laws, curricula, textbooks, and NFs) varied considerably. As Saldaña (2012) writes, descriptive coding summarizes the basic topic of a qualitative passage in a word or short phrase and codes become identifications of the topic, that is what is talked or written about instead of abbreviations of the content. In addition, in vivo coding prioritizes and honours the participants' voice. This method allowed me to use the teachers' original words as codes in the place of theory-driven terms. I applied these codes to interview data extracts.

Phases three and four, searching for and reviewing potential themes, fed into each other. These began after all the codes and relevant data had been collated and ended up with a fairly definitive list of "candidate" themes. I identified similarities, overlaps and relationships between themes. Themes worked towards a rich and complex story about the data. Then, I attempted two levels of review; first, checking themes against the coded data, and secondly, against the full data set. The former was designed to see if themes and coded data fit in with each other and if the themes tell a convincing and coherent narrative; the latter found out whether the themes capture the most relevant features of the data and adequately address the research questions.

During these phases, I found "triangulating" themes fruitful in conducting the two levels of review and assessing the overall fitness or suitability of the themes. I compared, contrasted, and cross-checked themes generated from a particular source of evidence against those from other sources. For example, I compared and contrasted potential themes constructed out of the current policies on language, general education, and EFL curricula with those out of the observations and interviews. In this way, not only did I look for similar or overlapping themes, but I also searched for significant differences among the themes. Exploring seemingly conflicting results enabled me to examine the coherence or otherwise of the themes or check whether a theme would remain one, be grouped into subthemes, or be discarded instead.

In phase five, defining and naming themes, it was necessary for me to clearly show the unique and specific characteristic of each theme that facilitates the development of a rich and complex analytic narrative. Ideally, themes had a singular focus and were related but neither repetitive nor overlapping. In addition to telling the story of each theme, theme 
definitions should indicate its central concept, scope, and boundaries as well as the connection with other themes and the broader research questions. Theme names should be informative, concise and catchy. They ought to encompass the "essence" of the theme.

In order that I could give clear definitions and workable names, I linked the themes to the wider issues covered in the guiding concepts of ILTL, EFL, native speakerness, and EIL. In practice, my research questions also foregrounded this phase. The definitions and names of themes would inescapably concern a broad range of topics, including the conceptualizations of language, culture and the language-culture nexus; approaches to language and culture teaching and learning; the goals of foreign language education; cultural representations of target language-culture; and so forth. The theoretical frameworks and accordingly the constructed themes might also relate to the use of English in intercultural communication and the [non]native-speakerness of English teachers in the context of EFL.

Phase six, that is writing up, is connected with analytic process in qualitative inquiry. The separation between report writing and data analysis can be blurry. Producing the report may involve 'assembling, editing, and (new) writing and further analysis, organisation, and reorganisation of the themes and relevant selected data extracts' (Clarke \& Braun, 2014, p. 1951). Among the potential pitfalls, a weak analysis and a mismatch between the data and analytic claims might occur. Illuminating examples should therefore be given to demonstrate the themes. It is crucial that data extracts present clear and convincing evidence to support analytic claims. Analyses need to go beyond description and make arguments that answer the research question. Also, the report should aim for a coherent, complex and compelling narrative.

In the data analysis and report writing, I shared Holliday's (2007) view that in a purely thematic approach, themes emerge as running through their totality under which the data was taken holistically and rearranged. Themes provided headings and stages in the argument and laid the basis on which the argument, the data extracts and the discursive commentaries were organised. I was of Coffey and Atkinson's (1996) opinion that the write-up should be treated as an analytical task in which thinking about how to represent the data allowed thoughtful reflection upon the meanings and understandings, voices, and experiences present in the data. Also, I strived to balance analysis and interpretations which involved "explaining the findings, answering "why" questions, attaching significance to particular results, and putting patterns into an analytic framework' (Patton, 2002, p. 438). 


\subsection{Ethics and trustworthiness}

This section accounts for the ethical stances and procedures I employed to uphold the principles of ethics and trustworthiness. As for me, a qualitative naturalistic study is deemed credible on the grounds that it not only maintains an intellectual rigour, but also displays such basic human qualities as honesty, trust and ethical responsibility of the researcher (Dörnyei, 2007; Merriam \& Tisdell, 2016).

\subsubsection{Ethics}

Patton (2002, p. 407) points out that 'qualitative inquiry may be more intrusive and involve greater reactivity than surveys, tests, and other quantitative approaches'. Qualitative procedures are highly personal and interpersonal, and naturalistic approaches take the researcher into the real social world where people live and work. There lies the researcher's moral character at the heart of research ethics (Dörnyei, 2007). According to Rallis and Rossman (2009), when faced with situations that demand complex moral reasoning, researchers develop their own standards for ethical practices. Yet, these ethical considerations cannot be wildly idiosyncratic. The formal code of ethics that prevails in the discipline or profession should then be recognised, along with the writings of other researchers on the ethical dilemmas that they have dealt with in their practice. Keeping these principles in mind, I made every effort to ensure that no mental or physical harm came to teacher and student participants as a result of their participation in this study. In the followings, I explain how I tackled some key ethical issues, including consent, privacy, anonymity, and confidentiality.

Before conducting the data collection, I had gained approval from the Human Ethics Committee at Victoria University of Wellington (Appendix 1). Then, I sought permission from heads of the District Office of MoNE and MoRA in Pendalungan to gain access to schools and gather data from teachers. Once I got the permission (Appendix 14 and 15), I sent letters and enclosed the Office permission to gain approval from the principals of schools where prospective teacher participants worked.

In order to recruit participants, I sent invitations written in Indonesian to a number of teachers from different high schools, and later from whom I received further information about other teachers who might be interested. I attached Information sheets in English and Indonesian to allow a better understanding of the study and the procedures for data collection (Appendix 7 and 8). I arranged meetings with the teachers who expressed interests in order that I would be able to give explanations in person and give them 
opportunities to ask question. The procedures were planned to take up to ten weeks. Following the meetings, nine teachers proceeded with the next step, that is the signing of a Consent form (Appendix 9). Both Consent forms and Information sheets were printed be on VUW letterhead. Of the nine teachers, five were teachers at GHS, two at VHS, and the other two at IHS. When the allocated time had run out, four teachers were unable to make it and withdrew their participation.

The method of recruitment of student participants was slightly different from that of the teacher. At first, I did not have any direct contact with the students. Teacher participants gave Information sheets to their respective students. Initially, nine students expressed their interest. Then, I contacted and arranged meetings with interested students where I was able to go through the Information sheet (Appendix 10 and 11) and answer questions about the study and the data collection in person. After the meetings, two students withdrew from their intended participation and seven students proceeded and signed the Consent forms (Appendix 12 and 13). All the students were over the age of 16.

\subsubsection{Trustworthiness}

The trustworthiness and rigour of this study might be attributed to the ways I approached the research paradigm and design, triangulation, potential bias, and thick description. At the beginning of this chapter, I clarified my philosophical and theoretical assumptions. Constructivism served as the undergirding principle. Readers could well anticipate how I perceive the world and interpret reality. I accepted the notion of interconnected research paradigm, strategy, and methodology. Following this perspective, I adopted the dynamic, non-essentialist approach to language-and-culture in language education.

Rather than making "fruitless attempts to convert the unconvertible", I focused efforts on understanding the personal belief system, demonstrating the value of research position, and producing research that proves its worth (K. Richards, 2003). I put the philosophical assumptions into practice by applying a research strategy or design that allowed me to look into the vast areas of real-life human experiences, recognize the context-bound and valueladen participants' meanings and interpretation, and gather the most relevant possible information (Patton, 2002), that is qualitative case study.

The triangulation in this study was obvious in the ways I decided to draw on various sources of evidence and apply different methods of data collection. By contrasting and comparing a particular type of data with the other types, I sought to enrich the analyses with supporting and/or contradictory information that would ultimately give a more 
balanced and deeper understanding of research findings (Roller \& Lavrakas, 2015). A mixture of different research techniques or the examination of data from different viewpoints would not reduce the complexity of our understanding, but rather reveal and construct such variety and complexity of the social world (Coffey \& Atkinson, 1996). In this respect, I wished to shed some light on the many different facets of the phenomenon in its full social complexity and give voice to the voiceless.

I made the likely causes of potential bias explicit. Being a Javanese and Muslim, that is the sociocultural and politically dominant ethnic and religious group in Indonesia, for example, might shape my attitude towards the respondents or my perceptions of their responses. With that in mind, I tried and recognised personal and cultural values that might affect my decisions and preferences during the research process. I had heightened such a self-awareness from the very beginning of and throughout the research act. By deliberating on the personal, cultural and professional backgrounds and experiences, my main intention was to detect the sources of bias, be able to constrain potential biases, and allow the least influence of personal preferences in the data collection and analysis.

Moreover, a thick description I offered was aimed to give the context of the EFL teachers' experience, state the intentions that organised experiences, and reveal the experience as a process (Holliday, 2007). The personal and professional backgrounds as well the cultural meanings the participants attached to their classroom activities, events, and behaviours would be described richly and in greater detail (Dörnyei, 2007). The transferability of the study hinges on the richness of the description and interpretation that may make this particular case interesting and relevant to those in other situations (K. Richards, 2003).

By leaving the extent to which this study's findings may apply to other situations up to the people in those situations, readers decide whether the findings can apply to their particular situation (Merriam \& Tisdell, 2016).

\subsection{Summary}

In Chapter 3, I set forth the method for collecting and analysing data of the present study. I used Guba and Lincoln's (1994, 2005) macro category of research paradigm, strategy and method to describe the methodological approach and processes. The tenets of constructivist paradigm and qualitative research principles underlying my research decisions. I collected the data in participants' real-world settings and made sense of the subjective opinions and significance they attach to their actions. I kept this study open to emerging details and went 
through an iterative research process. Also, I was the primary "research instrument" that made findings "speak" by drawing inferences and giving meanings to the data.

Five local EFL teachers working in two GHSs (Ambar, Ana and Aris), a VHS (Wati) and an IHS (Yanti) located in Pendalungan, Indonesia took part as primary participants and seven students as secondary participants of this study. I used classroom observations, NFs, SRs and in-depth interviews as the primary methods to get information from the EFL teachers. I elicited as detailed information as possible by observing the teachers' actual classroom behaviour, doing interviews, and seeing the teachers do activities in their natural settings. Prior to the field work, I analysed national laws and regulations on language, general education and EFL pedagogy to delve more deeply into the situatedness of the teachers' instructional judgment and decisions. In addition, I held a students' FGD to gain insights into the teacher's practices as well as classroom events and interactions.

I analysed the data by means of a qualitative thematic analysis framework developed by Braun and Clarke (2006, 2012) and Clarke and Braun (2014). I benefited from the flexibility of thematic analysis given that this study was neither purely deductive (theorydriven) nor rigidly inductive (data-driven). That is, the inductive reasoning allowed me to order bits and pieces of emergent information into larger themes; simultaneously, the inductive approach enabled me to use ILTL principles as a theoretical lens to figure out potential themes, explore the targeted phenomena, and make sense of the data. There were no clear-cut boundaries between data familiarisation, coding, theme development and report writing. The iterative nature of thematic analysis allowed for a constant back-andforth movement within and across the data set, during the analytic stages, and throughout the overall research processes.

The ways I approached the research design, triangulation, biases and thick description played a key role in establishing the trustworthiness of the present study. I drew on the interconnection between the research paradigm, strategy and method while conducting this qualitative study, which recognises the interactive link between the researcher, the object of inquiry and the context of investigation. The triangulations throughout the iterative research process enabled me not only to obtain various forms of data and corroborate findings, but also to appreciate the many different facets of social phenomenon in its multidimensionality and complexity. The richly detailed and vivid descriptions and interpretations of the case being studied might not only help me paint a fuller, meticulous picture of the phenomenon under investigation for the reader, but also establish its relevance to other EFL socio-educational settings. 
Finally, cultural and religious values as a Muslim Javanese might creep into my attitude towards the participants or perceptions of their responses. I made explicit and contained potential biases, allowing only the least possible influence of personal preferences. Also, I addressed such key ethical issues as privacy, anonymity and confidentiality before, during and after the study to uphold the principles of ethics. 
This page is intentionally left blank. 


\section{Chapter IV}

\section{The EFL Teachers' Cases}

\subsection{Introduction}

In this chapter, I present the cases of the five Indonesian high-school EFL teachers, i.e. Ambar, Ana, Aris, Wati and Yanti. The teachers' cases are built upon classroom observations, NFs, SRs and in-depth interviews as well as document analysis and students' FGD (Table 5). These are organised and described according to salient themes emerging from each case. Triangulations within the data set occurred throughout the research processes, drawing on the multiple forms of evidence obtained from the different data collection methods. The recap and remarks section after each case summarises and gives a critical response to the case, providing the basis for further cross-case discussion and analysis in Chapter 5.

\begin{tabular}{|c|c|c|c|c|c|c|}
\hline \multirow{2}{*}{$\begin{array}{l}\text { Method } \\
\text { NNEST }\end{array}$} & \multicolumn{4}{|c|}{ Primary } & \multicolumn{2}{|l|}{ Secondary } \\
\hline & Observation & SR & NF & Interview & Document analysis & FGD \\
\hline Ambar & 270 min. & $40 \mathrm{~min}$. & Indonesian & $60 \mathrm{~min}$. & \multirow{5}{*}{$\begin{array}{l}\text { Policy (language, } \\
\text { education, EFL) and } \\
\text { classroom doc } \\
\text { (syllabus, RPP) }\end{array}$} & \multirow[t]{5}{*}{$60 \mathrm{~min}}$. \\
\hline Ana & 270 min. & $45 \mathrm{~min}$. & English & $70 \mathrm{~min}$. & & \\
\hline Aris & $180 \mathrm{~min}$. & $40 \mathrm{~min}$. & Indonesian & $70 \mathrm{~min}$. & & \\
\hline Wati & $180 \mathrm{~min}$. & $50 \mathrm{~min}$. & Indonesian & $60 \mathrm{~min}$. & & \\
\hline Yanti & $270 \mathrm{~min}$. & $50 \mathrm{~min}$. & Indonesian & $60 \mathrm{~min}$. & & \\
\hline
\end{tabular}

Table 5: Participants and data collection methods

The presentation of the EFL Indonesian teachers' cases was first and foremost devised to address the research questions, i.e. the way the teachers worked with culture and interculturality in their teaching practice; pedagogic beliefs that informed the teachers' classroom behaviour; broader cultural and intercultural understandings and experiences that the teachers identified as shaping their representations of culture and interculturality; and, the ways a range of sociolinguistic, cultural, political and religious factors that are present in the immediate classroom and school environment as well as in the wider socioeducational contexts contributed to the teachers' instructional judgment and decisions.

In addition to submitting to developing patterns of data, I referred to the theoretical frameworks and captured salient themes emerging from each teacher's case, introducing them as section headings (Holliday, 2007). For example, I explained cultural themes in the data in relation to Indonesia's policies on general education and EFL pedagogy as well as the language ideology and nationally-imposed cultural, economic or political agenda. I 
described instances of culture in and around host and target language made by either the teachers or students in the EFL classrooms in relation to the importance of noticing linguistic or cultural similarities and differences between home and target language-andcultures as well of exploring and crossing linguistic and cultural boundaries

In the light of Indonesia's multilingualism and internal cultural diversity, the EFL teachers' reported beliefs and observed classroom behaviours were understood on the basis of the extent to which they drew on learners' home knowledge, languages and practices, and mined the sociolinguistic diversity of the classroom and the society. Furthermore, the high-school EFL teachers were evaluated whether they brought both the students' and their own cultural assumptions, norms and attitudes into consciousness; how they negotiated and mediated likely conflicting cultural values and behaviours; and, the way they established links between first and additional language-and-cultures.

\subsection{Ambar's case}

Ambar had taught English to Year 10, 11 and 12 pupils at GHS Jawa in Pendalungan for over five years and played an active role in preparing Year 12 students for a high-stake national examination. GHS Jawa is one of the "favourite" senior high-schools in the district. The school is known for relatively high school-admission grades, students' strong academic achievements and above average English skills. Being a co-educational public school, male and female students of any faiths are taught in a classroom together and engage in joint activities. Some female students wore hijab, which is locally known as jilbab, and some others did not.

Before teaching at GHS Jawa, Ambar had around 10 years' teaching in other high schools in different cities in East Java province, that is in Sumenep and Jombang. The two cities have different ethnolinguistic backgrounds. Sumenep is located on Madura Island where Madurese people are the majority whilst Jombang is in Java Island and predominantly Javanese. Sumenep and Jombang are known for the presence of many Islamic boarding schools (pesantren) and their general Islamic atmosphere. Ambar is a Christian. Major themes arising from Ambar's case are policy-oriented classroom actions, a personalisation of teaching and learning materials, and the divergence between pedagogic beliefs and practices. 


\subsubsection{Policy-oriented actions}

What happened in Ambar's English classes and how she worked with culture and interculturality in the classrooms to a degree hinged on the nationally- and locally-dictated policies on the EFL and general education. In two of the observed classes that were held in the first teaching hour, i.e. 7.00-7.45 am local time, for instance, Ambar opened the English lesson by asking a class monitor to lead a silent supplication. The student could be heard saying in English 'Before we start our lesson, let's pray together.' In principle, the school events comply with the general objectives of Indonesia's national education as stated in Law 20/2003, that is to strengthen pupils' faith and piety as well as enhancing their intellectual capacity. At the same time as the classroom silence, an Islamic supplication that was being made in Arabic and Indonesian could be heard from centralised school loudspeakers. The supplication appeared to formally commence the teaching hours, although as a public-school GHS Jawa welcomes teachers and pupils of any faith.

Following the supplication, Ambar asked students to jointly sing Indonesia Raya/Great Indonesia (Figure 11) to start the class. Prior to singing the national anthem, she explicitly stated the reason for doing so: 'Before starting our lesson, I would like to play a song, a national song, in order to increase our nationalism, in order [that] we love Indonesia, our homeland.' By using a laptop and classroom LCD projector and loudspeaker, Ambar played the song first and then asked students to sing together. It is interesting to note that there were English subtitles for the Indonesian lyrics. Another patriotic song to sing in the classroom was Tanah Airku (My Motherland) composed by late Sarijah Niung (widely known as 'Ibu Sud'), expressing a great admiration for the nation as follows:

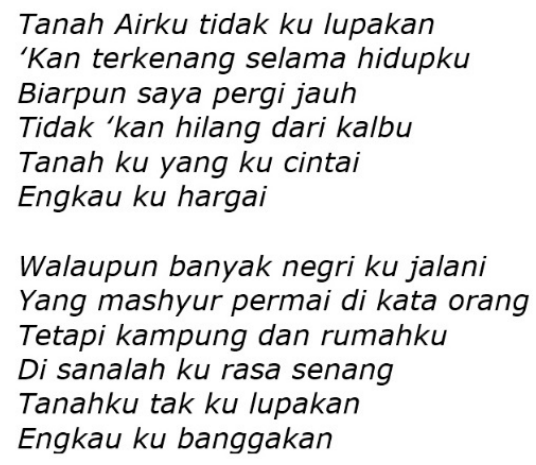

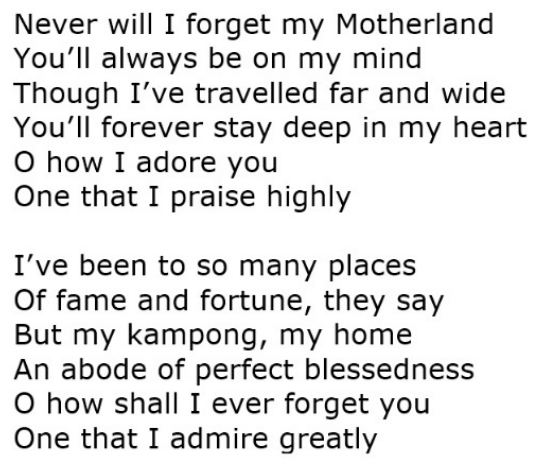




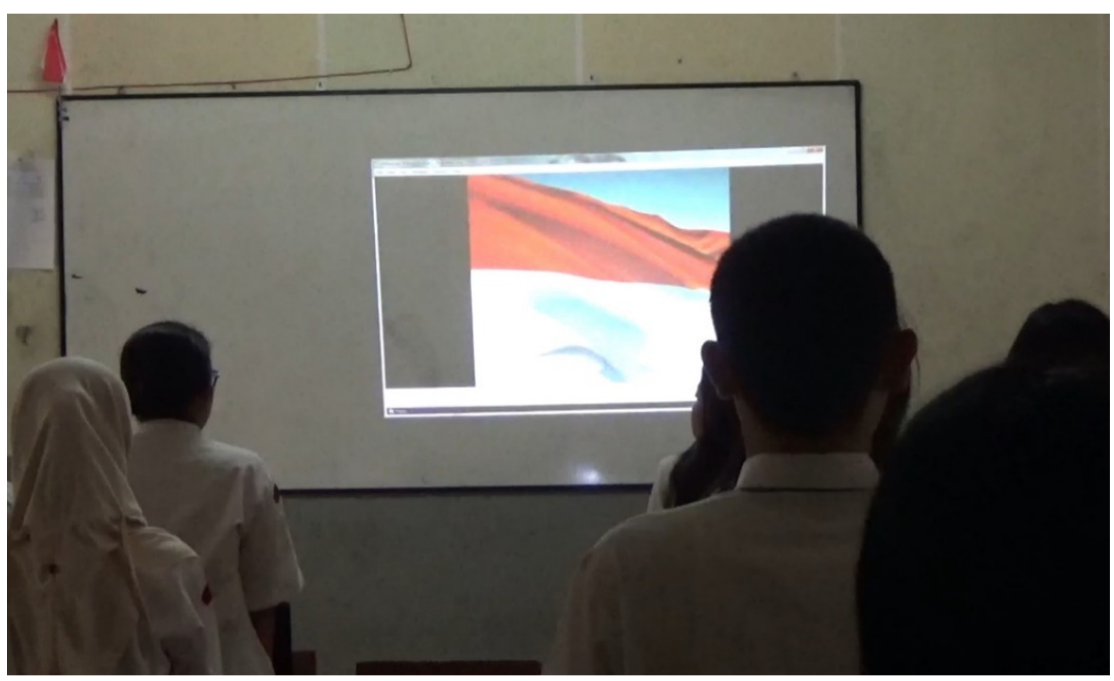

Figure 11: GHS Jawa students stand up singing Indonesia Raya

Issues relating to nationalism, local cultures, and folklores arose in Ambar's classroom practices and reported judgments. When asked why students sang such Indonesian songs to start their English classes, Ambar replied:

Itu sebenarnya wajib. Iya sekarang di Kurikulum 2013 yang pertama harusnya ini pak, Indonesia Raya, terus yang terakhir itu lagu nasional atau lagu daerah. Terus materimaterinya sekarang memang ... Misalnya kalau dulu naratif itu dari luar, sekarang itu misalnya Malin Kundang, Banyuwangi legend. Jadi mengarah ke Indonesia.

The activity [singing together] is in fact mandatory. In Curriculum 2013, the first [song to sing] is, Indonesia Raya, and then another national or local song to end class. This also concerns the teaching and learning materials ... For example, narrative [texts] were once originated from sources that are outside Indonesia, but these now include [folklores] such as Malin Kundang, legend of Banyuwangi, and so on. Thus, they are focused on Indonesia. (Interview with Ambar, 4/11/15)

What and how Ambar presented the teaching and learning materials and cultural content in her English classes fell within the nationally-mandated goals and the school's approved syllabus and lesson plan (Rencana Pelaksanaan Pembelajaran/RPP). Take, for example, the 'Syllabus and Assessment Systems' (Silabus dan Sistem Penilaian) for Semester 2Year 11 (Figure 12). The first 'Core competency' is 'To be deeply committed to and practice the religion of one's choice (Menghayati dan mengamalkan ajaran agama yang dianutnya), and the second one includes 'expressing a solution-oriented attitude towards problems arising from interaction with social and natural environment (menunjukkan sikap sebagai bagian dari solusi atas berbagai permasalahan dalam berinteraksi secara efektif dengan lingkungan sosial dan alam).' 


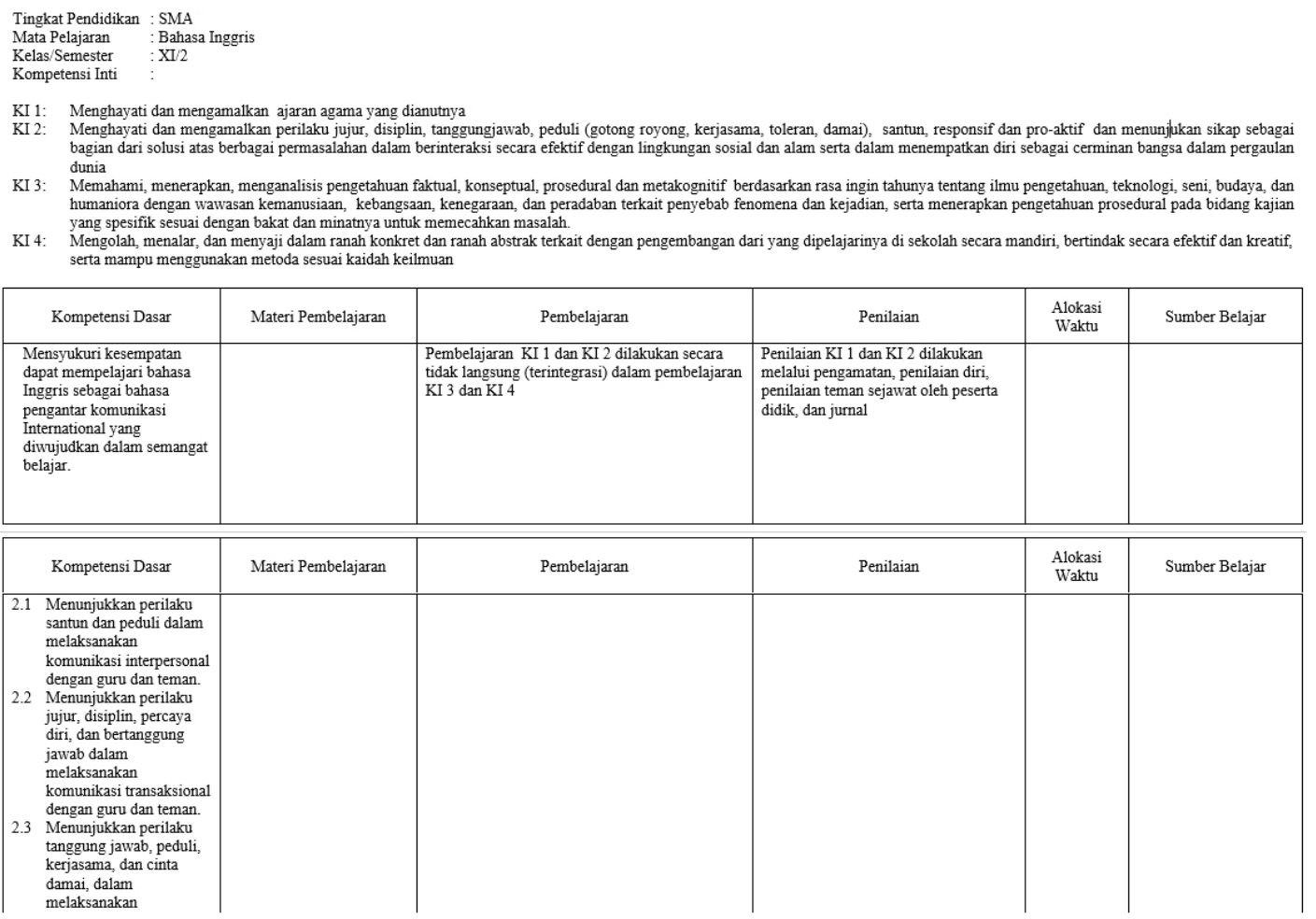

Figure 12: An excerpt from Ambar's English syllabus of Semester 2-Year 11

Moreover, the "core competency" stated in Ambar's RPP for Semester 1-Year 11 regarding 'personal letter text' (Teks surat pribadi) (Figure 13), refers to the approved syllabus and reflects the broad objective of the national education, i.e. '[To be able to] Understand, apply, analyse factual, conceptual, procedural and metacognitive knowledge in compliance with students' curiosity about natural science, technology, art, culture, and social science with a wider outlook on humanity, nationhood, statehood, and civilization ... (Memahami, menerapkan, menganalisis pengetahuan faktual, konseptual, prosedural dan metakognitif berdasarkan rasa ingin tahunya tentang ilmu pengetahuan, teknologi, seni, budaya, dan humaniora dengan wawasan kemanusiaan, kebangsaan, kenegaraan, dan peradaban ...).' Yet, its 'basic competence and indicator (of learning achievement)' is more specific, that is 'To distinguish the social function, text structure and linguistic aspect of a number of particular texts in personal letter ... according to its context of usage (Membedakan fungsi sosial, struktur teks and unsur kebahasaan beberapa teks khusus dalam bentuk surat pribadi ... sesuai dengan konteks penggunaannya).' 


$\begin{array}{cl}\text { RENCANA PELAKSANAAN PEMBELAJARAN } \\ \text { Sekolah } & : \\ \text { Mata Pelajaran } & : \text { Bahasa Inggris (wajib) } \\ \text { Kelas/Semester } & : \text { XI/1 } \\ \text { Materi Pokok } & : \text { Teks surat pribadi } \\ \text { Alokasi waktu } & : 8 \times 45^{\prime} \text { (4 x pertemuan) }\end{array}$

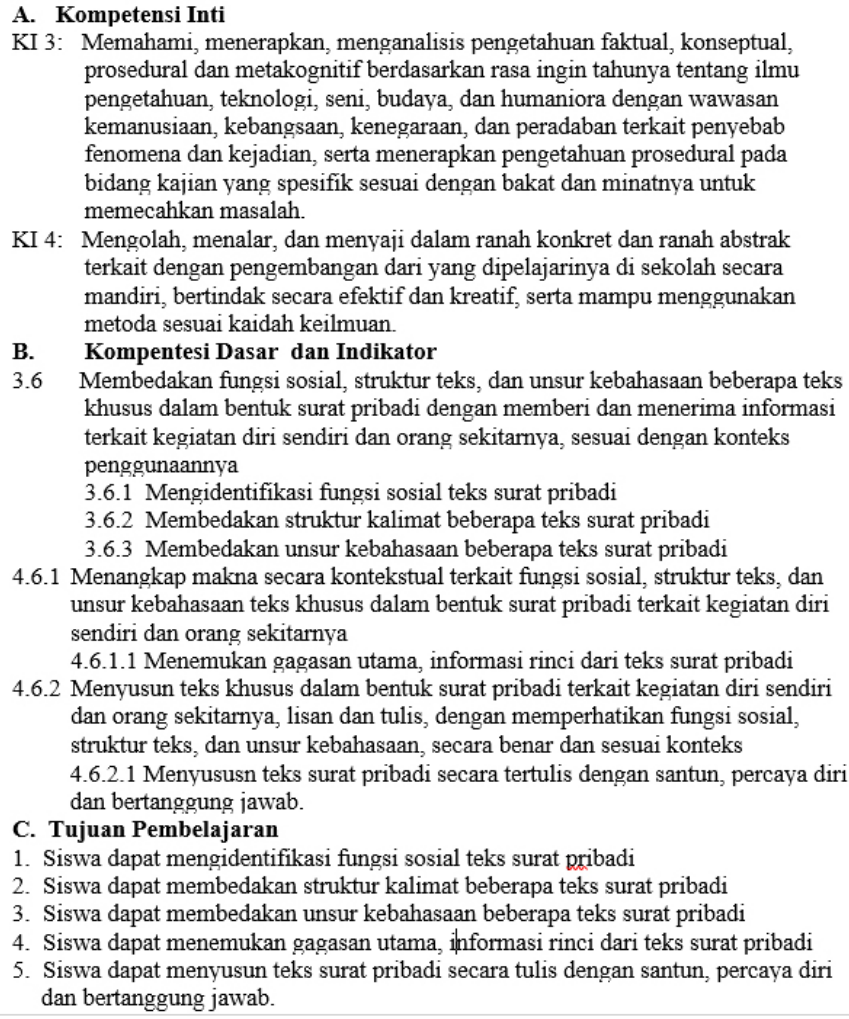

KI 4: Mengolah, menalar, dan menyaji dalam ranah konkret dan ranah abstrak terkait dengan pengembangan dari yang dipelajarinya di sekolah secara mandiri, bertindak secara efektif dan kreatif, serta mampu menggunakan metoda sesuai kaidah keilmuan.

B. Kompentesi Dasar dan Indikator

3.6 Membedakan fungsi sosial, struktur teks, dan unsur kebahasaan beberapa teks khusus dalam bentuk surat pribadi dengan memberi dan menerima informasi terkait kegiatan diri sendiri dan orang sekitarnya, sesuai dengan konteks penggunaannya

3.6.1 Mengidentifikasi fungsi sosial teks surat pribadi

3.6.2 Membedakan struktur kalimat beberapa teks surat pribadi

3.6.3 Membedakan unsur kebahasaan beberapa teks surat pribadi

4.6.1 Menangkap makna secara kontekstual terkait fungsi sosial, struktur teks, dan unsur kebahasaan teks khusus dalam bentuk surat pribadi terkait kegiatan diri sendiri dan orang sekitarnya

4.6.1.1 Menemukan gagasan utama, informasi rinci dari teks surat pribadi

4.6.2 Menyusun teks khusus dalam bentuk surat pribadi terkait kegiatan diri sendiri dan orang sekitarnya, lisan dan tulis, dengan memperhatikan fungsi sosial, struktur teks, dan unsur kebahasaan, secara benar dan sesuai konteks 4.6.2.1 Menyususn teks surat pribadi secara tertulis dengan santun, percaya diri dan bertanggung jawab.

C. Tujuan Pembelajaran

1. Siswa dapat mengidentifikasi fungsi sosial teks surat pribadi

2. Siswa dapat membedakan struktur kalimat beberapa teks surat pribadi

3. Siswa dapat membedakan unsur kebahasaan beberapa teks surat pribadi

4. Siswa dapat menemukan gagasan utama, informasi rinci dari teks surat pribadi

5. Siswa dapat menyusun teks surat pribadi secara tulis dengan santun, percaya diri dan bertanggung jawab.

Figure 13: An excerpt from Ambar's English RPP of Semester 2-Year 11 on personal letter

The syllabus and RPP primarily consist of indicators of competency achievement as well as the teaching and learning material, activity, assessment, and resources. The common practice is that a team of subject teachers develop syllabus referring to the national policies and individual teachers write RPP referring to the syllabus. Both syllabuses and RPPs are to be approved by the school before their implementation. When asked about why and how a certain topic was included in RPP and discussed in the classrooms, Ambar asserted that:

Itu disesuaikan dengan topik yang disampaikan di kelas karena kan sudah ada silabusnya. Di kurikulum itu sudah ada. Ini topiknya ini ini, jadi ya disesuaikan. Misalnya ada tentang globalisasi. Jadi anak-anak ya mengikuti itu sesuai dengan silabusnya, tapi tidak menutup kemungkinan juga informasi-informasi yang ada hubungannya dengan topik yang disampaikan itu dimasukkan.

It was made in line with topics to be discussed in the classroom because these are already covered in the syllabus. They are included in the Curriculum, too. The topics to be covered are this and that, so it should be aligned. Take, for example, a topic on globalisation. Students will discuss the topic according to the syllabus, but it is likely that relevant information will also be included. (Interview with Ambar, 4/11/15) 
Topics and materials for classroom discussions, in Ambar's opinion, should be related as much as possible to efforts to foster pupils' nationalism, maintain their national identity, familiarise them with more local cultures, and value the nation's cultural diversity.

Consciously or not, English can be part of the Government's political agenda for national unity. Accordingly, Ambar, for example, talked about a topic on globalisation in relation to or within the framework of a local tribe and cultural exploration as well as the preservation of national or cultural identity. As Ambar said:

Nah itu kan, yang tadi itu disampaikan, ingin mengangkat nasionalisme. Jadi yang diangkat itu dari budaya-budaya Indonesia. Ya itu tadi tujuan pemerintah kan membawa kita ke sana, mengenalkan kekayaan yang kita miliki sebenarnya itu. Kembali lagi kita-kita yang bangga dengan Indonesia.

Like I told you, [it was aimed at] strengthening students' nationalism. So, the materials should explore Indonesian cultures. The Government's objective is to familiarize [students] with Indonesia's [cultural] richness. Who else then should be proud of that? (Interview with Ambar, 4/11/15)

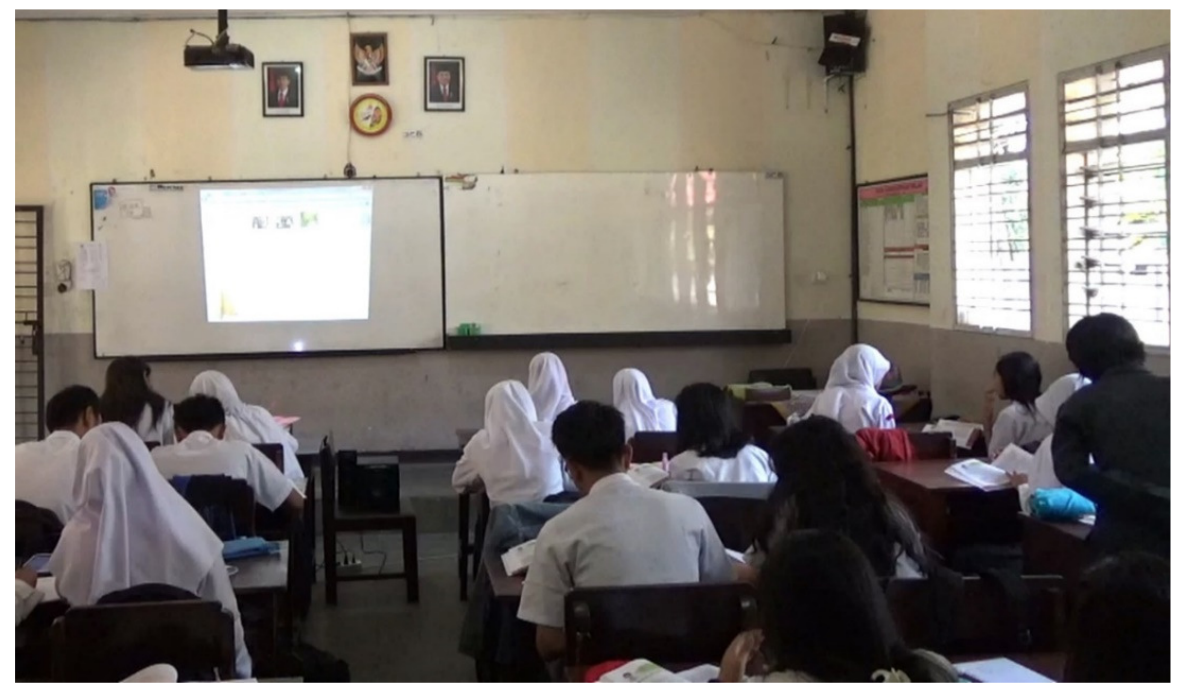

Figure 14: Ambar supervises students

In another statement, Ambar explained today's globalised world and contact with "foreigners" in terms of a lost sense of identity. As she elaborated, exploring the cultural richness of a local tribe or ethnic group, for example Baduy, could therefore be interesting and rewarding:

Jadi mengerucut mau dibawa ke sana. Meskipun kita hidup di dalam dunia global berhubungan dengan orang asing tapi jangan sampai kita itu kehilangan identitas kita. Intinya seperti itu. ... Sebenarnya lebih menarik kalau fenomena sosial yang suku Baduy itu, pak. Kita bisa menggali budaya di situ, ya yang mungkin kita banyak gak tahu dari suku itu. So, it [teaching and learning] was specifically directed towards the objective. Although we are now in a globalised world allowing for more contact with foreign people, we should never lose our identity. That is the key point. ... Thus, it'll be more interesting if the social 
phenomenon is about the Baduy Tribe. We'll be able to explore their culture with which we might be still less familiar. (Interview with Ambar, 4/11/15)

The above discussion helps explain how Ambar approached and engaged with culture and interculturality in her EFL classes. It also elucidates the extent to which the prevailing policies on general education and EFL teaching and learning had an effect on the ways she addressed the representations of culture and issues of interculturality.

The next section illustrates Ambar' personal initiatives and creativity in selecting materials and responding to pupils' cultural knowledge and their general academic and English competence.

\subsubsection{Personalising classroom materials}

What I could also immediately notice in Ambar's classrooms was the use of a variety of teaching and learning materials in terms of types (i.e. printed, audio-visual and video), levels of text difficulty, and especially sources (i.e. from local or foreign cultures). Today's advanced Internet technology, as Ambar noted in the interviews, had enabled her to find materials that were relevant to the prescribed topics and in particular to students' English competence. In the observed classrooms, when discussing job vacancies and application letters, for instance, Ambar displayed through an LCD projector a scanned, printed vacancy that uses Kathmandu, Nepal as a physical address. Another one showed Barbados' facsimile numbers. Conversely, Pandaan-an area in the neighbouring district of Pasuruan, East Java-was cited as sender's address.

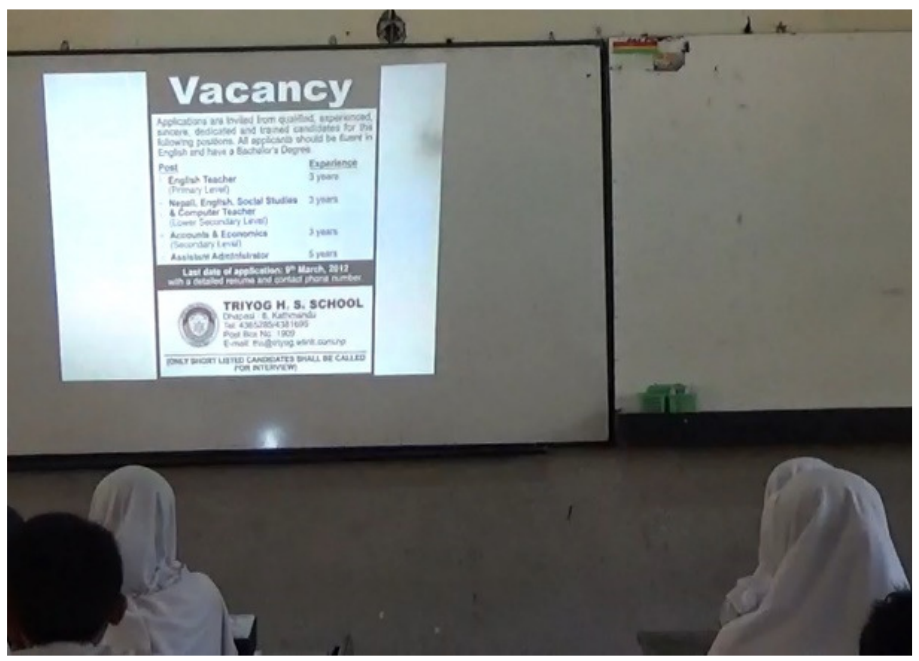

Figure 15: A vacancy with a Kathmandu's address 
In addition, when explaining factual report text, Ambar used an audio-visual passage about polar bears. In this respect, the perceived levels of text difficulty and pupils' general

English proficiency became her practical considerations:

Kalau saya memilih materi ini yang gampang dipahami anak-anak supaya nanti mengaplikasikannya gampang juga. ... Misalnya ada pertanyaan ini, bisa menjawab dengan mudah. Karena ada beberapa vakansi yang bahasanya rumit, anak-anak khawatir tidak bisa memahami dengan baik gitu. Jadi saya lihat dari segi bahasanya very simple. I chose this material because it is easy for students to understand and later to put into practice. ... If there is question [about it], it'll be easy to answer, too. The language of some vacancies was too complex. I' $m$ afraid it's hard for them to understand. Thus, the language should be very simple. (Interview with Ambar, 4/11/15)

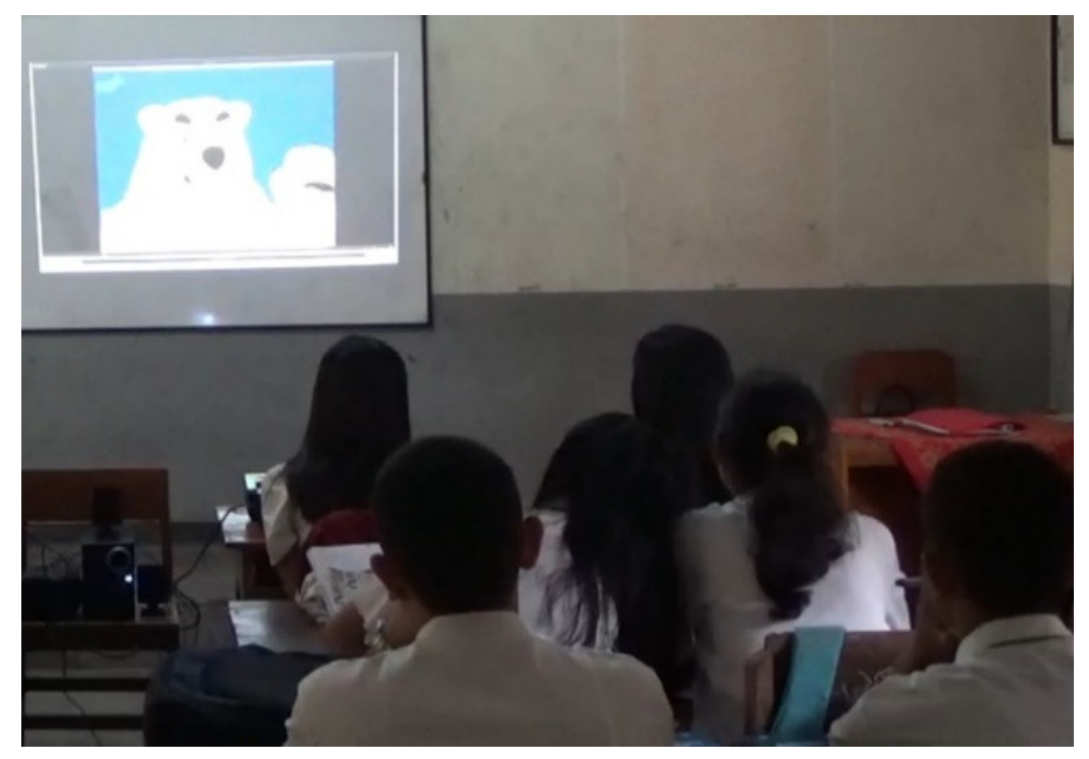

Figure 16: An audio-visual passage on polar bears

Apart from taking an average level of learners' English ability into account, Ambar considered the goal of teaching and learning for GHS students, which is different from VHS, when selecting and presenting the materials. That is, GHS students/graduates are oriented towards further study, whereas VHS students are towards joining the skilled workforce. As such, in Ambar's view, the materials used in GHS English classrooms including her classes should address general topics rather than specialized or vocational ones. The emphasis of the English teaching and learning in GHS is therefore on developing pupil's academic ability and general communication proficiency. As Ambar clarified:

Kalau SMA, mereka kan diarahkan untuk melanjutkan ke jenjang yang pendidikan yang lebih tinggi. Jadi materinya itu hal-hal yang umum dulu kalau di SMA. ... Jadi kalau misalnya bahasa Inggris, ya cuma alat komunikasi saja supaya mereka bisa berkomunikasi dengan baik, baik orang dari dalam maupun luar negeri. 
As with GHS [students], they are prepared to continue their study. That's why the English materials cover general topics. ... English is viewed merely as a tool of communication with which they will be able to communicate well with either domestic or foreign people.

(Interview with Ambar, 4/11/15)

While referring to the prescribed topics, Ambar acted on personal judgment and initiative in deciding what materials to use in the classrooms. In this case, learners' existing cultural knowledge as well as their average academic and English competence seemed to be the main considerations.

What comes next is about Ambar's beliefs and attitudes towards the presentation of cultural phenomenon and the cultural aspect of language and how she put such beliefs into classroom practices.

\subsubsection{Belief-practice gap}

Ambar acknowledged the importance of exploring interesting cultural phenomena or different cultural components of English and Indonesian expressions. This activity, as Ambar added, has been included in the syllabus and RPP. She also believed that in general GHS Jawa students are highly enthusiastic about foreign culture. By way of illustration, Ambar pointed out how excited the students were when Japanese college students made a visit to GHS Jawa and had talks in English about Japan and its culture. GHS Jawa students found a number of phenomena commonly associated with Japan including its education system, writing system, cartoon film, tsunami, etc. interesting. As Ambar said:

Oh ya misalnya tentang tsunami. Kenapa ini, kenapa ini ... Terus kemarin itu tentang sistem pendidikan di sana. Kok beda dengan di sini? Kenapa di sana kok gitu? Kenapa kok gak sama dengan di sini? Jadi apa yang tidak sama di sini meminta dia itu untuk apa ... Film, film kartun yang kamu sukai apa? Shinchan? ... Coba nggambar. Coba pakai bahasa Jepangmu ditulis di situ. Akhirnya nulis bahasa Jepang dengan artinya. Jadi anak-anak itu very excited gitu.

For example, about tsunami. [Students asked] [W] hy did or how could it happen? ... What about the education system in Japan? Why is it different from ours [Indonesia's]? Why is it like that? Why isn't it similar to ours? [Students] asked them [Japanese visiting students] to talk about what is different [from ours]. ... [They wanted to know] what film, or cartoon film, they like. Shinchan? ... [Students asked them to] make a drawing of it and write in Japanese characters and its meanings. They did that. Students were in fact very excited. (Interview with Ambar, 4/11/15)

However, attempts to explicitly mention or give further explanation of either different or similar sociolinguistic features of English and local languages were not evident in Ambar's classroom practices, and neither were comparisons between home and foreign cultures. 
The main reasons for such absence, as she later explained in the interviews, were limited teaching hours and examination-oriented teaching and learning. Ambar suggested that:

Memang dalam tahap pembelajaran harusnya seperti itu, tapi kadang kan kami terkendala oleh waktu. Kayak sekarang aja pak, tanggal 23 ini sudah ujian, padahal materinya masih banyak. Harusnya ulangan tiga kali itu gak sempat; cuman dua kali aja. He'eh, jadi kami dikejar-kejar waktu. ... Idealnya itu ada. Cuman kalau di kelas dipraktekkan kalau nutut waktunya. Kalau ndak, ya ndak gitu pak. Pokoknya anak-anak ngerti gitu akhirnya. Toh ending-nya juga akhirnya kan mereka supaya bisa garap EBTANAS kan, ujian itu. In the teaching and learning, it should go that way, but we're sometimes restricted by time. Take, for example, our current situation. We'll have an examination on 23rd even though we still have many materials to discuss. We're expected to sit three tests but could only do two. We're racing with time. ... Ideally, it should be discussed but in practice it will happen only if time allows. If it doesn't, we won't. The most important thing is that students have gained some understanding. And yet, the main goal is that students pass the national examination. (Interview with Ambar, 4/11/15)

In one of the Ambar's classes that I observed, Ambar was talking about 'factual report text'. Ambar seemed to miss some opportunity to dwell on certain issues that might be problematic in terms of different cultural practices and perspectives. The following is an observation note I made on the classroom situation, especially on what Ambar was doing while speaking on the topic:

Ambar was discussing 'factual report text' and using an audio-visual tool to help her explain the topic. Among the learning objectives were that the students can identify the social function and the language feature of the report text that refers to a range of natural, manmade and social phenomena. Ambar took flood and tsunami as examples of natural phenomena, temple as a man-made phenomenon, and wedding and political situation as social ones. She also cited specific habits or behaviours as part of the description of the text. However, Ambar did not seem to highlight and expand on some themes or issues that the students might find either interesting or challenging due to different 'factual' practices between host and target cultures and different cultural meanings or interpretations attached to the practices. Take, for example, wedding ceremony that Ambar mentioned. A marriage ceremony could be a heavily culture-laden event. This kind of social phenomenon could then be used in the classroom as a starting point for a deliberate and open discussion of cultural similarities and differences between home and target language-and-cultures. However, no further exploration of the examples was evident. (Observation note on Ambar's class, $21 / 10 / 15)$

Furthermore, the information obtained from a student focus group discussion (FGD) may also shed some light on the discrepancy between Ambar's professed beliefs and her teaching behaviours. When asked whether and how their English teachers highlighted any interesting cultural dimensions or different cultural values between English and local languages, students mentioned two events and described what commonly took place on such occasions, that is a lack of explicit discussion. The first is when the teacher played a video on English speakers from different national and cultural backgrounds who have different accent, as revealed by a student in the FGD: 
Kita juga di pembelajaran pernah disetelkan video pembelajaran tentang 'English in many accents', Inggris di berbagai aksen. Jadi, dalam video itu ada seperti kelas bahasa Inggris. Kemudian di situ ada berbagai orang dari berbagai negara, berbagai ras di mana dalam berbahasa Inggris itu karena aksen yang berbeda-beda, maka pemahamannya juga beda.... Pada saat itu sih nggak ada penjelasan, jadi cuman ditontonkan gitu.

We once watched an educational video entitled 'English in many accents.' It seems to show an English class. There are a number of people from different countries and races. As they speak English in different accents, they convey different meanings. ... At that time, there was no further explanation. [The teacher] only asked students to watch the video. (Student FGD, 11/12/15)

Another classroom event was when students noticed possible cultural differences between English and Indonesian expressions. In this situation, the teacher generally did not give further explanation about interesting or important cultural aspects for students to attend to. And if s/he did, it was largely because the students asked first rather than the teacher had the initiative to expand on the topic in question. This rings true when I saw how Ambar presented the vacancy with a Kathmandu's address mentioned earlier. She did not give any further information, for example, about where the city is or what nationality its people have. In the following interview, she admitted that she was not quite sure in what country Kathmandu is located. In this case, a student noted:

Biasanya dimulai dari pertanyaan dari siswa, [apakah] ada perbedaan antara kalau misalnya di dalam bahasa Inggris menjawab seperti ini. Dalam bahasa Indonesia bukan ditranslate langsung. ... Lalu siswa bertanya dan akhirnya dijelaskan. ... Inisiatif guru cuma terkadang. Jadi, kebanyakan pertanyaan dari siswa.

It usually started by student's question about some expression in English. Its equivalent in Indonesian was not a direct translation from the English version. ... Students asked and then explanation was given. ... The teacher rarely took the initiative. In most cases, [explanation was given] because students asked first. (Student FGD, 11/12/15)

There was a gap between Ambar's stated beliefs and observed teaching. In spite of recognising the need to pay attention to interesting cultural phenomena in the local and target community or cultural differences in home language and English expressions, in general what Ambar actualised in the classrooms did not match her reported beliefs.

\subsubsection{Recap and remarks on Ambar's case}

The salient themes I gleaned from Ambar's case described above highlight three crucial issues, i.e. a context-bound culture teaching, non-explicit culture teaching, and a classroom time-constraint. First, what cultural features for Ambar to discuss and how to represent them in the classrooms are subject to a variety of cultural, political and educational factors at the national and local contexts. The goals of Indonesia's national education are imbued with moral, cultural, and religious values to be inculcated into learners. Character 
education is an essential part of Indonesia's general education and English education is required by the Government to help achieve the general objectives. Islamic beliefs, which are embraced by the majority of the people, permeate into the public realms, including the school environment. In order to have a more informed understanding of the reasons why, for example, such a public school as GHS Jawa commenced the school hours with an Islamic supplication, or why Ambar opened her English classes by singing Indonesian patriotic or character-building songs, it is thus important for us to take such wider and immediate contextual factors into consideration.

Indonesia's EFL pedagogy is concerned not only with an acquisition of English skills but also with the nurture of nationalism and the development of good character. In Ambar's classroom actions, the implementation of the national policies was manifested, among other things, through an adherence to the national curriculum and to the prescribed teaching and learning materials, topics, and activities. As reported in the interviews, Ambar sought to enact the national and local policies by integrating more materials that write about local people and cultures into her classroom materials, exposing learners to Indonesia's cultural diversity and discussing foreign cultures in relation to home cultures.

Second, explicit teaching and learning of cultural elements escapes sufficient attention from Ambar's classes despite her recognising cultural topics in the curriculum and syllabus and the importance of cultural exploration. There was a gap between her espoused beliefs and observed classroom practices. This phenomenon can be problematic. Explicit teaching and learning of culture in the language classrooms, typically through comparisons and connections between home and target cultures, not only highlights the complex languageand-culture relationship but also raises pupil's awareness of one's cultural-laden perspectives and helps prevent uninformed cultural learning at the risk of stereotyping and stirring prejudice (Byram et al., 2002; Newton, 2016; Newton et al., 2010). A fuller understanding of home languages and cultures can be a stepping stone to a more engaging and productive intercultural exploration (Liddicoat, 2011; Scarino \& Liddicoat, 2009). Conversely, in the absence of cultural explicitness, pupils may be deprived of valuable information on the language-culture connectedness and of the opportunities to critically reflect on and constructively engage with the otherness and diversity. Nonetheless, the way Ambar personalised her instruction by considering the level of text difficulty, incorporating additional materials from varying sources, or selecting materials according to learners' general English proficiency can be seen as indicative of ample room for Ambar to exercise her agency, including explicitly addressing cultural issues. 
Another central issue is that in addition to an exam-centric education, a lack of explicit instruction of culture in Ambar's English classes was attributed to a heavy teaching load causing a lack of time. Here, the perceived or actual limited time available for the EFL classrooms can be associated with the teacher's reluctance or failure to deliberately and specifically attend to culture. Not only is culture understood as something that is separate and extra to be added to the language teaching and learning, but it also remains external to the students (Liddicoat, 2002, 2011). And yet, the pervasive and complex nature of culture and myriad cultural manifestations make it too much for the language classrooms to address all the dimensions of culture, however long or short the teaching hours might be. Fundamental to this view is that cultures are constantly changing and that people's identities and values develop throughout their lives. It is not possible to acquire all the knowledge and skills to communicate with anyone from any country in the ever-changing contexts of interaction, and language learners' competence is therefore never complete and perfect (Byram et al., 2002).

In the light of the idea that cultural values are in a constant flux and that cultures change more rapidly than language, as Damen (2003) has noted, the traditional role of teachers as "the all-knowing source of the correct" can no longer be assumed. In students' cultural exploration, teachers' role should include guidance and support and promoting culture learning skills rather than setting culture learning outcomes. Equally important is an understanding that cultural adjustment is highly idiosyncratic. Therefore, Damen (2003, p. 84) adds that language teachers are not expected to be "the purveyor of the good, the true, and the believable", but rather to serve as a trainer:

$\ldots$ in the development of sensitivity to cross-cultural differences, of social skills in communicating across cultures, and of personal skills in adapting to the inevitability of change in social and cultural patterns and appropriate behaviour as lifetime pursuits.

To conclude this section, evidence suggests that how Ambar approached culture and interculturality in her teaching was influenced by the prevailing policies on the general and EFL education as well as by school and classroom dynamics. Indonesia's policies on general education stipulate that cultural, moral and religious values embodied in the State ideology Pancasila are integrated into the schools' approved syllabus and RPP of all subjects within the framework of character education. These values are to be implanted in the students in the classroom instruction. Also, Ambar believed that the national curriculum and the syllabus have incorporated cultural components, that further cultural exploration is important for the students, and that cultural discussion is oriented towards 
more Indonesia's cultural richness than 'foreign' culture. However, there seemed to be mismatches between Ambar's professed beliefs and observed practices. An open, explicit discussion of cultural themes was largely absent in her instruction. Ambar cited an examcentric education, teaching load and time constraint as the main reasons for the beliefpractice gap. In this way, the students were deprived of opportunities not only to increase sensitivity to and understanding of their own cultural values and behaviours and Indonesia's cultural diversity in general, but also to notice, reflect on, compare and connect home language-and-cultures with those of other people.

\subsection{Ana's case}

Ana has over 25 years of teaching experience. Prior to teaching in the high school level, she was an English teacher at a junior high school. Ana has received recognition from the MoNE for her professional competence in various forms. These include teacher certification and appointment as a team member of the UKG module writers at the national level. Her extensive experiences and achievements have allowed Ana to take on different roles in English education forums outside the classroom, including competition jury, seminar speaker and workshop trainer. She has been involved in a number of professional development programmes at the local and national level. Ana also had the opportunity to travel Malaysia, Singapore and Thailand for both leisure and professional purposes. Key themes that emerged were the enactment of policies, negotiating values in the EFL classrooms, and English user/learner as authentic self.

\subsubsection{Acting on policies}

Like Ambar's classes, Ana's two classes were in the first two teaching hours, that is from 7.00 to 8.30 am and were started only after an Islamic supplication in Arabic and Indonesian was made through the school's loudspeakers. During the supplication, Ana and students stopped their activities for a moment and joined the recitation in silence.

In the first-hour lessons, soon after opening her class, Ana asked students to stand up and sing a patriotic or character-building song. In one of her observed classes, students sang an Indonesian song entitled Himne Guru (A Hymn to Teachers). This song holds teachers in profound respect, portraying them as unsung heroes. Javanese philosophy might be behind this view, informing that a guru (teacher) is one to gugu (trust, obey, act according to) and to tiru (imitate, model oneself on) (Robson \& Wibisono, 2002). Teachers are seen as "school-time parents" whom students trust and whose behaviours they must 
follow, that is by manut lan miturut (to agree with and obey) (Dardjowidjojo, 2001). It is thus a familiar sight, for example, that Indonesian students put the back of the teacher's palm to their check or forehead when shaking their hand. It is this kind of respect and character that students are expected to show and develop.

As regards the songs to sing together and to open her English classes, Ana mentioned some other nationalistic and character-building songs such as Indonesia Raya (Great Indonesia, the national anthem), Tanah Airku (My Motherland), Desaku (My Village), and Rayuan Pulau Kelapa (A Solace to Coconut Island). To have students jointly sing these songs in the English classes is part of Ana's efforts to enact nationally-dictated education policies. Being patriotic and nationalistic are among the 18 character traits of 'democratic and responsible' Indonesian citizen that should be instilled into students and thus incorporated into the syllabus, RPP and teaching practice within the framework of character education (Kementerian Pendidikan Nasional, 2010, 2011). Ana chose Indonesian songs whose lyrics she believed may arouse students' nationalistic sentiment.

As Ana stated:

... karena kan saya juga menanggapi apa yang diinformasikan oleh Bapak Anies Baswedan. Itu kan punya wacana bahwa untuk membentuk karakter peserta didik, itu salah satunya pada awal pelajaran, 5 sampai 10 menit, memberikan materi-materi kepribadian dengan motivasi. ... Berkenaan dengan saya mengapa waktu itu memilih lagu karena, satu, saya juga ingin meningkatkan, menggali kembali rasa-rasa nasionalisme anak. Kita tahu banyak ya, anak-anak itu sudah terkontaminasi dengan lagu-lagu yang tentunya lirik-liriknya itu kurang. Untuk situasi seperti itu, anak-anak saya ajak untuk kembali ke lirik-lirik yang membuat nasionalisme anak-anak tumbuh, dan ternyata berhasil. Saya sangat merasa berhasil. Karena anak-anak senang, kemudian ketagihan. Mereka mesti minta lagu-lagu. ... it was because I responded to what [former Minister of Education] Mr Anies Baswedan has instructed. He reaffirmed the need to build students' character. One of the ways is that within first 5 to 10 minutes of class [teachers] give students materials concerning personality by motivating them. ... The reason I chose to sing together was that, first, I'd like to revive and grow their nationalism. We may be aware that many teenagers have been 'contaminated' with songs that lack patriotic messages. To avoid such situation, I try to make students familiarised with ones that can make their nationalistic sentiment stronger. It worked well. I consider myself successful. Students love it, and they often ask for more. (Interview with Ana, 25/11/15) 


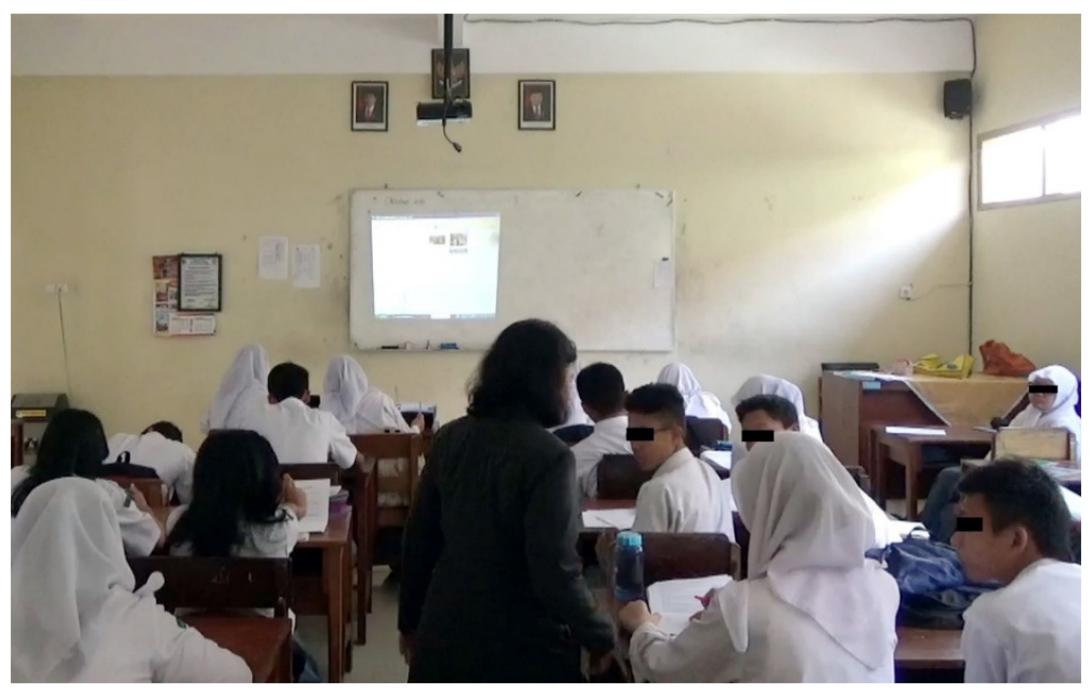

Figure 17: Ana supervises students

As noted earlier, Ana sought students' opinions after singing together. She asked: 'What do you think about this song?'; 'Please give me your opinion about this song, [student]'; 'What is in your mind when you sing the song?'; or 'Please take one lyrics that you like most, and tell me what's the content of the song', etc. The songs might be in Indonesian, but the question-and-answer was entirely in English. In this way, Ana sought not only to engage students in interactive dialogues but also to connect such an activity with the topic of the lesson, the goal of the teaching and learning, and efforts to provide a comfortable teaching and learning atmosphere. Ana used song or the singing together as a way to interact with students and believed that this activity is a valuable pedagogic tool:

Media itu bisa video, bisa lagu, atau anak-anak bisa diberi kesempatan untuk membaca buku non-pelajaran. Tujuannya apa? Ya untuk mengawal anak-anak untuk suasana belajar yang menyenangkan, joyful learning, ya. Biar tidak terkesan pada mereka bahwa belajar itu harus membuka buku saja, atau mengerjakan soal-soal saja. Tetapi harus diawali dengan suasana yang rileks, yang menyenangkan, yang tentunya nanti situasi itu rentetannya adalah ke materi yang akan kita ajarkan.

[Teaching and learning] media can be video or song. Students may be given time to read non-school books. It aims to bring about a pleasant, joyful learning. In this way, students will not end up making assumption that learning is only about reading book or doing exercises. Instead, it should be started by [creating] relaxing, comfortable learning atmosphere. This is eventually related to teaching materials. (Interview with Ana, 25/11/15)

Apart from implementing the character education policy and particularly developing a strong sense of nationalism, Ana connected the singing together with the teaching and learning of different areas of language skill (grammar, reading, speaking). She reiterated the importance of contextuality and spontaneity of students' response during the question- 
and-answer session. By not letting students know beforehand what song to sing in the classrooms, Ana prefers that students have an ability to make contextual and spontaneous responses to what is happening rather than giving memorised answers. In addition, Ana reported that some students even burst into tears when singing the Desaku (My Village), citing the incident as an example of how effective the activity could be in involving the affective dimension of teaching and learning:

... saya ingin menggali kemampuan berbicara anak-anak. Meskipun toh nanti materi saya ke grammar atau ke reading, tapi kemampuan berbicara tetap saya gali di awal. Karena saya ingin anak-anak berbicara sesuai apa yang mereka pikirkan saat itu. Jadi, kontekstual. ... Dengan lagu itu sangat penting. ... Bahkan di kelas atas waktu itu ketika saya awal-awal masuk, saya ajak nyanyi lagu 'Desaku'. Mereka bisa mengekspresikan perasaannya dengan mencucurkan air mata karena dia kangen dengan kampung halamannya. ... Nah, sebenarnya selain saya ingin mengeksplor ideas anak-anak, saya juga ingin mengeksplor speaking mereka. Saya yakin, ketika anak-anak berbicara, dan itu berasal dari dalam hati, maka itu akan lebih lancar daripada mengada-ada.

... I'd like to explore students' speaking skills. Although the topic is related to grammar or reading skill, I still want to improve their speaking ability. That's why I want them to say what is in their minds. So, [it must be] contextual. ... And singing together is very important. During my early days, I had Year 12 students sing Desaku, some of them burst into tears while expressing their feeling [by singing], saying that it makes them miss their beloved village. ... In fact, in addition to exploring students' ideas, I want to develop their speaking skills. I believe that if students speak from their heart, they can do it more fluently than if they make it up. (Interview with Ana, 25/11/15)

Furthermore, opening songs in Ana's classes were more often in Indonesian but English songs were selected as well. These included the classics Whatever will be, will be (Que sera, sera) by Doris Day and Mother how are you today by Maywood, and a more contemporary one You Raise Me Up by Josh Groban. Unlike Ambar, Ana ran a short question-and-answer session in English and asked four to five students about their thoughts on the message of the song. Ana stressed that the emphasis of the activity remains on building students' character and nationalism, yet she also referred to attempts to 'compensate for' some unfavourable situation and keep things balanced. As noted earlier, Ana talked about negative influence of lyrics that are lacking in patriotic messages. Here, she suggested that English teaching and learning and English songs in particular may go hand in hand with character education. When asked how relevant Indonesian songs are to English teaching and learning, Ana confirmed:

... saya kira untuk mengimbangi itu, jadi bahasa Inggris juga jalan, juga lagu. Harus dicatat bahwa meskipun kita belajar bahasa asing itu nasionalisme harus tetap dipupuk di dalam jiwa anak-anak dengan menyanyikan lagu nasional.

... My goal is to compensate for such a situation, that is English class keeps going on, and so does the singing. It should be noted that even though we are learning a foreign language, students' nationalism has to always be nurtured by singing patriotic songs. (Interview with Ana, 25/11/15) 
In the classrooms, Ana was seeking to act on and comply with the prevailing policies on the general and EFL education. This included an observed and reported compliance with the character education within which local cultural, moral and religious values are inculcated in the students. Strengthening patriotism and nationalistic sentiment was therefore part of her instructional goals. Ana also talked about "negative influence," "contamination of unpatriotic lyrics" or "compensation for unwanted situation." In this way, she might reveal her perceptions of 'inherent' cultural values of the English language and of behaviours commonly associated with the NSs of English.

\subsubsection{Teaching English, negotiating values}

Ana acknowledged the central role of cultural knowledge in English teaching and learning and connected such an understanding with (in)effectiveness of communication in real-life interaction. As revealed in the NF, the topics of 'interpersonal' and 'transactional' expressions recently came up in Ana's English classes. The materials on the theme were presented in the form of dialogues which, as she underscored, deal with attitudes toward and the actual practice of using expressions in daily activity. Interpersonal expressions, broadly defined, are used to maintain social relations between speakers, whereas the principal purpose of transactional function is to convey information (Brown \& Yule, 1983). In reality, most situations consist of a mixture of the two functions (Buck, 2001).

Unlike the interview which was conducted in Indonesian, Ana completed the NF by herself in English. As Ana wrote:

[A topic that I found particularly challenging to explain was] the transactional topic [because] the materials involve other people. It means that to practice the expressions, the students must interact with others. It needs a well-comprehension about the culture of with whom s/he is speaking. [What I realize from this experience is that] when the students don't know the cultures of their partner they are speaking with, their communication would be ineffective then. (Ana's NF, 15/11/15)

(Note: Italicised words in square brackets are sentence starters or clarifying phrases) 


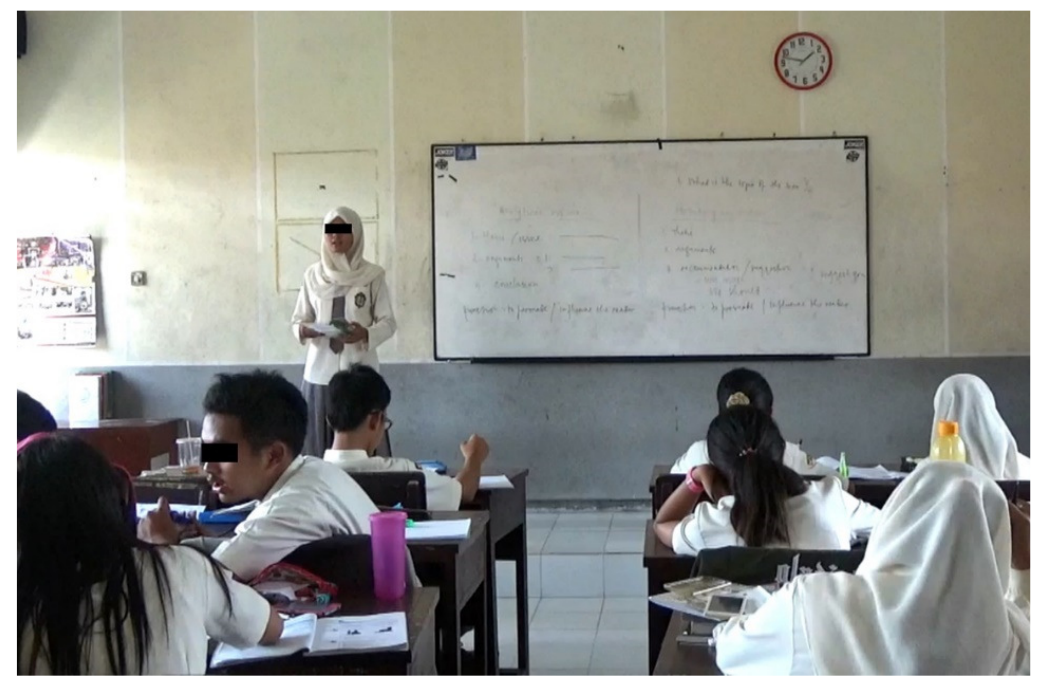

Figure 18: A student performs a speaking task

Ana's beliefs about and attitudes towards embedded cultural values of the English language were translated into practice especially when she selected and presented the teaching and learning materials. Among a number of aspects that came under her considerations were the suitability of material and the appropriateness of its content. The former largely dealt with the conformity of material with the topic in question, perceived student's English proficiency, and the level of language difficulty of the material; the latter was concerned with the educational and cultural appropriateness of the material. When considering the conformity of material, Ana wanted to ensure its language is not complex so that students would find it easy to understand. As with the appropriateness of material, she made personal judgments to decide whether or not the material contains both educational and cultural messages and whether the messages are in agreement with the nationally mandated values and thus culturally appropriate. As she underlined:

Yang saya pertimbangkan, pertama, tentunya kesesuaian dengan materi yang saya ajarkan. Misalnya compliment, saya cari video tentang compliment. Nah, setelah itu, di situ kan banyak muncul, model conversation, model videonya, tampilannya, macem-macem. Setelah itu, saya pilih yang sesuai dengan konsumsi anak-anak. Peserta didik saya SMA, sisi budayanya harus ada, sisi entertainment juga. Ada banyak, tapi saya pilih yang anak-anak masih bisa menangkap dan nanti saya punya kesempatan anak-anak itu bisa menirukan. Ada education-nya di situ, sehingga saya pilih video yang anak-anak itu nantinya menirukan, atau sesuai dengan karakter.

My consideration was, first, of course the conformity of material with the topic of the teaching and learning. Take giving compliments, for instance. There are many kinds of material, conversation model, video format, presentation, and so on. I will choose ones that match student's characteristics. My students are at a high school level, so the materials should have cultural content and be entertaining as well. There were many kinds of material, but I chose ones that students could understand and imitate. So, there must be an educational 
dimension to it because students may imitate, or ones that conform to the proposed character traits. (Interview with Ana, 25/11/15)

Ana filtered out what she thought of as unwanted or inappropriate materials. She based her considerations not only on the level of language complexity and students' general English proficiency but also on how the characters in the material look and what they wear. She believed that the characters' clothing may affect student's opinion if they are perceived as culturally inappropriate. As Ana described:

Ya kalau saya sih dilihat dari pakaian juga ya, kemudian bahasa yang dipakai. ... Kalau masalah dari segi budaya, ya itu saya kira yang tampilan pelakunya di video itu sesuai dengan anak-anak sehingga tidak menimbulkan, apa ya, pikiran yang kurang bagus. Pakaian yang dipakai kok seperti ini, tidak sesuai dengan budaya kita, gitu misalnya. For me, clothing should be taken into account in addition to language that is used.... In terms of culture, how the characters look and behave should conform to students' [cultural] expectations so that it will not create a negative perception in their mind. They might be wondering if they thought that the characters' clothing is unfit for our culture. (Interview with Ana, 25/11/15)

In Ana's classes that I observed, most of the time she spoke in English. Only rarely did Ana speak in Indonesian and/or local language(s). However, on some other occasions Ana admitted that she spoke Indonesian and Javanese. The NF and interview data confirm this information. Ana drew on her knowledge of home languages and practices to talk about certain concepts and expressions in English. At times, she mixed English with or switched to Indonesian to help students understand her explanation. In an observed class, when discussing the topic of expressing care and sympathy, Ana could be seen as saying:

Don't be too serious, jangan terlalu serius. Tenang sajalah. Take it easy. Jadi, itu adalah expressing care, to calm your friend, untuk menenangkan teman kamu; by giving touch, dengan memberi sentuhan. Don't think too much about it; jangan terlalu memikirkannya. Kalau dilanjutkan, jadi take it easy. Have you ever said like this? Very often in Indonesian, [but] not in English, right? (Observation note on Ana's class, 6/10/15)

Indonesian became an important part of Ana's explanation as she moved between English and Indonesian, clarifying different concepts and expressions between the two languages. In another observed class, when explaining direct speech, Ana was also recorded as making code-mixing and switching:

If the form of the sentence is question, you have to change [in]to statement. What are the characteristics of statement? Statement is object first, and then auxiliary verb, and predicate. Subjek dulu! Kalau seperti ini, apakah subjek dulu? Subjek dulu, bukan auxiliary dulu. Selalu begitu. Ya, jadi does, apakah dia menjadi ... [Subject comes first! If the structure is like this, does subject come first? Subject comes first, not auxiliary (verb). It's always like that .... ... baru auxiliary verb. Is that understood? Jadi, diubah dulu menjadi kalimat pernyataan. ... Meskipun kamu menggunakan kata tanya 'where', maka di sini harus subjek 
dulu, lalu auxiliary verb. [So, the structure should be first changed to question form. Even if you use a question word 'where', subject comes first, then auxiliary.] Misalnya, 'where she lives', bukan 'where does she live'. Subjek itu harus nempel ke kata tanya. [For example, 'where she lives', not 'where does she live'. Subject is attached to the question word.] (Observation note on Ana's class, 21/10/15)

The NF and interview data gave examples and provided further details on why and when Ana believed it was necessary to use and benefit from her own and students' knowledge of local languages. She compared and contrasted certain concepts and expressions in English with those in Indonesian and/or Javanese. As with Indonesian, Ana used the difference of tense to illustrate her point. Here, she might imply culturally-shaped differences in time perceptions between the speakers of Indonesian and English that are manifested in different grammatical features of the two languages. As Ana suggested:

Dealing with grammar, my students say that it is the most difficult material. That is because of the different verbs used in different time in English. It is quite different compare[d] with Indonesian. There is no change of verb in different time. They said that English grammar [is] so complicated. Students often make errors in expressing sentences involving grammar especially tenses. For instance, they said: "I have eaten fried rice this morning" instead of "I ate fried rice this morning." Of course, it is my [I found it] challenging to explain more about the tenses. (Ana's NF, 15/11/15)

In case of Javanese that students generally share, different social contexts may require different vocabulary, grammar or intonation. Differences in verb tenses and the levels of politeness were among the topics that Ana mentioned as allowing her to draw on the most widely spoken local language. Different language styles or speech levels in Javanese were compared with English, and productively used as a classroom resource. For

Poedjosoedarmo (1968), Javanese speech levels constitute a system for indicating a proper degree of formality, respect and politeness, and may reflect certain cultural values of the speakers. Likewise, as Holmes and Wilson (2017) point out, Javanese "provides a graphic example of a language where the stylistic choices are more clear-cut than in English" (p.

278). In this respect, Ana explained that:

Kalau masalah tingkat kesopanan politeness-nya itu ya saya jelaskan. Ketika ingin mengatakan dengan lebih sopan, ya gunakan saja "I would like to say something to you." Jadi ya kadang-kadang saya serukan. Bagaimana sih menyampaikan dalam bahasa Inggris? Ada ndak perbedaan per level atau seperti bahasa daerah? Saya jelaskan dengan bahasa Jawa. Kebetulan anak-anak tahu bahasa Jawa. Ada krama inggil, dan lain-lain. Tetapi tidak semua materi kan bisa masukkan ke situ. Seperti complimenting, kita ga perlu. Tapi kalau misalnya request, itu kita perlu. "Shut the door, please," itu mesti saya jelaskan. I also explained levels of politeness. If we want to say something in a more polite way, we can say "I would like to say something to you" or some sort. Sometimes I stressed the differences. How do we say it in English? Are there language levels like we do in local language? I gave explanation by [comparing with] Javanese. Students know Javanese. There are krama inggil [high style, most polite Javanese] and other styles. But not all topic could 
be discussed in that manner. I don't think the topic of [giving] compliments is relevant, but [making] request is. As with such expression as "Shut the door, please," I should offer further explanation. (Interview with Ana, 25/11/15)

Students also mentioned a productive use of another local language, that is Madurese, by the teacher and students in their effort to make sense of linguistic features and cultural dimensions of English. For the students, some English concepts and expressions could be more easily understood when equivalents in the local vernacular were given. Here, what I observed in Ana's classes and what the students reported might refer to a strategic deployment of existing linguistic repertoire and to the mental grammars and linguistic practices of bilinguals/multilinguals in the form of translanguaging (Otheguy, García, \& Reid, 2015). Translanguaging privileges students' bilingual performances and leverages the fluid languaging of language learners in ways that deepen their engagement with and comprehension of complex content and texts (Vogel \& García, 2017). As a student illustrated:

Saya pernah juga punya kasus kelas 2 guru saya Madura. Gurunya tidak tahu arti dalam bahasa Indonesia-nya, lebih tahu bahasa Madura. Jadi, saya dijelaskan dalam bahasa Madura. Ya, kalau dijelaskan dalam bahasa Indonesia saya malah tidak ngerti, pak. Kalau pas pake bahasa Madura, saya langsung tahu.

When I was in Year 11, I had an English teacher who is a Madurese. The teacher didn't know how to put [an English expression] in Indonesian, but knew how to say it in Madurese. So, the teacher gave explanation in Madurese. Well, when it was first explained in Indonesian, I didn't get it. But when it was in Madurese, I immediately got the point. (Student FGD, 11/12/15).

Ana recognised the importance of cultural knowledge in the classroom instruction and in the use of English in real-world situation. The cultural suitability or appropriateness became one of her main considerations, that is, among other things, by ensuring that the teaching and learning materials and activities are in agreement with the mandated character traits and students' cultural values, beliefs and practices. This was partly because she believed that some values and behaviours associated with English and the NSs of English might be different from or inconsistent with students' cultural beliefs and practices. Also, Ana and the students benefitted from a shared knowledge of local language-and-cultures and multilingualism with which they grappled with new or possibly conflicting linguistic and cultural features that come with English. 


\subsubsection{Authentic user}

In one of the classes that I observed, Ana discussed the topic of expressing care and giving compliments and showed a video featuring NS characters. In addition to that video, she showed another one submitted by former students. It was an assignment that allowed the students to make and practice their dialogue concerning relevant topics they had previously learned in the classrooms. Students were also required to video-record the task and allowed to upload their video to YouTube if they wanted to. When asked what her reasons for showing student's video were, Ana explained:

Nanti yang semester 2, harapan saya kan anak-anak sudah mulai terlatih bahasa Inggrisnya, pronunciation-nya, dan sebagainya. ... Nah, ini salah satu contoh. Jadi saya ada tujuannya saya milih yang ini, kenapa tidak yang native, kayak gitu ya. Karena anak-anak saya tunjukkan, ini lho mereka bisa, kenapa Anda tidak bisa. Kita harus bisa dan kalau ada yang mau mengunggah di YouTube bisa.

I expect that in semester 2 students' English skills, their pronunciation, will improve. ... Well, this is one of the examples. I have a specific purpose for doing that. Why shouldn't it be native [speaker]? I just want to show students that if they [former students] could do it, then you [current students] can either. We must be able to do it and they may upload their work to YouTube if they want. (Interview with Ana, 25/11/15)

The NF data revealed Ana's perception of NSs and how she related it to an expected level of student's competence. She talked about student's grammar mastery and her approach to teaching speaking skills. Her account of and comparison between of NSs' and learners' understanding of grammar may also imply the sociolinguistic diversity of both NSs and learners of English.

[Some questions my students have asked me about English speaking people or countries are] whether the NSs speak in proper grammar as we do as English learners. I answer[ed] "Yes, of course". They think the NSs don't speak in proper grammar. Yes, I told them that they are the same with [as] us Indonesians as English learners. ... I said to them that in expressing idea in English they don't need to think so much about grammar. They just need to express what they think. As long as their speaking is understandable, it'll be okay. (Ana's NF, 15/11/15).

Ana raised the issue of 'authentic self' when discussing her cultural identity, the role of local EFL teachers, and speaking skill. Ana explicitly mentioned the immediate context of English teaching and learning and use, that is Pendalungan. She recognised the value of 'being oneself' as a Javanese teacher or learner of English. While highlighting the difficulty of achieving NS's competence and overlooking the importance of imitating the NSs, Ana emphasised the need to have good pronunciation of English and maintain one's own accent and speaking style. This view seemed to help Ana to see herself as a 
'legitimate' pedagogic model and to focus on giving students more realistic examples as

well as more achievable learning goals. As she said:

Saya ga punya pikiran saya harus menjadi native. Jadi Javanese, jadi apa adanya saya. Saya hidup di Pendalungan, maka semampu saya seperti ini. Yang penting pronunciationnya betul, mendekati betul, terus lancar, gitu. Nah, kalau kita ingin membentuk mereka harus seperti native, saya saja kesulitan, apalagi anak-anak. Ya udah, yang penting Anda apa adanya. Yang penting pronunciation-nya, usahakan betul. Kalau style of speaking-nya, ya yourself. Gitu, accent-nya yourself aja. Saya juga sering mengatakan pada anak-anak. Jadi Anda harus paham itu. Jadi berbahasa Inggris itu ga harus begini, begitu, dan sebagainya. Itu ga harus, karena kita ga bisa menjadi orang lain. Kalau saya itu, pak. Makanya saya fokus mencontohkan itu.

I don't think I need to be like the native [speaker]. [I] just to be a Javanese [teacher/user of English], the way I am. I live in Pendalungan, and I just have to do my best. So long as your pronunciation is correct, [or] almost correct, and you speak fluently, that'll be okay. How can I ask my students to be like the NS when I myself find it difficult to do so? So, I tell my students just to be themselves, as long as they pronounce correctly. You have your own style of speaking, and accent as well. I tell them many times; they have to understand that. To speak English doesn't need to be this or that way. It shouldn't be that way because we can't be someone else. That's what I'm thinking. Thus, I focus on giving them examples. (Interview with Ana, 25/11/15)

Ana also talked about pronunciation skill and accent of English learners and connected the skill and accents with speaking intelligibility. She reiterated her view that speaking grammatically correct English fluently is important. It appears that Ana wanted to set the sociolinguistic norms, the standards of competence, and the goals of English teaching and learning. At the same time, she played down the significance of modelling on the NS of English. As Ana said:

Tapi saya berusaha semaksimal mungkin untuk menggunakan bahasa Inggris dengan baik dan benar. Pronunciation, benar, meskipun kadang ada slip tongue. Ya mungkin nanti lancar, kan ending-nya begitu. Tapi saya selalu fokus untuk berkata "as long as your English is understandable, it's okay”. Saya gitu. Jadi a mistake isn't a mistake in English. Jadi kesalahan bukan berarti kesalahan dalam bahasa Inggris, tetapi adalah learning. ... Sehingga anak-anak tidak takut untuk berbicara bahasa Inggris dan tidak harus berkiblat pada native. Tidak, yang penting kamu lancar, bisa mem-produce kata-kata dengan runtut sesuai dengan kaidah bahasa. Itu sudah bagus.

But I try my best to use English correctly and properly, pronounce correctly, although slip of the tongue sometimes occurs. In the end, I will become more fluent. But I always say [to my students] "as long as your English is understandable, it's okay." For me, a mistake in English isn't [necessarily] a mistake, but [part of] learning. In this way, students will not be afraid of speaking English and they don't need to emulate the NSs. No, you don't. I think so long as you can speak fluently, and use the expressions grammatically, it'll be good. (Interview with Ana, 25/11/15)

Moreover, Ana's previous intercultural encounters that involved the use of English have helped shape her perception of an 'authentic' user or learner of English, an expected role of local EFL teachers, and shared cultural values among non-native English speakers. Ana 
reported that she had been to a number of ASEAN countries (i.e. Malaysia, Singapore and Thailand) where she used English as a means of intercultural communication. In Indonesia, Ana also had an opportunity to work as a Liaison Officer to a contingent of Vietnamese athletes taking part in a sport event in Pendalungan. Ana believed that although she spoke with them in English, they share what she called as 'the level of politeness' in communication. Despite the national and sociolinguistic differences between speakers of English in the ASEAN context, Ana found not much difference in how they communicate in English because of quite similar cultural backgrounds. As Ana remarked:

Kok menurut saya tidak jauh berbeda ya, tentang budaya itu, tentang tingkat kesopanan dalam komunikasi dengan orang lain. Saya juga tidak terlalu menggali kepada anak-anak karena anak-anak sudah tahu etikanya berkomunikasi. Terus kan di negara lain juga sama. Seperti orang Vietnam. Seperti saya sudah kumpul selama sepuluh hari. Mereka juga sopan. ... Ya hanya itu tadi, beberapa dialog yang saya tunjukkan. Kalau ingin berkomunikasi dengan teman pakai ini. Kalau orang tua, dengan guru, harus pakai yang seperti ini, lebih sopan seperti ini, mesti saya sampaikan.

I don't think there is much difference in the cultures, especially in the level of politeness in communication. I don't really explore the issue because students already have some knowledge of the ethics of communication. Also, [people of] other countries, such as the Vietnamese, have similar values. I had mingled with them for ten days. They were polite [like us] ... [In that regard, in the classroom] I showed students some dialogues. If you're speaking with friends, use this expression. If you're speaking with your parents or teacher, you should use this expression. It's more polite. I just have to explain this topic. (Interview with Ana, 25/11/15)

In short, Ana preferred that she retains her cultural identity and authenticity as a Javanese teacher and user of English and that students keep theirs as learners of English. She connected such views with her professional identity and legitimacy as a local EFL teacher as well as with students' expected competence and their learning objectives. Ana's extensive professional experience and personal intercultural interaction in English with people from Indonesia's neighbouring countries seemed to have an effect on her pedagogic beliefs and classroom practices regarding culture and interculturality. While questioning the relevance of making the NS of English as a pedagogic model, Ana asserted the importance of liberating the sociolinguistic norms, the standards of competence, and the teaching and learning goals from NS-preoccupied notions.

\subsubsection{Recap and remarks on Ana's case}

Three major issues that have arisen from Ana's case are cultural appropriateness, authentic self, and teacher as mediator. First, cultural appropriateness has been one of Ana's primary concerns when deciding what teaching and learning materials to use and how to present 
them in the classrooms. Not only was Ana paying heed of students' average level of academic and English competence, but she also aimed to make sure that the materials were culturally appropriate and acceptable to students. This was indicative of her agency amidst the nationally- and locally-imposed policies and resources. It was evident, for instance, in her attempt to include additional materials obtained from sources other than the recommended textbooks or sources, such as from YouTube. Ana assessed the cultural appropriateness or otherwise of the materials when preparing and using the materials. In general, she intended to act on the curriculum and the school-approved syllabus by integrating cultural, moral and/or religious values into her teaching practices. To this end, Ana was relying on her personal values and judgments to decide whether or not the contents of the lessons comply with the national and local teaching guidelines and resources. She drew on her cultural understanding and sensitivity in order to ensure that the materials were not inconsistent with students' values and local practices.

Second, Ana believed that becoming an 'authentic self' is important for her as a local EFL teacher and students as learners of English. By expressly mentioning being a 'Javanese speaker/learner of English,' Ana took into account her ethnic identity and cultural background as well as those of her students. What makes the sense of self especially interesting is that it affected the way Ana perceived her professional identity and English proficiency, her role as a local EFL teacher, and the goal of teaching and learning. That a video of former students performing their task was used as reference material in the observed classroom may suggest that such an approach has a direct effect on her teaching. For Ana, so long as her English is "understandable" and her pronunciation or speaking is “intelligible", it should be acceptable. This also applies to students' general English and speaking skills in particular. In Ana's opinion, there is no need to imitate the NS speaker in terms of language competence and teaching role. She had no intention of making the NS a pedagogic model, instead expressing self-confidence in her own competence and showing an awareness of self as a non-native teacher, user and learner of English.

Third, that Ana drew on and benefited from home languages and cultures in the English classrooms highlights a pivotal role she has played as intercultural speaker and mediator. On several occasions, Ana used Indonesian and/or Javanese, especially by code-mixing or code-switching, to clarify some ideas, events or practices commonly associated with the English language or the NSs of English. These might concern ones that are absent in or alien to home language-and-culture. At times, different levels of politeness between Indonesian/Javanese and English expressions, which may reflect different values and 
worldviews, were also compared. Ana connected unfamiliar concepts and experiences in the target language and made comparisons with home knowledge and practices, moving between host and target languages and cultures.

The fact that Ana as a local EFL teacher shuttled between home and target languageand-cultures may showcase the skills of interpreting and relating (savoir comprendre) necessary for language teachers as intercultural speakers or mediators (Byram, 1997, 2009; Byram et al., 2002; Liddicoat \& Scarino, 2013). These skills can be especially relevant as Ana tended to believe that English has a set of cultural and ideological baggage that may be different from home values and thus regarded as inappropriate. Such a less favourable impression about English and the target-culture can be a source of misunderstanding and dysfunction. According to Byram et al. (2002), the skills of interpreting and relating help intercultural mediators put ideas, events and documents from two or more cultures side by side. They compare and explain the factual information from the perspective of each, and see how each might look from the other perspective. Not only do they need to be able to identify how misunderstanding can occur, but also to negotiate between conflicting perspectives and interpretations of phenomena.

For Liddicoat and Scarino (2013), the capabilities to engage with, reflect on, and reconcile multiple languages and cultures reside at the heart of the lived experience of being an intercultural mediator. Similarly, Kohler (2015) argues that the mediation dimension of ILTL is built around teachers' orientation towards their own language-andculture, understandings of language and culture (and their relationship), and overall stance on language teaching and learning. Teachers' conceptual frames of mediation are mutually shaped by their practices and ways of being and are interwoven over time in their classroom teaching. In Kohler's view, it is important that foreign language teachers:

simultaneously mediate learners' knowledge of the target language and culture, the relationship between language and culture and their knowledge of ways to act as intercultural mediators. They are constantly building connections between a familiar and a new language and culture, and through this, a familiar and new way of being (2015, p. 194).

What Ana did in the actual teaching and what generally happened in her EFL classes show a local sociolinguistic environment in which the multilingual speakers operate, use and acquire English. Unitary collections of lexical and structural features of Indonesian, Javanese, Madurese and possibly Arabic that constitute the full linguistic repertoire of the local EFL teachers and students were selected and deployed as valuable classroom resources (Otheguy, García, \& Reid, 2015, 2018). The existing and local languages were 
used to make sense of different cultural values embedded in English, to come to terms with possibly conflicting behaviours associated with the speakers of English, and at the same time to encourage a deeper engagement with and understanding of linguistically and culturally complex instructional materials (Vogel \& García, 2017).

\subsection{Aris' case}

Aris, another GHS teacher, had taught in a junior high school for around 15 years before teaching at GHS Pari. When Aris was a junior high school teacher, he had been from 1996 to 1999 assigned by the local Education Office in Pendalungan to write English workbooks (Lembar Karya Siswa) for local junior high school students. Following his becoming a high school teacher, in GHS Pari Aris taught English to Year 10, 11 and 12 students. At the school and the district level, Aris had also been in charge of co-writing the written and listening test items for different purposes, including the school-admission and the national examination. Recurrent themes that arise from Aris' case are setting EFL classes in its educational and sociocultural context and instilling values implicitly.

\subsubsection{Setting EFL contextually}

Aris' teaching practices appear to be highly contextualised in which a number of educational, linguistic, socio-political, cultural, and religious factors in the national and local settings influenced his instructional judgements and decisions outside and inside the high-school EFL classrooms. The relationship between personal values, pedagogic beliefs, and social forces, or the way such influences affected Aris' classroom behaviours, was often not clear-cut because these factors related to or overlapped with one another in a dynamic, complex manner. Take, for example, the Islamic supplication, patriotic song, and greeting at the beginning of the school hours and the goals of the English teaching and learning in GHS. Like in GHS Jawa, an Islamic supplication in Arabic and Indonesian was made over GHS Pari loudspeakers to commence the school hours. Students in Aris' classrooms jointly sang Indonesia Raya to begin their English lesson, which is similar to what I observed in Ambar's and Ana's classes. Aris reported that the students commonly sung the national anthem to start their English class and chose to sing a traditional or local song to end the class. As Aris explained:

Oh gini pak, ada aturan menteri yang baru. Mulai tahun ajaran baru kemarin, untuk menanamkan jiwa patriotisme itu sebelum mulai pelajaran, semua pelajaran itu harus menyanyikan lagu 'Indonesia Raya.' Terus nanti di akhir pelajaran itu sebetulnya harus 
menyanyikan lagu daerah. Namun ini ada sekolah yang melaksanakan, ada sekolah yang tidak melaksanakan.

Well, there is a new decree of the Minister [of Education], which has been effective since last year. In order to instil patriotism, classes have to sing Indonesia Raya before starting the teaching and learning. Before ending the lesson, they should sing a local song, too. However, some schools do this, some don't. (Interview with Aris, 11/11/15)

What was different from Ambar's and Ana's teaching practices was that Aris always gave students an Islamic greeting Assalamu'alaikum (Peace be upon you) before starting and ending the lesson. In Aris' view, the Islamic supplication, the singing together of patriotic songs, and the exchange of salam are parts of the stipulated character education. As Aris clarified:

Jadi karena ini mayoritas Muslim, maka itu untuk awal mengucapkan salam. Kita kan ada karakter. Karakter itu kan ada 18 karakter. Termasuk tadi membaca salam itu termasuk salah satu relijius. Umpama saya sisipkan, itu malah dianjurkan, pak.

Because the majority [of students] is Muslim, we start our lesson by offering salam. We implement the character education by referring to the [stipulated] 18 character traits. Religiosity is one of the traits. Offering salam is part of the recommended activities. (Interview with Aris, 11/11/15)

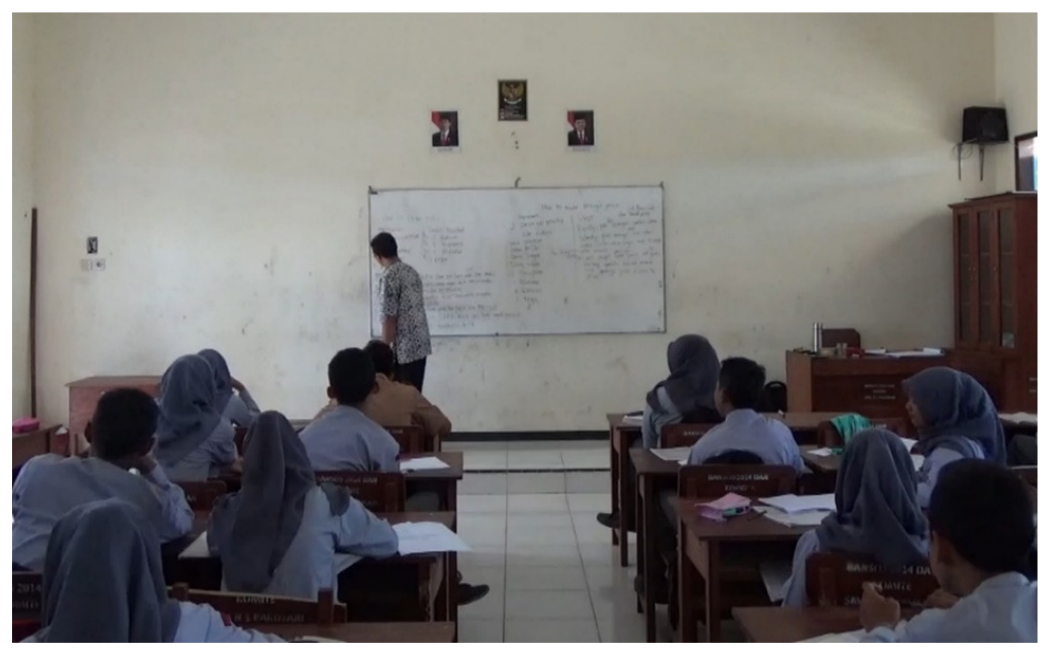

Figure 19: Aris discusses students' work

Aris mentioned the national curriculum, the educational goal, and a 'meaningfulness approach,' which lays great emphasis on communicative competence, as factors affecting his classroom instruction. At the time of the data collection, the K13 ('Curriculum 2013') has just been introduced. Some schools, including GHS Pari, were allowed to implement the KTSP (School-based Curriculum) to Year 12 students because they would sit an approaching KTSP-based national examination, and to introduce the K13 to Year 10 and 
11 students. Teachers were given trainings on the implementation of the K13 curriculum. Throughout the academic year when the data collection was conducted, Aris taught Year 10 and 11 students and made favourable comments about the then KTSP, especially about its focus on the development of students' ability to use English in real-world communication. For Aris, it is the communicative competence that distinguishes the teaching and learning goal of EFL in GHS from that of VHS. As Aris has underlined:

Begini, pak. Kalau KTSP itu lebih mengacu pada pendekatan kebermaknaan atau lebih menekankan pada kemampuan berkomunikasi anak-anak. Lalu semua yang diajarkan itu hampir aplikatif semua, bukan teoritis. Contohnya, teks prosedur, lain dengan dulu pak. Kalau dulu itu kan structure, dulu kan pelajarannya itu simple present tense, jadi tidak digunakan setelah itu. Tapi kalau ini, kalau SMA itu memang pas cara menyajikan pada anak-anak, maka anak-anak bisa mengaplikasikan pada kegiatan sehari-hari, pak. Well, the KTSP adopts a 'meaningfulness approach' and puts a stronger emphasis on students' communicative skills. Almost all the teaching and learning materials are applicative rather than theoretical. Take, for example, procedural text that is different from [what is included in] the previous [curriculum]. It focused on structures, including 'simple present tense', which were not used after [outside] class. But, concerning this [KTSP] curriculum, if its implementation suits high school students well, they would be able to practice it in daily life. (Interview with Aris, 11/11/15)

As Aris hinted at above, the difference of the teaching and learning goal and emphasis between GHS and VHS influenced his classroom actions. In his view, high school EFL classes are aimed at allowing the students to develop their general knowledge and communicative skills and prepare them for further study. Different emphases might be placed on various study programmes in VHS. As Aris remarked:

Kalau anak itu masuk SMA, tujuannya bahasa Inggris itu untuk memperoleh pengetahuan dan berkomunikasi. Lha nanti lain kalau kita ke SMK. Itu mempunyai tujuan lain sesuai dengan jurusan itu. Ya mungkin lebih pada aplikasi. Tapi kalau pada SMA, itu lebih mengacu pada ilmu pengetahuan untuk melanjutkan ke jenjang yang lebih tinggi. Jadi antar jenis lembaga itu sudah beda, pak.

For GHS students, their EFL will be oriented towards gaining knowledge and communicative skill. It's different if they study in VHS. They'll have other goals set according to their vocational programmes. They'll be concerned more with the application [of the knowledge/skill]. In GHS, the main focus is on developing knowledge necessary for further study. So, there are differences [in the focus/emphasis] between different types of school. (Interview with Aris, 11/11/15)

Aris believed that students' general academic knowledge and their English skills in particular had an effect not only on the teachers' classroom decisions but also on their instructional competence. For Aris, the average academic and English ability of students in city schools is higher than that of ones in rural schools. These differences and what the teachers face in their day-to-day classroom activities, in turn, affect the teachers' teaching skills. As Aris noted: 
Sebetulnya antar SMA itu berbeda, pak. Contohnya, bagi SMA tertentu, apalagi SMA yang K13, itu bukan hanya pesan. Itu grammar-nya, intonasinya sudah baik. Secara menyeluruh itu sudah baik. ... Menyesuaikan input pada siswa, pak. Teman-teman yang sudah ngajar di kota itu dengan guru yang berada di sini, karena kebiasaan setiap harinya, itu juga beda. Begitu kita kumpul di MGMP, yang mengajar di kota itu mempunyai nilai lebih pada kompetensi gurunya soalnya melihat siswanya seperti itu.

There are actually differences in high schools. For some schools, especially ones that implement the K13, the emphasis is not just on contents. [Students' mastery of] grammar and intonation is generally good. ... [Teachers should] adjust input to students' characteristics. That's why there are also differences between teachers teaching in schools in the city and ones teaching here. It's because their daily [teaching] activities are different, too. When we meet in MGMP, those who teach in the city seem to show better English competence due to students' characteristics. (Interview with Aris, 11/11/15)

Moreover, Aris took the socio-educational setting of GHS Pari and the academic background of students into account when selecting and presenting the teaching and learning materials. GHS Pari is located on the outskirts of Pendalungan. Its students are mostly from the neighbouring suburbs and rural areas. The socio-economic status of their family might be largely classified into a middle-low one. In general, students have a relatively low academic and English skill compared to students of 'favourite' schools located in and around the city. There were also students from another Indonesia's island who had been-in Aris' word-“entrusted" by the MoNE to study in GHS Pari. They had even a generally lower academic and English skill than that of GHS Pari students. Aris thought that students' socio-economic background relates to their general academic and English abilities, which then has an impact on what and how he teaches in the classrooms.

When discussing the topic of "procedural text" and taking the way to prepare local foods as an example, for instance, Aris felt the need to make sure that students had some familiarity with the food so that the focus would be on the language skill rather than on background knowledge. As such, he chose a locally popular instant noodle mie gelas in preference to burger as an example during the classroom practice of writing English procedural texts. As Aris suggested:

Kalau di pembelajaran, saya itu kan mengajarkan langkah-langkah untuk mengerjakan sesuatu. ... Tapi kalau yang itu kan familiar, yang saya tanyakan sehari-hari. ... Iya, yang saya pikir kalau masalahnya nanti ke burger, dia sendiri nanti kalau membuat bingung. Ini kan mengajarkan bahasanya. Kan kalau ndak ngerti, jadi berpikirnya bisa dua kali itu. Mana mikir bagaimana cara membuatnya. Kalau ini kan sudah tinggal langkahnya. In the classrooms, I taught procedures for doing something. ... It's about what students were familiar with, something in their daily life. If it's about burger, they would be confused about how to prepare for it. I taught them about [English] language. If students don't understand [the subject matter], they might need to think harder, perhaps about how to make it. Thus, I took this [mie gelas] as an example, so that we could focus on [learning about] the procedures. (Interview with Aris, 11/11/15) 
Aris contextualised his pedagogic beliefs and practices regarding the teaching and learning of culture and interculturality in the high-school EFL classes by integrating various values and forces in the national and local settings into his instructional judgments and decisions. These might range from the national education goals and EFL curriculum, school-based instructional focuses and priorities, students' cultural and socio-economic background to the level of students' general academic and English competence.

\subsubsection{Instilling values implicitly}

Aris was seeking to act on the nationally-mandated character education and accordingly to instil moral, cultural and/or religious values in the students. He incorporated aspects of the stipulated character traits into his RPPs and teaching and learning materials. What may be particularly intriguing is that Aris expressly stated that the character education in the EFL classes would be best implemented in implicit ways in the light of the myriad dimensions and manifestations of moral, cultural and/or religious traits and values to address during his classroom practices. As Aris asserted:

Di antara 18 karakter, maka karakter itu tidak diajarkan secara lisan, tapi secara tersirat. Contoh kita mengucapkan salam. Itu sudah karakter toleransi sudah masuk di situ pak. ... Yang pertama ini pak, religius, jujur, toleransi.

Out of the 18 character traits, these should not be verbally taught, but rather implicitly. Take, for example, offering salam. The character trait of tolerance is included [implicit] in such an action. ... The first [trait] is being religious, honest, and [then] tolerant. (Interview with Aris, $11 / 11 / 15)$

Iya, jadi karakter itu langsung diintegrasikan; kegiatan belajarnya itu langsung, tanpa harus kita sampaikan. Ya contohnya tadi sebelum pelajaran itu kita bersyukur pada Tuhan. Itu sudah menanamkan rasa syukur.

Well, character traits are directly integrated, implicit in the teaching and learning activities, without necessarily being expressly stated. For example, before starting our lesson we show gratefulness to God. As such, [we're] implanting the sense of gratitude. (Interview with Aris, $21 / 11 / 15)$

While acknowledging the compulsory character-building instruction, Aris believed that the ways and the extent to which the policies enacted in the EFL classrooms depend on the teachers' own initiative and awareness. In this respect, Aris stressed the significance of the teachers' understanding of their 'expected' role, that is beyond merely 'teaching', and of their subjective judgments on aspects or issues related to the character education. Also, by referring to student's age, Aris believed that the teachers' insights into the students' psychological development apart from their educational needs and priorities can be very useful for the character education. As Aris explained: 
Sebetulnya yang tertulis itu harus dipilih. Kalau pelajaran ini karakter apa yang cocok.... Tapi kalau saya mungkin beda. Ini subjektif sekali, pak. Kalau saya mungkin 25\%. Mungkin guru lain bisa juga 15\% saja, 20\%. Tergantung dari kepedulian dalam menyampaikan karakter itu. Kalau hanya sekadar mengajar, tidak perlu diulang itu. Tapi kalau untuk usia seperti ini, walaupun secara garis besar, perlu sedikit pembahasan.

Actually, [teachers] have to select from the written [character traits], that is [to decide on] which traits suit their lesson. ... But I may be different, and this can be very subjective. I may allocate $25 \%$ of my teaching hour. Other teachers may allocate $15 \%$ or $20 \%$. It depends on the teacher's awareness. If we merely teach the traits, reiteration may not be necessary. But if we consider their age, a brief and general explanation may be required. (Interview with Aris, 21/11/15)

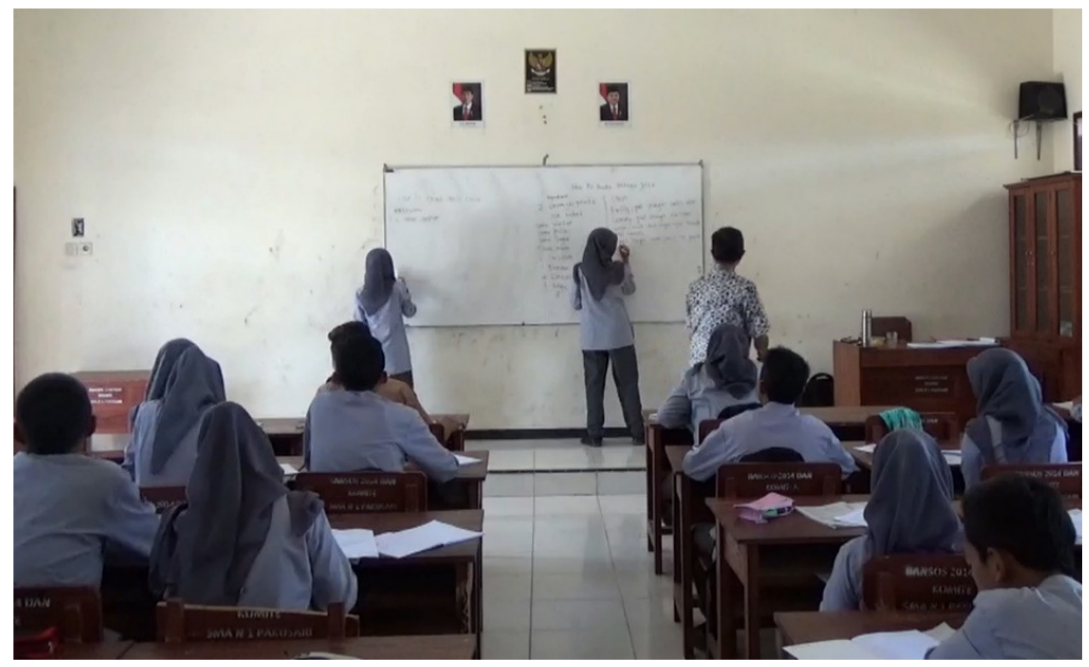

Figure 20: Students in Aris' class complete tasks

In Aris' opinion, students' level of English ability and the strength of their character can also influence the amount or percentage of character-building contents to discuss in the EFL classrooms. As Aris underlined:

Jadi begini pak, tidak bisa dikaitkan secara umum. Kalau di SMA-SMA tertentu, karena karakter itu sudah melekat pada siswa, itu persentase untuk learning Inggrisnya itu bisa $85 \%$ atau $90 \%$. Lalu yang kedua, karena kemampuan input kita itu seperti ini, lalu dalam menyampaikan karakter itu bisa lebih banyak pak 25-30\%.

Well, character education should not be implemented according to general situation. In some high schools, the percentage of English learning can reach up to $85 \%$ to $90 \%$, depending first on the strength of students' character. Secondly, in view of our [GHS Pari] students characteristics, the character education content may reach up to 25-30\%. (Interview with Aris, 11/11/15)

For Aris, the school's different socio-educational setting could even contribute to the development of the students' character. Regarding the strength of the students' personality, cultural profile or 'Indonesianness,' he differentiated students studying in the urban or city schools from those in the rural or outskirts ones. As Aris said: 
Apalagi siswa-siswa yang ada di SMA-SMA kota seperti SMA X, SMA XX. Itu mungkin dua tiga kali kepribadiannya lebih tinggi mereka walaupun mereka di kota. Justru siswa-siswa di kota itu, apalagi di SMA yang terbaik, itu sangat Indonesia sekali pak. Budayanya sangat kental sekali. ... Lebih berkarakter, jauh lebih berkarakter daripada sekolah-sekolah yang di pinggiran. Sopan santunnya, cara berperilakunya, itu jauh lebih sopan pak. Jadi kalau dulu yang di desa lebih sopan, tapi yang di kota itu khusus yang SMA-SMA tertentu.

Students in some GHSs in the city, like GHS X or XX, may even be different. Their personal character can be three times stronger although they study in schools in the city.

The students, especially ones of the 'favourite' schools, have a strong Indonesian character. They have a high cultural profile. ... They have a more distinctive character than ones studying in the suburb schools. They behave politely and properly. Rural schools were once deemed to be more polite, but now [this condition] is especially true for [students of] certain high schools. (Interview with Aris, 11/11/15)

Under the character education policy, rather than directly or explicitly inculcating moral, cultural and/or religious values, Aris preferred implicitly implanting in the students the stipulated character traits. The ways and the extent to which the teachers instil the values and traits largely depend on their awareness of and insights into the significance of the character education, the school's socio-educational setting as well as of the students' level of English competence and the strength of their personal character.

\subsubsection{Recap and remarks on Aris' case}

Two larger issues emerged from Aris' case, i.e. the cultural situatedness of EFL and an implicit culture teaching and learning. First, Aris' professed beliefs and observed practices in the EFL classrooms are to a certain degree subject to the complex interplay of various factors present in the immediate classroom and school socio-educational settings as well as to the cultural, religious, and political milieu. The nationally-mandated character education, the Islamic supplication made over school's loudspeakers before the school hours, the singing of patriotic and traditional songs, and the exchange of Islamic greeting at the beginning and the end of the English classes are interrelated in one way or another. Aris reported taking into account students' background knowledge, general academic and English skills, and the socio-economic background of their family as well. When describing English procedural texts, Aris attempted to ensure that students were familiar with the food and its suggested preparation that they used as an example in the classroom practice of writing the texts. As such, a locally-popular instant noodle brand with which students had some familiarity was chosen in place of burger. Aris believed that the students' familiarity with the local food helped them more easily understand his explanation of the topic and at the same time enabled him to focus on improving students' English skills without having to develop their general knowledge first before working with 
the topic. The fact that Aris and local EFL teachers can make such classroom decisions is owing largely to their familiarity with how English is taught, learned and used in the local context and to their keen awareness of the students' needs, goals, and priorities as well.

Aris' instructional practices and reported beliefs reflect how ELT is culturally situated in the Indonesia's high-school EFL context in which multiple cultures at work at the local, national and global levels are competing for a space in the classrooms. This phenomenon calls a closer attention to the notion of a culturally appropriate pedagogy. In this view, Kramsch and Sullivan (1996) conceptualise an appropriate ELT/EFL pedagogy as one that revises the authentic and adapts it to local conditions, attends to culturally-specific rules of interpretation and discourse conventions, and fulfils both the global and local needs of English learners. It is deemed necessary to strike a fine balance between prevalent social norms that fit the larger societal conditions and local norms under which specific, individual meanings are expressed and interpreted. Thus, under a pedagogy of 'global appropriacy' and 'local appropriation', Kramsch and Sullivan (1996, p. 211) maintain that:

The English language will enable students of English to do business with NS and NNSs of English in the global market, and for that they need to master the grammar and vocabulary of standard English. ... Appropriate pedagogy should therefore prepare learners to be both global and local speakers of English and to feel at home in both international and national cultures.

Elsewhere, Kramsch (1998, p. 81) posits that the concept of cultural appropriateness is replaced with 'appropriation' whereby 'learners make a foreign language and culture their own by adopting and adapting it to their own needs and interests'. Central to the idea is that language learners retain control of their own languages and cultures while seeking to acquire someone else's language and understand another person's culture.

The cultural situatedness of Aris' EFL classroom events and interactions may also have to do with the concept of a culturally-sensitive EIL pedagogy. It grapples with a number of pedagogical issues and implications, including the variety of forms of modern-day English, the diversity of the socio-educational contexts of English teaching and learning and use, and recognition of local languages and cultures (McKay, 2002, 2018; McKay \& BokhorstHeng, 2008; McKay \& Brown, 2016). For McKay (2003, 2018), the many varieties of English spoken worldwide highlight not only the fluidity and hybridity of English, but also the fact that it has been de-nationalised and de-linked from the so-called Inner Circle countries and the NSs of English. Echoing Smith's (1976) idea of an international auxiliary language, McKay $(2011,2018)$ argues that English can no longer be associated with a particular sociocultural context and should therefore be considered as culturally neutral. In 
this view, there is no reason for English learners to internalise the cultural norms of the NSs because EIL belongs to its users who in their linguistic ecology have modified the language in order to adapt to various local contexts and serve their own communication needs and priorities.

Moreover, the global reach of English has allowed for an extremely diverse context of English teaching and learning and use in terms of country, age of learners, formal or informal education, length and intensity of programme, etc. Aris' classroom practice in the Indonesia's EFL context is characterised by the teaching and learning of English that takes place in a non-English-speaking environment, limited opportunity to use English in the immediate social context, and common language(s) to use in the classroom (McKay, 2018). A large number of the students are from the Madurese ethnic background and speak Madurese as a first language, which is mutually unintelligible to Javanese spoken by the dominant ethnic group. Yet, many of them speak both Madurese and Javanese in addition to Indonesian, the national language. Code-switching/mixing is prevalent in this sociolinguistic setting. Multilingualism is the norm and often taken for granted.

Given the sheer socio-educational diversity of ELT context worldwide, McKay and Brown (2016, p. 20) stress that it is 'unreasonable to think that any particular learning goal, curriculum, method, or assessment procedure can be applicable to all learning contexts', and that 'all pedagogical decisions should be made in reference to local language needs and local social and educational factors' (p. 22). In addition, a culturally-sensitive pedagogy gives full recognition to home languages and cultures as a valuable classroom resource. That is, an existing linguistic repertoire of the students is viewed as an indispensable part of their own sense of personal and social identity, a reflection of different culture-specific ways of conceptualizing reality as well as a means for achieving and increasing proficiency in English (Alptekin, 2010; McKay, 2011; McKay \& BokhorstHeng, 2008). In other words, the students' culturally-shaped knowledge structures and frames of understanding, which develop from socialization into first language and culture, are used as starting points for making sense of and engaging with different cultural concepts and belief systems embedded in the English language (Buttjes, 1991). As Byram (1991, p. 18) puts it:

... it would be misguided to teach as if learners can acquire foreign cultural concepts, values and behaviours as if they were tabula rasa; just as it is misguided to teach language structures as if there will be no transfer from the first language. Equally it would be shortsighted to assume that the first language cannot be used to help learners grasp aspects of the foreign culture. 
Second, Aris believed that in English classrooms the teaching and learning of moral, cultural and/or religious values that are in accordance with the nationally-stipulated character traits would be better conducted in an implicit manner rather than verbally communicated or explicitly stated. In Aris' view, within the framework of the character education, the recommended values should be incorporated into the classroom materials and inculcated in the students indirectly or implicitly during the teaching and learning process. Take, for example, the exchange of the Islamic greeting to begin and end class. The action was aimed at instilling religiosity, honesty and tolerance into the students although explicit further discussion on it was absent. Also, for Aris the extent to which the character-building topics and contents are included in the teaching and learning materials and discussed in the classroom depends on the 'strength of the student character.' It is the teachers' awareness and personal judgment of how strong or otherwise the students' character is that provides a basis for the teachers to decide on such an extent.

Aris' instructional beliefs and behaviours bring up another key issue of how culture should be addressed in language teaching and learning. An ILTL perspective advocates a deliberate, explicit discussion of culture in the language classroom (Byram, 1997; Byram et al., 2002; Liddicoat \& Scarino, 2013). Fundamental to this notion is that we are usually not aware of the beliefs, values, worldviews and patterns of behaviour that shape our ways of being, or how the cultural orientation informs our ways of seeing and doing. This might be because the process of learning one's culture, which takes place particularly as we learn our first language(s) and are being socialised into our first culture(s), comes largely as a subconscious effort (DeCapua \& Wintergerst, 2016; Jackson, 2014). For Byram et al. (2002), equally important is to understand that one's beliefs, values and behaviours are deeply embedded and can cause reaction and rejection, however curious about, open towards and tolerant of other people's belief systems and behaviours we are.

In the case of English, its global spread and use may further complicate how it is taught and learned in EFL classrooms in that English brings its cultural baggage, that it is now widely used in real-life communications involving people from diverse cultural backgrounds, and that the users or learners of English with their ingrained attitudes and behaviour have to navigate values and practices commonly associated with the English language and the NSs. In an era of globalization, as Kramsch (2013b) argues, communities can be so hybrid and complex that they can no longer be bound by their national languages and that well-defined rules of behaviour and pragmatic appropriateness need to be observed and negotiated on a case by case basis if communication is to proceed smoothly. 
Likewise, as with the use of English as a global lingua franca, Kramsch and Hua (2016, pp. 47-48) note that:

English, by its global nature, makes it possible to communicate with more people than ever, but it does not necessarily enable people to understand other people's motives, memories and aspirations. These are embedded in the language or language varieties in which their speakers were raised, socialised and schooled and in which they express their innermost aspirations.

To sum up Aris' case, how and the extent to which Aris worked with culture in the EFL classrooms at GHS Pari were in many ways situated. A variety of cultural, economic, political and religious factors present in the immediate and broader socio-educational settings fed into the classroom events and Aris' instructional decisions. In this respect, Aris' conceptions and representations of culture and interculturality intersect with the issue of cultural appropriateness in the EFL pedagogy. Not only is English in the Indonesia's EFL context often associated with cultural values and behaviours assumed to be inconsistent with home knowledge and practices, but the EFL pedagogy also needs to implement the Government's cultural and political agendas, to serve the goals and priorities of the multilingual EFL learners, and thus to allow for 'global appropriacy' and 'local appropriation' (Kramsch, 1998; Kramsch \& Sullivan, 1996). Moreover, Aris believed that instilling cultural, moral and religious values in students under the mandated character education is best conducted in an implicit manner. As with Ambar's case, Aris' indirect approach to culture teaching and learning runs the risk of students losing opportunities to raise awareness of their own cultural values that are developed during the enculturation into first language-and-cultures and largely buried in the subconscious mind (Buttjes, 1991; DeCapua \& Wintergerst, 2004). A fuller awareness and understanding of one's own values and belief systems provides an important basis for comparing and connecting with target language-and-cultures (Byram et al., 2002; Newton et al., 2010).

\subsection{Wati's case}

Wati had taught English in VHS Agri for approximately 10 years, plus over 15 years' teaching experience at a junior high school level. Her Master's degree in English education also allowed her to become a part-time lecturer in a local university. The educational qualification and experience gave her opportunities to participate in various academic programmes at the national and international level resulting in intercultural encounters with NSs and NNSs of English within and outside Indonesia. In 2006, for instance, Wati attended a workshop on Education Monitoring and Evaluation organised by the Australia- 
Indonesia Basic Education Partnership in Jakarta. In 2007, Wati had the opportunity to visit Malaysia and Thailand under the Education Study Programme for Outstanding Teacher organised by Pendalungan's Education Office. In 2015, she also joined the Apprenticeship Programme for Indonesian and Thailand Vocational High School that was held in Lopbury College, Thailand. Wati wore jilbab in her daily activities, including when she was teaching at school. Underlying themes revealed in Wati's case were an authenticity of teaching and learning materials, NSs as desired pedagogic models, and an instrumental orientation towards English and EFL.

\subsubsection{Authenticity is crucial}

Unlike Ana's notion of authenticity that is concerned with cultural identity, that is an 'authentic self' of learner and user of English, Wati relates authenticity to the cultural component or context of the teaching and learning material used in her English classes. In Wati's opinion, authentic materials are ones that are used by real people, preferably the NSs of English, in real situations rather than ones that are originally created for educational purposes. These issues were immediately apparent in Wati's observed classes and reported in interviews. When discussing the topics of 'procedure text' and 'news report', she presented both video and audio materials by using classroom LCD projector and loudspeaker. All the materials featured the NSs of English characters. No context of language use referred to local settings. When asked whether and why she took additional materials from outside the compulsory textbooks or other resources provided by the MoNE, Wati replied:

Ya, saya berusaha menggunakan materi autentik, agar tidak terkesan terlalu textbook. Saya rasa materi di buku kurang, hanya itu-itu saja. ... Yang langsung bisa diambil dari sumbernya. Kalau mungkin di toko-toko, recipe-nya, atau apanya, menurut saya adalah salah satu dari authentic material.

Well, I always try to use authentic materials so that [teaching and learning] does not become too textbook-oriented. I think materials on textbook are not adequate, presenting already familiar topics. ... [Authentic materials are] Ones obtained directly from original sources. Whether the materials are ones coming from stores, be they receipts or any other forms, these are parts of authentic materials. (Interview with Wati, 17/11/15) 


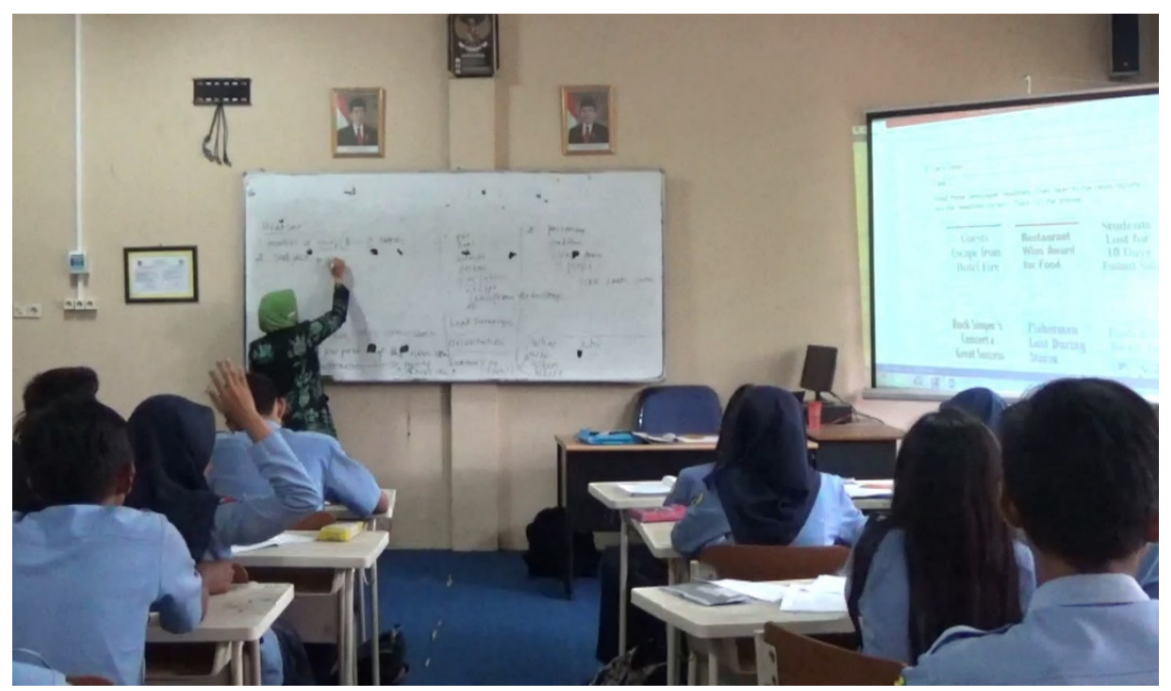

Figure 21: Wati explains English news report

Wati's conception of authenticity may be shaped by perceived students' needs and the context of English use. There had been an exchange programme at VHS Agri under which students from Thai's schools took up a short study at VHS Agri and in exchange VHS Agri students studied at the school's partner institutions in Thailand. VHS Agri also had a cooperation with a number of companies in Japan allowing students to attend an on-the-job training programme in the country. Moreover, Wati took some programmes at VHS Agri, i.e. information technology (IT) and agriculture mechanisation, into account when talking about teaching and learning materials. In this regard, authentic materials were associated with the conformity to students' characteristics and the suitability for their specific needs. As Wati suggested:

Tapi saya tidak berhenti di situ. Pada program berikutnya ke manual, yang penggunaan alat, kemudian tips-tips. Kalau dari pemerintah ya hanya ini saja. Crispy. Simple sekali. Sudah kelas 3 kok cuma disuruh gini aja, padahal yang berhubungan dengan IT. Mereka kan jurusan IT. Jadi, tugas berikutnya, mereka saya suruh speaking-nya. Karena waktu terbatas, jadi bisa terserah mereka mau download model dari video.

But I didn't do only that. The next lesson was about the use of manual and then tips. Materials provided by the MoNE were just like these. [It's about] crispy; very simple. Year 12 students learn this kind of materials. What for? They are students of IT programme. So, their next task was about speaking skills. Because of the limited time available, I left them to get and download example videos from YouTube. (Interview with Wati, 17/11/15)

Not only did Wati believe that her selection and presentation of the additional 'authentic materials' were to comply with the national curriculum, but she also seemed assured that her practices had to do with an expected quality of students/graduates in general and of 
their English skills in particular. In view of the mandated policies, Wati mentioned the

National Examination and the Standard Contents in her considerations:

Yang pertama, harus sesuai dengan yang sudah ditulis di Standar Isi, karena tidak bisa keluar dari situ. Itu standar minimum yang harus kita penuhi. Ini di buku paket ada, pak, berupa reading sederhana. Gambarnya juga persis seperti itu. ... Terlalu enteng kalau hanya dari buku itu. Tapi dengan diberi listening yang panjang seperti ini, karena saya juga mempersiapkan mereka untuk ujian kelas 3. Ada listening, monolog, dan salah satunya adalah procedure text.

First of all, the materials must conform to what is covered in the [national] Standard Contents. We are not allowed to deviate from it. We have to meet the minimum standard. These are available in textbooks in the form of simple reading passages. Even the pictures are exactly the same. ... It'll be too easy if materials are [taken] from the textbooks only. I was giving these long listening exercises because I was also preparing them for the 3rdgrade [national] examination. These included listening, monologue, and procedure text exercises. (Interview with Wati, 17/11/15)

As with graduates' expected degree of competence, Wati referred to the objectives of VHS and especially its role as a 'producer of work force' and thought about some serious competition in the job market that the graduates will be entering as work force. Here, English is seen as a vital part of graduates' quality and competitive edge necessary for the competition which may involve foreign workers. As Wati said:

Kita ini kan mencetak tenaga kerja. Kalau kita tidak meningkatkan kualitas, kita nanti diberondong dari luar. Bangsa sendiri sudah seperti ini, apalagi nanti kompetitornya dari luar. Kualitas itu harus standar. Menurut saya juga ada beberapa contoh. Contoh saja di jurusan mekanisasi diminta empat atau lima orang dikirim ke Kubota, Jepang.

We are supposed to 'produce' workforce. If we don't improve our quality, we'll be defeated by foreign [workers]. The competition between local workers has been so tight, let alone one involving foreign workers. Students' quality should be standardised. Take, for example, four or five students of the mechanisation programme were sent to Kubota [Corporation], Japan. (Interview with Wati, 17/11/15)

Wati raised the issue of authenticity of her teaching and learning materials and connected her idea about it primarily with the cultural content of the materials and a perceived real or original context of English use, expressing a preference for ones featuring the NSs of English. In the classroom practices, Wati linked her selection and use of 'authentic materials' to the national Standard Contents, the quality of available teaching and learning resources, students' communication needs as well as to their expected levels of English competence.

\subsubsection{Native-speakerness does matter}

The use of authentic materials and in particular downloaded videos from YouTube featuring only the NSs of English was largely because Wati wanted her students to see NSs 
as pedagogic models in the English classes. This was to a certain degree influenced by Wati's perception of her own language competence and of the expected role of the NSs in the Indonesia's EFL context. Wati measured her English proficiency against what she called 'international standards' and believed that she was still below the standards. Despite having an above-the-minimum educational qualification and a relatively long teaching experience, when asked whether she saw or wanted to see herself as a 'role model' for students, Wati stated:

Kalau saya berusaha, iya. Cuma apabila menjadi model dengan standar internasional, menurut saya sendiri belum, sehingga sering saya minta anak-anak untuk melihat model dari YouTube. ... Kalau modelnya hanya dari saya, mungkin mereka hanya dapat sedikit bayangan. Saya download-kan banyak model dan mereka juga bebas download sendiri. Yes, I'm trying to. But I don't see myself as a model to international standards. I haven't reached that level, so I let students get models from YouTube. ... If they got models only from me, they might get a few instances. In fact, I gave them many videos but they're also free to download by themselves. (Interview with Wati, 17/11/15)

In one of Wati's classes that I observed, Wati used video and audio materials to help her explain 'procedure text', both featuring only NS characters. My observation note on the classroom events is as follows:

Wati formally started the English lesson by asking a student to lead a silent prayer. However, she had beforehand projected an image of chocolate-covered strawberries onto the screen, telling students that they would be watching a video on how to make the dessert. Her opening talks included asking the students whether they had had breakfast, saying Alhamdulillah (praise be to Allah) upon hearing their reply. Prior to playing the video, Wati asked the students to identify the ingredients of the food, the steps to make it, and language features used to describe the order. The video featured a female NS of English presenter giving information about the not-so-familiar food to the ordinary locals. After watching the video, Wati asked the students to make a group of three or four and describe the procedure for making the food. The students mostly spoke Indonesian rather than English to one another when working on the task. At the same time, Wati moved around the class and spoke to a number of students in English. Then, she asked several groups to present the results of their discussion. Wati further discussed the language features and especially transition signals of procedure text by referring to a text book. After this, Wati presented audiovisual materials on the process of making crêpe, another 'foreign' food. The students were asked to select correct images of its ingredients as they were listening to an audio material that featured a male voice of English NS. The class then burst into laughter when a student mentioned a locally popular snack that is roughly similar to crêpe, i.e. dadar gulung, a 'crêpe' stuffed with coconut and palm sugar. (Observation note on Wati's class, 10/11/15) 


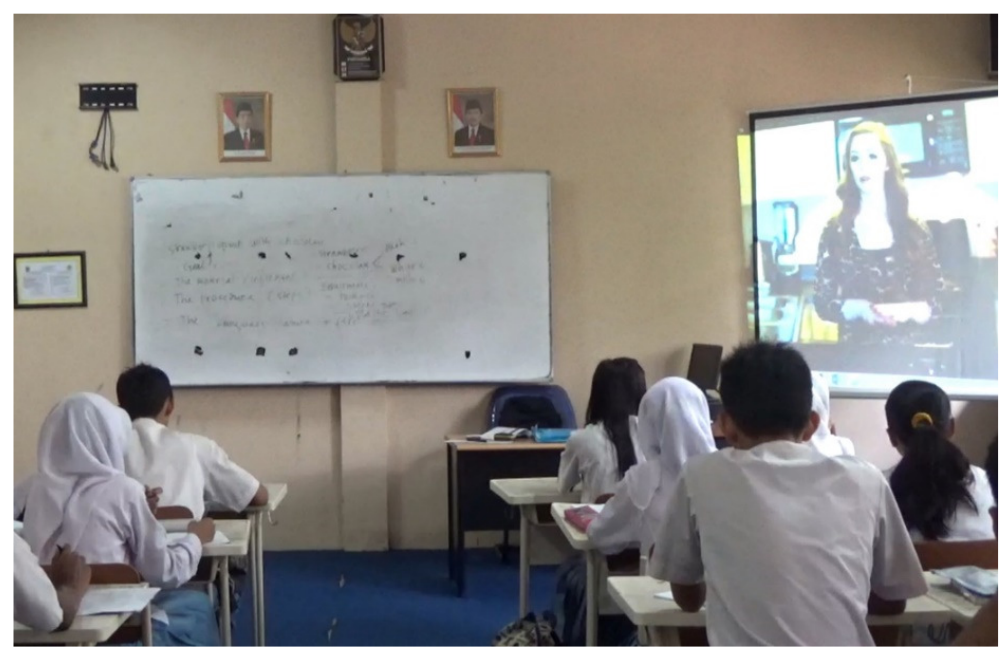

Figure 22: VHS Agri students watch a video featuring English NSs

Wati related the idea of authenticity and native-speakerness to accuracy, which she found very helpful in her teaching practice. What is particularly interesting is that in principle, as Wati stressed, the authority or legitimacy of pedagogic models is concerned more with accuracy than anything else, no matter whether they are NSs or NNSs of English. In her opinion, the models could be either NSs or NNSs but in terms of accuracy NSs are always more reliable than NNSs. Providing further confirmation of whether or not models should be NSs, Wati added:

Bisa jadi, tapi menurut saya tidak harus native. Ini kebetulan video ya. Mungkin yang saya katakan tadi untuk recipe, semacam brosur. Itu kan bisa juga. Tapi kalau yang diproduksi oleh dalam negeri, artinya yang dibahasa-inggriskan oleh orang Indonesia, itu kadangkadang tingkat akurasinya ... kadang-kadang bahasa Inggris, tapi doesn't sound English. Saya kadang-kadang juga ragu-ragu, pak. Jadi saya lebih percaya, bukan berarti tidak percaya, tapi lebih percaya ke yang native. ... Pasti tidak salah kan pronunciation-nya, ekspresinya, menurut saya.

It might be, but they are not necessarily NSs. This happens to be an [example] video. Using NNSs as models in recipe or brochure is possible. However, as for locally produced materials, that is ones translated into English by Indonesians, sometimes there are problems with their accuracy ... they are in English, but do not sound English. Sometimes I have some doubts about it, too. That's why, I believe more in NSs, although this does not mean ... [that I don't believe in NNSs]. NSs' pronunciation, expressions, cannot be wrong, I suppose. (Interview with Wati, 17/11/15)

Such a perspective not only made Wati convinced of her teaching approaches but was also practically useful and especially more time-efficient in that she did not feel the need to double check the "accuracy" of the models she gave to her students. In other words, so long as the characters in the teaching and learning materials are NSs, Wati believed that they have the necessary language skills, give good examples to students, and thus should 
be imitated. Regarding the possibility of using materials produced by or featuring NNSs, Wati considered it unfavourable:

Kerjaan tambahan buat saya. Saya harus ngecek dulu accuracy-nya, semuanya. Kadangkadang saya sendiri juga belum yakin, harus ngecek dari kamus juga, karena saya juga terbatas ingatannya. Kadang-kadang pronunciation saya juga tidak pas. Saya lebih percaya native, pasti benar.

That means more jobs to me. I have to check its accuracy, and all other aspects. When [that is the case and] I have doubts about it, I have to consult with dictionary, because my memory [competence] is also limited. Sometimes my pronunciation is also not proper. [That's why] I believe more in native [speakers]; [they are] always correct. (Interview with Wati, 17/11/15)

Wati tended to believe that native-speakerness goes hand in hand with language competence and that the NSs of English are a more authoritative and legitimate pedagogic model. In Wati's line of argument, an authenticity of the teaching and learning materials would therefore be more reliably measured against the NSs of English rather than the NNSs. This approach had given Wati both peace of mind and practical advantages in that she did not feel the need to double check the accuracy of expressions used in the classroom materials.

\subsubsection{English as a globalising tool}

Seeing VHS as a "producer of workforce" affected how Wati conceived of the role of the English language and English skill, that is as a "globalising tool" for the students and graduates. The education goals and characteristics of VHS feed into the ways she approached English and the mastery of English as a language of wider communication.

Socio-cultural and economic values could be generated simultaneously with the acquisition of vocational skills. In a broader scope, Wati envisaged that in addition to enhancing the cognitive ability of the students, EFL teaching and learning materials should develop their sensitivity to people of different backgrounds and cultural diversity. As Wati wrote:

[Menurut saya tema atau materi yang paling bermanfaat] adalah materi yang tidak hanya meningkatkan kemampuan kognitif, tetapi juga menanamkan kepekaan antar manusia dan keragaman. Juga keberlangsungan lingkungan hidup memperhitungkan nilai sosial, ekonomi, dan budaya sesuai dengan bidang kejuruan yang didalami sehingga siswa merasakan langsung pentingnya belajar bahasa Inggris. Selain untuk semakin memperdalam ilmu kejuruannya, juga bisa belajar bersosialisasi dan mendapatkan keuntungan secara ekonomi.

[What I have found mostly helpful in these materials has been] one that not only improves the cognitive ability, but also increases the sensitivity to other people and diversity. It should also concern the natural environment by taking socio-economic and cultural values into consideration which are aligned with specific programmes students are majoring, so that they become more aware of the importance of learning English. While developing their vocational skills, students could learn how to get along with others and gain some economic advantages. (Wati's NF, 12/11/15) 


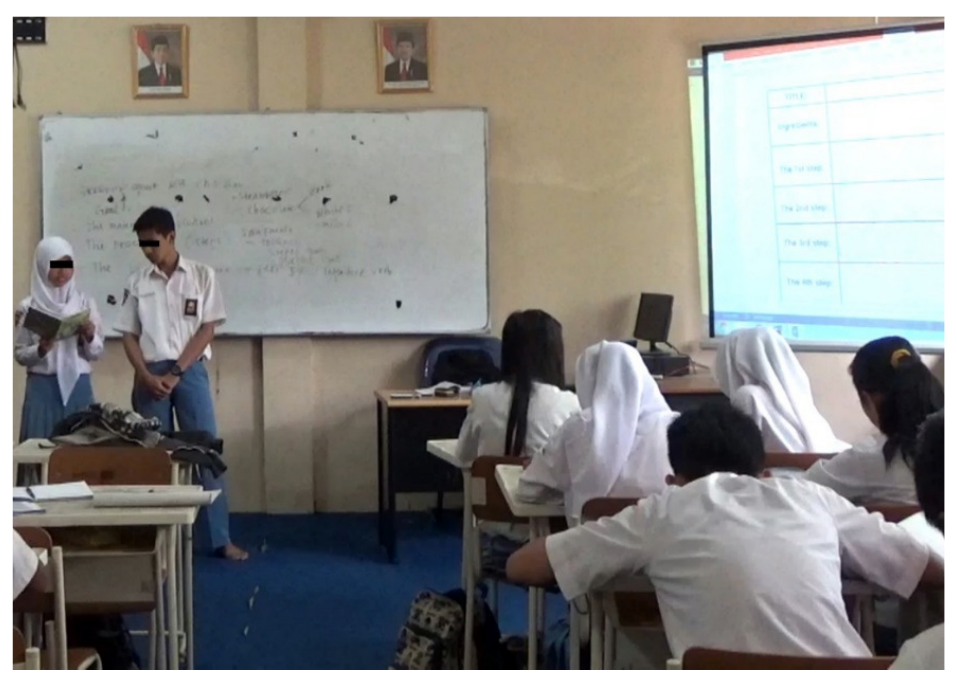

Figure 23: VHS Agri students practice in pair

For Wati, English is part of entrepreneurship which can yield economic benefits. It is also

viewed as an indispensable tool for international communication. Indonesian is as useful to the local communication setting and needs as English to the global context. In Wati's understanding, English proficiency is important for students as they learn how to advertise, broaden product market, and attract international customers, allowing them to 'go global' and be more economically productive. As Wati noted:

Dengan kemampuan bahasa Inggris mereka, dengan mengiklankan produk mereka, kembali ke produktif ya, pak. Entrepreneur. Kalau dengan bahasa Indonesia saja kan konsumen atau pembeli hanya terbatas orang sini. Kalau dengan bahasa Inggris, mungkin lebih luas lagi jangkauannya, dan mungkin bisa lebih 'go international'. Itu bayangan saya. Yang kedua, makanya ada sosial. Sosial mungkin berawal dari sini saja. Tapi kalau sudah ke bahasa Inggrisnya, sudah lebih jauh. ... Yang ekonomi pasti ada, yang sosial berhubungan dengan bagaimana mereka menerima order, bagaimana mengirim dan seterusnya.

By using English, they [students] can advertise products, and become [more] productive. [It's part of] entrepreneurship. If they merely use Indonesian, they will attract only local customers. If they use English, they will have a wider reach, and start 'go international.' That's what I first imagine. Secondly, it has social functions. It may start from the local contexts. But if English is involved, the scope can be wider. ... There must be economic aspects, and the social ones may deal with how they receive and send orders, and so forth. (Interview with Wati, 17/11/15) 


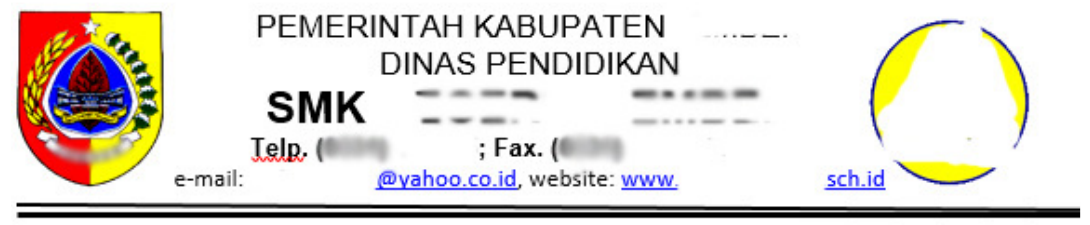

RENCANA PELAKSANAAN PEMBELAJARAN (RPP)

$\begin{array}{ll}\text { Satuan Pendidikan } & : \\ \text { Mata Pelajaran } & \text { Bahasa Inggris } \\ \text { Kelas/Semester } & \text { : X/1 } \\ \text { Materi Pokok } & : \text { Teks Deskriptif } \\ \text { Alokasi Waktu } & : 6 \text { X 45 menit (3 pertemuan) }\end{array}$

\section{A. Kompetensi Inti}

1. Menghayati dan mengamalkan ajaran agama yang dianutnya

2. Menghayati dan mengamalkan perilaku jujur, disiplin, tanggungjawab, peduli (gotong royong, kerjasama, toleran, damai), santun, responsif dan pro-aktif dan menunjukkan sikap sebagai bagian dari solusi atas berbagai permasalahan dalam berinteraksi secara efektif dengan lingkungan sosial dan alam serta dalam menempatkan diri sebagai cerminan bangsa dalam pergaulan dunia

3. Memahami, menerapkan, menganalisis pengetahuan faktual, konseptual, prosedural berdasarkan rasa ingintahunya tentang ilmu pengetahuan, teknologi, seni, budaya, dan humaniora dengan wawasan kemanusiaan, kebangsaan, kenegaraan, dan peradaban terkait penyebab fenomena dan kejadian, serta menerapkan pengetahuan prosedural pada bidang kajian yang spesifik sesuai dengan bakat dan minatnya untuk memecahkan masalah

4. Mengolah, menalar, dan menyaji dalam ranah konkret dan ranah abstrak terkait dengan pengembangan dari yang dipelajarinya di sekolah secara mandiri, dan mampu menggunakan metoda sesuai kaidah keilmuan

B. Kompetensi Dasar dan Indikator

1.1 Mensyukuri kesempatan dapat mempelajari bahasa Inggris sebagai bahasa pengantar komunikasi internasionalyang diwujudkan dalam semangat belajar.

2.3 Menunjukkan perilaku tanggung jawab, peduli, kerjasama, dan cinta damai, dalam melaksanakan komunikasi fungsional.

3.7 Menganalisis fungsi sosial, struktur teks, dan unsur kebahasaan dari teks deskriptif sederhana tentang orang, tempat wisata, dan bangunan bersejarah terkenal, sesuai dengan konteks penggunaannya.

1. Mengidentifikasi fungsi sosial teks deskriptif tulis tentang tempat wisata

2. Mengidentifikasi struktur teks deskriptif tulis tentang tempat wisata

3. Mengidentifikasi unsur kebahasaan teks deskriptif tulis tentang tempat wisata

4.9 Menyunting teks deskriptif tulis, sederhana, tentang orang, tempat wisata, dan bangunan bersejarah terkenal, dengan memperhatikan fungsi sosial, struktur teks, dan unsur kebahasaan yang benar dan sesuai konteks.

1. Menyunting isi teks deskriptif tulis tentang tempat wisata sesuai dengan struktur teks deskriptif

2. Menyunting bahasa teks deskriptif tulis tentang tempat wisata sesuai dengan

Figure 24: Wati's syllabus for Semester 1-Year X on Teks Deskriptif (descriptive text)

Wati expected that the students by means of their English skill and any medium of communication have the ability to menduniakan (globalise) Pendalungan. English is

localised to suit the teaching and learning goals and students' needs and, at the same time, is used as a globalising tool with which the students can achieve pragmatic gains and spread information about local cultures and cultural products to other people. For Wati, English could even be part of the students' nationalism when they use the language to let the world know about what their own places of interest and cultures which they can [mem]banggakan (boast of). As Wati commented: 
Dengan kemampuan mereka berbahasa Inggris, yang saya harapkan mereka bisa menduniakan Pendalungan lewat media apa pun. Kalau tidak bisa berbahasa Inggris, bagaimana membanggakan tempat sendiri atau pun daerah sendiri, negara sendiri, ke luar? Jiwa nasionalismenya.

By using English, I hope that students can globalise Pendalungan through any medium. If [they] cannot use English, how can [they] boast and let the world know about their own place or country? [It's about] their nationalism. (Interview with Wati, 17/11/15)
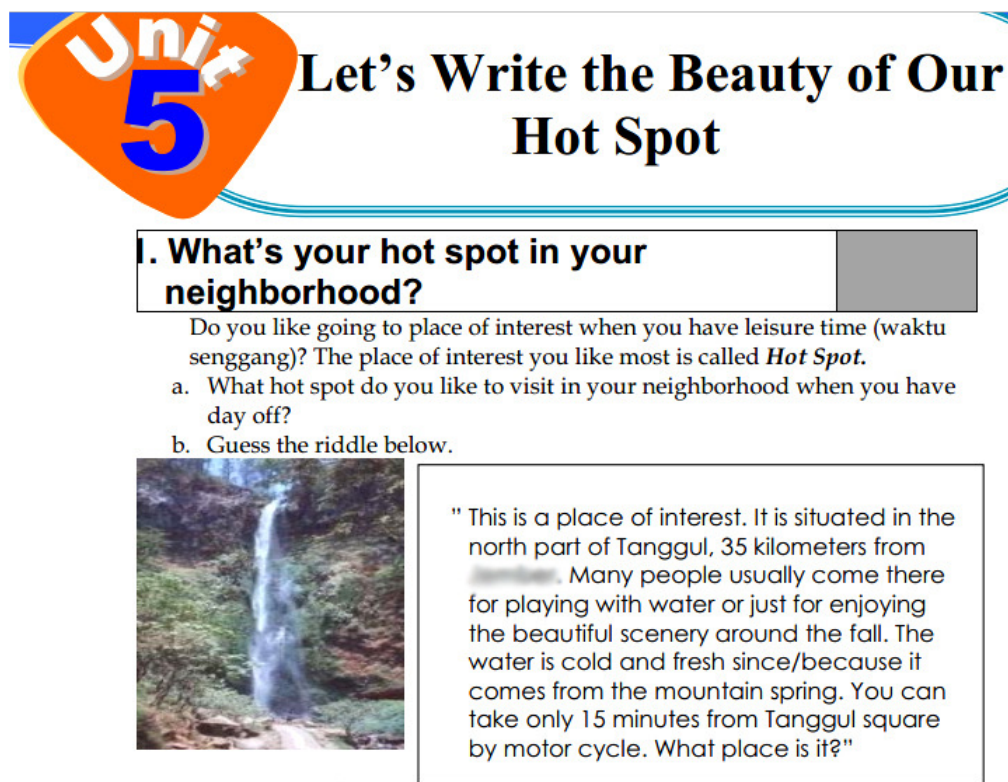

Source of picture iwww castjava.com

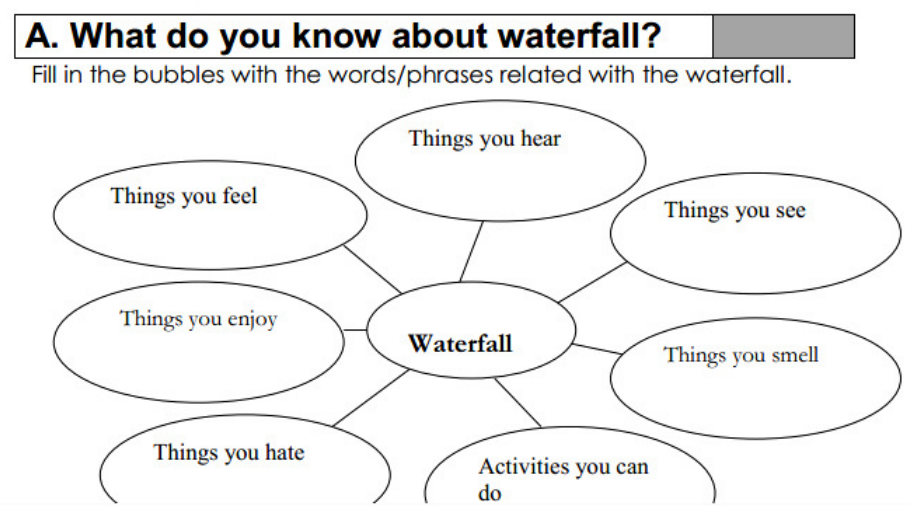

Figure 25: Wati's RPP for Semester 1-Year X on Teks Deskriptif (descriptive text)

Wati also connected her utilitarian approach to English and EFL with the character education and the revival of nationalism. Stressing the need for the EFL teachers to make the students become aware and feel proud of their country, Wati took Stonehenge as an example of descriptive texts. That is, other national and local historic buildings should be explored as part of the discussions about such an international ancient or historic site as Stonehenge. As Wati illustrated: 
Guru hanya menambah materi yang tidak ada di buku paket jika dirasa perlu. Misalnya materi yang terdapat di kelas X bab 8 tentang Stonehenge, tentang teks deskriptif terkait dengan bangunan bersejarah dunia. Akan lebih baik jika materi ini dilengkapi dengan bangunan bersejarah nasional, bahkan regional yang berada di daerah sekitar siswa. Selain untuk menambah rasa bangga terhadap bangsa sendiri (nasionalisme) dan patriotisme, juga rasa memiliki dan peduli terhadap lingkungan sekitarnya.

Teachers only need to add materials that are absent from the textbooks if necessary. Take, for example, the material on Chapter 8 for Year 10 students about Stonehenge, [and] descriptive texts about world's historic buildings. It would be better if these were supplemented with the national or regional historic buildings in students' area. This will make them proud of their country (nationalistic) and patriotic and develop a sense of belonging to and awareness of the local environment. (Wati's NF, 12/11/15)

Moreover, Wati gave her students tasks that allowed them to practice what they had learned in the English classes. The students were asked to discuss local places of interest in Pendalungan and to present them in the form of video clips in English. Take, for example, Wati's syllabus and RPP for Semester 1, Year X students concerning descriptive text. The topics covered in the syllabus were tourist destination and historic building, and the tasks included RPP were designed to discuss one of tourist destinations located in Pendalungan. With the help of today's internet technology, students were also encouraged to upload their works to YouTube. During the FGD, a student talked about a task that gave him and his friends opportunities to explore local tourist destinations and cultures:

Ya, kalau dari kelas saya itu, di sana gurunya mengajarkan kita buat untuk memperkenalkan budaya lokal Pendalungan seperti membuat, memperkenalkan kayak pariwisata-pariwisata di daerah Pendalungan itu. Nanti kan disuruh membuat video klip di situ. Nah, kebetulan kan jurusan kami multimedia. Kami di sana disuruh membuat iklan tentang untuk memperkenalkan budaya-budaya yang ada di lokal Pendalungan. Terus pernah juga membahas tentang budaya legenda. ... Kemudian di situ, kami mulai proyek itu selama kurang lebih dua minggu. Setelah itu, dipresentasikan dan di-share ke YouTube. In my class, the teacher taught us how to introduce local cultures and tourist destinations in Pendalungan. We were asked to make video clips. Luckily, we are majoring Multimedia. We were asked to create advertisements to promote local cultures, and once also asked to discuss [local] legends. ... We had undertaken the project for around two weeks. Then, we presented our work and shared it via YouTube. (Student FGD, 11/12/15).

Wati viewed English as a language of wider communication and English skill as a means for the students/graduates to communicate with a larger audience at a global level. English is regarded as a globalising tool with which the students can get more economic advantages and reap various pragmatic gains. At the same time, Wati expected that the students could benefit from English and English proficiency while strengthening their sense of nationalism. 


\subsubsection{Recap and remarks on Wati's case}

Two key themes emerge from Wati's case described above, i.e. a NS-based authenticity and competence and English as a "globalising tool". First, for Wati the teaching and learning materials are authentic not only because they are obtained from original sources, created for non-educational purposes, and used in the real world, but also because they are from the NSs of English whose language accuracy (grammar, word choice, pronunciation) is beyond doubt. Wati's pedagogic beliefs and classroom practices in principle deal with the issues of the legitimacy and authority of the NSs as she benchmarked the accuracy of expressions in the materials and her English competence against those of the NSs. What is also worthy of note is that despite a relatively high educational qualification and extensive experience, Wati did not see herself qualified for being a pedagogic model for students and felt her competence was still below what she called "international standards".

Comparing one's own competence and being preoccupied with the so-called NS competence can lead to the feeling of inadequacy, insecurity, and inferiority at worst (McKay, 2002; Medgyes, 2001, 2017). It is not uncommon that ESL/EFL teachers are concerned about their English proficiency. Medgyes (2001, 2017) suggests that in some cases non-native ESL/EFL teachers feel that they are handicapped by their lack of English skills. However, the nature and process of language teaching and learning are too complex to be attributed to a single factor or few definite ones. In the field of ELT/EFL, while stressing the pivotal role of English competence, Medgyes draws our attention to such nonlanguage-specific variables as experience, age, gender, aptitude, motivation, training, and so on that may have a direct bearing on the effectiveness of English teaching and learning. These non-linguistic variables, too, are sure to equally apply to NESTs and NNESTs. That is, English proficiency cannot be viewed as the one and only determining factor in teacher's effective classroom performance. Similarly, Richards (2010) stresses that although a threshold level of English proficiency should be reached in order to teach English well, it is not necessary for non-native EFL teachers to have a nativelike command in order that they teach the language effectively. As Richards notes:

Some of the best language classes I have observed have been taught by teachers for whom English was a foreign or second language. Conversely, some of the worst classes I have observed have been taught by native-speakers (p. 103).

Wati and other Indonesian EFL teachers might give an equal weight to all the many aspects and competencies of language teaching and learning so as to be "ideal teachers" rather than to language competence only. As Richards (2012, p. 46) states, there are in 
"good teaching" 'dimensions of teacher knowledge and skill that seem to be at the core of expert teaching competence and performance in language teaching', i.e. language proficiency, content knowledge, teaching skills, contextual knowledge, language teacher identity, learner-focused teaching, pedagogical reasoning skills, theorizing from practice, membership in a community of practice, and professionalism. Language competence chiefly concerns what and how much teachers need to know in order to teach effectively, including the ability to understand text accurately, provide good language models, select target-language resources, and give correct feedback on student language. In other words, without overlooking the importance of English proficiency, it is but one of the many factors contributing to an effective EFL education. Thus, despite a threshold language proficiency level that English teachers need to have achieved and the content knowledge of language teaching that they need to know in order to reach their full potential as English teachers, aiming for a nativelike production or aspiring to a NS-based authenticity and competence can otherwise be discouraging and counterproductive.

In a similar vein, in a general aspect of education, Article 10 of Indonesia's Teacher Law 14/2005 (Undang-Undang Republik Indonesia No. 14 Tahun 2005 tentang Guru dan Dosen [Law No. 14/2005 on Teacher and Lecturer], 2005) stipulates that teachers, regardless of school subject they teach, have kompetensi pedagogik (pedagogic competency), kompetensi kepribadian (personal competency) and kompetensi sosial (social competency) in addition to kompetensi profesional (professional competency). In this regard, it could therefore be argued that language education in general and ELT/EFL in particular constitute a multidimensional enterprise and that English proficiency representing the professional competency cannot and should not be regarded as the only contributory factor to non-native ESL/EFL teachers' competence, expertise, and professionalism.

Second, Wati sees English as a "globalising tool" that offers VHS Agri students economic and social benefits. With their English skills, the students are expected to be able to share ideas and spread information about local cultures, products and places of interest to the world. An instrumental orientation towards EFL education is immediately apparent in that by means of English skills the students are prepared and encouraged to make pragmatic gains. In the Indonesia's sociolinguistic and educational setting, English serves as both a foreign and an international language. For Wati, EFL education is important in developing the students' competitive edge in the domestic and overseas job market competition, enhancing the skills necessary for intercultural exchanges and international 
communication, and at the same time fostering a deep sense of patriotism. Wati's English classes, as McKay and Brown (2016) note, are by no means apolitical given that economic, moral, and ideological agendas are set by the State in terms of educational objectives.

Wati's local high-school EFL classrooms discussed above can in the first place attest to a great diversity of ELT contexts around the globe within which the local EFL teaching, learning, and use vary in the goal, need, approach, priority, and so forth. Richards and Burns (2012) assert that socio-educational contexts are many and different and that effective language teaching entails 'understanding what the characteristics of the teaching context are and how they shape the nature of teaching and learning' (p. 9). Differing contexts, as Richards and Burns observe, also represent different educational purposes as well as students' needs and priorities, adding that in specific school or classroom environments locally-designed materials can be more appropriate to specific teaching and learning goals. Various language needs of the local VHS students, the ways English is used in the immediate sociocultural context as well as local educational, economic, and political factors that help define the exigencies of English and EFL education in the nation highlight the significance of the relevance or suitability of pedagogic decisions and practices. In the light of such an educational and sociocultural milieu, as McKay and Bokhorst-Heng (2008) and McKay and Brown (2016) stress, if English curriculum is to bear direct relevance to students' lives, all pedagogic decisions should be made in reference to the language demands of the students and the domains in which English is used in the specific socioeducational situation.

Another crucial point pertinent to Wati's idea of English as a "globalising tool" is the nature of English. In Wati's EFL classrooms and the wider socio-educational setting in Indonesia, English that is legally sanctioned and socially spoken as a foreign language is taught and learned by multilingual teachers and students primarily as a language of wider communication across national borders. The intended purposes are to communicate ideas to people from different cultural backgrounds, make economic gains, and advance science and technology. The importance of EIL is well acknowledged and the intentions to capitalise on EIL seem clear, too. Yet, English is now used in more NNS-NNS interactions taking place in multilingual contexts than in NS-NNS exchanges in English-speaking countries (McKay \& Bokhorst-Heng, 2008). According to McKay (2004, p. 5), '[I]f an international language ... belongs to no single culture, then it would seem that it is not necessary for language learners to acquire knowledge about the culture of those who speak it as a native language'. 
In this line of reasoning, the nature of English as a "globalising tool" like what Wati had conceived of can no longer be construed only in terms of the NS communities, but also of its current bi-/multilingual users who are linguistically, culturally, and nationally diverse and use English to serve their various, situated communicative purposes. In this case, McKay and Brown (2016) and McKay $(2012,2018)$ further suggest that rather than promoting so-called "standard English" that implies a monolithic view of English as well as a perceived cultural homogeneity and inherent superiority of the NSs of English, standards are determined by local contexts of use rather than external ones, and that the teaching and learning of the many new varieties of English as a natural result of its global diffusion should be encouraged.

Wati's understanding of "English as a globalising tool" can, however, be seen as a starting point for going beyond the NS-based authenticity and competence, Englishspeaking Western cultures or NS-NNSs interactions. In this way, in her teaching practice Wati has ample opportunity to encompass a wide variety of socio-educational contexts for the teaching and learning and use of English, describe a varied cultural background of present-day English users, highlight different varieties of English spoken worldwide today, and present more examples of actual NNSs-NNSs interactions (McKay, 2009; McKay \& Bokhorst-Heng, 2008; McKay \& Brown, 2016).

\subsection{Yanti's case}

By the time of data collection, Yanti had about 12 years' teaching experience. Before teaching at IHS Negeri, Yanti had taught English in primary education for around three years. Yanti is a certified teacher, meaning that she has the required academic qualifications and passed the national UKG. Yanti has also been actively involved in the MGMP for IHS English teacher. IHS Negeri is one of IHSs in Pendalungan that is characterised by Islamic ethics. All teachers and students are Muslims. Female teachers and students are required to wear hijab, which is locally known as jilbab or hijab. Announcements made by the school office over the loudspeaker are in three languages, that is Indonesian, English and Arabic. Yet, unlike traditional Islamic boarding schools or pesantren, IHS is a co-educational one where male and female students study in the same class and school complex. Four common themes that emerged from Yanti's case are English and EFL education as imbued with Western culture, EFL teachers as "cultural guards", home culture as springboard, and NSs as resource persons. 


\subsubsection{Different Western culture}

Yanti recognised the importance of English teaching and learning in today's globalised world but at the same time perceived that English is a representation of a different "English-speaking, non-Muslim Western culture" and that the difference could be a threat to local Eastern/Asian or Muslim cultures. The understandings and representations of culture seem like between "our" and "their" culture. Yanti talked about "Eastern culture," "Muslim culture," "Islamic culture," and "Indonesian culture" vis-à-vis "Western culture" or "non-Muslim culture." She raised concerns about students being "contaminated by" or wanting to imitate "non-Muslim Western culture". By indicating the need to give explanations about the differences between the cultures, Yanti implied the fear of influence of Western culture in a not-so-positive sense. Two excerpts from Yanti's NF and interview below illustrate her views of different Eastern, Muslim, and Western cultures and especially her concerns over the potential influence of "English-speaking, non-Muslim Western culture" on students' cultural beliefs and behaviours:

[Berkaitan dengan topik-topik tersebut, salah satu yang saya anggap penting adalah] saya harus selalu mengajarkan siswa tentang adat ketimuran dan atau budaya Muslim itu berbeda dengan budaya Barat karena bagaimanapun juga belajar bahasa Inggris penting untuk menguasai dunia global, tetapi jangan sampai terkontaminasi dengan budaya Barat yang non-Muslim.

[Of these topics, one which I felt was important was] that I had to teach students about Eastern and/or Muslim cultures which are different from Western culture. Notwithstanding the importance of learning English in keeping up with the globalised world, (we) should not be contaminated by non-Muslim Western culture. (Yanti's NF, 25/10/15)

Maksudnya seperti anak-anak itu misalnya sudah belajar budayanya sendiri. Terus begitu mengenal budaya luar, 'Kok beda ya?' Takutnya ada kecenderungan meniru mungkin. Tetapi kalau misalnya pun untuk mempelajari budaya Barat, ya harus disertai penjelasan bahwa itu budaya mereka, budaya kita seperti ini.

What I mean is that students have learned about their own culture. And when they learn about other culture, [they may ask] 'Why is it different?' [I' $\mathrm{m}$ ] concerned about a tendency to imitate. Thus, learning about Western culture must be accompanied by explaining that it is their culture, and this is our culture. (Interview with Yanti, 18/11/15)

Yanti put across her points of the different values of Eastern/Muslim and Western/nonMuslim culture with examples drawn from the compulsory textbook. She compared English expressions presented in the textbook with possible equivalences in Indonesian. Yanti recognised some similarities between English and Indonesian expressions, while also acknowledging the role of cultural values in the different linguistic expressions, and highlighted the influence of religious values on different perspectives between the cultures. As Yanti explained: 
[Saya juga pernah mengulas tentang] ungkapan "love" (ada di KTSP kelas XI). Di dalam buku paket bahasa Inggris, disebutkan contoh-contoh ungkapan perasaan cinta dengan gamblang sehingga saya harus ekstra keras mengingatkan, menjelaskan dan menasehati anak-anak tentang perbedaan sudut pandang "cinta" antara dunia Barat dan Timur dan non-Muslim dan Muslim.

[I remember once I also talked about] the expression of "love" (included in the KTSP of Year XI). The textbook gives explicit examples of expressions of love so that I had to strongly remind, explain and advise students about the different perspectives of "love" between the West and the East, the non-Muslim and Muslim worlds. (Yanti's NF, 25/11/15)

Taking some types of speech act as other specific examples, i.e. inviting and accusing, Yanti compared the differences between English and Indonesian expressions, reflecting her pedagogic beliefs that any differences between expressions in the two languages are more likely caused by their cultural contents than the linguistic forms. As Yanti said:

... jadi kalau misalnya invitation ekspresinya berbeda, menuduh ekspresinya berbeda antara yang digunakan dalam bahasa Inggris, sedangkan mungkin dalam bahasa Indonesia juga berbeda ... Kalau menurut saya kebanyakan karena beda budaya. Salah satu yang paling ini aja, dari segi agama saja kan sudah beda. Tapi kalau untuk persamaan linguistiknya, sebetulnya mirip, cuma mungkin budaya yang paling memengaruhi.

... so, for example, the expressions for writing invitation or making accusation in English are different from those in Indonesian. ... I think it is largely because of different cultures. One of the aspects is the difference of religion. Regarding the linguistic structure, it may be similar, but culture has a stronger effect. (Interview with Yanti, 18/11/15)

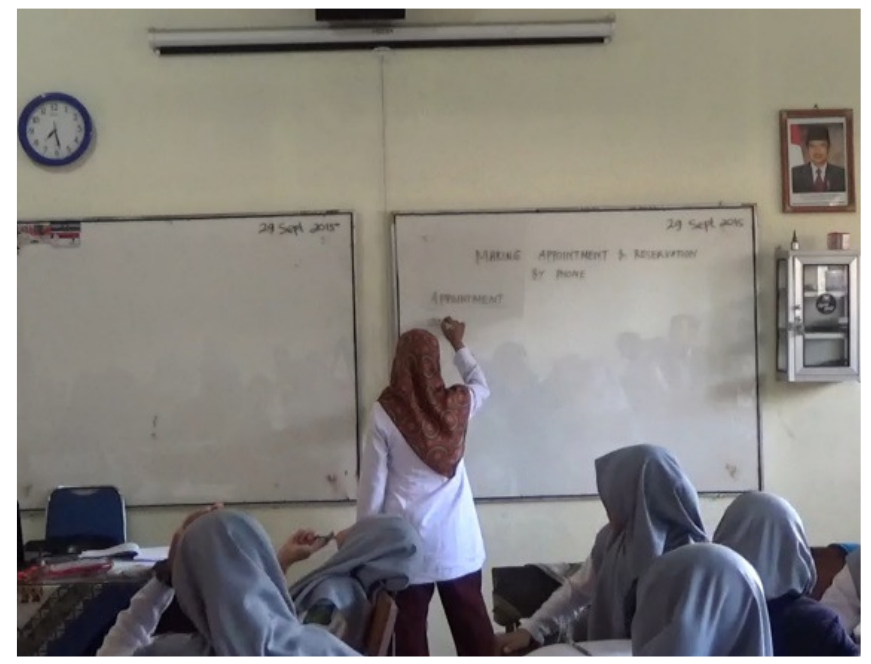

Figure 26: Yanti writes on 'making appointment and reservation by phone'

In spite of the apparent simplification and over-generalisation of culture, when asked whether her opinions sounded like sweeping generalisations, Yanti denied it and instead immediately acknowledged both "positive" and "negative" sides of Western and Eastern cultures. In the classroom practices, she picked up what she saw as positive values of 
either Western, Indonesian, Asian or Muslim cultures, and taught these to her students. As

Yanti stated:

Iya, gak pernah, gak sampai. Soalnya untuk antara budaya Barat sama budaya Indonesia karena saya masih kadang memasukkan nilai-nilai budaya Barat yang bagus ke anak-anak, dan juga memberitahukan ke anak-anak bahwa budaya di kita yang gak baik gitu. Jadi artinya masih saling ini lah, pak.

No, [I] never made [generalisations]. Regarding Western and Indonesian cultures, sometimes I talked about positive values embodied in Western culture and at the same time discussed negative values in our culture. I mean, these [values] are [basically] complementary. (Interview with Yanti, 18/11/15)

Equally intriguing is that for Yanti explicitly discussing Islamic and Eastern/Asian cultural, moral and religious values and implanting these in the students is one of the unique characteristics and strengths of Indonesian EFL teachers. Here, according to Yanti, selecting what is positive or otherwise in each culture is essential. As Yanti asserted:

Kalau kelebihan kita ya itu pak, dalam bagaimana memberikan pelajaran lebih ke nilai-nilai Islami atau nilai-nilai budi pekerti yang ketimuran kepada siswa. ... Mungkin perlu disampaikan ke anak-anak bahwa di budaya Barat itu tidak semuanya jelek, jadi masih ada yang bagus dan perlu diberikan, perlu didisiplinkan ke para siswa.

Our strength is that we inculcate Islamic or Eastern morality in the students. ... It is important to let students know that not all Western cultures are negative, so there are positive values that can be instilled into students. (Interview with Yanti, 18/11/15)

While recognising the crucial role of English as a global lingua franca, Yanti's understandings of culture and particularly Western culture might be problematic. She tended to oversimplify and over-generalise the concept of culture and accordingly see values embedded in English as inherently different from local worldview. For Yanti, the NSs of English are the embodiment of non-Muslim, Western culture which is potentially inconsistent with IHS students' beliefs and behaviours rooted in Islamic teachings. In Yanti's view, it is imperative that Indonesian EFL teachers explain the differences between so-called English-speaking, non-Muslim Western culture and Muslim or Eastern culture to the students and that the EFL teachers "shield" the students from some "malign influence" that Western culture could exert.

\subsubsection{EFL teachers as cultural guards}

How Yanti perceived "culture" and "Western culture" affected the ways she approached the teaching and learning of English and particularly the role of Indonesian EFL teachers in the EFL classrooms. She saw the teachers as expected not only to improve students' English skill but also to uphold local values, inculcate these values in the students, and 
safeguard students' cultural, moral and religious identity. For Yanti, English and EFL are infused with different world views and these differences can "contaminate" students' cultural beliefs and behaviours. In her opinion, it is part of Indonesian EFL teachers' duties to inculcate moral, cultural and spiritual values into students. The values that Yanti instilled were drawn primarily from what she understood as the values, beliefs and behaviours of the Indonesians, Muslims, or Asians. As Yanti described:

Kalau misalnya untuk materi, saya bebas, pak. Jadi ndak pernah materi harus yang bernuansa seperti ini itu. Hanya saja nanti itu saya di sela-sela saja memberikan misalnya bagaimana kita seharusnya bersikap, bagaimana seharusnya kita, sebagai orang Indonesia, orang Muslim atau orang Timur.

The materials that I used are flexible. I never want the materials to be like this or that. Nonetheless, I also touch briefly during the teaching and learning on how to behave well as an Indonesian, a Muslim, or an Asian. (Interview with Yanti, 28/10/15)

In implanting the cultural, moral and religious values, Yanti connected her pedagogic beliefs and classroom decisions with the prevailing policies, i.e. the K13 and character education. In particular, she highlighted the key role of EFL teachers in instilling the values in the students in the classroom practices. As Yanti said:

Kan sudah ada upaya seperti di Kurikulum 2013 aja sudah ada penilaian karakter untuk siswa lah istilahnya. Di sana dinilai juga misalnya kejujuran, tanggungjawab, kerjasama dan lain sebagainya. Tinggal masing-masing guru aja mungkin pak yang perannya sangat penting. ... Inggih, termasuk dalam pelajaran bahasa Inggris. Jadi memang selain memberikan pembelajaran juga menyelipkan nilai-nilai di antara pembelajaran.

The assessment of student character is incorporated in the Curriculum 2013. The suggested values include honesty, responsibility, cooperation, and so on. The implementation depends on the teachers. Their role is crucial. ... This includes English language teachers, too. So, they have to include and discuss recommended values briefly during lessons. (Interview with Yanti, 18/11/15)

It appears that IHS as the immediate context of the teaching and learning of English also influences how Yanti approached culture and interculturality in the English classrooms. She wanted to have and integrate more religious or Islamic contents in the teaching and learning materials. As Yanti noted, these may include the biography of the companions of Prophet Muhammad. This practice could help avoid unfavourable impressions resulting from the use of the materials for students at large that are devoid of Islamic teachings and can be specifically intended for IHS students. Two excerpts from the interviews below illustrate how Yanti conceived of the EFL teachers' teaching duty and linked it with the need to avoid negative impressions left by a general lack of specific Islamic contents and relevant explanation: 
Kalau misalnya yang agamis gitu, ya misalnya yang kaitannya sama Islam sendiri masih belum. Jadi misalnya bacaan-bacaan bahasa Inggris yang tentang Islam gitu. ... Kalau untuk kebudayaan Indonesia sudah, tapi kalau tentang biografinya sahabat Nabi, itu belum. The availability of religious contents, especially in relation to Islam, is still limited. These include reading materials on Islam in English. There are some [materials] about Indonesian culture, but there is none about the biography of the Prophet's companions. (Interview with Yanti, 18/11/15)

Tapi ya di sana kan juga harus secara ndak langsung, kan memang harus menyelipkan pesan moral atau apa yang memang itu, bahwa itu budaya mereka [sedangkan] di kita tidak ada. Meskipun ya anak-anak sendiri sudah tahu ya, cuman ya saya merasa itu kewajiban guru. Soalnya kan takutnya nanti kalau tidak disampaikan ... ada anak yang berpikiran 'Guru bahasa Inggris kita Islam kok nuruti teman-temannya pingin muter film, nyetel lagu, tapi kok lagu seperti ini yang diputar?'

However, [teachers] have to indirectly [discuss] or touch on moral values and assert that their value is not shared in our culture. Although students may have had some knowledge [about the difference], it is still part of the teacher's duty [to discuss such a difference]. I am afraid that if we do not do that ... there may be students who come to think 'Our teacher is Muslim. How come s/he allowed students to watch film or play song like this?' (Interview with Yanti, 18/11/15)

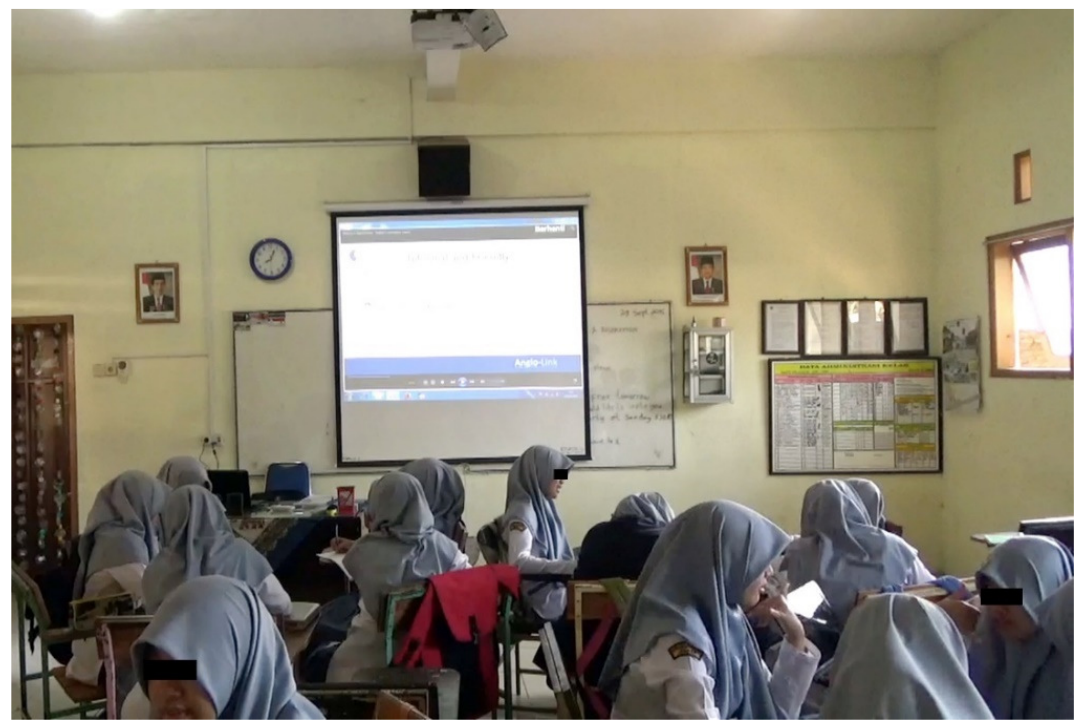

Figure 27: IHS Negeri students work in groups

Yanti's broad conception of "culture" and "English-speaking, Western culture" appeared to be the impetus behind her indicating the need for Indonesian EFL teachers, especially ones working in IHS, to forge and maintain students' cultural, moral, and religious identity. These local EFL teachers serve as though they are "cultural guards" who "safeguard" the students from values, beliefs and behaviours deemed to be inconsistent with local knowledge and practices. For Yanti, this goal could be achieved by identifying differences between Muslim or Eastern and Western cultures; always incorporating and 
explicitly discussing cultural, moral, and religious values; integrating more Islamic contents; and, deliberately instilling these values in the students.

\subsubsection{Home cultures as classroom resources}

Yanti's observed classrooms practices and interview reports demonstrate that home language-and-cultures often become a point of departure for Yanti to explain and students to understand new concepts, ideas and ways of doing something that come with English. In Indonesia's and particularly in Pendalungan's linguistic and cultural context, this deals with both Indonesian and such local vernaculars as Javanese and Madurese as well as Muslim belief systems. Yanti and the students at varying degrees benefited from their greater familiarity with local language, knowledge, and practices as they moved between the native and target language-and-cultures. Students once asked Yanti how to say Alhamdulillah (Praise be to Allah) in English. On another occasion, they wanted to know how to say "Hormat gerak!” [Salute!] in English, as exemplified in the following excerpt:

Tapi kadang anak-anak, misalnya, tanya, “"Hormat gerak!” itu bahasa Inggrisnya apa, bu?' Tapi banyak juga yang lupa itu anak-anak tanyanya.

Students once also asked, 'How do we say “Hormat, gerak!" in English, mam?' They asked many other questions [about such expressions], but I forgot what they were. (Interview with Yanti, 18/11/15)

In addition to "foreign" or "Western" foods, for instance, the students responded to Yanti's prompts, either seriously or jokingly, by mentioning local foods that are popular in the locality like pecel or gado-gado (mixed vegetables with peanut sauce), rawon (beef black soup), and segá jagung ("corn-rice”). In an excerpt below, Yanti explained what the event really was and why it was happening:

Mungkin saya waktu itu berpikirnya gini, pak. Makanan khas dari luar itu burger dan pizza. Kalau misalnya yang healthy food dari luar, saya kurang paham. Jadi pahamnya yang dari Indonesia. Jadi misalnya kalau healthy food yang di Amerika, anak-anak kurang. What I was thinking was perhaps typical foreign foods are burger and pizza. I am not familiar with healthy foods from other countries. What I am familiar with are ones from Indonesia. Students are not familiar with healthy foods from the US, too. (Interview with Yanti, 28/10/15)

Yanti started and ended her classes with the Islamic greeting Assalamu'alaikum. During the classroom interactions, when Yanti talked about English expressions for inviting, students brought up Islamic ceremonies or local rites of passage, e.g. akikah (Islamic baby welcoming celebration), tahlilan (prayers for the deceased), or hajian (pilgrim welcoming ceremony), where either formal or informal invitation would normally be made. When 
practising making appointment and reservation by phone in English, students opened and closed their conversation by saying the Islamic greeting. Such culture-laden phrases as Assalamu'alaikum and In Shaa Allah are freely used as though the expressions are common in any situations. What I observed in the classroom event is as follows:

Yanti's class was discussing the topic of 'making appointment and reservation by phone'. The discussion was part of the previous teaching and learning activities as Yanti first asked the students to make a group of four and talk about their homework on the topic. before the students started their group work, Yanti appointed a student to have a sample dialogue with her. The student opened the dialogue by saying Assalamu'alaikum and Yanti replied Wa'alaikumsalam. Then, Yanti let the class proceed with their work. After some time, she asked several students to write the results of their discussion on the white board. A student wrote 'Askum' that stands for Assalamu'alaikum as a greeting in her sample dialogue and its reply 'Wassalam' that stands for Wa'alaikumsalam, meaning peace be with you, too. Afterwards, she asked other students to come forward and practice using phrases and expressions for making appointment and reservation by phone. All the pairs opened their dialogues by exchanging the Islamic greetings. That is, such a practice seems to be 'natural' parts of the EFL classroom interactions and reflect the students' religio-cultural identity as well as their ingrained attitudes and behaviour. (Observation note on Yanti's class, 29/9/15)

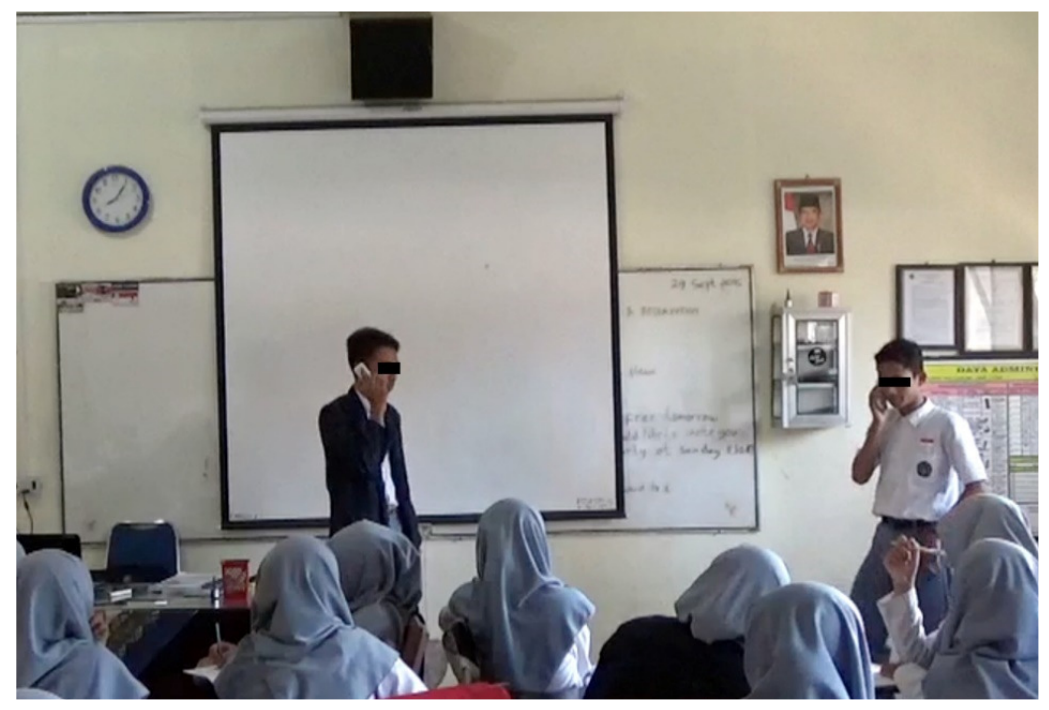

Figure 28: Male students practice making appointment by phone 


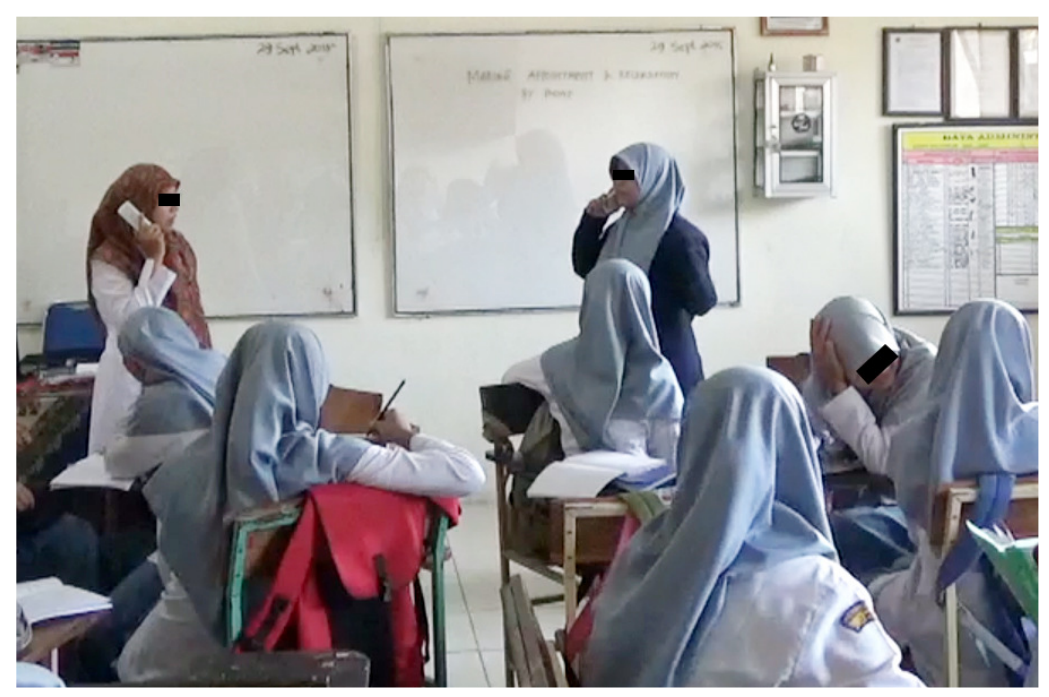

Figure 29: Female students practice making appointment by phone

Yanti also reported that students related local Islamic terms or concepts such as suudzon (prejudice), In Shaa Allah (God willing), and 'zina mata' ('adultery of the eyes') to the expressions for accusing and making invitation in English and the idea of making eyecontact during conversation respectively. Among these terms, In Shaa Allah is commonly used in daily communication by millions of Muslims worldwide no matter what their native language or religion is, including Arab Christians and Arabic-speakers of other religions (“Inshallah,” 2018; Sussex, 2012).

Yet in some cases In Shaa Allah is used in contradiction to its intrinsic meaning. Rather than expressing one's submission to or belief in Divine Will, which is one of the fundamental tenets in Islam, In Shaa Allah is used-or abused, to be precise-when one is not willing to fulfil commitment, attaching to it a new, undesirable meaning (Al-Ammar, 2015; Alho, 2010). Worse still, it is grossly misunderstood, simplified, and exaggerated by people, particularly non-Muslims, who are unaware of the original meaning or significance for its speakers, that is, it is "potentially threatening" simply because it is Arabic (W. Ali, 2016). In fact, the topic of future possibility, which is also concerned with the Islamic concept of In Shaa Allah, was included and practically discussed in Yanti's syllabus (Figure 30), RPP (Figure 31) and classroom teaching. As Yanti described:

Misalnya di kelas 3 aja, ada ungkapan memuji, ungkapan complaint. Misalnya itu, menuduh, menyalahkan, dan mengakui kesalahan. ... Kadang lucunya, kalau lagi belajar seperti itu, misalnya ya ungkapan accusing, menuduh. Jadi anak-anak berkelakar 'Nggak boleh menuduh, bu; [itu] dosa'. Gitu ya, jadi kalau misalnya suudzon ... ungkapan dalam invitation ... kadang itu anak-anak juga ada yang guyonan, dijawab 'In Shaa Allah, bu'. For example, Year 12 students learn about the expressions of giving compliment, making complaint, accusing, blaming, and expressing guilty. ... What was funny, when learning the 
expression of accusing, students said, 'We are not allowed to accuse, mam. It's sinful.' They seemed to relate it to [the idea of] suudzon ... When discussing the expression of invitation, they also jokingly said 'In Shaa Allah, mam.' (Interview with Yanti, 18/11/15)

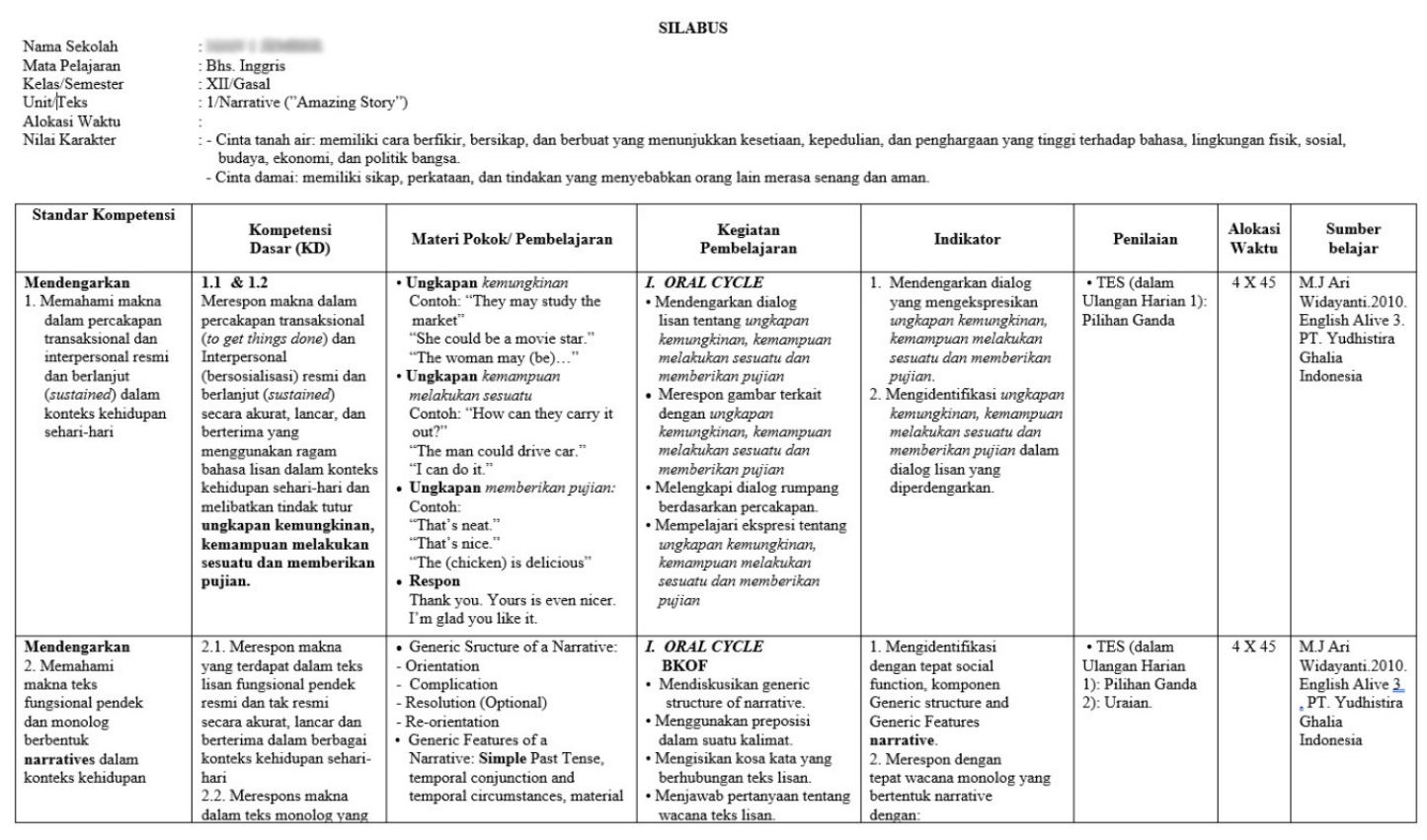

Figure 30: Part of Yanti's syllabus for 'Odd Semester'-Year 12

Furthermore, Yanti preferred using EFL classroom materials that both reflect "Western culture" and can be related to Eastern values. At the same time, she took a student' answer about "eye-contact" as an example and connected the general principle of politeness in foreign (Western) cultures with Islamic teachings. As Yanti noted:

Ya jadi belajar bahasa Inggris yang masih mungkin materinya dikaitkan dengan budaya ketimuran. Tetapi nanti memungkinkan juga untuk belajar budaya Barat itu seperti apa. Jadi kan dulu kan saya pernah itu ... kalau di luar negeri, misalnya, ngomong terus misalnya gak menatap mata yang ngomong, katanya dianggap gak sopan gitu, pak. Tapi kalau misalnya di kita kan, kadang anak-anak yang sudah belajar agama [berkata]: 'Bu, saling berpandangan itu nanti kan katanya "zina mata”.'

Well, we study English by using the teaching and learning materials that can be related to Eastern culture. These should also allow us to explore what Western culture is. I once heard that ... in foreign countries, when you're talking to someone, it is considered impolite if you do not make an eye-contact. In our culture, sometimes for students who have some knowledge about religion [Islam], [they might say] 'Mam, making eyecontact could also be regarded as an "adultery of the eyes".' (Interview with Yanti, $18 / 11 / 15)$ 


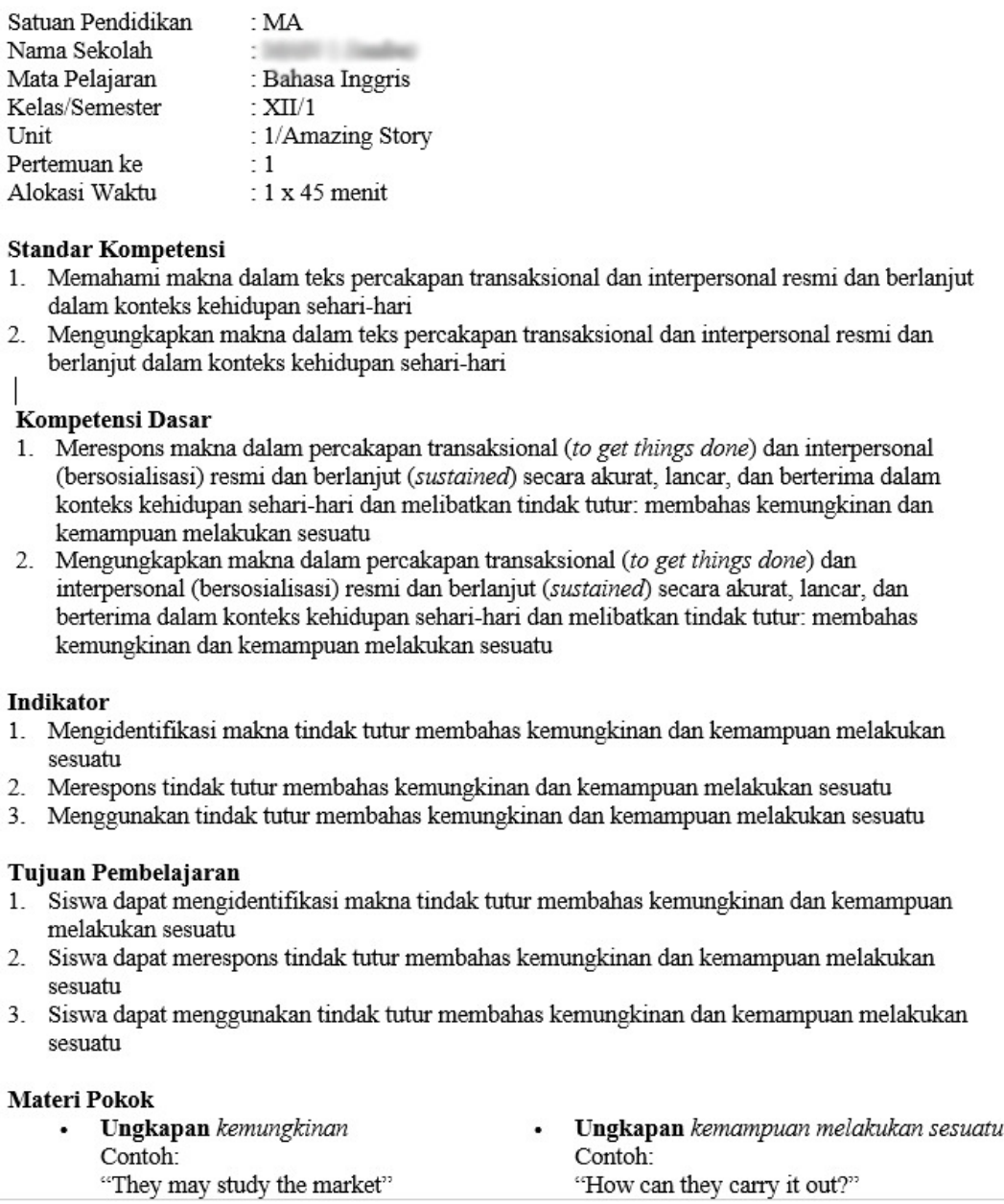

1. Merespons makna dalam percakapan transaksional (to get things done) dan interpersonal (bersosialisasi) resmi dan berlanjut (sustained) secara akurat, lancar, dan berterima dalam konteks kehidupan sehari-hari dan melibatkan tindak tutur: membahas kemungkinan dan kemampuan melakukan sesuatu

2. Mengungkapkan makna dalam percakapan transaksional (to get things done) dan interpersonal (bersosialisasi) resmi dan berlanjut (sustained) secara akurat, lancar, dan berterima dalam konteks kehidupan sehari-hari dan melibatkan tindak tutur: membahas kemungkinan dan kemampuan melakukan sesuatu

Indikator

1. Mengidentifikasi makna tindak tutur membahas kemungkinan dan kemampuan melakukan sesuatu

2. Merespons tindak tutur membahas kemungkinan dan kemampuan melakukan sesuatu

3. Menggunakan tindak tutur membahas kemungkinan dan kemampuan melakukan sesuatu

Tujuan Pembelajaran

1. Siswa dapat mengidentifikasi makna tindak tutur membahas kemungkinan dan kemampuan melakukan sesuatu

2. Siswa dapat merespons tindak tutur membahas kemungkinan dan kemampuan melakukan sesuatu

3. Siswa dapat menggunakan tindak tutur membahas kemungkinan dan kemampuan melakukan sesuatu

- Ungkapan kemungkinan - Ungkapan kemampuan melakukan sesuatu Contoh:

"They may study the market"

\author{
Contoh: \\ "How can they carry it out?"
}

Figure 31: Part of Yanti's RPP/lesson plan of Odd Semester-Year 12

In the EFL classrooms, both Yanti and the students drew on home language-andcultures and used these as a starting point for making sense of new or different ideas and practices associated with English and English-speaking Western culture. This is evident, for example, from students' mentioning of local foods and traditions when they were exposed to some Western foods and ceremonies. Yanti and the students compared and connected target language-and-cultures with home knowledge, language, and practices with which they are more familiar. Islamic teachings served as a crucial part of the teacher' and students' existing knowledge and linguistic repertoire. Take, for instance, when they talked about such specific expressions as alhamdulillah, suudzon, In Shaa Allah, and "zina mata" ("adultery of the eyes"). Yanti also pointed out a lack of Islamic contents and thus the need to integrate more Islamic materials into the local EFL and particularly into IHS EFL resources. 


\subsubsection{NSs as resource persons}

Yanti believed that the NSs of English are indispensable for the teaching and learning of English in EFL classrooms because of their "native competence." The NSs were perceived as most legitimate and authoritative sources of the production and interpretation of English expressions. In this regard, topics that Yanti found particularly challenging to explain were Indonesian and English expressions that students asked in the classroom interactions. She thought that the use and the teaching and learning of "daily expressions" in both Indonesian and English are different from grammar, structure or pronunciation. Yanti found it difficult to appropriately translate Indonesian expressions into English, suggesting a lack of personal English competence, and the authority of the NSs to decide whether or not English expressions are "correct" or "appropriate." She was also not confident in explaining or translating some English expressions due to a perceived limited knowledge.

As Yanti reported in an excerpt below:

[Namun demikian, hambatan utamanya mungkin adalah] apabila saya punya pertanyaan dari siswa yang menanyakan tentang ungkapan dalam bahasa Inggris dan saya tidak tahu ungkapan dalam bahasa Inggrisnya, saya rasa saya membutuhkan penutur asli bahasa Inggris untuk tempat bertanya.

[A major constraint, though, might be that] I had questions from the students concerning Indonesian expressions with which their equivalents in English I was not familiar. I think [in this situation] I need a NS of English to ask. (Yanti's NF, 25/10/15)

Yanti specifically identified the difficulties in dealing with unexpected daily English expressions in her classroom practices. Not only is the difficulty concerned with understanding and explaining the meaning of the expressions, but it can also be related to how to pronounce the expressions. In such a situation, she highlighted the importance of the NS of English as a resource person. As Yanti exemplified:

Kalau misalnya kesulitannya itu ungkapan-ungkapan yang keseharian, itu ungkapan apa, bagaimana mengucapkannya. Itu karena tidak ada, misalnya tidak ada native speaker $d i$ sini. ... Kadang-kadang kan anak-anak tanyanya kan agak melenceng dari pelajaran. What I found difficult is daily expressions, in terms of meanings or pronunciations. It's because there is no NS here. ... Sometimes what students ask are out of the lesson's topic. (Interview with Yanti, 18/11/15)

The presence of the NSs of English, in Yanti's opinion, could be more significant in the light of the nature or type of Indonesian expressions. Some daily Indonesian expressions that students asked about were "out of topic" or deviated from the prescribed materials. Given a limited knowledge of English-whether real or perceived-and a lack of confidence 
in finding possible English equivalents of such expressions, Yanti felt that the NSs might be the only recourse. As Yanti explained:

Ya pada saat anak-anak ada pertanyaan yang ungkapannya ada di sini. Maksudnya sering kita ungkapkan sehari-hari tetapi dalam konteks bahasa Inggrisnya saya tidak tahu gitu pak. ... untuk di-translate secara literal gitu kan pastinya ndak sama. Apa ya bahasa Inggrisnya ungkapan ini? Kadang takutnya nanti juga malah keliru. Jadi akhirnya ya sebisa mungkin saya. Ya cuman kadang akhirnya takutnya nanti mengarang ungkapan sendiri tapi gak bener gitu menurut penutur aslinya.

It was when students asked about local expressions. We often use these expressions, but I have no idea how to put them in English. ... literal translations will not work. How should I put them in English? I'm afraid I'll end up with incorrect [English] equivalents. I just have to try the best I can at times. But I'm afraid I'll end up making the expressions up, which are not correct according to the NSs. (Interview with Yanti, 18/11/15)

Yanti's understanding of language and cultural competence and her perception of professional competence as a local EFL teacher appeared to have driven her to see that the NNESTs or NSs of English in general are more legitimate and authoritative resource persons in the use and teaching and learning of English than the NNSs. By illustrating the difficulties in finding English equivalents of some Indonesian expressions or vice versa, Yanti implied a lack of language and cultural competence and assumed an "intrinsic superiority" of the NSs of English. In fact, in the IHS EFL classrooms it seemed unavoidable that students used their pre-existing knowledge of and familiarity with ideas and practices related to Indonesian, Javanese and Madurese as well as to Islamic teachings in order to understand ones that come with English. By attaching the language and cultural "superiority" to the English NSs, Yanti might overlook the abilities to navigate through, shuttle and build bridges between home knowledge, languages and practices and new-and possibly alien-values, beliefs and behaviours associated with English in the teaching and learning processes, irrespective of whether or not the teachers are the NSs of English.

\subsubsection{Recap and remarks on Yanti's case}

Yanti's case has brought up two major issues, i.e. "Othering” and home cultures as a springboard. First, Yanti tended to believe that "other" Western culture is inherent in English and EFL education. The cultural values of English-speaking Western communities are perceived as different from "Indonesian culture," "Muslim culture" or "Eastern/Asian culture", exerting some influence on home values in a way that has a bad effect. For Yanti, "their" Western cultural values are rendered unfit for use by the introduction of undesirable elements to "our" local belief systems. As such, the ways Yanti made social categorization, compared the native and target cultures, and approached members of target culture are 
potentially in danger of Othering whereby "the "foreign" is reduced to a simplistic, easily digestible, exotic or degrading stereotype' (Holliday, 1999, p. 245). This in turn can cause significant sociocultural inhibitions to EFL education in which exposure to and interaction with the foreign and different others are by nature involved in the process of teaching and learning and intercultural communication.

According to Holliday et al. (2010), the "foreign others" may refer to any other group of people which is perceived as different in terms of nationality, ethnicity, religion, political alignment, class or caste, or gender. These primordial interests are always with us. Holliday et al. posit that it is of vital importance to understand how easy we are to misconstruct and reduce people from other societies, to be misled by our own preconceptions, and to walk into the trap of Othering. If we are to communicate successfully, the weight of responsibility is thus on us to understand ourselves and the forces that prevent us from seeing others as individuals rather than members of such externally-ascribed large entities as cultural, racial, ethnic or religious groups (Holliday, 1999; Holliday et al., 2010).

Holliday et al. (2010) go on to suggest that stereotype, prejudice, culturism, and essentialism constitute Othering. Stereotypes, which refer to 'blanket generalizations that attribute group characteristics to individuals based on their cultural membership' (DeCapua \& Wintergerst, 2016, p. 95), are often infected by prejudice, i.e. deeply held negative feelings associated with a particular social group and its members (Samovar et al., 2009). By culturism, one can 'reify "cultures" as objects, places, physical entities within which and by which people live' (Holliday et al., 2010, p. 26), imagining something to be real when it is not. Moreover, essentialism presents 'people's individual behaviour as entirely defined and constrained by the cultures in which they live so that the stereotype becomes the essence of who they are' (Holliday, 2011, p. 197), and 'that all people from that culture will behave in that way' (Holliday, 2016, p. 34).

In contrast, a non-essentialist approach to culture, cultural membership, and cultural behaviour is a prerequisite for foreign language education and intercultural communication. The fundamental understandings are that culture and intercultural communication are 'moveable concepts with fluid and negotiable boundaries' (Holliday, 2011 , p. 1), that culture is 'associated with a value, and can relate equally to any size of group for any period of time, and can be characterised by a discourse as much as by a language' (Holliday et al., 2010, p. 2); and, that 'people are influenced by or make use of a multiplicity of cultural forms' (Holliday et al., 2010, p. 4). These notions stress the 
complex, fundamentally-changing, context-bound, and multidimensional nature of culture as well as of cultural membership and behaviour.

As the data shows, Yanti's simplistic and over-generalising view of "culture" not only makes "Western culture" perceived as solid, static, homogenous, and inherently different from local cultures, but also creates negative stereotypes of members of the so-called "English-speaking, non-Muslim Western culture". Loaded words like "contaminated [by non-Muslim, Western culture]", "our" or "their" culture, and "[concern over] tendency to imitate [Western culture]" can be cases in point. A perceived intrinsic inconsistency of Western cultural values and behaviours with home knowledge and practices had given Yanti underlying reasons to stress the need for Indonesian EFL teachers to "safeguard" the students' cultural, moral, and religious identity. Elsewhere, the findings of a recent nationwide survey involving more than 2,200 Indonesian kindergarten, primary, and secondary school teachers of all subjects show that language teachers-apart from physical education, arts and crafts, and classroom teachers-have an alarming tendency towards intolerant and exclusive attitude (Bhaskara, 2018). One of the issues highlighted in the survey was that over $40 \%$ of the teachers agreed that Muslims no longer need to seek knowledge supposedly originating from the West because all knowledge has already been contained in the Qur'an (Rochmi, 2018; Sitepu, 2018). This attitude intersects with Yanti's perception of Western culture and suggests a monolithic, reductionist, essentialist approach to the cultural values of the English-speaking West.

Second, home language-and-cultures provide Yanti and the IHS students with a springboard for grappling with concepts, ideas, and practices commonly associated with English, the NSs of English, and English-speaking Western culture in general. Yanti and the learners used their existing knowledge, native languages, and local practices with which they have a more thorough familiarity as classroom resources in an effort to make sense of new, different or alien values embedded in English expressions. On various occasions, Yanti and the pupils were curious as to how to produce the nearest equivalents of Indonesian expressions in English, and vice versa. Take, for instance, how the learners wanted to know how to say 'Hormat gerak!' (Salute!) in English, how they subconsciously exchanged the Islamic greeting when practising making appointment in English by phone, or the ways they linked some concepts of English speech acts to Islamic perspectives and local practices. The students scaffolded understandings of a particular set of value systems and behaviours that come with English by moving and making constant connections between native and target language-and-cultures. 
Not only did the IHS EFL classroom interactions suggest that learners' first and additional language systems are simultaneously active and interconnected rather than compartmentalised in their minds and that L1 may become a useful learning tool (Cook, 2001, 2007), but it might also highlight the crucial role that Yanti and the local EFL teachers could play in an interculturally-informed EFL classroom within the specific sociocultural context of English teaching and learning and use. The high-school pupils have formed their personalities and minds as well as mental and social lives as multilingual young adults through their first languages (Cook, 2001, 2016). The learners' actual, strategic classroom use of first language-and-cultures in the EFL classes is all part and parcel of their natural use in the real world outside the classrooms.

Acquiring an additional language, be it a second, third or even fourth one, Cook opines (2016, p. 177), 'does not mean acquiring the self-contained language system of a monolingual but gaining a second language system that fits in with the first in the same mind.' The multilingual learners bring to the classroom what they have socialised into and already internalised through first languages and in turn the value system shapes how they get to grips with and make sense of new perspectives and practices. Thus, it may be hardly surprising that the IHS students were seeking to grasp new concepts or meanings embedded in English by harnessing their prior knowledge, experiences and understandings of the world, and utilising home language-and-cultures that are embodied in Indonesian, Javanese and Madurese-or perhaps Arabic as well-in cognitively and sociolinguistically productive ways (Buttjes, 1991; Buttjes \& Byram, 1991; Liddicoat \& Scarino, 2013; Macaro, 2009; Turnbull \& Dailey-O'Cain, 2009).

In the light of the particular socio-educational circumstances, Yanti's awareness of and sensitivity to native language-and-cultures play an important role in allowing local EFL teachers to foster proper linkages between students' and target language-and-cultures. In other words, orientating the students only around the cultures of English-speaking countries is not only theoretically and practically problematic considering the complex and dynamic nature of culture as well as considerable cultural diversity in the English-speaking communities, but it also provides the learners with a more limited opportunity to increase knowledge of cultures beyond those of English-speaking countries and to use English to communicate across cultural and linguistic boundaries. In this line of argument, there is no reason to assume a priori that the NESTs are better qualified to teach the cultural dimensions of ICC, such as savoir être (attitudes) or savoir s'engager (critical cultural awareness) (Byram, 2015). The privileged cultural knowledge of the NESTs would be 
redressed by the EFL teachers' privileged knowledge of learners and their cultural experiences, and the privileged knowledge of NESTs' linguistic norms in grammar and semantics might be counterbalanced by the EFL teachers' pedagogic competences. For Byram, NNESTs are just as important as NESTs because both are at no a priori advantage or otherwise with respect to different dimensions of language teaching and learning.

So, to conclude Yanti's case, the data shows that Yanti was inclined to see English as an embodiment of other "Western culture" which is ostensibly different from home language-and-cultures. On the one hand, English was rigidly tied to the culture of Englishspeaking communities, but on the other hand culture was understood as a solid and static entity referring to a single and homogeneous group of people. Yanti tended to lump together members of English-speaking Western culture as though they are essentially defined by the imagined characteristics of the culture and would behave in similar ways (Holliday, 2011, 2013). English was sometimes perceived to be incompatible with-and even threatening to-local values and especially to the Islamic world view as the language was linked to Christianity and conceived of as a carrier of "non-Muslim Western cultural values". Also, evidence suggests that in the observed EFL classrooms at IHS Negeri Yanti and the students used their prior knowledge, local languages and lived experiences as points of departure for making sense of and connections with ideas and practices expressed in the English language. In this respect, it is important that Yanti and other local English teachers in the EFL classrooms draw on their keen awareness and understandings of home language-and-cultures in order to help students address any cultural disparities between home and target language-and-cultures in addition to making the "foreign" language-andcultures more accessible and less threatening to the students (Y.-F. C. Liu, 2016).

\subsection{Summary}

In Chapter 4, I presented the cases of the five Indonesian EFL teachers, i.e. Ambar, Ana, Aris, Wati and Yanti. I described each teacher's conceptions of language and culture and how they worked with culture and interculturality in their EFL classrooms. A contextbound EFL education, a non-explicit culture teaching and classroom constraints were the central themes of Ambar's case. A variety of cultural, political and educational factors at the national and local contexts influenced what cultural topics Ambar discussed and how she represented them in the classroom. Ambar highlighted her compliance with the policies as she was seeking to integrate more materials about local culture and expose the students to Indonesia's cultural diversity. There was a gap between Ambar's stated beliefs and 
actual teaching. Despite recognising the importance of culture, explicit culture teaching and learning was largely absent from the classroom practice. Such classroom constraints as heavy teaching load and limited time might account for her lack of cultural explicitness.

Cultural appropriateness, authentic self and teacher as mediator were major issues that arose from Ana's case. She drew on her cultural sensitivity to ensure that the classroom materials are consistent with local values and thus culturally appropriate to the students. Ana connected her ethnic and cultural background with professional identity, English proficiency, the role of EFL teacher, and instructional goals, asserting her "authentic self" as a "Javanese [Indonesian] speaker and teacher of English". Ana shuttled and negotiated between home and target language-and-cultures, showcasing the skills of interpreting and relating necessary for language teachers as intercultural speakers and mediators.

Two key themes emerging from Aris' case were the situatedness of EFL pedagogy and an implicit culture teaching. The subtle interplay of socio-educational factors that are present in the school's immediate and broader context influenced the situatedness of Indonesia's EFL pedagogy. The way Aris addressed culture and interculturality in the classrooms was shaped by his understandings of how English is used, taught and learned in the local setting as well as of students' needs and level of English proficiency. Aris felt confident that cultural, moral and religious values to be instilled into the students under the mandated character education are better conducted in an implicit than explicit manner.

Wati's case raised issues relating to the NS-based authenticity and English as a "globalising tool". Wati presumed that the authenticity of EFL materials depends primarily on whether or not they are created by the NSs of English whose language competence considered to be superior to the non-natives. Wati measured her English and pedagogic competence against that of the NSs/NESTs. She perceived English as a globalising tool with which the students could benefit socially and economically. For Wati, EFL education is concerned with developing students' competitiveness and nationalism. Wati's case might portray the sheer diversity of how English and EFL pedagogy around the world meet with local aspirations and exigencies.

Two major themes emerging from Yanti's case were "Othering" and home cultures as a springboard. Yanti was inclined to believe that "other Western culture" is an intrinsic part of English and that the value systems of Western countries are inconsistent with local values and behaviours. This overly simplistic approach to English-speaking, "secular Western culture" made her think that the local EFL teachers have a dual role, teaching English and "safeguarding” students' cultural and religious identity. Classroom 
observation data showed that Yanti and the students used home knowledge and languages as a starting point for getting to grips with new and likely differing ideas that come with English. Sharing home languages and practices helped Yanti and her students to address cultural disparities.

The following chapter is a cross-case discussion, analysis and interpretation of the salient themes that emerged from each teacher's case and across the entire data set. While bringing all the important findings and key themes together, the discussion chapter deconstructs and digs into the findings to determine the significance of the findings and glean further insights into what lies beneath them (Bloomberg \& Volpe, 2008). 
This page is intentionally left blank. 


\section{Chapter V}

\section{Cross-case Discussion}

\subsection{Introduction}

In this chapter, I discuss, analyse and interprete salient themes within and across the data set. Preconceptions, hunches, personal biography, research agendas, the literature and prior research fed into the process of expanding on the significance of the emergent themes in each teacher's case and across the five cases (Bloomberg \& Volpe, 2008; Holliday, 2007). I paid a close attention to the sociolinguistic, cultural, educational, political and religious elements that might be simultaneously at play, unique to Indonesia's EFL setting, and likely to impact on the pedagogic beliefs and classroom practices of the EFL teachers regarding the teaching and learning of culture and interculturality.

As I recognised emerging details and the complexities of the targeted phenomenon, I organised the discussion chapter into four stages and headings: teaching culture, enacting policy; culture in the EFL classrooms; EFL teachers as intercultural mediators; and EFL, Islam and interculturality. These constituted the emergent, holistic themes across the EFL teachers' cases. First, the State hegemonic policies on language, general education and EFL pedagogy were behind the EFL teachers' conception of language, culture and interculturality and how they addressed related issues in their teaching. Second, the EFL teachers' assumptions and beliefs about culture informed their approach to home and target language-and-cultures and classroom actions. Third, amidst the State hegemonic policies, the EFL teachers showed an active agency and served as intercultural mediators in their working with the complexities of culture and the situatedness of culture teaching. Fourth, EFL pedagogy and interculturality in the predominantly Muslim Indonesia ineluctably intersect with local Islamic thoughts and traditions.

The themes and issues presented in the four different sections grew out of the data itself, represented the character of the data as a whole, and were in some ways related to each other. Summary and concluding remarks in the Conclusion chapter that follows recap and demonstrate the significance of and the relationships between the key themes.

\subsection{Teaching culture, enacting policy}

As reported in the interviews and evidenced by the observed classroom events and interactions, the ways the Indonesian EFL teachers worked with culture and interculturality 
in the high-school EFL classrooms were influenced by the State policies on the EFL pedagogy, general education, and language. EFL policy in Indonesia is inescapably part of the nation's cultural, economic and political agenda (Ferguson, 2006; Shohamy, 2006). Whilst the relationships between the policies and their impacts on the use of languages and the teaching and learning of EFL may be far from straightforward, such policies are mutually-informing and help shape the teachers' pedagogic beliefs and attitudes towards language and especially towards English and its embedded values. In turn, these beliefs and attitudes towards English, its inherent values and behaviours associated with the NSs of English impact on the teachers' instructional decisions on culture and interculturality.

The fact that public schools formally start the school hours with a supplication in Arabic and Indonesian (which happened to be an Islamic one only), that the high-school EFL teachers begin their classes by asking students to jointly sing Indonesian national anthem or a patriotic song, or that more stories about local people and culture are to be integrated into the classroom materials, can be closely related to the current K13 which incorporates the character education as a compulsory part of the national education goals. Indonesia's law number 20/2003 on National Education System stipulates that Indonesian students are educated and trained not only to become knowledgeable, competent and creative, but also to be faithful to God, nationalistic, and of good character. EFL curricula are no exception. They are accordingly required to inculcate in the students moral, cultural and/or religious values rooted in the State ideology Pancasila (Kementerian Pendidikan Nasional, 2010, 2011).

For example, Ambar asserted her belief that the singing together of patriotic and/or traditional songs as well as the inclusion of local folklores in the teaching and learning materials and classroom practices are mandatory under the K13, stressing that:

\section{Excerpt 1: \\ Itu sebenarnya wajib. Iya sekarang di Kurikulum 2013 yang pertama ... Indonesia Raya, terus yang terakhir itu lagu nasional atau lagu daerah. .... Jadi mengarah ke Indonesia. That [singing together] is in fact mandatory. In the 2013 Curriculum, the first [song to sing] is, Indonesia Raya, and then another national or local song to end class. ... Thus, they are oriented towards Indonesia. (Interview with Ambar, 4/11/15)}

Similarly, both Ana and Aris stated their practice of asking students to stand up and jointly sing the national and local or traditional songs to begin or end their classes was to comply with what is required by the current policies on the English language and general education, especially the character education and the revival of students' nationalism. They offered the following reasons for this: 
Excerpt 2:

... Itu kan punya wacana bahwa untuk membentuk karakter peserta didik. ... saya juga ingin meningkatkan, menggali kembali rasa nasionalisme anak.

... He [Minister of Education] stressed the need to build students' character. ... I'd also like to revive and strengthen their nationalism. (Interview with Ana, 25/11/15)

Excerpt 3:

... untuk menanamkan jiwa patriotisme itu, semua pelajaran harus menyanyikan lagu 'Indonesia Raya.' ... di akhir pelajaran itu sebetulnya harus menyanyikan lagu daerah. ... In order to instil patriotism, students have to sing Indonesia Raya before starting their class. ... Before ending it, [they] should sing a local song, too. (Interview with Aris, $11 / 11 / 15)$

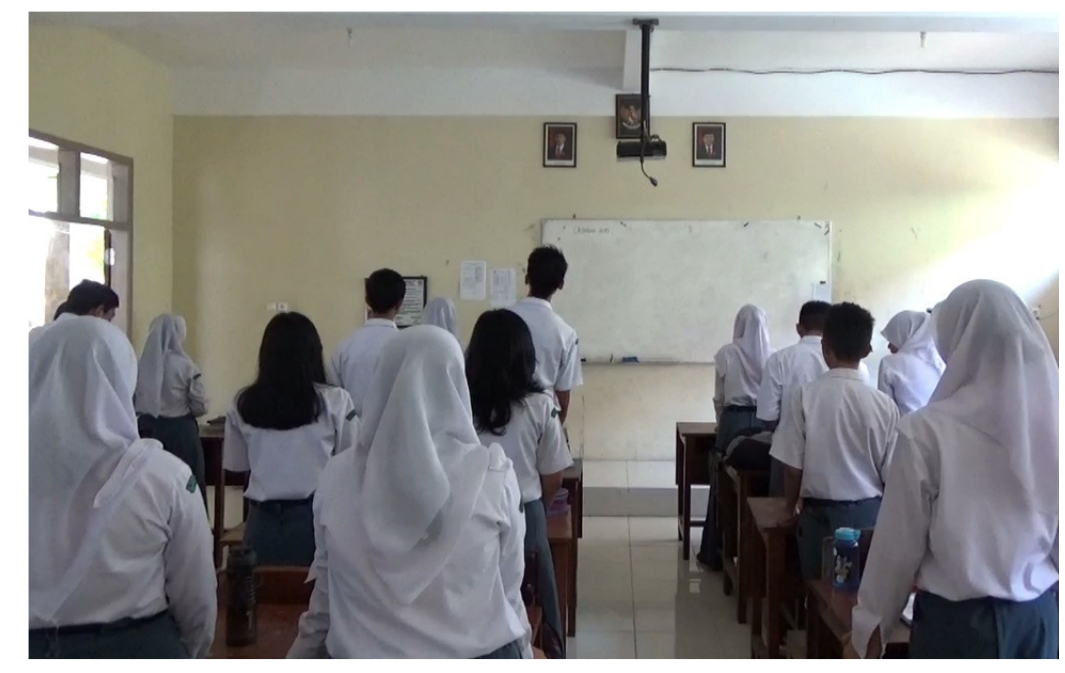

Figure 32: Students stand up singing patriotic songs

The content and classroom implementation of the RPPs (lesson plans) for which the teachers are individually responsible should be in line with the national curriculum, its implementation guidelines, and the school-approved syllabus. The levels of student core and basic competency as well as the graduate competency standard are nationally established. Any topics and relevant information that the teachers wish to include in the RPPs should be chosen in reference to the nationally- and locally-prescribed guidelines, resources and materials. This requirement also applies to the tasks, assessments, and any other forms of learning activity the teachers want students to perform inside and outside the EFL classrooms. For example, when asked about the reason for picking a certain topic, Ambar reiterated her conformity with the national curriculum and the school's syllabus as follows:

Excerpt 4:

Itu disesuaikan dengan topik yang disampaikan di kelas karena kan sudah ada silabusnya. Di kurikulum itu sudah ada. 
It was aligned with topics to be discussed in the classroom because these are already covered in the syllabus, and prescribed in the Curriculum. (Interview with Ambar, 4/11/15)

Aris' and Wati's RPPs (Figure 33 and 34) were also written in response to the syllabus, K13, and character education. Despite the topic being Teks Deskriptif (descriptive text), point 1-4 of the student core competencies (Kompetensi Inti) in Wati's RPP can be seen as referring or being more related to the proposed character traits rather than the topic in question. Take, for instance, '[M]enghayati dan mengamalkan ajaran agama yang dianutnya (Committed to and practice the religion of one's choice),' or '[M]enghayati dan mengamalkan perilaku jujur, disiplin, tanggungjawab, peduli ... (Committed to and exhibit honest, disciplined, responsible, attentive ... behaviour ...).' Similarly, as Aris' RPP suggests, one of the things to do within the first ten minutes of the teaching and learning is to show the relationship between the teaching and learning material or the targeted competency and the character traits incorporated in the syllabus and government-approved resources, i.e. 'Mengaitkan materi/kompetensi yang akan dipelajari dengan karakter dengan merujuk pada silabus, RPP, dan bahan ajar, menyampaikan butir karakter yang hendak dikembangkan selain yang terkait dengan SK/KD [Relate the material/targeted competency to character traits by referring to the syllabus, lesson plan, and teaching and learning materials, and explain the relevant character traits in addition to ones set out in the Competency Standard/Basic Competency].'

Langkah-langkah Kegiatan Pembelajaran

- Kegiatan Awal (10')

- Mengucapkan salam dengan ramah kepada siswa ketika memasuki ruang kelas (nilai yang ditanamkan: santun, peduli)

- Mengecek kehadiran siswa (nilai yang ditanamkan: disiplin, rajin)

- Mengaitkan materi/kompetensi yang akan dipelajari dengan karakter dengan merujuk pada silabus, RPP, dan bahan ajar, menyampaikan butir karakter yang hendak dikembangkan selain yang terkait dengan $\mathrm{SK} / \mathrm{KD}$

- Siswa berdiskusi mengenai pertanyaan yang tertera di buku teks

\section{- Kegiatan Inti (70')}

\section{Eksplorasi}

Dalam kegiatan eksplorasi guru:

- Memberikan stimulus berupa pemberian materi pertanyaan teks monolog sederhana berbentuk procedure.

- Mendiskusikan materi bersama siswa (Buku: Bahan Ajar Bahasa Inggris mengenai pertanyaan teks monolog sederhana berbentuk procedure.

- Memberikan kesempatan pada peserta didik mengkomunikasikan secara lisan atau mempresentasikan mengenai pertanyaan teks monolog sederhana berbentuk procedure.

- Siswa diminta membahas contoh soal dalam Buku: Bahan Ajar Bahasa Inggris mengenai pertanyaan teks monolog sederhana berbentuk procedure.

Figure 33: Part of Aris' RPP 


$\begin{array}{ll}\text { RENCANA PELAKSANAAN PEMBELAJARAN (RPP) } \\ \text { Satuan Pendidikan } & : \\ \text { Mata Pelajaran } & \text { : Bahasa Inggris } \\ \text { Kelas/Semester } & : \text { X/1 } \\ \text { Materi Pokok } & : \text { Teks Deskriptif } \\ \text { Alokasi Waktu } & : 6 \text { X } 45 \text { menit (3 pertemuan) }\end{array}$

\section{A. Kompetensi Inti}

1. Menghayati dan mengamalkan ajaran agama yang dianutnya

2. Menghayati dan mengamalkan perilaku jujur, disiplin, tanggungjawab, peduli (gotong royong, kerjasama, toleran, damai), santun, responsif dan pro-aktif dan menunjukkan sikap sebagai bagian dari solusi atas berbagai permasalahan dalam berinteraksi secara efektif dengan lingkungan sosial dan alam serta dalam menempatkan diri sebagai cerminan bangsa dalam pergaulan dunia

3. Memahami, menerapkan, menganalisis pengetahuan faktual, konseptual, prosedural berdasarkan rasa ingintahunya tentang ilmu pengetahuan, teknologi, seni, budaya, dan humaniora dengan wawasan kemanusiaan, kebangsaan, kenegaraan, dan peradaban terkait penyebab fenomena dan kejadian, serta menerapkan pengetahuan prosedural pada bidang kajian yang spesifik sesuai dengan bakat dan minatnya untuk memecahkan masalah

4. Mengolah, menalar, dan menyaji dalam ranah konkret dan ranah abstrak terkait dengan pengembangan dari yang dipelajarinya di sekolah secara mandiri, dan mampu menggunakan metoda sesuai kaidah keilmuan

Figure 34: The core competency in Wati's RPP on Teks Deskriptif (descriptive text)

The evidence suggests that what the Indonesian EFL teachers think, believe and do regarding the teaching and learning of culture and interculturality in the high-school EFL classrooms is in a way dependent on the policies on language, general education and the English language education. In this regard, a more intriguing possibility is to examine the nation's implicit and explicit language ideology that informs the policies and in turn exerts an influence over the teachers' beliefs and practices. The examination of the policies is concerned in general with the concept of language-and-culture that the existing laws and regulations introduce and in particular with how English is positioned in society at large and in the formal education.

In a politically-neutral term, Verschueren (2012, p. 10) defines ideology as 'any basic pattern of meaning or frame of interpretation bearing on or involved in (an) aspect(s) of social "reality" (in particular in the realm of social relations in the public sphere), felt to be commonsensical, and often functioning in a normative way.' The language ideology of a speech community can be about different realms of social reality, including the nature of language, its own language and other languages, language use, language learning, and language users (Johnson, 2013; Spolsky, 2004). For Liddicoat (2013), ideology can be seen as a purposeful intervention in the social world and gains power in the social and political world when it becomes normalised as a common-sense way of thinking about the world. Ideology can even be hegemonic when it affords a social or political group the possibility 
to organise society as a whole and shape their perceptions in accordance with its interests and consciousness.

As previously noted, some recent policies on language, general education and in particular the teaching and learning of English in Indonesia may cast light on the official language ideology. The policies also indicate that EFL in Indonesia is very much influenced by the nation's cultural, political and economic agenda. Take, for example, the fact that English was removed from primary school curriculum or that English teaching hours in secondary schools were significantly reduced. These measures were taken against the nationally-imposed character education and the ideas that students' nationalism and religiosity ought to be strengthened and the prominence of the national and local languages should be maintained. On similar grounds, the international-standard school (SBI) was ruled unconstitutional by Indonesia's Constitutional Court considering that, among other things, an extensive use of English as a medium of instruction in several subjects was feared to spur 'Englishization', erode Indonesian and local vernaculars, corrode students' nationalism and character-building, and lead to discriminatory practices by such a school against economically-disadvantaged students, contrary to the 1945 Constitution and law number 20/2003 on National Education System.

What can be inferred from the above decision and other relevant laws and regulations is that language is not only understood as an integral part of the so-called national culture, but it also functions politically to unite the nation and construct national identity. It is not uncommon that culture is viewed as a national culture (Dervin \& Liddicoat, 2013). In this way, nation is understood as an "imagined community" which has finite boundaries beyond which lie other nations as well as a deep, horizontal comradeship and fraternity making it possible for its people to kill and die for (Anderson, 2006). In Indonesia's policy documents, too, language tends to be viewed as a fixed and static linguistic code which is associated with discrete national boundaries and monolithic intrinsic values. In this line of argument, it is little wonder that the use and teaching and learning of English can be conceived of as a "threat" to home values, the national culture or identity, or the existence and importance of local languages, especially in view of the economically, politically and culturally dominant position of today's English at the global level. In this case, as Shohamy (2006, p. 78) writes, language policy cannot be neutral because it is 'embedded in a whole set of political, ideological, social and economic agendas,' and language-ineducation policy 'serves as the vehicle for promoting and perpetuating such agendas.' 
Moreover, how the national language, local vernacular (especially Javanese), and English compete for a space in Indonesia's contemporary language ecologies is discussed, for example, in Coleman' and Zentz' studies. For Coleman (2016), English as the language of glamour, ambition and escape as well as a threat to the prominence of Indonesian are two sides of the same coin. English seems like a "necessary evil" whose promotion is made possible by 'a combination of commercial interests, the intangible influence of globalisation and the connivance of government' (p. 69). Likewise, Zentz $(2016,2017)$ looks at underpinning mechanisms that inspire English usages in the local and national contexts. Such apparent paradoxes as the ubiquitous presence of English, a negligible number of proficient English users, the Government's rush to provide internationally competitive education, or reduced English teaching hours in secondary school, illustrate the sociocultural, political and economic processes at play in different levels. That the removal of English from the primary school curriculum was attributed to the need to have a stronger sense of nationalism and religiosity and that the elimination of the internationalstandard school was linked to social justice and fear of degrading Indonesianness may come as no surprise when the teaching and learning of English as a globally-dominant language has been faced with the dynamic sociopolitical, cultural and economic processes in the national and local settings. As Zentz (2017, p. 159) further explains:

... English language is distributed at best to those who already have access to mobility, wealth and international standard education, and legislative tampering with the presence and amount of English in educational curricula seems to be trapped between desires for constructing a monolithic and impenetrable national identity and actually controlling the spread and use of English in the nation, and keeping its uses instrumental only.

In sum, the local EFL teachers' reported and observed compliance with the policies regarding the teaching and learning of culture and interculturality in the high-school EFL classrooms do not take place in a vacuum. The current laws and regulations on the English language education, general education, and language govern the legal status, use and formal education of Indonesian, local vernacular, and English. In addition, such policies constitute the nation's underlying language ideology that feeds into how language and its cultural values and experiences are to be viewed and treated in the classrooms. In Indonesia, language is perceived as part of culture and connected with the national existence, character and identity. Language-and-culture is understood in terms of discrete, separate geographical or national blocks, and tends to be seen as a solid, closed and static entity rather than an open, fluid and dynamic concept with negotiable and sociallyconstructed boundaries (Holliday, 2011, 2016). In the classroom practices, these beliefs 
and attitudes towards languages and especially towards English shape the EFL teachers' approach to foreignness, representations of Self and Other, and the ways they navigate through and negotiate between different values and behaviours associated with the host and target language-and-culture.

In what follows, I will discuss the nature of the EFL teachers' conception of culture and show how it informs their approaches to and representations of English as well as values and practices associated with English-speaking Western culture in the EFL classrooms.

\subsection{Culture in the EFL classrooms}

The Indonesian EFL teachers' conceptions of culture have an important bearing on how they approached and represented culture and interculturality in the high-school EFL classrooms. The teachers' understandings of culture intersect with the expected role of a local EFL teacher and influence their judgments and instructional decisions. First, the teachers either implicitly or explicitly acknowledged the relationship between language and culture, although this belief might not be explicitly translated into actual classroom practices. This was evident, among other things, in the ways they described an (in)effectiveness of communication in terms of interlocutor's cultural knowledge, and linked some English words and expressions to cultural values and behaviours of the NSs of English. They considered cultural appropriateness when discussing English expressions and compared the level of politeness of the expressions with their equivalents in Indonesian, Javanese or Madurese. This is illustrated in Yanti's mention of the influence of cultural values in the different forms and uses of speech act in English and Indonesian, or Ana's emphasis on the importance of cultural knowledge in the use of linguistic expressions in daily social interactions. In Yanti's view, it is culture rather than linguistic properties that gives a more powerful influence on the use and meaning of speech acts and distinguishes English from Indonesian expressions:

Excerpt 5:

... persamaan linguistiknya, sebetulnya mirip, cuma mungkin budaya yang paling memengaruhi.

... Regarding linguistic features, they may be similar, but perhaps culture has a stronger influence. (Interview with Yanti, 18/11/15)

Likewise, Ana wrote in the NF that cultural knowledge is necessary in order to facilitate effective communication in real-life social interactions. That is, language and culture are thought of as interrelated in actual communication, and linguistic knowledge alone may 
not be enough to establish good communication. Her statement 'the cultures of their partner they are speaking with [interlocutor]' implies intercultural contact and the importance of intercultural knowledge and understanding. As Ana said:

Excerpt 6:

... when the students don't know the cultures of their partner they are speaking with, then their communication would be ineffective. (Ana's NF, 15 November 2015)

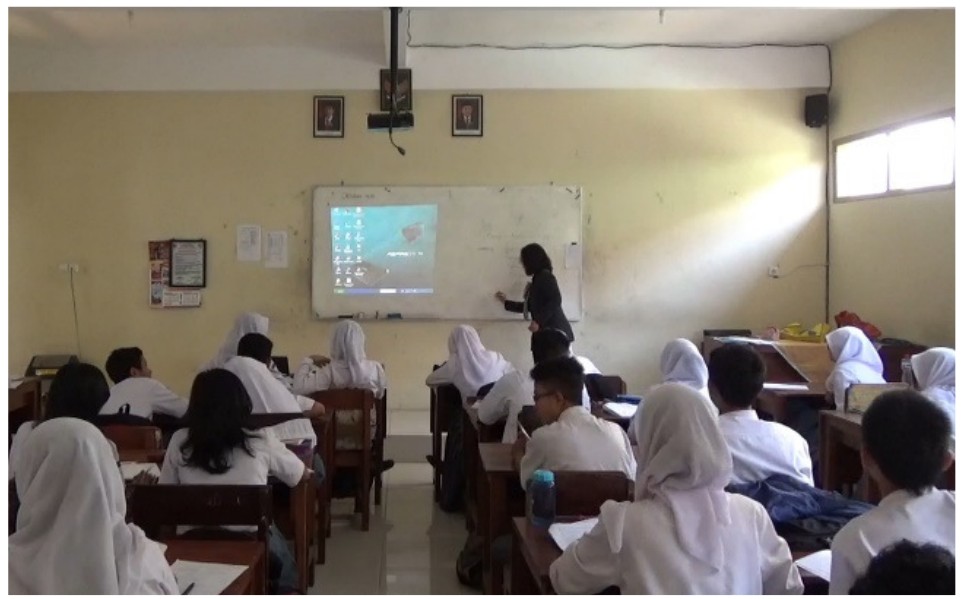

Figure 35: Ana explains phrases for complimenting

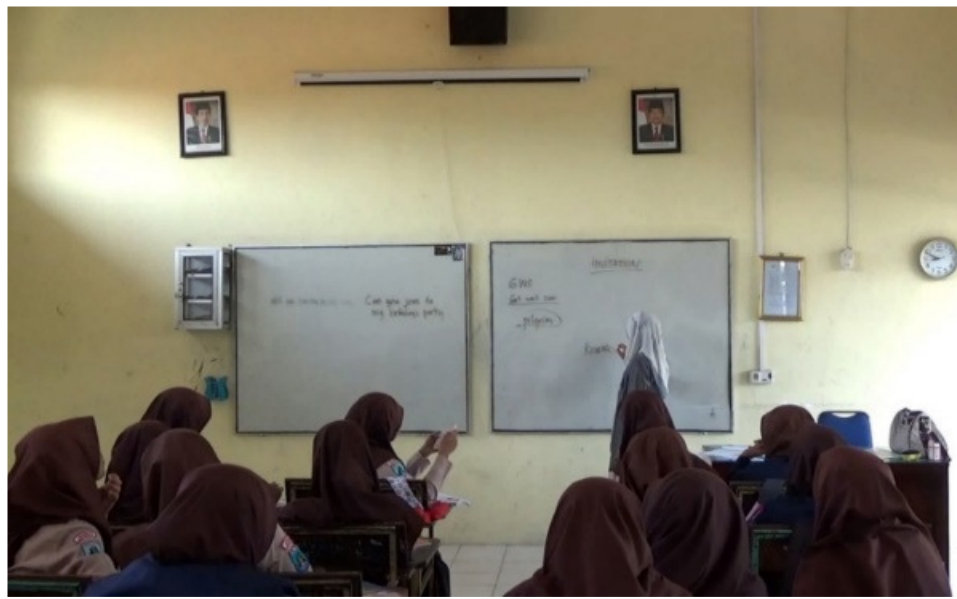

Figure 36: Yanti discusses expressions for making invitation

Second, the EFL teachers tend to believe that some sociocultural values entrenched in the English language are inconsistent with home knowledge and practices. They see these inherent yet incompatible values as a "threat" to students' cultural values and identity. In response, the teachers took initiatives to ensure that the classroom materials did not create a negative perception among students and divert their attention away from the topic being discussed. For example, how the characters in the video that was used as an additional 
classroom material dress and behave did not escape the teachers' attention. These could be seen by the learners as culturally inappropriate and therefore counterproductive. The teachers also voiced concern over a possibility that the local students may imitate or think and behave like different "Others" when they are exposed to alien cultural values and behaviours, as suggested by Yanti and Ana in the following excerpts:

Excerpt 7:

... terus begitu mengenal budaya luar, "kok beda ya?” Takutnya ada kecenderungan meniru mungkin.

.. but when they learn about other culture, [they may ask] "Why is it different?" I'm afraid there is perhaps a tendency to imitate. (Interview with Yanti, 18/11/15)

Excerpt 8:

Pakaian yang dipakai kok seperti ini, tidak sesuai dengan budaya kita, gitu misalnya. They might be wondering if they thought, for example, that the characters' clothing is unfit for our culture. (Interview with Ana, 25/11/15)

Third, some sociolinguistic norms and cultural values inherent in the English language can be seen as incompatible with local beliefs, values and practices, and this drove the EFL teachers to see themselves and act as "cultural/moral guards." Not only did these teachers actively search for, select, and use what they perceived as culturally-appropriate teaching and learning topics or activities, but they also reminded the students and further explained their disapproval in case there were some information or activities that were deemed culturally unfit for them. The teachers relied on their own cultural understandings and exercised personal judgments to filter out and decide on whether or not the classroom resources and materials were culturally appropriate and acceptable. What Yanti wrote in the NF and Ana reported in the interview below illustrate what they did inside and outside their classrooms to "safeguard" their students' cultural or religious identity and national character from "contamination" or unfavourable influence from other different cultural beliefs, values, and behaviours:

Excerpt 9: ... saya harus ekstra keras mengingatkan, menjelaskan dan menasehati anak-anak tentang perbedaan sudut pandang "cinta” antara Barat dan Timur, non-Muslim dan Muslim. ... I had to strongly remind, explain and advise students about the different perspectives of "love" between the West and the East, between non-Muslim and Muslim worlds. (Yanti's NF, 25/10/15)

Excerpt 10:

... saya pilih video yang anak-anak itu nantinya menirukan, atau sesuai dengan karakter. I chose materials that have educational values because students may imitate, or be ones that conform to the [prescribed] character traits. (Interview with Ana, 25/11/15) 
Having said that, further important questions from the perspective of ILTL are around the nature and implications of the EFL teachers' general concept of culture on their instructional decisions. The influences are concerned with the extent to which the EFL teachers put their cultural orientations into classroom practice and whether these were within or outside the framework of the general education and in particular the character education. As with the teachers' concept of culture, two crucial issues seem to surround the view, i.e. the language-culture nexus and the "large culture" approach (Holliday, 1999, 2005; Holliday et al., 2010). The data shows that the teachers acknowledged, implicitly or explicitly, the language-and-culture interrelationship. Take, for instance, Ana's conviction that communication would be ineffective unless speakers know the culture of their interlocutor, or her practice of describing the level of politeness of English expressions in terms of Indonesian or Javanese expressions. Likewise, Yanti believed that cultural values have a stronger effect than linguistic forms and make Indonesian and English speech acts different. In other words, the EFL teachers highlighted the influence of culture on communication success or breakdown, linking the use of linguistic codes to cultural features. The teachers also drew a comparison between the level of politeness in English sentences and those in the local languages, implying the role that culture plays in affecting the (in)appropriateness of language use.

Fundamental to ILTL is the idea that culture in some ways shapes and is shaped by language, that developing intercultural awareness in language learners is essential, and that the introduction of the notion of language-and-culture connection ideally starts from the beginning of language education (Byram, 1997; Byram et al., 2002; Kramsch, 1993; Liddicoat, 2011; Liddicoat et al., 2003; Liddicoat \& Scarino, 2013; Newton et al., 2010). As Kramsch (1993, p. 1) expresses it, '[C]ulture in language learning is not an expandable fifth skill, tacked on ... to the teaching of speaking, listening, reading, and writing. It is always in the background, right from day one.' In the Indonesia's EFL setting, the local EFL teachers' recognition of the language-and-culture relationship can be viewed as a good starting point for adopting ILTL principles. The teachers were aware of the influence of cultural values in the meaning and use of linguistic expressions, and in a way acknowledged the need to familiarise students with the cultural aspects of English expressions and possible equivalents in the local languages.

Multilingualism is common practice in Indonesia and as such it can be viewed, experienced, and productively used as a valuable teaching and learning resource in interculturally-informed EFL classrooms. The local EFL teachers and learners can explore 
different cultural norms, values, perspectives and worldviews offered by the different languages. Despite such espoused beliefs, the teachers gave little explicit attention to cultural dimensions during the classroom observations. There seemed to be a divergence in what they said and did. When asked whether it is important to further discuss or explore cultural aspects of some words and expressions in English and the local languages, the teachers reiterated their support for such actions. However, when the discrepancy was highlighted, they generally attributed the phenomenon to the teaching load, time constraint, and examination-centric education system. In spite of the apparently belief-practice gap, Aris' position may help clarify the situation as he stated that within the framework of the mandated character education, cultural, moral and religious values should be directly integrated into the teaching and learning materials and implicitly discussed in the classrooms:

Excerpt 11:

Di antara 18 karakter, maka karakter itu tidak diajarkan secara lisan, tapi secara tersirat. ... jadi kegiatan belajarnya itu langsung, tanpa harus kita sampaikan.

Out of the 18 character traits [that are incorporated], these are not verbally [directly] taught, but rather implicitly. ... It is implicit in the teaching and learning activities, without necessarily being expressly stated. (Interview with Aris, 11/11/15)

Within the limited classroom time, cultural dimension is often underestimated, if not largely neglected. What is then of primary importance is to develop in both the teachers' and students' attitude, awareness, knowledge, and skills that are necessary for effective intercultural communication in the diverse, constantly-changing contexts of interaction. The role of teachers in cultural inquiry needs to be redefined. Byram (1997), for example, stresses that language learners need to foster curiosity, openness and non-judgmental attitudes towards different others. Likewise, rather than merely providing information about the characteristics of one's own and other people's cultures that can be static, simplified or even stereotypical, Tomlinson and Masuhara (2004) advocate the development of cultural awareness consisting of one's perceptions of his/her own and other people's cultures that are internal, dynamic, variable, multi-dimensional, and interactive. That is, the perceptions that develop in our minds are constantly being added to and changed; modified from experience; represented through sensory images, mental connections, affective associations, and the inner voice; and, connect with and inform each other. In this line of reasoning, Liddicoat (2011) maintains that the development of interculturality is an ongoing process and as such ILTL is an unfinishable work in that 
learners' new experiences inside and beyond language classrooms and critical reflection on the actions continuously feed into one another.

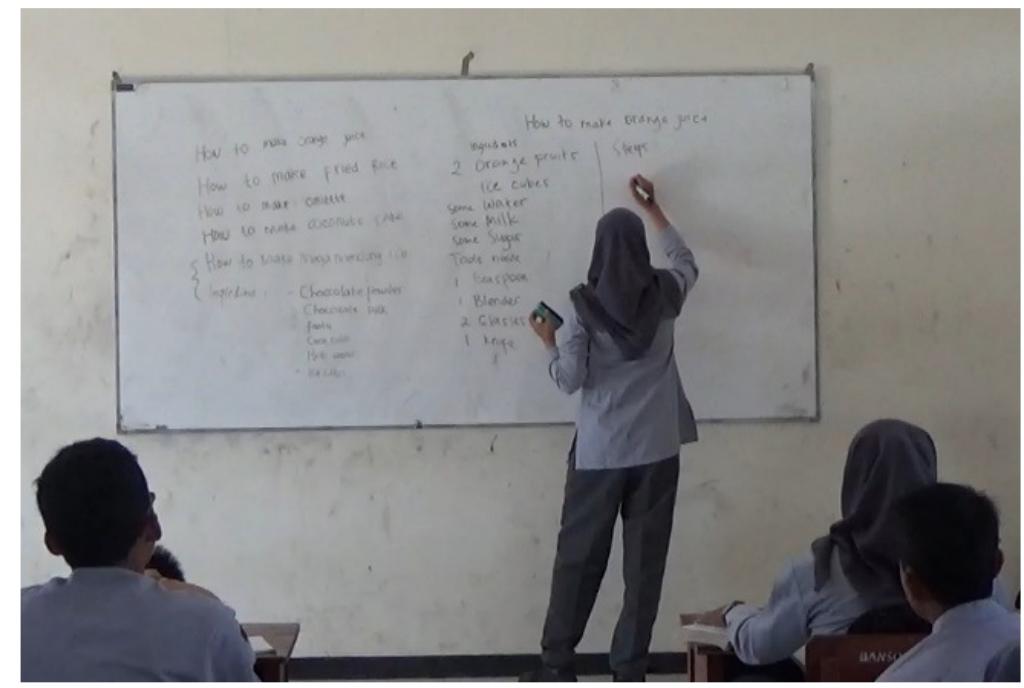

Figure 37: Students in Aris' class of GHS Pari perform task on 'procedure text'

Viewed from an ILTL perspective, lack of explicit culture teaching and learning can deprive students of opportunities for becoming aware of home language(s) and embedded cultural assumptions, beliefs and values made manifest in language choices that underlie the perspectives, products and patterns of behaviour of their own cultural groups as well as those of target language culture. We are generally unaware of our own beliefs and values due to the largely subconscious, complex nature of socialization in our first language-andculture(s) (Buttjes, 1991; DeCapua \& Wintergerst, 2016). Not only are these values buried in the human's subconscious, but they are also likely to be so deeply entrenched in the belief systems that can make people resistant to change (Byram et al., 2002). With enculturation being subliminal, as Agar (1996) asserts, teachers need to bring learners' buried frames of understanding to consciousness and introduce them to other possible frames that are operating and they are not using. Only then, Agar adds, can the students build a bridge between the two ways of looking at and doing things so that they can get back and forth, step above the native language-and-culture and the new one they are reaching towards, and forge a higher-level identity that contains both of them and shows their connections.

The above ideas may further underline not only how deeply ingrained cultural beliefs and assumptions can be but also the need to bring values position to consciousness and 
make them explicit in language teaching and learning. Under the concept of critical cultural awareness (savoir s'engager), Byram et al. (2002) propose that language teachers first need to encourage students to be aware of their own and other people's cultural values and how the value systems influence their perspectives, practices and products as well as those of other people. The basis on which students make evaluative responses to others should be made explicit, allowing them to be aware or conscious of the culturallydetermined basis for making judgments about others and to see how people from different culture might consider their religious, secular, ethical, philosophical or pragmatic position.

Agar's ideas of uncovering students' value system, shuttling between first and additional languages, and establishing a higher-level identity go along with intercultural theorists' support for explicit culture teaching that includes critical reflection on languages, guided comparisons and connections of cultures, and intercultural exploration (Crozet \& Liddicoat, 1999, 2000; Crozet, Liddicoat, \& Bianco, 1999; Newton et al., 2010; Scarino \& Liddicoat, 2009). In the classrooms, a critical reflective attitude towards first and additional languages and the interrelationship between these help students not only to foster a conscious awareness of what they think, know and learn, but also to develop the ability to recognize diverse languages, appreciate the difference, and decentre from own values (Liddicoat \& Scarino, 2013). Comparisons and connections of cultures can allow for an open, explicit and early-on discussion of cultures which will avoid delayed or misleading cultural information and raise students' cultural awareness and develop positive cross-cultural attitudes (Newton et al., 2010).

Guided comparisons and connections of cultures can involve noticing cultural similarities and differences inside and beyond the classrooms as well as comparing and making connections between what students already know about language-and-cultures and new information and lived experiences they have (Liddicoat \& Scarino, 2013; Scarino \& Liddicoat, 2009). As for intercultural exploration, it is a personal and interpersonal creative process that cannot be controlled by external forces and thus cannot be 'taught' (Crozet \& Liddicoat, 1999). The role of the teachers is more of a supportive one by which they provide a teaching and learning environment conducive to recognising cultural differences, negotiating and reconciling sometimes differing values, and creating an intercultural linguistic space (Crozet \& Liddicoat, 1999; Crozet, Liddicoat \& Bianco, 1999; Kramsch, 1993; Kumaravadivelu, 2008). Moreover, attempts to address cultures explicitly and to facilitate intercultural exploration can start with simple language features that are often culturally-laden, e.g. pronoun forms and greetings (Liddicoat, 2004; Newton et al., 2010). 
In this line of reasoning, the cultural significance of what may look basic, simple or familiar within and outside the local EFL classrooms, such as the discussion of different English and Indonesian tenses in Ana's class, Yanti's students reply of the Islamic-Arabic expression In Shaa Allah (God willing) or the exchange of the Islamic greeting Assalamu'alaikum in Aris' classes, can be brought to students' consciousness, given specific attention, and explicitly discussed for intercultural exploration. The differences of tenses between English and local languages and the common use of In Shaa Allah can be broadly examined in terms of culturally-shaped time orientations. In this respect, echoing Hall and Hall's (1990) idea of polychronic (P-time) and monochronic (M-time) time orientation, DeCapua and Wintergerst (2016) write that members of P-time and M-time culture tend to regard and organise time differently. African, Arabic, Asian and Latin American cultures generally follow P-time systems, whereas Americans and most Northern and Western European cultures follow M-time ones (Jackson, 2014).

P-time culture is associated with the idea that time is linear or sequential. P-time people are generally committed to regimented schedules because time is regarded as if a commodity segmented into precise, small units and scrupulously apportioned (DeCapua \& Wintergerst, 2016; Jackson, 2014). Conversely, members of M-time cultures may have a more elastic perception of time, clinging to the idea that time is flowing and as such focus should be placed on the here and the now rather than the unknown and unforeseeable future. That English verbs conjugate to show the time, continuance, or completion of an action or state-and that Indonesian or Javanese verbs do not-can be related in one way or another to the different perception of time. The fact that In Shaa Allah is used not only by non-English and English-speaking Muslims whatever their nationalities worldwide but also by Arab Christians and Arabic-speakers of other religions (“Inshallah,” 2018; Sussex, 2012), it can also be a case in point by alluding it to the belief that the future can turn out not as one has planned or expected because everything works and happens under God's will, or that only God knows for sure what will happen in the future, which is different from general Western attitudes towards time and human intentions. As Sussex (2012, p.

117) shrewdly observes:

In Arabic ... such confidence about future events is presumptuous. The realization of statements about future action depends on God's will, and inshallah is required. The standard Anglo interpretation of the future is therefore radically different from the Islamic-Arabic one in terms of how we view God's will in relation to human intentions, the notion of free will, and the role of God in everyday human affairs. 
Given that time orientation affects how people use and structure time, it influences their attitudes towards the world, lifestyle and communicative behaviour, and thus may lead to a cultural clash when individuals familiar with different time systems yet lacking in intercultural awareness interact. Intercultural misunderstandings can occur insofar as members of some culture view members of another culture who do not subscribe to the same perception of time as disrespectful and disorganised, or attribute such negative personality traits to the others no matter the different concepts or connotations of time that they have (DeCapua \& Wintergerst, 2016; Jackson, 2014; S. Liu et al., 2015).

Furthermore, another crucial aspect of the Indonesian EFL teachers' concept of culture that may relate to a broader issue in ELT/EFL is a 'large culture' paradigm (Holliday, 1999; Holliday et al., 2010). In the local EFL classes, this phenomenon can be inferred from the use of such expressions in the teachers' self-reports as "budaya kita" (our culture), "budaya timur" (Eastern/Asian culture), "budaya Muslim" (Muslim culture) or “orang Indonesia/Muslim/Timur" (Indonesian/Muslim/Asian people) as assumingly opposed to "budaya mereka" (their culture), "budaya barat" (Western culture) or "budaya non-Muslim" (non-Muslim culture), as implied by the following excerpts:

Excerpt 12:

... bagaimana kita seharusnya bersikap, bagaimana seharusnya kita, sebagai orang Indonesia, orang Muslim atau orang Timur.

... [on] how to behave well as an Indonesian, a Muslim, or an Asian. (Interview with Yanti, 28/10/15)

\section{Excerpt 13:}

... tampilannya yang mungkin kurang sesuai dengan budaya kita. ... Kadang ada yang bajunya terlalu terbuka. Saya bilang ke mereka, jangan fokus ke bajunya.

... the way the characters look is incompatible with our culture.... Sometimes they are too revealing, so I told students not to focus on their clothing [appearance]. (Interview with Wati, 17/11/15)

\section{Excerpt 14:}

... pakaian yang dipakai kok seperti ini, tidak sesuai dengan budaya kita.. ... the characters' clothing is unfit for our culture. (Interview with Ana, 25/11/15)

In Indonesia's EFL classrooms, it is not uncommon that English is too closely-if not exclusively, at worst-tied to the English-speaking West. Apart from what the data of the present study has indicated, Zacharias' studies (2003, 2014b), for example, suggest that English has continued to be viewed as a Western language, that the English-speaking West is a legitimate provider of "perfect" English, and that the teaching and learning of English should be about the teaching and learning of the culture of English-speaking countries. Similarly, Gandana (2014) reveals that many of the images of the West constructed by the 
Indonesian teachers contain cultural stereotypes, which are especially prone to being trapped in "large culture" essentialist framings (Holliday, 2011; Holliday et al., 2010).

According to Holliday (1999, p.237), "large culture" refers to "prescribed ethnic, national and international entities,' and this notion of "culture" has become the default in applied linguistics and much social science and popular usage. "Large" ethnic, national and international cultural differences or stereotypes serve as the basic units with which language classrooms work, which may result in 'reductionist overgeneralization and otherization of "foreign" educators, student and societies' (Holliday, 1999, p.237-238, 2009). In Indonesia, a "large culture" approach to the teaching and learning of culture and interculturality could draw more serious attention to the expected dual role of the local EFL teacher as a language teacher and a cultural/moral guard. Instilling cultural, moral and/or religious values in the students in order to safeguard their cultural and national identities apart from developing their language skills is considered by the local EFL teachers not merely as part of their educational roles and responsibilities, but more importantly as a "kelebihan," roughly meaning an advantage or a strong point. In the interviews below, for instance, Ana and Yanti highlighted such a unique dual role:

\section{Excerpt 15:}

Jadi fokus tujuan saya yang pertama adalah menanamkan kepribadian, sense anak. Kalau dengan lagu mungkin nasionalisme yang saya tanamkan.

My primary goal was to develop students' personality/character. The song we sang was to inculcate nationalism. (Interview with Ana, 25/11/15)

\section{Excerpt 16:}

Kalau kelebihan kita ya itu pak, dalam bagaimana memberikan pelajaran lebih ke nilai-nilai Islami atau nilai-nilai budi pekerti yang ketimuran kepada siswa.

Our strength is that we also inculcate Islamic values or Eastern morality in students. (Interview with Yanti, 18/11/15)

How the teaching and learning of culture and interculturality in the high-school EFL classrooms is viewed from Islam-based perspectives in such a predominantly Muslim country as Indonesia, as Yanti's account particularly shows above, will be specifically discussed in the following section 5.5 on EFL, interculturality and Islam. It can however be argued that the local EFL teachers' "large culture" paradigm may easily slip into the trap of cultural prejudice and essentialism that "presents people's individual behaviour as entirely defined and constrained by the cultures in which they live so that the stereotype becomes the essence of who they are" (Holliday, 2011, p.4). Non-Muslim Englishspeaking Western culture is imagined not only being homogenous or unitary but also potentially incompatible with, if not pernicious to, that of the East/Asian or the Muslim. 
Cultural difference is connected with nationality, described in terms of a particular race or ethnicity, linked to static values, and locked in geographical places (Holliday, 1999, 2005, 2016). According to this essentialist view of culture, all members of a particular national culture are believed to behave in a similar way rather than having the capacity to behave differently and under various circumstances resist the major forces of their national culture. 'Easy answers' most often associated with unacknowledged, essentialist and innocent discourses seem to be the default ways of making sense of cultural differences and complex realities. An essentialist "large culture" is also implicit in "Othering" in that a group of different others are to be reduced to a demeaning stereotype, vulnerable to an idealised Self and yet a demonised Other (Holliday, 2011, 2013).

In contrast, a non-essentialist "small culture" paradigm entertains the idea that concedes the importance of national structures which may influence people differently and recognises underlying cultural abilities and emergent social processes that allow members of any cultural groups to expand and move across ethnic or national boundaries. At the same time, a "small culture" approach avoids putting the different others together and considering them as a single group 'as though all the same under a grossly simplistic, exaggerated and homogenous, imagined, single culture' (Holliday, 2011, p.5). Instead, this view attaches "culture" to all types of social activities or groupings, large or small, wherever there is cohesive behaviour (Holliday, 1999; Holliday et al., 2010).

To summarize, the ways the Indonesian EFL teachers' worked with culture and interculturality in the high school EFL classrooms is clearly affected by their conceptions of culture. That the teachers acknowledged the language-and-culture interrelationship, implicitly or explicitly, can be seen as a positive point of departure for introducing an interculturally-framed EFL pedagogy in the local socio-educational context. The teachers were well aware of the students' sociolinguistic backgrounds as well as the immediate and situational factors at play during the teaching and learning processes, which helped them to move, mediate, and operate between native and target language-and-cultures. A shared knowledge of home languages, values and practices was generally used and experienced by both the teachers and learners as a valuable classroom resource and a starting point for making sense of and engaging with sometimes differing and alien outlooks embedded in the English language. In spite of this, the teachers' essentialist 'large culture' paradigm is likely to hamper the implementation of ILTL principles. Different or foreign others were rigidly tied to particular national cultures and monolithic values and conceived of as a single and homogeneous entity confined in geographical blocks. Instead, a non-essentialist 
"small culture" paradigm should be advocated under which "culture" is viewed as 'moveable concept[s] with fluid and negotiable boundaries' (Holliday, 2011, p.1), and liberated from the notions of ethnicity and nation as well as from the perceptual dangers that they carry with them (Holliday, 1999).

In the following section, I will examine the complexity of socio-educational context within which the high-school EFL classroom is situated, identify possible impetus behind the EFL teachers' pedagogic beliefs and practices, and illuminate how the teachers responded to the particularities when addressing culture and interculturality in their classrooms.

\subsection{EFL teachers as intercultural mediators}

Despite the apparently hegemonic language and educational policies and the dominant ideology behind the policies shaping the teachers' conceptions of culture, the fact remains that the Indonesian EFL teachers demonstrated an active agency in working with the complexities of culture and its representations and served as intercultural mediators in the EFL classrooms. A variety of contextual and situational factors contributed to their pedagogic beliefs and classroom behaviours. On the one hand, the teachers' expected compliance with the policies may be indicative of the Government's powerful position in the centralised public education sector in which the policies on language, general education and EFL are executed. On the other, personal agency was also visible in how the teachers made various efforts to search for, filter out, adapt and select the educational resources in order to make them not just practically suitable and effective but also culturally appropriate. They localised and contextualised the classroom materials, tasks and activities. Here, second/foreign language teachers acted as mediators in a culturally responsive pedagogy that is sensitive to local cultural realities and relevant to a "real world" beyond the language classroom is a crucial issue (Byram, 1997; Byram et al., 2002; Gay, 2010; Kohler, 2015; Kramsch, 2014c; Kramsch \& Sullivan, 1996; Kumaravadivelu, 2001, 2006; Newton, 2008). That is, the ways the EFL teachers responded to local aspirations and exigencies, students' linguistic and socioeconomic background as well as to the school and classroom dynamics lent valuable insights into how they actually engaged in the teaching of culture and interculturality in the local EFL classrooms.

In reference to the emergent evidence obtained in this study, some contextual and situational factors that inform the EFL classrooms and foreground how the EFL teachers worked with culture and interculturality can be summed up as follows: 
a) National policy

The national policies on language, general education and EFL that take the form of law (especially the Language law and law on National Education Systems), government regulation, and ministerial decree stipulate and govern a number of language and educational matters, including ones pertaining to the English language and English language education. The policies deal with, among other things, the status of languages (e.g. English merely as a 'foreign language' like any other 'foreign' one), the national educational goals, the national curriculum, the amount of teaching hours, core competencies as well as the graduate competency, content and process standards. School-level decisions, educational resources, teaching and learning processes and classroom materials and activities should be consistent with the prevailing policies.

b) Character education

Character education is one of the essential and distinctive elements of the Indonesia's education system. Generally, it is aimed at developing in students an 'Indonesianness' that suggests the national character and identity rooted in religious principles and local cultures and embodied in the State ideology Pancasila. Teachers of any subject, including English language teachers, are accordingly required to incorporate and enact the prescribed characters traits in their RPPs and teaching. As such, the EFL teachers seem to have the propensity for having a "double role" as a language teacher and a moral/cultural guard. Issues concerning nationalism, cultural appropriateness or religious identity then become crucial to the local EFL teachers.

c) School characteristics

Three different types of Indonesia's high school, i.e. general (GHS), vocational (VHS) and Islamic (IHS), have different educational goals and characteristics. GHS students and graduates are largely orientated towards further study, VHS students are towards professional job, and IHS students are towards a deeper Islamic knowledge and a stronger Islamic identity. These differences are evident not only in different educational contents and priorities but also in everyday school discourses and practices as well as wider issues deemed relevant to their specific fields of study. While GHS and VHS made announcement through the school's loudspeaker in two languages (i.e. Indonesian and English), for example, IHS made it in three languages (i.e. Indonesian, English and Arabic). Also, the EFL teachers of the three different schools might raise the same issues of cultural authenticity and the role of the NSs of English in ELT/EFL but adopt different approaches and orientations. 
d) Academic and English skills

Students' level of academic and English skills varies and enters into the teachers' instructional judgments and decisions. Schools may have different educational characteristics and emphases, apply different admission grades, and accordingly target and accept students of different academic and in particular English abilities. The EFL teachers took into account the average level of the students' academic and English competencies and considered these differences, especially when deciding on what materials to use or how to present them in their classrooms.

e) Shared multilingualism

Both the teachers and students generally speak Indonesian and a local vernacular or more. In the sociolinguistic context of Pendalungan, the local languages can be Javanese, Madurese or Osing. On various occasions, the teachers switched from English to or mixed it with Indonesian or local language(s). Such a code-switching and code-mixing were used by the teachers to serve different purposes, including giving further explanation about new or different concepts in English and allowing students to draw on the cultural richness and significances as embodied in and expressed by host language-and-cultures. It is not uncommon that students answered the teacher's question, had a chat between themselves and interrupted, seriously or jokingly, in the national and local languages, juggling with and moving between different cultural frames of reference manifested in different languages.

f) Socioeconomic background Students' socioeconomic background played a part in the teachers' classroom judgments and decisions. The teachers connected different socioeconomic backgrounds to the students' general knowledge of and familiarity with certain teaching and learning materials or topics of discussion. Take, for instance, how they preferred a locally popular, more affordable noodle brand mie gelas over burger and used a variety of local foods in addition to the 'foreign' ones as examples in the classroom materials and activities. The teachers related students' socioeconomic background to prior cultural knowledge and lived experiences and used this to facilitate comparisons and to establish meaningful connections between existing and new concepts embedded in home and target language-and-cultures.

It could be argued that how the Indonesian EFL teachers addressed culture and interculturality in the high-school EFL classrooms indicates a context-boundedness and a 
culture-sensitivity in that a variety of local linguistic, sociocultural, educational, religious and political particularities feed into their instructional judgements and decisions. What the EFL teachers generally do in their classrooms and the immediate situational and wider context within which they engage in the world of day-to-day teaching and learning illustrate aspects of what Kumaravadivelu (2001, p. 538) terms as a 'pedagogy of particularity' referring to 'a particular group of teachers teaching a particular group of learners pursuing a particular set of goals within a particular institutional context embedded in a particular sociocultural milieu'. Elsewhere, Stritikus (2003) maintains that our understandings of teachers' roles in policy can be enriched by examining their individual responses to policy that "exist in a recursive relationship with the environments in which they work" (p. 33). Likewise, Farrell and Bennis (2013) assert that the realisation of language teacher's complex beliefs in their actual teaching depends on a number of potential reasons, and some of these might be closely related to the context of teaching and learning. These views reinforce the notion that teachers' pedagogic beliefs and classrooms actions are context-bound, interactive, and mutually-informing.

In view of the particularities of the EFL teachers' beliefs, instructional decisions and teaching context, it is intriguing to delve into some teachers' practices and classroom interactions and then to explore the extent to which such location-specific, culturallyshaped teaching behaviours and events relate to much larger issues. One of the salient phenomena is the use of the teaching and learning materials in various forms and from a variety of sources and how mediation is at play in this situation. What may escape our attention and is thus worth further examining is the complex process of the EFL teachers' mediating not only between language and culture, but also between students' first language-and-culture and that of people of different origins and cultural identities in the use of such a foreign and international language as English in real-life communication. 


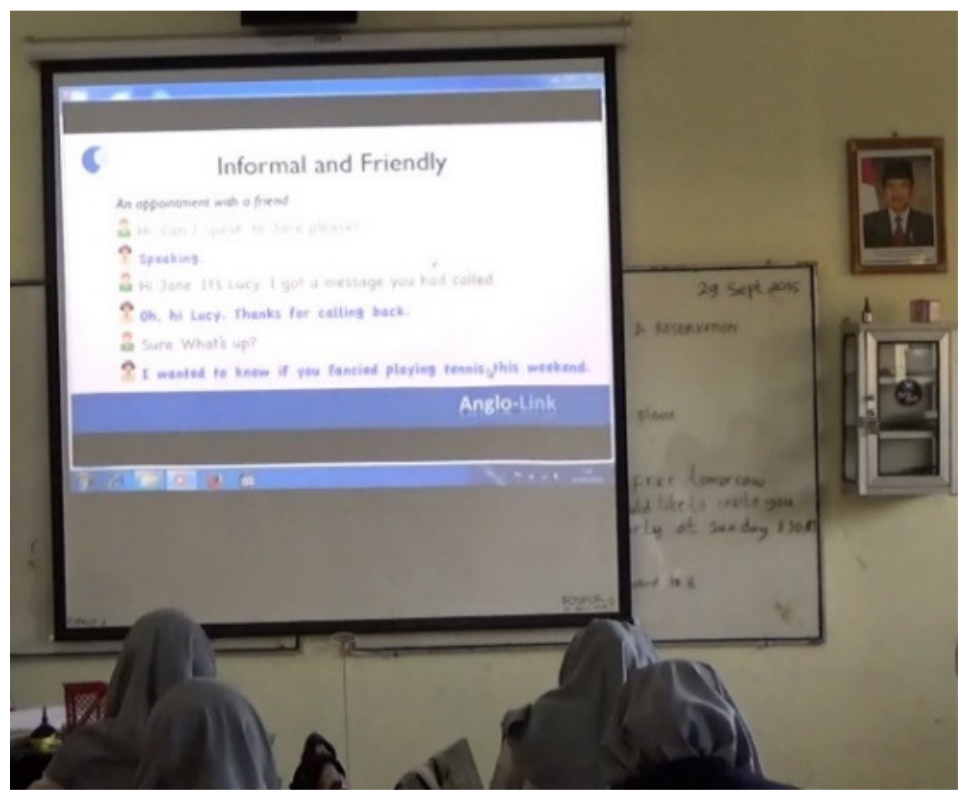

Figure 38: Anglo-Link materials used in Yanti's class

Figure 38, for example, describes a situation when Yanti showed a projected image that was obtained from 'Anglo-Link' containing expressions used for making an appointment by telephone while students were listening an audio material played over the classroom's loudspeakers. During the classroom interactions, students mentioned several local events, especially the Islamic ones, for which an appointment or invitation is normally made, including tasyakuran (thanksgiving), hajian (pilgrim farewell/welcoming ceremony), akikah (baby welcoming ceremony), and tahlilan (communal prayer for the deceased). When practicing the expressions, students usually started their dialogue by exchanging the Islamic greeting Assalamu'alaikum. It seems likely that the students subconsciously used such a religiously-inspired expression in conformity with tacit local cultural norms irrespective of what language they speak.

Equally interesting, as figure 39 shows, is when Ana was playing a video in Chinese by using an LCD projector and loudspeaker in her class. Ana then held a brief question-andanswer session in English by asking some students what their opinions were regarding the contents or messages of the video. In an interview that followed, she explained her reasons for playing the video:

Excerpt 17:

Ini kan termasuk character-building, juga anak-anak punya karakter yang baik sebagai anak. ... saya ingin menggali speaking anak-anak, ide anak-anak tentang itu. ...

This [practice] belongs to character-building, in order that students have good character. ... I'd like to improve their speaking skills, exploring their ideas.... (Interview with Ana, 25/11/15) 


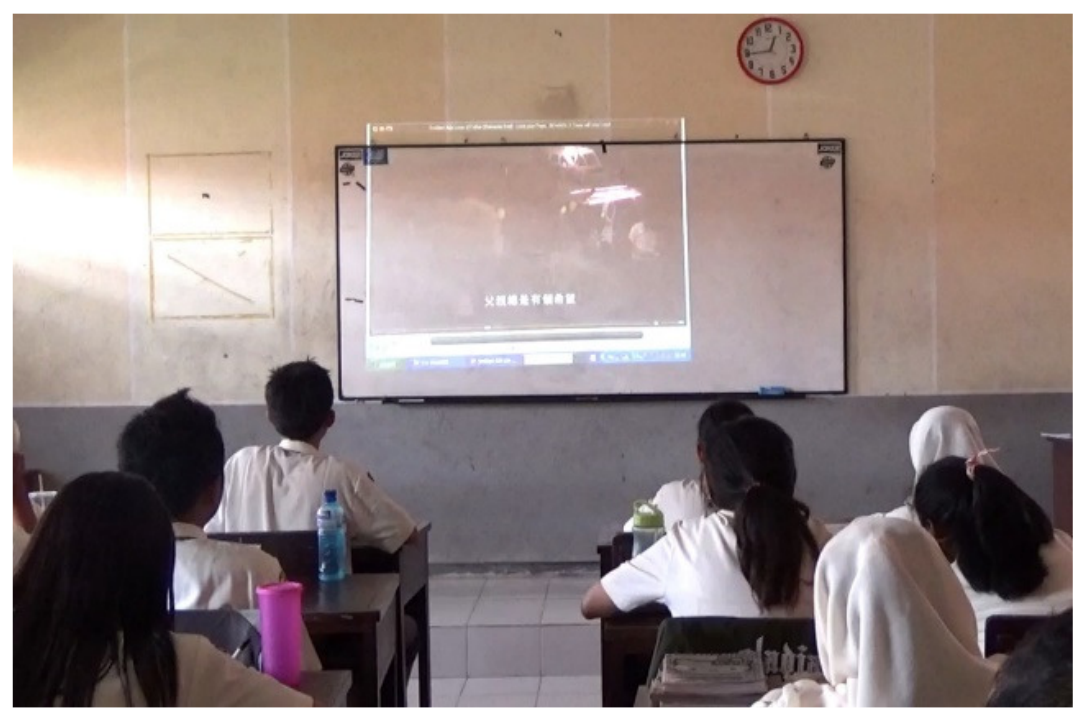

Figure 39: A video in Chinese shown in Ana's class

Apart from the audio-visual and video, as shown in Figure 17 (p. 104), Ambar projected a sample vacancy whose addressee is in Kathmandu, Nepal. The topic was writing a personal letter that includes an application letter. In the following explanation, the address of an applicant was in Pandaan, a local town located in a neighbouring district of Pendalungan. As for Figure 40, it shows a situation in Wati's class in which "foreign foods" such as crêpes and pizza were used as examples of how to prepare food, describe its process, and write a "procedure text." Despite the fact that no local food was used as an example, students replied to Wati's question by relating crêpes to a local snack called dadar gulung, perhaps due to its similar appearance. In Aris' class, local foods and ingredients were also used as part of the discussion and practice of writing "procedure text" (Figure 41), whereas in Wati's class local and foreign foods were used in the lesson on "making suggestion". 


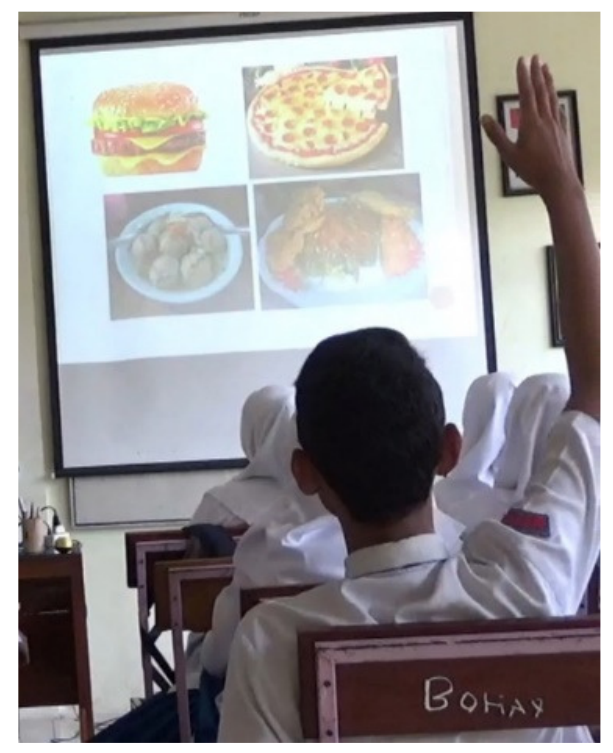

Figure 40: Local and foreign foods used as examples in Wati's class

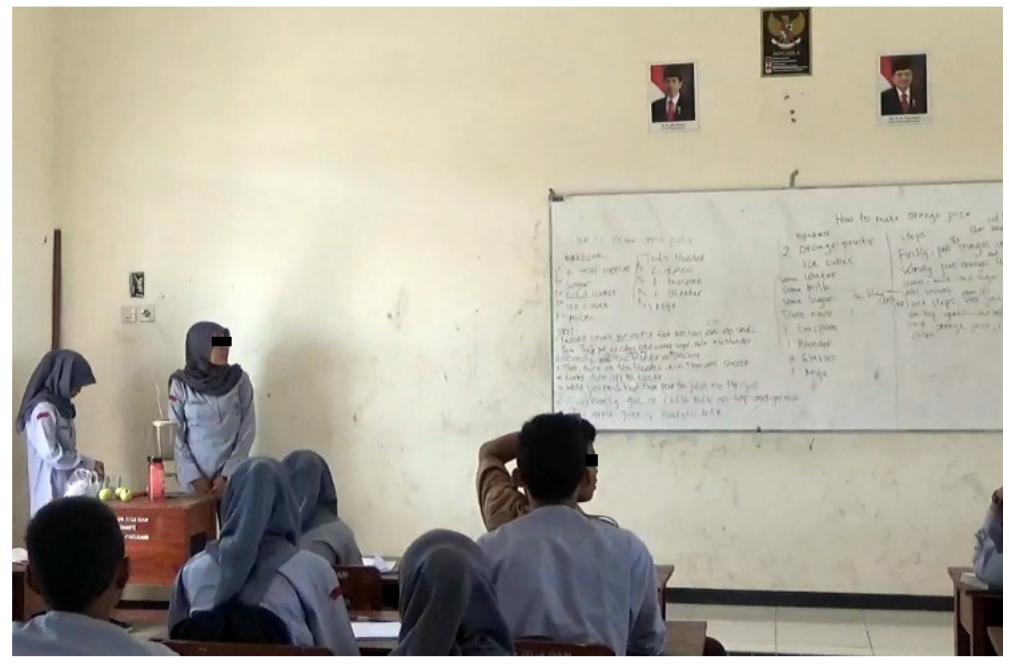

Figure 41: Students practice writing 'procedure text' in Aris' class

The complicated cognitive processes on the part of both the teachers and students during the classroom events and interactions, for example when Ana was playing a video in Chinese aimed at simultaneously developing students' character and their speaking skill or when the students used their initial knowledge and experiences to come to grips with new concepts in English, stress the value of teacher's mediation skill in the second/foreign language classrooms. For Byram and Risager (1999), in real life interactions beyond the language classrooms, the complexity of communication increases when NNSs of English meet and have to communicate through English as a third language or a lingua franca. In 
an era of globalisation, as Kramsch (2013b) remarks, communication can no longer be simply about 'the accurate, concise, and effective exchange of information,' partly because communities have now 'become too hybrid and too complex to have well-defined rules of behaviours that need to be observed if communication is to proceed smoothly' (p. 409). In this view, pragmatic appropriateness needs to be redefined, negotiated and constructed on a case by case basis.

Within the framework of an ILTL, it is of vital importance that the local EFL teachers aspire to become and serve as intercultural speakers or mediators rather than idealised NSs (Alptekin, 2002; Byram et al., 2002; Corbett, 2003; Liddicoat \& Scarino, 2013). Central to this idea is the ability to navigate through and shuttle back and forth within one's set of linguistic and cultural contexts and that of other people of different cultural origins and identities. Other key attributes and capabilities necessary for the EFL teachers acting as intercultural speakers/mediators include the following:

- sensitise themselves and students to the sociolinguistic richness that surrounds their home, classroom, school and locality at large;

- reflect critically on and alert students to the operation of cultural difference between their own and another culture;

- identify own values and behaviours as embodied and reflected in home languages and practices and relate these to other people's values and behaviours;

- identify and explain potential areas of stereotypicalized view, dysfunction and misunderstanding;

- negotiate the cultural distance and mediate between different perspectives; and, - overcome conflicting interpretations of phenomena and identify common ground.

In an interculturally-framed EFL pedagogy, what students and teachers bring to the classrooms and the target language-and-culture are seen as equally valid and important and as such the students' home knowledge, languages and experiences should be used as a productive classroom resource (Gay, 2010; Newton, 2016). The data of this study indicates that the students in the local EFL classrooms readily drew upon and used first languages and existing knowledge and skills as a springboard for making sense of and building links with new values, beliefs and behaviours that come with English. The onus is on the EFL teachers to recognise the potential of home knowledge and make maximal use of the first languages and lived experiences in a selective and systematic manner and in judicious 
doses as well in order to support the teaching and learning process in the classrooms (Cook, 2001, 2016; Littlewood \& Yu, 2011).

At the same time, the local EFL classrooms are conceived of as a site of intersection of multiple worlds of discourse, and the students are encouraged to create a "third culture" as a conceptual space within which the familiar meanings of the local culture and the unexpected meanings intersect and overlap (Kramsch, 1993; Kumaravadivelu, 2003). In the teaching and learning, the cultural meanings and significance of such local traditions or rites of passage with which they have been familiar as tasyakuran and akikah, for example, can be drawn to students' close attention, further explored and explicitly connected to similar practices like "thanksgiving" and "baby shower" respectively in both English-speaking speech communities and many other non-English-speaking countries in the world. In this way, as Kumaravadivelu (2003) asserts, in addition to students constructing personal meanings which lie at the boundaries between the NSs' meanings and their own everyday life, they may not be held hostage to particular values and beliefs associated with either the native culture or any specific target culture.

That said, what is also essential for the local EFL teachers is how they experience and put such dualities as us/them, native/non-native, home/target culture, local/global, etc. into classroom practice. On the one hand, the various forms of globalisation and advancement in information technology have brought about more intense and complex intercultural contacts. On the other, much of the debate over cultural authenticity and appropriateness has still revolved around NS-based models (Kramsch, 1998; Pinner, 2016b). For Kramsch (1998), the relevance of NS-based concepts to many diverse teaching and learning contexts can no longer be tenable for two underlying reasons. First, what is real, genuine or appropriate in one context might not be so in another. Authenticity and appropriateness vary according to such many different contextual variables as age, gender, ethnicity, religion, socio-economic status, etc., and to various subcultures to which such people may belong within their own communities (Kramsch, 1998; Nunan, 2013). Secondly, imposing a NS-based concept of authenticity on NNSs might devalue the sense of self, constrain their autonomy, and undermine their legitimacy and autonomy as teachers, learners, and users of English as a foreign and international language (Alptekin, 2002; Kramsch, 1998; Lowe \& Pinner, 2016). The focus of concern on learners and non-native teachers should therefore remain on "what they are" and "what they are becoming", that is as "intercultural speaker" who "stands in a complex relationship with languages, cultures, and communities, 
as insider or outsider ... recognized as a member of many speech communities' (Liddicoat \& Scarino, 2013, p. 53).

Another salient point of the EFL teachers' beliefs and practices is concerned with authenticity and native-speakerness. These two issues relate to one another as the teachers attached the concept of 'authenticity' of the teaching and learning materials to ones produced and used by the NSs of English in a real-life context outside their EFL classroom. They benchmarked the accuracy of interpretation and production of the teachers and students against the NSs' performance, measuring their competence against the socalled 'native competence'. That is, the NSs of English are generally seen as a more legitimate source and authoritative model of linguistic and pedagogic knowledge than the NNSs. The following excerpts from Yanti's NF and Wati's interview show that the unpredictability of question that students might ask and the NNSs' pronunciation or expression of doubtful accuracy have led them to give primacy to the NSs:

Excerpt 18: ... dan saya tidak tahu ungkapan dalam bahasa Inggrisnya. Saya rasa saya membutuhkan penutur asli bahasa Inggris untuk tempat bertanya.

.. with which their equivalents in English I was not familiar. I think [in this situation] I need a NS to ask (Yanti's NF, 25/10/15)

\section{Excerpt 19:}

... Jadi saya lebih percaya, bukan berarti tidak percaya, tapi lebih percaya ke yang native. Pasti tidak salah kan pronunciation-nya, ekspresinya, menurut saya.

That's why, I believe more in the NSs, although this does not mean that I don't believe in the non-natives. The pronunciation or expression of the NSs must be right, I suppose. (Interview with Wati, 17/11/15)

While Wati's and Yanti's account above may suggest a perceived limited language competence and some lack of self-confidence, some scholars have noted that the concept of "authenticity" and its application to the second/foreign language classrooms have always been problematic, partly because its tie to native-speakerness (Alptekin, 2002; Kramsch, 1993, 1998, 2014c; Lowe \& Pinner, 2016; Pinner, 2016a; Widdowson, 1994, 1996). Kramsch (1993), for example, has flagged up some aspects of "authenticity," i.e. representative usage, cultural competence, and authentic language learning. The question about which socially established traditions or usages are representative of the NS speech community has remained contentious in terms of linguistic and pragmatic perspectives. 


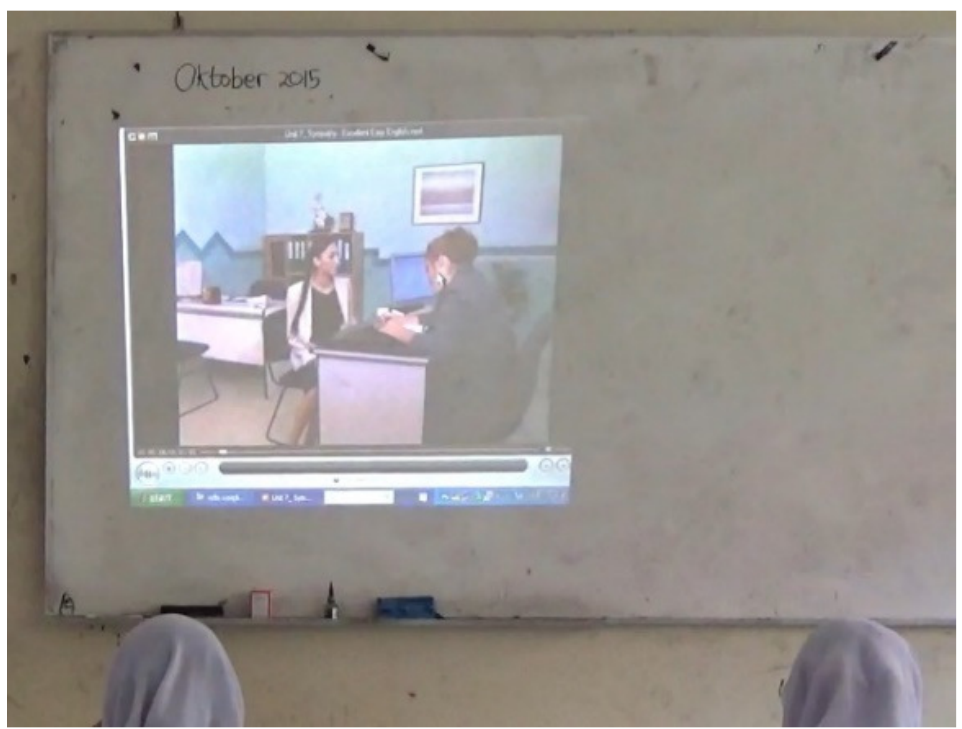

Figure 42: A video features English NSs in Ana's class

Authenticities within one speech community or national society are in fact diverse, depending on the many different contextual factors, including age, gender, social status, race, ethnicity, occupation, religion, etc., so that 'what is authentic in one context might be inauthentic in another' (Kramsch, 1998, p. 81). A NS-based cultural competence refers to the "obligation" to behave and comply with the social conventions, whereas plagiarizing the NSs might devalue one's authentic self as a learner. Even behaving in the same way as the NSs will not guarantee a recognition by or an easy acceptance into the target speech community. The reality of NS language use is not likely to be real for learners (Widdowson, 1996), and thus associating authenticity with the sociocultural milieu or sociolinguistic norms of the NS is constraining the autonomy of the teacher and learner (Alptekin, 2002). In this sense, the NS-preoccupied concept of authenticity can be not only delusive but also demotivating.

However, as Newton (2008) has noted, within the context of workplace intercultural communication training, using authentic language allows for a closer alignment between language training programmes and worksites rather than a disjuncture. In Newton's words, the use of authentic language helps us 'identify important sociopragmatic features of workplace language that are rarely highlighted in artificial materials used in intercultural communication training and provides participants with resources that are directly relevant to their needs' (p. 519). In this regard, what the local EFL teachers and students have reported can also draw our attention to the idea that language learners' needs and priorities, the purpose of language teaching and learning, and the context of real-world language use 
are so diverse that a single agreed definition of authenticity is hardly plausible. Take, for example, Wati's account. As an EFL teacher in a vocational high-school understood as a 'producer of work force,' she connected her conception of authenticity with the students' expected degree of competence and the job competition that the students will be facing upon graduation. English is seen as a globalising tool for the students/graduates. VHS Agri also has overseas partner schools and companies where students can enrol in an exchange and an internship programme, and yet this involved mainly non-English speaking countries such as Thailand and Japan. In today's globally interconnected world, the following excerpt from students' FGD may point up the way students actually use English outside the language classroom and how their authentic language use can be like:

Excerpt 20:

Teman saya juga banyak yang dari Malaysia, Singapura, Thailand, Cina. ... kita bukan native speaker, tapi bahasa pengantar antar komunitas kita adalah bahasa Inggris. I have many friends from Malaysia, Singapore, Thailand, and China. ... We are NNSs [of English] but our common language is English. (Student FGD)

Students' awareness of cultural background and authenticity when using English in an intercultural communication in a way concurs with Ana's view of cultural identity. Here, what is intriguing is that the cultural belief affects the way Ana approached professional competence and classroom practices. Take, for example, the reasons why she chose to play a video featuring former students as a task reference (Figure 43) and connected such practice with the immediate sociocultural milieu where she and the students live. Rather than emulating the so-called NS competence, Ana aspired to be 'who she is' as a Javanese learner of English. It is also worth mentioning that not only does Ana's understanding of "authentic self" as a local EFL teacher shape her perception about linguistic and professional competence, but it also informs her view of students" "authentic selves" as learners and the way she developed and assessed their English competence. 


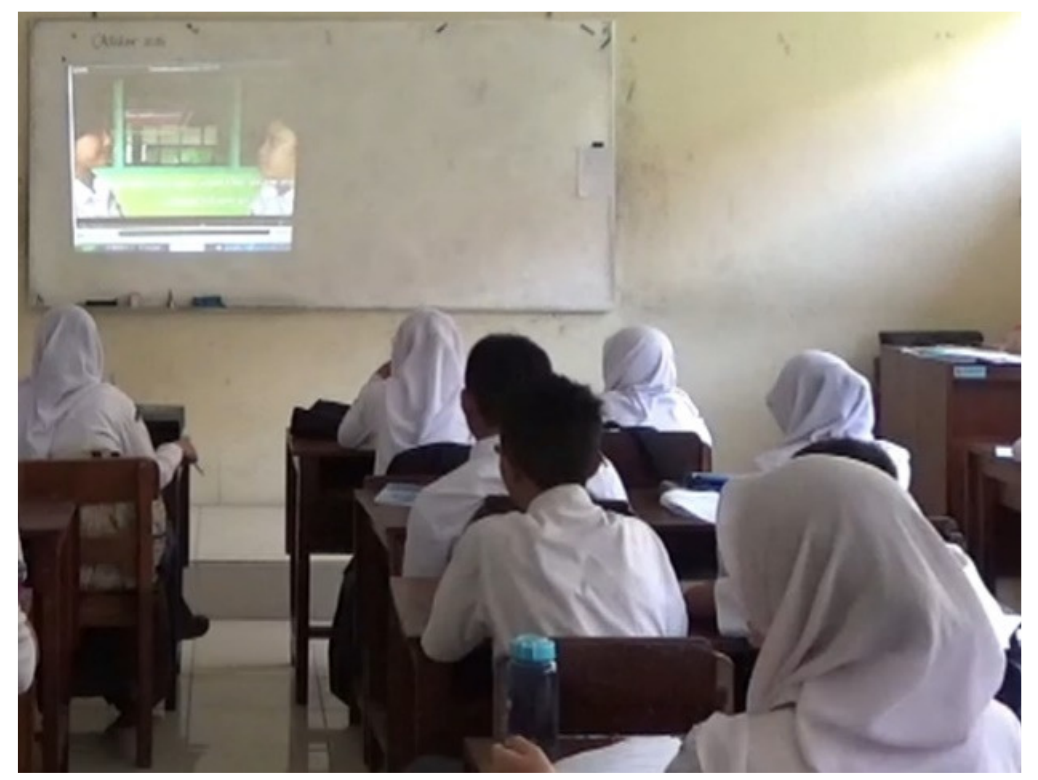

Figure 43: Students watch a video featuring senior students

\begin{abstract}
Excerpt 21:
Jadi saya ada tujuannya saya milih yang ini, kenapa tidak yang native. Karena anak-anak saya tunjukkan, ini lho mereka bisa, kenapa Anda tidak bisa.

I had a [specific] reason for selecting this one, which does not feature the NS. I just wanted to show [current] students that if they [senior students] could do it [making the video], you can do it, too. ... (Interview with Ana, 25/11/15)

\section{Excerpt 22:}

Saya ga punya pikiran saya harus menjadi native. ... Nah kan, kalau kita ingin membentuk mereka harus seperti native; saya saja kesulitan, apalagi anak-anak. ...Karena kita ga bisa menjadi orang lain.

I don't think I have to be like the NS. ... How can I ask my students to be like the NS when I myself find it difficult to do so? ... We can't be someone else. (Interview with Ana, $25 / 11 / 15)$
\end{abstract}

Summing up what has been said thus far in this section, the local EFL teachers displayed an active agency in working with culture and interculturality in the high-school EFL classrooms amid the nationally-imposed policies on language, general education and particularly EFL. Their pedagogic initiatives inside and outside the classrooms cannot be considered in isolation from various immediate and wider contextual factors affecting their conceptions and representations of culture and interculturality in the classrooms. The national education goals and in particular the character education, for example, seem to exert a direct impact on their teaching practices in that the policy requires an incorporation of local cultural, moral and/or religious values into the teaching and learning materials and classroom instruction. What the teachers believed and did in the classrooms regarding a 
number of issues, such as patriotism, national identity or cultural appropriateness, can be attributed to the policies. The teachers' classroom decisions are also subject to a variety of local and situational forces, including shared multilingualism, school characteristics, students' sociolinguistic and socioeconomic backgrounds as well as their general academic and English proficiency. The EFL teachers' cultural sensitivity plays a crucial role in catering to local aspirations as well as mediating between likely different values of host and target-language communities.

In the next section, I will discuss from an intercultural perspective several emergent themes concerning the relationship between English, EFL pedagogy and Islam in the context of Indonesia as a predominantly Muslim country.

\subsection{EFL, Islam and interculturality}

While allowing the teachers and students to engage with the "foreign others", EFL pedagogy in a Muslim-majority country such as Indonesia inevitably intersects with local Islamic thoughts and traditions. At the macro level, Indonesia's education policy documents stipulate that religiosity and spiritual values are integral parts of the national education goals (Kementerian Pendidikan Nasional, 2010; Undang-Undang Republik Indonesia No. 20 Tahun 2003 tentang Sistem Pendidikan Nasional [Law No. 20/2003 on National Education System], 2003). At the micro level, as the EFL teachers self-reported and I directly observed in their schools and EFL classrooms, religious ideas and practices permeate school and classroom discourses. That public schools formally started the teaching hours following an Islamic supplication, or that the Islamic greeting was exchanged to begin and end EFL classes, is another case in point.

The unique socio-educational environment offers challenges and opportunities for theorists and practitioners to accommodate religious perspectives and especially Islamic outlook. However, at least as much as I am aware of, there has been little discussion about the place of Islamic worldviews in an interculturally-oriented EFL pedagogy, focusing on Indonesian teachers/learners of English, and in the broader field of ELT as well. Hence, this section seeks to problematize the relationship between English and Islam. It identifies a number of relevant issues emerging from the data, and offer some ideas on the potential integration of Islamic viewpoints into an ILTL model.

Religion plays a crucial role in the construction of the ethnic, cultural, and national identity of Indonesians. Around 87\% of over Indonesia's 250 million population is Muslim (“Indonesia population 2018," 2018; “Islam in Indonesia,” 2018). Global surveys indicate 
that more than $90 \%$ of the Indonesians affirm the importance of religion in their lives ("Chapter 2. Religiosity," 2008; Theodorou, 2015). Following the collapse of the authoritarian New Order regime in 1998, Indonesia has now become the world's third largest democracy ("A look at election in Indonesia, world's 3rd largest democracy and most populous Muslim nation," 2014; Walden, 2017). An insight into how religion is understood, believed, imagined and practiced in the local socio-educational context is essential. For Amstrong (2002), human beings are religious creatures who are imaginative because they have to use their creative imaginations while looking beneath the unpromising surface to find the sacred within it. In Amstrong's word, religious people are:

... so constituted that they are compelled to search for hidden meaning and to achieve an ecstasy that makes them feel fully alive. Each tradition encourages the faithful to focus their attention on an earthly symbol that is peculiarly its own, and to teach themselves to see the divine in it (p. xi).

In the broader context of intercultural education, as Leganger-Krogstad (2011) writes, the double role of religion should be highlighted in that it can serve both as the reason for sharp differences in individual's mental mapping and worldviews and as a significant contributor to intercultural dialogue and understanding. Leganger-Krogstad adds that a contextual understanding of the religious dimension of intercultural education is encouraged, one which is rooted in the sociocultural theory and holds that learning is situated and dependent on the context. Here, context is understood as a socio-cultural milieu in time and space influenced by local and global culture. Religious artefacts and traditions are read from inside and outside the community of production, creating an interface between them. That is, the situatedness and context-dependence of religious understandings, beliefs and behaviours cannot be separated from the dynamics of the immediate local and wider global sociocultural, religious and political processes.

As discussed earlier in this study, the local EFL teachers generally believe that language and culture are intimately related and tend to see that some cultural norms and values inherent in the English language shaping the beliefs and behaviours of English speakers can be inconsistent with local practices and value systems. The teachers' understanding of language-and-culture informs how the teachers perceive new or different values and behaviours of the foreign others made manifest through their language use and communicative behaviour. Not only may the values and behaviours be regarded as alien or incompatible but these can also be conceived of as a threat to native language-and-cultures. Take, for example, when Ana stressed the importance of singing the national and local 
songs in her EFL classrooms in order to strengthen students' patriotism. What was implied is that English or EFL is not in alignment with such an effort. A more extensive use of English than only as a school subject in the formal education, like in the case of the then RSBI/SBI, was related to the fear of degrading students' nationalism and the prominenceor even existence-of the national language. That is, English is reckoned to be not just a language in that the much bigger package of Western cultures and ideologies that come with English (Karmani \& Pennycook, 2005) is supposedly exposing students to different beliefs and behaviours eroding their cultural, national and religious identity. This religiously inspired "attitudinal resistance" (Mohd-Asraf, 2005) towards English is especially evident in Yanti's reports below:

Excerpt 23:

... bagaimanapun juga belajar bahasa Inggris penting untuk menguasai dunia global, tetapi jangan sampai terkontaminasi dengan budaya Barat yang non-Muslim.

Notwithstanding the importance of learning English in keeping up with the globalised world, (we) should not be contaminated by non-Muslim Western culture. (Yanti's NF, 25/10/15)

Excerpt 24:

... ya harus disertai penjelasan bahwa itu budaya mereka, budaya kita seperti ini.

... must be accompanied by giving an explanation that it is their culture, and this is our culture. (Interview with Yanti, 18/11/15)

Yet, in other self-reports Yanti recognised "positive" and "negative" aspects of both Western and host cultures, suggesting her efforts to decide on and implant in the students positive values of the two cultures:

Excerpt 25:

... karena saya masih kadang memasukkan nilai-nilai budaya Barat yang bagus ke anakanak, dan juga memberitahukan ke anak-anak bahwa budaya di kita yang gak baik gitu. ... because sometimes I talked about positive values embodied in Western culture and at the same time discussed negative values in our culture. (Interview with Yanti, 18/11/15)

\section{Excerpt 26:}

Mungkin perlu disampaikan ke anak-anak di budaya Barat itu tidak semuanya jelek ... It is perhaps important to let students know that not all aspects of the Western culture are negative ... (Interview with Yanti, 18/11/15)

Despite Yanti's mitigating recognition and the fact that the figurative sense of the Indonesian word "[ter-] kontaminasi" ( terkontaminasi dengan budaya Barat [contaminated by Western culture]') and its English equivalence 'contaminate[-d]' might be different, that is the Indonesian kontaminasi is less strong in meaning than "contamination," the word kontaminasi clearly puts 'non-Muslim Western culture' in an unfavourable light. The words "budaya Timur/Barat/Muslim/non-Muslim [Eastern/ Western/Muslim/non-Muslim culture]" used in Yanti's account above also imply a 
simplistic, mono-dimensional understanding of culture, lumping together members of different cultures. In this respect, the existing literature shows that an attitudinal resistance, resentment or rejection of Muslims to English can be attributed to a number of reasons. First, different conceptions of knowledge between secular/Western and religious/Islamic worldviews. Daud (cited in Pennycook 1994) explains that in Islamic worldview, knowledge is an aspect of divinity and seeking and spreading knowledge are fundamentally important acts of divine worship. Pennycook (1994) asserts that what is especially significant here is a substantial difference between Western secular thought embodied in technological-rational knowledge and the integrated concept of divine knowledge manifested in Islamic thought. Equally important is the close connection between the spread of English and the spread of Western secular thought.

Likewise, Mohd-Asraf (2005) contends that the presumed conflict between the Western cultural values and worldview as conveyed through English and one's Islamic values can be understood by looking into how language and worldview may shape the thoughts and identities of Muslims. Echoing Al-Attas' idea, Mohd-Asraf argues that language can reflect the nature of truth and reality (ontology) as understood by a certain religion, culture, and civilization. The languages of Muslims have been infused by what Al-Attas termed as 'Islamic basic vocabulary' that embraces such core concepts as God, truth, reality, religion, knowledge, education, justice, freedom, and so on. These ideas can be different in some fundamental points from the Western conceptions.

Second, English is tied to Christianity. Although the relationship between English and the Bible in Christianity is not as direct as between the Arabic and the Qur' an in Islam, it is not only Muslims who believe that English is a language of the Christians or-in a more emotive and pejorative term-a language of the infidel/kafir (Karmani \& Pennycook, 2005; Pennycook, 1994), but also non-Muslims, particularly some 19th century writers, who accept that "English and Christianity are indelibly linked" (Pennycook \& Makoni, 2005, p. 140). This sentiment can be traced back to the colonial era when English and other major European languages were the languages of the colonial rulers in occupied Muslim countries and became closely related with the missionary projects. Pennycook and Coutand-Marin (2003) and Pennycook and Makoni (2005) state that in the post-colonial era, with the global demand and spread of English, ELT is seen as a legitimate site for the missionary work. They go on to argue that, on the one hand, the use of English as the bait to lure the unsuspecting learners into missionary schools and to convert them to Christianity raises profound ethical and political questions. On the other, religious 
conversion as targeted by the missionaries has always been a serious issue in the Islamic world partly because it is closely related to proselytising and apostasy that are strongly denounced in Islam and associated by some scholars with strict sanction or punishment (Leaman, 2018; Mambu, 2016, 2017; Saeed, 2018).

Third, English is seen as an embodiment and carrier of Western culture. Sociocultural, political and historical baggage that English brings conjure various images-positive as well as negative-to the myriad people who use, teach or learn it. Omar (cited in Pennycook 1994) says that the word barat (the West) may trigger positive and negative reactions, presenting both good images of knowledge, science, technology, progress, modernization, and so on, and bad images of moral permissiveness and degradation. Tensions usually arise when modernization is equated with westernization, which is reckoned to be something negative if it violates Islamic teachings, and when "bad" images of the Western culture outweigh the "good" ones. Gallup's study involving Muslims around the world shows that it is a perceived moral decay and breakdown of traditional values that large majorities of Muslims least admire about the West, and an attachment to Islamic spiritual values is what Muslims most admire about themselves (Esposito, 2010; Esposito \& Mogahed, 2007).

Nonetheless, what is perhaps more worrying and leads to negative attitudes among some Muslims is a negatively-charged "transforming effect" of the teaching and learning and use of English. That is, the teaching and learning and use of English may change students' cultural or religious character and identity as they are exposed to new values, belief systems and behaviours that come with such a socially, culturally and politically dominant language in the global arena as English. As Mohd-Asraf (2005) observes, the concern, apprehension and even 'fear' that grow among some Muslim parents are due largely to the belief that their children can become westernised or secularised as a result of the teaching and learning and use of English. In other words, the teaching and learning and use of English are linked to the possibility of being secularised, westernized or even proselytised. This idea concurs with what Pennycook (1994, p. 208) has pointed out: ... whether there is an inherent tension between Western and Islamic knowledge or not, there is strong feeling that English is connected to forms of knowledge and culture that are oppositional or even threatening to an Islamic way of life.

That being said, what is then important is to examine how language relates to the conception of knowledge, especially the separation of religious/secular knowledge, and to diversity viewed through an Islamic lens. The belief that seeking knowledge is highly encouraged or even obligatory in Islam is shared by many Muslims, but whether religious 
and secular knowledge is distinguished remains a highly debatable point. Muslims hold varying opinions as to whether there is compelling theological justification or otherwise for making a distinction between secular/Western and religious/Islamic knowledge. As Pennycook (1994) explains, some argue that a unidimensional, Western secular theory is a direct threat to the Islamic tenets and its secular programmes are at the root of the most serious problems in Muslims societies. Shafi (ibid.) furthers this idea by connecting the secular/religious knowledge split to ELT, saying that there is a wide disparity between the objective of teaching and learning English and the ultimate goal of Muslim education in Muslim countries.

However, others, such as Daud (cited in Pennycook 1994), Batchelor (2015) and Maarif (2015), take the view that there is no clear-cut distinction not only between religious and secular knowledge but also between Islamic and Western thought because much of what is now taken to be Western actually can be attributed significantly to its contact with the Muslim world and Islamic/Arabic thought. For Batchelor (2015), while acknowledging the world's divine origin, a Muslim scientist inspired by the Quran would maintain a connection of science with spirituality. The term 'ilm used in the Quran refers to knowledge in the broadest sense which does not separate knowledge of the manifested world from the vastly greater world of the unseen. Maarif (2015) also stresses that under the concept of 'the unity of knowledge' all areas of knowledge have a single purpose, that is to bring humankind closer to God as the ultimate source of knowledge. In Maarif's words:

Dengan tenda ini pula, upaya "Islamisasi ilmu pengetahuan" yang dilakukan oleh beberapa pemikir Muslim kontemporer juga sia-sia. Jika seluruh kegiatan ilmu pengetahuan adalah untuk mencari dan mendekati Allah dengan membaca tanda-tanda kebesaran dan kekuasaan-Nya, maka atribut-atribut serba-Islam yang ditempelkan kepada berbagai disiplin ilmu tidak diperlukan lagi. [Under this umbrella term, the "Islamisation of knowledge" proposed by some contemporary Muslim thinkers should be regarded as a futile effort, too. If all scientific endeavour is oriented towards seeking and getting closer to Allah by way of understanding His Signs and Sovereignty, any Islamic labels attached to different disciplines are pointless.] (p. 231).

Islam teaches that the Quran is the actual Word of God (Kalamullah) and Muslims consider the Quran as the most fundamental source of Islamic knowledge as well as the definitive authority of Islamic law and practice. According to the Quran, the creation of the different nations and tribes is among His Signs for men of knowledge and understanding. For example, in the Chapter of Al-Hujurat (The Inner Apartments) 49:13 (Yusuf Ali, Trans., 2016), God says: 
O mankind! We created you from a single (pair) of a male and a female, and made you into nations and tribes, that ye may know each other (not that ye may despise (each other). Verily the most honoured of you in the sight of Allah is (he who is) the most righteous of you. And Allah has full knowledge and is well acquainted (with all things).

A greater focus is usually given to the original Arabic expression lita'arafu with respect to its divine message. Ali (2016) translates the phrase and gives an explanatory note in brackets, i.e. 'that ye may know each other (not that ye may despise (each other))'. Irving (1991) interprets and translates it into English and gives a supplementary information in square brackets: "so you may recognize [and cooperate with] one another." In a similar vein, Maarif (2018) elaborates on the issue by underlining that what is enjoined in the Quran is not simply to recognise people from different nations and tribes or to know one another, but more importantly to exchange ideas, share knowledge and mutually learn from each other's culture or civilisation. Maarif goes on to argue that part of another verse ( $\mathrm{Al}$ Baqara [The Cow] 2:148) exhorts humankind to 'fastabiqul khairat' ('vie with one another in good works') irrespective of their national, ethnic or cultural backgrounds, that is to strive towards all that is good and contribute to humanity.

The Quran is even specific about language and colour with which mankind is invited to think about its existence and especially its differences, as mentioned in the Chapter of ArRum [The Romans] 30:22 (Yusuf Ali, Trans., 2016) as follows:

And among His Signs is the creation of the heavens and the earth, and the variations in your languages and your colours: verily in that are Signs for those who know.

There is arguably ample theological justification from the Islamic perspective for the important position and role of language and necessarily language education on the grounds that these are regarded as a vehicle for understanding His Signs manifested in the diversity of human languages. Language and language teaching and learning activities are to be used as a means of knowing people of different ethnics, colours, nationalities or cultural groups, sharing knowledge and ideas as well as facilitating mutual cooperation and good deeds as enjoined in the Quran.

From the above discussion, the next important issue is about the extent to which English can express Islamic worldviews and carry the weight of Muslim's cultural experiences. How English is used in Indonesia and Pakistan, as Kadarisman (2005) and Mahboob (2009) highlight respectively, may shed some light on the topic in question. Although Indonesian and Pakistan have different historical and sociopolitical backgrounds in relation particularly to how English is taught, learned and used, both countries are 
predominantly Muslim. In Indonesia's EFL context, as Kadarisman (2005) has observed, the 'divine presence', which is deeply rooted in verbal activities in the nation's sociocultural life, goes ineluctably into $\mathrm{MA} / \mathrm{PhD}$ theses written in English, full-fledged academic writings presumed to be 'conventionally' free from supernatural affairs. Take, for example, the following excerpts:

a) Alhamdulillahi rabbil 'alamiin. All praises and gratitude be to Allah, Lord of the 'Alamin. It is entirely because of Allah that I was able to finish writing this dissertation entitled ...

b) What has been existed ... in this dissertation is with the permission of the Lord of Universe. It is therefore to Allah SWT whom I, first of all, have to express my Thanks. Secondly, love and my prayers are hopefully expressed to our beloved Muhammad SAW, his family and companions. (ibid. p.15)

In the above examples, the 'divine presence' is identifiable in the Arabic words/phrases and the English expressions used, for instance, to praise or show gratitude to God and offer prayer to the Prophet. Abbreviations in Arabic are inserted and written as they are, potentially leaving audience unfamiliar with Indonesia's religio-cultural situation in the dark. Whether in Arabic or English, code-mixed with or switched to English, such culturally-laden expressions can be indicative of how the writers bring with them part of the Indonesian religio-cultural values and conventions. Sacred and daily mundane affairs seem so closely interrelated in the people's psyche that the transfer of culture-specific, religiously-inspired expressions to written scholarly works in English commonly associated with the secular world may, consciously or not, become the norm.

A similar phenomenon, as Mahboob (2009, p. 187) explains, can also be observed in $\mathrm{MA} / \mathrm{PhD}$ theses written by the users of Pakistani English as exemplified in the following excerpts:

c) This thesis was written by the guidance of Allah, who made the completion of this project possible...

d) All thanks to Almighty Allah, the sole creator and benefactor who endowed us with the gift of wisdom and bestowed on us the responsibility of exploring the infinitude of knowledge. And to Prophet Muhammad (peace be upon him) who showed us how to seek knowledge.

I feel great pleasure in paying my heartiest compliments to Prof. ... who helped me on each and every step of this research.

This reference to Allah and the Prophet, which is pervasively made not only in the $\mathrm{MA} / \mathrm{PhD}$ theses but also in English language textbooks, gives some evidence for the claim that English has been linguistically and culturally adapted to local cultural and religious norms in Pakistan and appropriated to express a Pakistani Muslim identity. The lexical, 
semantic and pragmatic dimensions of Pakistani English that reflect Muslim cultural practices include the use of such common expressions as Assalamu'alaikum (greeting), Masyaallah and Alhamdulillah (praise and appreciation), and In Shaa Allah in both personal exchanges and public discourses including English newspapers. Instead of being a colonizing language, Pakistani English has absconded from colonial messages and represented a language of opposition to colonial discourses. Mahboob (2009, p. 188) asserts that:

... the English language in Pakistan represents Islamic values and embodies South Asian Islamic sensitivities. ... On the basis of the analysis shared here, I believe that in some societies and cultures, English is indeed carrying the weight of Islamic experiences, cultures and ideologies.

The idea that English can be used to embody values and principles supposedly tied to another culture or worldview, such as the nature of English used to incorporate Islamic ideals and reflect Muslim identities in Indonesia and Pakistan, strongly resonates with an 'expanded view' of language proposed by Shohamy (2006). In this view, language is understood as 'an open, free, dynamic, creative and constantly evolving process with no defined boundaries, involving multi-modal representations and different forms of "languaging",' as opposed to what is commonly perceived as a 'closed, stagnated and rulebound entity' (p. xvii). Language is fluid, dynamic, creative, energetic, changing, fluctuating and varied in terms of the unique and different individual needs, characters, and personalities as well as of diverse social contexts, categories, and possibilities. Language is personal, uncontrollable and has no closed or static boundaries as with language people have a free choice with regard to infinite language features they can use, adapt, modify, and manipulate according to what suits them best in given context or to what they perceive as appropriate, convenient, effective, etc.

At the same time, language is social, interactive, dynamic and changing resulting in hybrids and countless varieties as people endlessly create, share, negotiate, approximate and re-create meanings for communication and creation as social creatures who use language in social contexts. In this line of argument, Liddicoat and Scarino $(2013 ; 2009)$ argue that understanding 'language as social practice' serves as a broader view of language to transcend ideas of a fixed set of linguistic structures and system of communication and accordingly helps language classrooms to escape from the constraint and restriction of the definitions of language it has commonly held and enacted in the teaching and learning processes. Language learners are from the beginning of the teaching and learning seen as 
independent users and analysers of language through which they present themselves as well as construct and explore their worlds as they engage in diverse and situated social practices and participate in the social life.

In short, the paths of EFL pedagogy and Islamic thoughts and traditions held and practiced by the locals in such a predominantly Muslim country as Indonesia ineluctably cross. The evidence obtained in this study has revealed that religious values and belief systems permeate the teaching and learning processes and feed into the actual use of English of the EFL teachers and learners. And yet in the current literature on an intercultural EFL pedagogy, there is a relatively limited discussion about the influence of religious faiths and particularly Islamic worldviews on the teachers' or students' conceptions and representations of culture and interculturality. The cases reported in the present study may then help spark a more extensive discussion on related issues.

\subsection{Summary}

In Chapter 5, I presented a cross-case discussion and analysis of salient themes within the data set. I arranged the discussion into four sections, i.e. i) teaching culture, enacting policy, ii) culture in the EFL classrooms, iii) EFL teachers as intercultural mediators, iv) EFL, Islam and interculturality. First, evidence shows that the Indonesian EFL teachers conception of culture and how they represented culture and interculturality in the local high-school EFL classrooms were influenced by the State policies on language, general education and EFL pedagogy. In Indonesia, language is regarded as the nation's cultural wealth and tied to the national existence and identity. Language-and-culture is understood as a solid and static entity in terms of a discrete, geographical block. The policies on language, general education and EFL pedagogy are mutually-informing and reflect the nation's underlying language ideology, feeding into the EFL teachers' assumptions about language and about English and its sociocultural baggage in particular. In turn, these beliefs and attitudes shape how the teachers approached culture, foreignness as well as values and behaviours associated with English and English speakers.

Second, the EFL teachers' approach to culture and interculturality intersected with the expected role of local EFL teachers and had an effect on their instructional decisions. The teachers implicitly or explicitly acknowledged the complex relationship between language and culture. They considered cultural appropriateness of expressions in English and local languages and related an effectiveness or otherwise of language use to interlocutor's cultural knowledge. Also, the EFL teachers tended to believe that some sociolinguistic 
values inherent in English are inconsistent with local beliefs and behaviours. In line with that belief, they sought to ensure that classroom materials are culturally acceptable to the students. The assumed incompatibility of home cultures and cultures of English-speaking countries drove the EFL teachers to act as "cultural guards". They selected and used classroom materials that are deemed culturally appropriate to the local society. Yet, the EFL teachers' recognition of language-and-culture nexus might not be explicitly translated into practices. Such a belief can instead be taken as a positive point of departure for introducing an interculturally-oriented EFL teaching and learning in the local socioeducational setting.

Third, the local EFL teachers showed an active agency in working with the complexities of culture and interculturality in the EFL classrooms amid the State hegemonic policies on language and education imposed. On the one hand, the EFL teachers compliance with the national policies may reflect the State powerful position in the centralised public education sector. On the other, their personal agency and pedagogic initiatives inside and beyond the classrooms were also visible in the ways they actively filtered out and adapted the classroom materials. They took account of situational and contextual factors in order that their practices and materials are not only practically suitable to the students' learning needs, but also fit for their sociolinguistic backgrounds and cultural expectations. Here, the EFL teachers served as intercultural mediators in that they displayed sensitivity to local cultural realities, built bridges between the students' existing knowledge and new conceptual systems, as well as navigating and mediating between host and target cultures.

Fourth, in the context of Indonesia as a predominantly Muslim country, the paths of EFL pedagogy and Islamic world view inevitably cross. Indonesia's education policy incorporates religiosity into the formal education. Religious and in particular Islamic ideas and practices permeate school and classroom discourses, including the EFL classes. In the observed classroom interactions, the Muslim EFL teachers and students used Islamic words and expressions to make sense of and connect with new concepts that come with English. Islamic belief systems enter into the actual use of English and the EFL teaching and learning processes in the local socio-educational setting, shaping both the EFL teachers' and students' conceptions and representations of culture and interculturality. 


\section{Chapter VI}

\section{Conclusion}

\subsection{Summary and concluding remarks}

The findings from the present study indicate that the Indonesian EFL teachers' pedagogic beliefs and classroom practices regarding the teaching and learning of culture and interculturality were influenced by the State policies on language, general education, and EFL pedagogy. That is, the prevailing policies and underlying ideologies feed into the EFL teachers' instructional judgments and decisions. Take for instance the official status of languages in Indonesia (i.e. national, local and foreign), the education systems and goals, the curriculum and character education, student core competencies and standard educational contents. These matters are governed by centrally-imposed laws and regulations. In this respect, the policies cannot be seen as neutral, considered in isolation from sociocultural, political, economic and religious forces at different levels, and devoid of ideological agenda (Liddicoat, 2013; Shohamy, 2006; Spolsky, 2012). Explicit or implicit ideology shapes and is shaped by the policies, which in turn impacts on the highschool EFL teachers' pedagogic beliefs and attitudes towards language-and-culture in general and towards English and its cultural baggage in particular.

Under current national policies, especially the 1945 Constitution and Language law, language is conceived of as an integral part of the nation's cultural wealth as well as of the national character and identity. English in Indonesia is expressly sanctioned as a "foreign language" and at the same time widely held as a politically, economically, and culturally dominant international language. Elsewhere, the prominence of the national and local languages is connected with the extent to which English lesson is allocated in formal education and the prevalence of English in the local society. On the one hand, English is associated with modern science, technological advancements and economic benefits; on the other, it is linked to alien values, hegemonic forces, or Westernisation (Coleman, 2016; Dardjowidjojo, 2001, 2006; Zentz, 2017). Language is fundamentally viewed more as form than as a dynamic set of social practices (Liddicoat \& Scarino, 2013), and culture more as static knowledge or information than as fluid and creative social forces (Holliday et al., 2010). Just as nation is imagined as a discrete entity confined to separate geographical blocks, language is understood as a static code with monolithic values. In this line of argument, it may come as no surprise if English continues to be viewed by some, if not many, EFL teachers and pupils alike as a language of English-speaking countries and to be 
rigidly tied to Western cultural values (Gandana, 2014; Zacharias, 2003, 2014a, 2014b). It may well be that this paradox has in one way or another coloured how the local EFL teachers conceptualise language-and-culture, approach English, and represent culture and interculturality in the local EFL classrooms.

Evidence obtained in this study also shows that the EFL teachers either implicitly or explicitly acknowledged an interrelationship between language and culture and tended to believe that some values inherent in English are oppositional to and can erode learners' cultural, moral or religious identities. These beliefs had led the EFL teachers to see themselves as 'cultural guards' apart from being 'merely' EFL teachers and to act accordingly in their teaching to safeguard the students' character. However, there was a gap between the EFL teachers' professed beliefs and observed practices in that an explicit discussion of culture was largely absent from the classrooms. Within the framework of the character education, for example, Aris expressly stated the need to directly integrate cultural, moral, and religious values into the classroom materials and teaching practices, yet he preferred implanting such values in the students in an implicit or indirect manner. In a similar vein, from an Islamic perspective Yanti stressed the importance of instilling local values in the learners and building their cultural and religious identity. Nonetheless, an explicit instruction of religio-cultural values was lacking. The other EFL teachers explained the belief-practice divergence as a consequence of a limited teaching-time, a heavy teaching load, and an examination-oriented education system.

While the absence of an explicit teaching and learning of culture may deprive students of a heightened awareness of and sensitivity to the cultural components of home and target languages, the teachers' acknowledgement of the language-culture nexus can be seen as an important affordance for bringing varied and complex manifestations of culture to the surface. Indeed, Indonesia's extraordinary cultural diversity, which showcases more than 500 ethnic and cultural groups and local vernaculars, can be a valuable point of departure for noticing and exploring the cultural dimensions of language and language use. Here, raising a deeper awareness of the largely unconscious socialization into first language-andculture entails a sustained, deliberate effort for the teachers and pupils. Only then will the EFL teachers and students be able to lay a basis for critically and constructively reflecting on and decentring from their own culturally-shaped frames of understanding, finding differences and similarities with other culture, and building bridge between native and target language-and-culture. 
Yet, amid the State hegemonic policies and a generally lack of explicit discussion of culture, the local EFL teachers displayed various pedagogic initiatives and active agency, largely in response to the immediate sociolinguistic, cultural, economic and religious factors as well as to the situated school and classroom dynamics. For instance, when presenting classroom materials or giving tasks, the EFL teachers took into account a variety of socio-educational aspects, including the teaching and learning goals, cultural appropriateness, the nationally-stipulated character traits, students' general academic and English competence, and their sociolinguistic background. Code-switchings and mixings involving Indonesian, Javanese or Madurese were commonplace. The learners deliberately drew on their home knowledge, languages, and prior experiences in order to come to grips with new and sometimes conflicting values, ideas, and practices that are commonly associated with English, the NSs of English, and English-speaking countries.

What can be reasonably inferred from the classroom events and interactions is a crucial role of home language-and-cultures as the students' learning resource and of the EFL teachers' mediation skill as intercultural speakers and mediators. Both the teachers and learners strategically used their existing knowledge and lived experiences manifested through first language-and-cultures as a springboard for making sense of likely differing concepts and ideas in English. In several instances, a variety of local foods (e.g. mie gelas, pecel, rawon, segá jagung, dadar gulung), ceremonies (e.g. akikah, hajian, tasyakuran), and specific expressions such as alhamdulillah, In Shaa Allah or Hormat gerak! were parts of classroom interactions, reflecting the normal use of the linguistic repertoire of multilinguals inside and outside the classrooms. Both the teachers and learners constantly navigated through and negotiated between the native and target language-and-cultures. This situation puts the onus on the teachers to sensitize themselves and the pupils to the cultural richness of their immediate sociolinguistic surroundings, the cultural significances of local practices, and to the influence of culturally-contexted frames of understanding on the communicative behaviours of local and target speech communities.

The data in this study too indicates that the EFL teachers did not share views on nativespeakerness and cultural authenticity. Wati and Yanti, for example, believed that the NSs of English are the more legitimate pedagogic models and the more authoritative resource persons due to their language competence and cultural knowledge. For Wati, the classroom materials that are made by and feature the NSs of English are more reliable than ones created by and involve the NNSs because "[the grammar, diction, and pronunciation of] the NSs are always correct." She benchmarked her English competence against the "NS 
competence," leaving her feeling "below international standards." Yanti also stressed the need to ask English NSs if her students have questions about English expressions with which she was not really familiar. Trying to find similar expressions by herself only made her feel worried about the accuracy of expressions through the eyes of English NSs.

Conversely, Ana thought there is no point in modelling herself and learners on the NS competence. Ana featured the NS and NNS characters, including senior students, and found the immediate socio-educational environment valuable to the processes of EFL teaching and learning situated in the local cultural, economic, political, and religious contexts. Shrugging off the importance of imitating the pronunciation, accent or speaking style of the NSs, Ana emphasized the value of her being an "authentic" Javanese Indonesian teacher and user of English and the students' being "authentic" (Indonesian) learner of English, working towards more achievable educational goals, and setting herself and other EFL teachers as a more realistic pedagogic model.

The EFL teachers' conflicting views discussed above point to an ever-disputed topic of NS-based notions of competence and authenticity in ELT, due in part to the intricacies of defining who "native speaker" really is, what constitutes "native speaker norms", or what characterises "authentic" communication (Alptekin, 2002; Kramsch, 1998, 2013a). As Kramsch (1998) notes, apart from stereotyped features of appearance and demeanour, native-speakerness is nothing less than an abstraction of arbitrarily selected features of the linguistic repertoire (including pronunciation, grammar, and lexicon) of monolingual monocultural speakers, and cultural authenticity varies according to a wide variety of sociocultural factors and contextual variables even in one national society.

Similarly, Cook $(1999,2017)$ argues that bi-/multilingual L2 speakers are different from monolingual NSs in their knowledge of L2 and L1 and in some of their cognitive processes. In this way, L2 learners and users can be regarded as speakers in their own right rather than as "failed NSs." In addition, NS-based notions are hardly tenable given the fact that English as an international language is now used by more NNSs in multilingual contexts than by NSs in English-speaking countries (Crystal, 2003; Graddol, 1997; McKay, 2002). Linking English competence and the cultural authenticity of language use rigidly to NS-based ideas may not only make EFL teachers and learners lose the opportunity to go beyond target-language culture, but it can also constrain the autonomy of the EFL teachers and students and devalue their own "authentic selves" as multilingual users of English (Kramsch, 1998; McKay, 2009; McKay \& Brown, 2016; Widdowson, 1996). 
Another salient point emerging from this study is a "large culture" paradigm (Holliday, 1999; Holliday et al., 2010), as evidenced by the policy documents and the teachers' reports. Some expressions like "budaya kita" (our culture), "budaya timur" (Eastern culture) or "budaya Muslim" (Muslim culture) were treated in a simplistic and polarised manner as opposed to "budaya mereka" (their culture), "budaya barat" (Western culture) or "budaya non-Muslim" (non-Muslim culture). In this sense, cultural beliefs, memberships, and behaviours are seen as entirely defined or constrained by externallyascribed "large" attributes such as nation, race or ethnicity (Holliday, 1999, 2005). Members of a certain culture are assumed to be homogenous and lumped together as if they behave in particularly similar ways. These essentialist views are especially prone to cultural prejudice and othering in which culturally different people are reduced to demeaning stereotypes and demonised others (Holliday, 2011, 2013).

In addition, the EFL teachers' reports and the classroom observations show an interplay of Islamic thoughts and cultural norms linked to English and Western culture. Religiosity is integrated into Indonesia's formal education, underlining the importance of religion for the people's life. Religious and especially Islamic ideas followed by the majority of the people permeate school and classroom discourses. EFL classes are no exception. By way of example, when practicing English speech acts, the learners subconsciously exchanged the Islamic greeting Assalamu'alaikum and mentioned akikah and tasyakuran, referring to the local baby welcoming ceremony and thanksgiving infused with Islamic teachings. The underlying processes at play here may involve the EFL teachers bringing buried cultural understandings to consciousness, building greater awareness of cultural differences, relating cultural attitudes and expectations entrenched in the local society to other people's values and belief systems and mediating differing perspectives.

However, some EFL teachers' preconceived ideas about English and their "large culture" perspective of Western culture could well be impediments to adopting an intercultural stance that advocates sparking genuine interest in and curiosity about other cultures, withholding judgments on culturally different others, and cultivating positive attitudes towards foreignness and cultural diversity (Byram, 1997, 2009; Byram et al., 2002). The Indonesian EFL teachers tended to see Western culture as unitary and homogenous, inherently different from home culture, and thus inconsistent with local values. These general attitudes might be closely related to the teachers' static view of language-and-culture and rigid link to the NS of English. 
By taking instead a non-essentialist "small culture" approach, the EFL teachers and learners can liberate language-and-culture from a particular culture, speech community, and NS-preoccupied notions (Holliday, 1999, 2005; Holliday et al., 2010). From the "small culture" perspective, language is viewed as social practice of meaning-making and interpreting that is open, dynamic, creative and constantly evolving rather than closed and fixed (Liddicoat \& Kohler, 2012; Liddicoat \& Scarino, 2013; Shohamy, 2006). Likewise, just as culture is attached to social groupings, large or small, wherever there is cohesive behaviour (Holliday, 1999; Holliday et al., 2010), this highlights the idea that cultures may be seen as 'varied, subjective and power-based constructions of lived experience' (Dervin \& Liddicoat, 2013, p. 7). Here, English can no longer be seen as an embodiment or carrier of so-called secular, English-speaking Western culture, which is intrinsically incompatible with religious worldviews and an Islamic way of life. Rather, English is conceived of as an open, fluid, flexible and free entity (Shohamy, 2006) with which people can creatively exploit, adapt, manipulate, and appropriate its infinite features to serve their multifarious personal and social needs, including describing religious experiences and expressing Islamic identity (Kadarisman, 2005; Karmani \& Pennycook, 2005; Mahboob, 2009; Mahboob \& Lin, 2016; Mohd-Asraf, 2005).

\subsection{Areas for further research}

This section explores some areas for further research and wider research implications derived from the key findings and overall research processes. I begin with a number of potential limitations to this study affecting its breadth and depth, which can be regarded as areas for improvement in future research. First, the time available for fieldwork was limited. I conducted the field work in around two and half months, despite my scholarship's time frame of two months. In addition to fitting data collection activities into the teacher participants' schedule, I had to ensure that the data collection methods, i.e. classroom observation, SR interviews, NF, and in-depth interviews, were carried out in sequence. This was in practical challenging. Because of a relatively limited time frame and conflicting schedules, four out of nine teacher participants could not participate in all the data collection activities and so were excluded in the next process. Five other participants managed to take part in all parts and stages of the data collection procedures, get involved in the case studies, and thus included in the data discussion and analysis.

A more significant consequence of the limited fieldwork time is perhaps that I only managed to conduct two to three classroom observations for each participant. As 
mentioned by the teachers, some interesting or potentially relevant classroom materials, topics or events were missed. In practice, this influenced what teacher practice or classroom events to show and ask in the SR and in-depth interviews and to explore in their self-reports. The more naturalistic classroom observation could be made, the more evidence could be gathered. This might facilitate further corroboration or validation of the teachers' professed beliefs against their teaching practices. Thus, a longer fieldwork time frame or a longitudinal data collection could produce more and richer data and, in turn, improve the quality of data triangulation.

A second limitation was that the participants had similar backgrounds and the research sites shared similar features. The teacher participants had relatively homogeneous cultural and professional backgrounds. All the four female and one male teacher participants were Javanese. Three of them were Muslim, one was Christian, and another one did not want to disclose her religious affiliation. Regarding their professional status, all teacher participants were certified teachers and had over 10 years' teaching experience. Despite the different types school, i.e. general, vocational and Islamic, all schools are state highschools rather than private ones. Some of these private schools are under or affiliated with certain religious foundations, primarily Muslim and Christian organisations.

The idea that more culturally and professionally diverse participants and research sites could offer more diverse experiences and perspectives was confirmed when a pilot participant, who was a novice teacher at a VHS with around three years' experience, appeared to provide potentially rich data. A "generation gap" could be at play here. The novice teacher seemed fairly familiar with and confident in intercultural contacts and learning opportunities her students might have in the use of information and communication technology, a specific issue which was generally absent from the experienced teachers' classroom events and interactions in this study. Another case in point might be when a student participant of the FGD shared his classroom experiences of a teacher who gave further explanation in Madurese and helped him understand better since Madurese is his first language.

Third, there was a limited student involvement. Because the focus of the study was on teachers, student participants were involved only in an FGD. This data collection method was initially designed to generate data from students as part of the corroboration and triangulation strategy. That is, students were to confirm or otherwise what their teachers were in fact doing in the classrooms. Apart from stressing the need to involve more diverse culturally and professional diverse participants, the student's experience mentioned above 
points to what they could in fact contribute to the findings. Not only did the students present a fuller picture of what was really happening and what the EFL teachers were actually doing in the classrooms, but they also managed to give valuable information about intercultural lived experiences inside and beyond their schools and English classrooms. Thus, a greater involvement of students in similar future research is likely to give fresh insights into the phenomenon under study.

In addition to the potential areas for future research described above, there are at least three key features which carry wider implications for educational stakeholders in the Indonesia's EFL setting and other similar EFL contexts. These include EFL learners, preservice and in-service teachers, teacher educators, curriculum designers, and policy makers. Foremost among such features is an explicit teaching and learning of culture. The data of the present study shows that deliberate, specific attention to and explicit discussion of culture was largely absent in the high-school EFL classroom events and interactions for various reasons. These include the belief that the discussion of cultural, moral and religious values within the framework of character education would be better conducted in an indirect or implicit manner. Some other reasons deal with practical consideration such as a relatively limited teaching time and a heavy teaching load. However, a substantial body of research and literature sees the need for language teachers to deliberately and explicitly address cultural components in their classrooms. Regardless of the reasons offered by the local EFL teachers, working deliberately and explicitly with the cultural aspects of language and language use can be three-fold: first, to highlight the language-culture relationship; second, to emphasise the importance of culture and culture teaching and learning in EFL education; and third, to recognise the place and validity of home languageand-culture in EFL pedagogy.

As previously noted, the Indonesian EFL teachers generally acknowledged the language-culture relationship. Both the teachers and students also benefited from a shared multilingualism, drawing productively on home knowledge, languages, and experiences. The remarkable cultural diversity of Indonesia can serve as a positive starting point and a rich source of cultural information. What this sociocultural phenomenon may mean is that local EFL teachers have in fact a good basis and valuable classroom resources for specifically and explicitly draw students' attention to the cultural dimensions of first and target language-and-culture in their teaching. For Byram et al. (2002), it is important that language teachers bring the basis of student's evaluative response to consciousness and make it explicit in order that they become more aware of their own values and how 
culturally-constructed understandings and behaviours operate in home and target cultures. Thus, the discussion and analysis of the teachers' cases in this study hopefully present a general, realistic picture of the potential advantages, opportunities, and challenges that the teachers have when consciously and explicitly working with culture and interculturality in their high-school EFL classrooms.

A second major feature is concerned with the teachers' conception of language and culture. The data shows that the implications of the teachers' views could be wide-ranging, from the ways the teachers selected and presented classroom materials, their perception about the dual professional role as a "language teacher" and a "cultural guard," the role of the NS/NNS in EFL pedagogy to the notion of cultural authenticity. That the teachers looked for and chose to use culturally appropriate materials, for instance, may stem from a conception that cultural values are implicit in language and that the values ostensibly entrenched in the target culture are incompatible with the local societies' values. Another example might be a NS-preoccupied idea of language competence and cultural authenticity. This implies a static approach to language and culture in which the English NSs are the ideal model and the legitimate source of language competence and cultural authenticity. This view can easily overlook the legitimacy and "authentic selves" of the students and EFL teachers as language learners and users. In this sense, the NS-based conceptions can be demotivating and constraining rather than encouraging and liberating. Thus, the teachers' current conceptions of language-and-culture could demand more serious attention from all the educational stakeholders concerned with teacher continuing professional development considering the broader and significant impacts, favourable or otherwise, that these are likely to create on the various aspects of the teaching and learning, including the teaching and learning objectives, attitudes towards foreignness and otherness, classroom decisions, and learning motivation.

Another significant feature that has possible wider implications is the discourse of "othering." As previously discussed, the teachers tended to view the culturally different English-speaking West through an overly simplistic and generalising lens. Such expressions as "our/their [culture]", "Eastern/Western [culture]" or "Muslim/non-Muslim" seem to be understood and used in a stereotypical, polarised manner. What the discourse has shown are inclinations towards reducing culturally different others to demeaning stereotypes, idealising selves and demonising others, that are also implicit in a "large culture" approach (Holliday, 2011, 2013). As Palfreyman (2005) observes, "othering" involves a particular group defining other groups in opposition to itself, maintains social 
distance, and makes value judgements, which are often negative, based on stereotypical images or representations of the group as a whole. Considering the damaging consequences of othering not only on intercultural communication but also, perhaps more importantly, on both the EFL teachers' and students' construct of culture and their perception of foreignness and diversity, it is imperative that, among other things, the different paradigms, understandings, and interpretations of language-and-culture be introduced to the EFL teachers and learners. This professional and cultural stance highlights the complexity, fluidity, and hybridity of language-and-culture as well as the need to abandon a reductionist, essentialist "large culture" approach to members of other culture (Holliday, 1999; Holliday et al., 2010; Kramsch, 2013a, 2013b; Kumaravadivelu, 2008; Liddicoat, 2002; Liddicoat et al., 2003).

The above ideas bear immediate relevance to a recent tragic event, i.e. family suicide bombings, taking place in Surabaya (Lamb, 2018; Lipson, 2018), my "second hometown", in the course of me writing this thesis. It was the first family suicide attack in Indonesia. Quoting police sources, some children of the bomber parents were not enrolled in public schools, but were in religiously closed home-schooling, in order to limit the children's exposure to outside influence (Damarjati \& Rinanda, 2018; Yulika, 2018). In the following crackdowns on terrorist cells in other cities, a civil-servant English teacher in a VHS was among the suspects arrested (Faisol, 2018; Rofiq, 2018). In this regard, EFL teachers could play a positive role given the fact that English in Indonesia is officially sanctioned as a compulsory school subject from junior high school onwards. By nature, such a foreign language education as English engages both the teachers and students with foreignness and otherness. The cultural, political and economic baggage that English brings and cultural behaviours that are often associated with it can be inconsistent with local values ingrained in the society and even perceived as a threat to their belief systems and behaviours. By realising the danger of and then fighting the discourse of 'othering,' EFL classrooms in Indonesia can and should therefore serve as fertile ground for the dissemination of informed understanding, genuine interest and curiosity, and constructive engagement with different cultures. 


\section{References}

A look at election in Indonesia, world's 3rd largest democracy and most populous Muslim nation. (2014, July 9). Retrieved July 17, 2017, from Associated Press website:

http://www.foxnews.com/world/2014/07/09/look-at-election-in-indonesia-world-3rdlargest-democracy-and-most-populous.html

Agar, M. H. (1996). Language shock: understanding the culture of conversation. New York: William Morrow Paperbacks.

Ahearn, L. M. (2017). Living Language: an introduction to linguistic anthropology (2nd ed.). Malden, MA: Wiley-Blackwell.

Al-Ammar, I. (2015, March 9). 'Insha Allah'-please don't fear this phrase! Retrieved June 16, 2018, from Arab News website: http://www.arabnews.com/columns/news/715716

Alho, L. (2010, December 19). The abused "Inshallah.” Retrieved June 16, 2018, from Blue Abaya website: https://www.blueabaya.com/2010/12/abused-inshallah.html

Ali, A. Y. (2016). The meaning of The Holy Qur'an. Beltsville, MD: Amana publications.

Ali, W. (2016, April 22). Inshallah is good for everyone. Retrieved June 16, 2018, from https://www.nytimes.com/2016/04/24/opinion/sunday/inshallah-is-good-for-everyone.html

Alisjahbana, S. T. (1976). Language planning for modernization: the case of Indonesian and Malaysian. The Hague, Netherlands: Mouton.

Allen, L. Q. (2002). Teachers' pedagogical beliefs and the standards for foreign language learning. Foreign Language Annals, 35(5), 518-529.

Alptekin, C. (2002). Towards intercultural communicative competence in ELT. ELT Journal, $56(1), 57-64$.

Alptekin, C. (2010). Redefining multicompetence for bilingualism and ELF. International Journal of Applied Linguistics, 20(1), 95-110.

Alqahtani, S. M. A. (2019). Teaching English in Saudi Arabia. In C. Moskovsky \& M. Picard (Eds.), English as a foreign language in Saudi Arabia: new insights into teaching and learning English (pp. 120-137). Oxon, UK: Routledge.

Alrahaili, M. (2019). Cultural and linguistic factors in the Saudi EFL context. In C. Moskovsky \& M. Picard (Eds.), English as a foreign language in Saudi Arabia: new insights into teaching and learning English (pp. 85-101). Oxon, UK: Routledge.

Al-Samarrai, S., Chang, M. C., Ragatz, A. B., Shaeffer, S., Stevenson, R., \& de Ree, J. (2013). Teacher reform in Indonesia: the role of politics and evidence in policy making. Washington DC: World Bank.

Altheide, D. L., \& Schneider, C. J. (2013a). Qualitative media analysis (2nd ed.). Thousand Oaks, CA: SAGE Publications, Inc.

Anderson, B. (2006). Imagined communities: reflections on the origin and spread of nationalism. London: Verso.

Armstrong, K. (2002). Islam: a short history. New York: Modern Library.

Badan Standar Nasional Pendidikan. (2006). Standar isi untuk satuan pendidikan dasar dan menengah - Standar kompetensi dan kompetensi dasar SMA/MA [Content standard of primary and secondary education - Competency standard and basic competency of general/Islamic high school].

Badger, R., \& MacDonald, M. (2010). Making it real: authenticity, process and pedagogy. Applied Linguistics, 31(4), 578-582.

Baldwin, J.R., Faulkner, S.L., Hecht, M.L., and Lindsley, S.L. (Eds.) (2006). Redefining culture: perspectives across the disciplines (2nd ed.). Mahwah, NJ: Lawrence Erlbaum.

Baker, W. (2009). The cultures of English as a lingua franca. TESOL Quarterly, 43(4), 567-592.

Barkhuizen, G. (2008). A narrative approach to exploring context in language teaching. ELT Journal, 62(3), 231-239.

Barkhuizen, G. (2014a). Narrative research in language teaching and learning. 47(4), 450-466.

Barkhuizen, G. (2014b). Revisiting narrative frames: an instrument for investigating language teaching and learning. System, 47, 12-27. 
Barkhuizen, G., Benson, P., \& Chik, A. (2014). Narrative inquiry in language teaching and learning research (1st ed.). New York: Routledge.

Barkhuizen, G., \& Wette, R. (2008). Narrative frames for investigating the experiences of language teachers. System, 36(3), 372-387.

Barnard, R., \& Burns, A. (2012). Introduction. In R. Barnard \& A. Burns (Eds.), Researching language teacher cognition and practice: international case studies (pp. 1-10). Bristol, UK: Multilingual Matters.

Basturkmen, H. (2012). Review of research into the correspondence between language teachers' stated beliefs and practices. System, 40(2), 282-295.

Batchelor, D. (2015, June 19). The Quran encourages scientific enquiry. Retrieved September 15, 2018, from NST Online website: https://www.nst.com.my/news/2015/09/quranencourages-scientific-enquiry

Bennett, M. J. (1997). How not to be a fluent fool: understanding the cultural dimension of language. In A. E. Fantini (Ed.), New ways in teaching culture (pp. 16-21). Alexandria: TESOL Publications.

Benson, P. (2014). Narrative inquiry in applied linguistics research. Annual Review of Applied Linguistics, 34, 154-170.

Bhaskara, Ign. L. A. (2018, October 19). Ancaman guru intoleran di Indonesia [Threat of Indonesia's intolerant teachers]. Retrieved December 29, 2018, from tirto.id website: https://tirto.id/ancaman-guru-intoleran-di-indonesia-c7Dc

Bianco, J. L., Liddicoat, A. J., \& Crozet, C. (Eds.). (1999). Striving for the third place: intercultural competence through language education. Melbourne: Language Australia.

Bloomberg, L. D., \& Volpe, M. F. (2008). Completing your qualitative dissertation: a roadmap from beginning to end. Los Angeles: SAGE Publications, Inc.

Borg, S. (2003). Teacher cognition in language teaching: a review of research on what language teachers think, know, believe, and do. Language Teaching, 36(2), 81-109.

Borg, S. (2006). Teacher cognition and language education: research and practice. London: Continuum.

Boyatzis, R. E. (1998). Transforming qualitative information: thematic analysis and code development. Thousand Oaks: SAGE Publications, Inc.

BPS-Statistics Indonesia (2018). Statistical Yearbook of Indonesia 2018. Jakarta, Indonesia; CV. Dharmaputra

Braine, G. (2010). Nonnative speaker English teachers: research, pedagogy, and professional growth. New York: Routledge.

Braine, G. (2013). The nonnative speaker (NNS) movement and its implications for ELT in Asia. In N. T. Zacharias \& C. Manara (Eds.), Contextualizing the pedagogy of English as an international language: issues and tensions (pp. 12-25). Newcastle upon Tyne, UK: Cambridge Scholars Publishing.

Braun, V., \& Clarke, V. (2006). Using thematic analysis in psychology. Qualitative Research in Psychology, 3(2), 77-101.

Braun, V., \& Clarke, V. (2012). Thematic analysis. In H. Cooper, P. M. Camic, D. L. Long, A. T. Panter, D. Rindskopf, \& K. J. Sher (Eds.), APA handbook of research methods in psychology, Vol 2: Research designs: Quantitative, qualitative, neuropsychological, and biological (pp. 57-71). Washington, DC: American Psychological Association.

Breen, M. P., Hird, B., Milton, M., Oliver, R., \& Thwaite, A. (2001). Making sense of language teaching: teachers' principles and classroom practices. Applied Linguistics, 22(4), 470501.

Brown, G., \& Yule, G. (1983). Teaching the spoken language. Cambridge, UK: Cambridge University Press.

Buck, G. (2001). Assessing listening. Cambridge, UK: Cambridge University Press.

Buendgens-Kosten, J. (2013). Authenticity in CALL: three domains of "realness." ReCALL, 25(2), 272-285.

Burns, A. (1992). Teacher beliefs and their influence on classroom practice. Prospect, 7(3), 56-65. 
Buttjes, D. (1991). Mediating languages and cultures: the social and intercultural dimension restored. In D. Buttjes \& M. Byram (Eds.), Mediating languages and cultures (pp. 3-16). Clevedon, England: Multilingual Matters.

Buttjes, D., \& Byram, M. (Eds.). (1991). Mediating languages and cultures. Clevedon, England: Multilingual Matters.

Byram, M. (1991). Teaching culture and language: towards an integrated model. In D. Buttjes \& M. Byram (Eds.), Mediating languages and cultures (pp. 17-30). Clevedon, UK: Multilingual Matters.

Byram, M. (1997). Teaching and assessing intercultural communicative competence. Clevedon, UK: Multilingual Matters Ltd.

Byram, M. (2009). Intercultural competence in foreign languages: the intercultural speaker and the pedagogy of foreign language education. In D. K. Deardorff (Ed.), The SAGE handbook of intercultural competence (pp. 321-332). Thousand Oaks: SAGE Publications, Inc.

Byram, M. (2012). Conceptualizing intercultural (communicative) competence and intercultural citizenship. In J. Jackson (Ed.), The Routledge handbook of language and intercultural communication (pp. 85-97). New York: Routledge.

Byram, M. (2015). Culture in foreign language learning - the implications for teachers and teacher training. In W. M. Chan, S. K. Bhatt, M. Nagami, \& I. Walker (Eds.), Culture and foreign language education: insights from research and implications for the practice (pp. 37-58). Boston: De Gruyter Mouton.

Byram, M., Gribkova, B., \& Starkey, H. (2002). Developing the intercultural dimension in language teaching: a practical introduction for teachers. Strasbourg: Council of Europe.

Byram, M., \& Risager, K. (1999). Language teachers, politics and cultures. Clevedon, England: Multilingual Matters.

Cahyani, H., Courcy, M. de, \& Barnett, J. (2016). Teachers' code-switching in bilingual classrooms: exploring pedagogical and sociocultural functions. International Journal of Bilingual Education and Bilingualism, 1-15.

Canagarajah, S. (2011). Codemeshing in academic writing: identifying teachable strategies of translanguaging. Modern Language Journal, 95, 401-417.

Canale, M. (1983). From communicative competence to communicative language pedagogy. In J. C. Richards \& R. W. Schmidt (Eds.), Language and communication (pp. 2-28). London: Routledge.

Canale, M., \& Swain, M. (1980). Theoretical bases of communicative approaches to second language teaching and testing. Applied Linguistics, I(1), 1-47.

Canh, L. V. (2015). Uncovering teachers' beliefs about intercultural language teaching: an example from Vietnam. The European Journal of Applied Linguistics and TEFL, 4(1), 83-103.

Celce-Murcia, M. (2007). Rethinking the role of communicative competence in language teaching. In E. A. Soler \& M. P. S. Jordá (Eds.), Intercultural language use and language learning (pp. 41-58). Dordrecht, The Netherlands: Springer.

Cenoz, J., \& Gorter, D. (2013). Towards a plurilingual approach in English language teaching: softening the boundaries between languages. TESOL Quarterly, 47(3), 591-599.

Chapter 2. Religiosity. (2008, September 17). Retrieved September 7, 2017, from Pew Research Center's Global Attitudes Project website: http://www.pewglobal.org/2008/09/17/chapter2-religiosity/

Clarke, V., \& Braun, V. (2014). Thematic analysis. In T. Teo (Ed.), Encyclopedia of critical psychology (pp. 1947-1952). New York: Springer.

Clarke, V., \& Braun, V. (2017). Thematic analysis. The Journal of Positive Psychology, 12(3), 297-298.

Cochran-Smith, M. (2003). Learning and unlearning: the education of teacher educators. Teaching and Teacher Education, 19, 5-28.

Coffey, A., \& Atkinson, P. (1996). Making sense of qualitative data: complementary research strategies. Thousand Oaks: SAGE Publications.

Coleman, H. (2016). The English language as Naga in Indonesia. In P. Bunce, P. R. Phillipson, V. Rapatahana, \& R. Tupas (Eds.), Why English?: Confronting the Hydra (pp. 59-71). London: Multilingual Matters. 
Constitution of Indonesia. (2016). In Wikipedia. Retrieved from

https://en.wikipedia.org/w/index.php?title=Constitution_of_Indonesia\&oldid=745453767

Cook, V. (1999). Going beyond the native speaker in language teaching. TESOL Quarterly, 33(2), $185-209$.

Cook, V. (2001). Using the first language in the classroom. Canadian Modern Language Review, $57(3), 402-23$.

Cook, V. (2007). The goals of ELT: reproducing native-speakers or promoting multicompetence among second language users? In J. Cummins \& C. Davison (Eds.), International handbook of English language teaching (1st ed., pp. 237-248). New York: Springer.

Cook, V. (2016). Second language learning and language teaching (5th ed.). London: Routledge.

Cook, V. (2017). What are the goals of language teaching? Iranian Journal of Language Teaching Research, 1(1), 44-56.

Corbett, J. (2003). An intercultural approach to English language teaching. Clevedon, UK: Multilingual Matters.

Creese, A., \& Blackledge, A. (2015). Translanguaging and identity in educational settings. 35, 20 35 .

Creswell, J. W. (2013). Qualitative inquiry and research design: choosing among five approaches (3rd ed.). Los Angeles: SAGE Publications, Inc.

Croker, R. A. (2009). An introduction to qualitative research. In J. Heigham \& R. A. Croker (Eds.), Qualitative research in applied linguistics: a practical introduction (pp. 3-24). Houndmills, UK: Palgrave Macmillan.

Crozet, C., \& Liddicoat, A. J. (1999). The challenge of intercultural language teaching: engaging with culture in the classroom. In A. J. Liddicoat, J. Lo Bianco, \& C. Crozet (Eds.), Striving for the third place: intercultural competence through language education (pp. 113-125). Melbourne: Language Australia.

Crozet, C., \& Liddicoat, A. J. (2000). Teaching culture as an integrated part of language: implications for the aims, approaches and pedagogies of language teaching. In A. J. Liddicoat \& C. Crozet (Eds.), Teaching languages, teaching cultures. Melbourne: Language Australia.

Crozet, C., Liddicoat, A. J., \& Bianco, J. L. (1999). Introduction: intercultural competence-from language policy to language education. In J. L. Bianco, A. J. Liddicoat, \& C. Crozet (Eds.), Striving for the third place: intercultural competence through language education (pp. 120). Melbourne: Language Australia.

Crystal, D. (2003). English as a global language (2nd ed.). Cambridge, UK: Cambridge University Press.

Crystal, D. (2008). Two thousand million? English Today, 24(1), 3-6.

Dailey-O'Cain, J., \& Liebscher, G. (2009). Teacher and student use of the first language in foreign classroom interaction: functions and applications. In M. Turnbull \& J. Dailey-O'Cain (Eds.), First language use in second and foreign language learning (pp. 131-144). Bristol, UK: Multilingual Matters.

Damarjati, D., \& Rinanda, H. M. (2018, May 15). Bomber Surabaya tak sekolahkan anak, ngakunya homeschooling [Surabaya bomber's children not entered in school, disguised as homeschooling]. Detiknews. Retrieved from https://news.detik.com/read/2018/05/15/103054/4020895/10/bomber-surabaya-taksekolahkan-anak-ngakunya-homeschooling

Damen, L. (2003). Closing the language and culture gap: an intercultural communicative perspective. In D. L. Lange \& R. M. Paige (Eds.), Culture as the core: perspective on culture in second language learning (pp. 71-88). Greenwich: Information Age Publishing.

Dardjowidjojo, S. (2000). English teaching in Indonesia. English Australia Journal, 18(1), 22-30.

Dardjowidjojo, S. (2001). Cultural constraints in the implementation of learner autonomy: the case of Indonesia. Journal of Southeast Asian Education, 2(2), 309-322.

Dardjowidjojo, S. (2006). The implementability of Western approaches in Eastern societies. Indonesian JELT, 2(1), 1-20. 
de Lotbinière, M. (2012, November 13). Indonesia to end teaching of English in primary schools. The Guardian. Retrieved from https://www.theguardian.com/education/2012/nov/13/eltdiary-november-indonesia-english

DeCapua, A., \& Wintergerst, A. C. (2004). Crossing cultures in the language classroom. Ann Arbor: University of Michigan Press/ELT.

DeCapua, A., \& Wintergerst, A. C. (2016). Crossing cultures in the language classroom (2nd ed.). University of Michigan Press ELT.

Denzin, N. K., \& Lincoln, Y. S. (2011). Introduction: the discipline and practice of qualitative research. In N. K. Denzin \& Y. S. Lincoln (Eds.), The SAGE handbook of qualitative research (4th ed., pp. 1-20). Thousand Oaks: SAGE Publications, Inc.

Dervin, F., \& Liddicoat, A. J. (2013). Introduction. In F. Dervin \& A. J. Liddicoat (Eds.), Linguistics for intercultural education (pp. 1-25). Amsterdam, The Netherlands: John Benjamins Publishing Company.

Ding, N. (2013). Study on Intercultural Teaching for EFL Teachers in China. In Y. Yang \& M. Ma (Eds.), Proceedings of the 2nd International Conference on Green Communications and Networks 2012 (GCN 2012): Volume 3 (pp. 527-532). Springer Berlin Heidelberg.

Dodd, C. H. (1998). Dynamics of intercultural communication (5th ed.). Boston: McGraw-Hill Humanities/Social Sciences/Languages.

Dörnyei, Z. (2007). Research methods in applied linguistics. Oxford: Oxford University Press.

Elyas, T., \& Badawood, O. (2016). English language educational policy in Saudi Arabia post 21st century: enacted curriculum, identity, and modernisation: a critical discourse analysis approach. FIRE: Forum for International Research in Education, 3(3), 70-81.

Esposito, J. L. (2010). Rethinking Islam and secularism. Retrieved from Pennsylvania State University website: http://www.thearda.com/rrh/papers/guidingpapers/Esposito.pdf

Esposito, J. L., \& Mogahed, D. (2007). Who speaks for Islam? What a billion Muslims really think. New York: Gallup Press.

Faisol, A. (2018, May 17). PNS terduga teroris Probolinggo adalah guru Bahasa Inggris di SMK [Probolinggo's suspect terrorist civil servant is VHS English teacher]. Retrieved from https://regional.kompas.com/read/2018/05/17/21030121/pns-terduga-teroris-probolinggoadalah-guru-bahasa-inggris-di-smk

Fantini, A. E. (1997). Language: its cultural and intercultural dimensions. In A. E. Fantini (Ed.), New Ways in Teaching Culture (pp. 3-15). Alexandria, Va.: TESOL Publications.

Fantini, A. E. (2012). Language: an essential component of intercultural communicative competence. In J. Jackson (Ed.), The Routledge handbook of language and intercultural communication (pp. 263-278). New York: Routledge.

Fantini, A. E., \& Tirmizi, A. (2006). Exploring and assessing intercultural competence. Retrieved from http://digitalcollections.sit.edu/worldlearning_publications/1

Farrell, T., \& Bennis, K. (2013). Reflecting on ESL teacher beliefs and classroom practices: a case study. RELC Journal, 44(2), 163-176.

Farrell, T., \& Lim, P. C. (2005). Conceptions of grammar teaching: a case study of teachers' beliefs and classroom practices. TESL-EJ: Teaching English as a Second or Foreign Language, $9(2)$.

Ferguson, G. (2006). Language planning and education. Edinburgh: Edinburgh University Press.

Ferguson, G. (2012). English in language policy and management. In B. Spolsky (Ed.), The Cambridge handbook of language policy (pp. 475-498). Cambridge: Cambridge University Press.

Finegan, E. (2009). English. In B. Comrie (Ed.), The world's major languages (1st ed., pp. 59-85). New York: Routledge.

Gandana, I. S. S. (2014). ELT, interculturality and teacher identity: an inquiry into Indonesian university teachers' beliefs and practices (Thesis, Monash University. Faculty of Education. Department of Education). Retrieved from http://arrow.monash.edu.au/vital/access/manager/Repository/monash:130819

Gass, S. M., \& Mackey, A. (2000). Stimulated recall in second language research. Mahwah, NJ: Lawrence Erlbaum Associates, Publishers. 
Gay, G. (2010). Culturally responsive teaching: theory, research, and practice (2nd ed.). New York: Teachers College Press.

Gerring, J. (2007). Case study research: principles and practices. New York: Cambridge University Press.

Gilmore, A. (2007). Authentic materials and authenticity in foreign language learning. Language Teaching, 40(2), 97-118.

Graddol, D. (1997). The future of English. The British Council.

Graddol, D. (1999). The decline of the native speaker. In U. H. Meinhof \& D. Graddol (Eds.), English in a changing world (AILA Review). Milton Keynes: English Company.

$\mathrm{Gu}, \mathrm{X}$. (2016). Assessment of intercultural communicative competence in FL education: a survey on EFL teachers' perception and practice in China. Language and Intercultural Communication, 16, 1-20.

Guba, E. G., \& Lincoln, Y. S. (1994). Competing paradigms in qualitative research. In N. K. Denzin \& Y. S. Lincoln (Eds.), Handbook of qualitative research (pp. 105-117). Thousand Oaks: SAGE Publications, Inc.

Guba, E. G., \& Lincoln, Y. S. (2005). Paradigmatic controversies, contradictions, and emerging confluences. In N. K. Denzin \& Y. S. Lincoln (Eds.), The SAGE handbook of qualitative research (3rd ed., pp. 191-216). Thousand Oaks: Sage Publications, Inc.

Hall, E. T., \& Hall, M. R. (1990). Understanding cultural differences: Germans, French and Americans. Boston: Intercultural Press.

Haviland, W. A., Prins, H. E. L., Walrath, D., \& McBride, B. (2005). Cultural anthropology: The human challenge (11th ed.). Belmont: Wadsworth.

Heigham, J., \& Croker, R. A. (Eds.). (2009). Qualitative research in applied linguistics: a practical introduction. Houndmills, UK: Palgrave Macmillan.

Heryanto, A. (2006). Then there were languages: Bahasa Indonesia was one among many. In S. Makoni \& A. Pennycook (Eds.), Disinventing and reconstituting languages (pp. 42-61). Clevedon, UK: Multilingual Matters.

Holliday, A. (1994). Appropriate methodology and social context. Cambridge: Cambridge University Press.

Holliday, A. (1999). Small cultures. Applied Linguistics, 20(2), 237-64.

Holliday, A. (2005). The struggle to teach English as an international language. Oxford: Oxford University Press.

Holliday, A. (2006). Native-speakerism. ELT Journal, 60(4), 385-87.

Holliday, A. (2007). Doing and writing qualitative research (2nd ed.). London: SAGE Publications Ltd.

Holliday, A. (2009). The role of culture in English language education: key challenges. Language and Intercultural Communication, 9(3), 144-155.

Holliday, A. (2011). Intercultural communication and ideology. London: SAGE Publications Ltd.

Holliday, A. (2013). Understanding intercultural communication: negotiating a grammar of culture. London: Routledge.

Holliday, A. (2016). Studying culture. In Z. Hua (Ed.), Research methods in intercultural communication: a practical guide (pp. 23-36). West Sussex, UK: Wiley-Blackwell.

Holliday, A., Kullman, J., \& Hyde, M. (2010). Intercultural communication: an advanced resource book for students (2nd ed.). London: Routledge.

Holmes, J. (2013). An introduction to sociolinguistics (4th ed.). Harlow, UK: Routledge.

Holmes, J., \& Wilson, N. (2017). An introduction to sociolinguistics (5th ed.). Oxon, UK: Taylor \& Francis.

Holmes, P. (2014). The (inter)cultural turn in foreign language teaching. In N. Pachler \& A. Redondo (Eds.), A practical guide to teaching modern foreign languages in the secondary school (2nd ed., pp. 76-86). London: Routledge.

Honna, N. (2005). English as a multicultural language in Asia and intercultural literacy. Intercultural Communication Studies, XIV(2), 73-89.

Hood, M. (2009). Case study. In J. Heigham \& R. A. Croker (Eds.), Qualitative research in applied linguistics: a practical introduction (pp. 66-90). Houndmills, UK: Palgrave Macmillan. 
Hornberger, N. H., \& Link, H. (2012). Translanguaging in today's classrooms: a biliteracy lens. Theory into Practice, 51(4), 239-247.

Houghton, S. (2010). Savoir se transformer: knowing how to become. In S. Houghton \& Y. Tsai (Eds.), Becoming intercultural: inside and outside the classroom (pp. 194-228). Newcastle upon Tyne, England: Cambridge Scholars.

Hua, Z. (2016). Identifying research paradigms. In Z. Hua (Ed.), Research methods in intercultural communication: a practical guide (pp. 3-22). West Sussex, UK: Wiley-Blackwell.

Hymes, D. (1972). On communicative competence. In J. B. Pride \& J. Holmes (Eds.), Sociolinguistics: selected readings (pp. 269-293). Harmondsworth: Penguin.

Indonesia population 2018. (2018, July 18). Retrieved September 6, 2018, from http://worldpopulationreview.com/countries/indonesia-population/

Inshallah. (2018, July 17). Retrieved September 3, 2018, from Wikipedia website: https://en.wikipedia.org/w/index.php?title=Inshallah\&oldid=850694589

International-standard school unconstitutional: MK. (2013, January 8). Retrieved from http://www.thejakartapost.com/news/2013/01/08/international-standard-schoolunconstitutional-mk.html

Irving, T. B. (1991). The Noble Qur'an: Arabic text and English Translation. Brattleboro, Vt.: Amana Books.

Iskandar, S., Ree, J. D., \& Al-Samarrai, S. (2012). Teacher certification in Indonesia: a doubling of pay, or a way to improve learning? (No. 73264) (pp. 1-6). The World Bank. Retrieved from http://documents.worldbank.org/curated/en/422651468285048834/Teachercertification-in-Indonesia-a-doubling-of-pay-or-

Islam in Indonesia. (2018, September 1). Retrieved September 6, 2018, from Wikipedia website: https://en.wikipedia.org/w/index.php?title=Islam_in_Indonesia\&oldid=857611621

Jackson, J. (2014). Introducing language and intercultural communication. London: Routledge.

Jackson, J. (2016). Ethnography. In Z. Hua (Ed.), Research methods in intercultural communication: a practical guide (pp. 239-254). West Sussex, UK: Wiley-Blackwell.

Johnson, D. C. (2013). Language policy. Houndmills: Palgrave Macmillan.

Kabupaten Pendalungan. (2016). Retrieved October 22, 2016, from Wikipedia bahasa Indonesia, ensiklopedia bebas website: https://id.wikipedia.org/w/index.php?title=Kabupaten_Jember\&oldid=11520191

Kadarisman, A. E. (2005). Linguistic relativity, cultural relativity, and foreign language teaching. TEFLIN Journal, 16(1), 1-25.

Kagan, D. M. (1990). Ways of evaluating teacher cognition: inferences concerning the Goldilocks principle. Review of Educational Research, 60(3), 419-469.

Kagan, D. M. (1992). Implications of research on teacher belief. Educational Psychologist, 27(1), 65-90.

Karmani, S., \& Pennycook, A. (2005). Islam, English, and 9/11. Journal of Language, Identity \& Education, 4(2), 157-172.

Kementerian Pendidikan dan Kebudayaan. Peraturan Menteri Pendidikan dan Kebudayaan RI No. 22 Tahun 2006 [Regulation of Minister of Education and Culture of the Republic of Indonesia No. 22 of 2006]., (2006).

Kementerian Pendidikan dan Kebudayaan. Peraturan Menteri Pendidikan dan Kebudayaan RI No. 69 Tahun 2013 tentang Kerangka Dasar dan Struktur Kurikulum Sekolah Menengah Atas/Madrasah Aliyah [Regulation of Minister of Education and Culture No. 69/2013 on General/Islamic High School Curriculum Basic Framework and Structure]., (2013).

Kementerian Pendidikan dan Kebudayaan. Peraturan Menteri Pendidikan dan Kebudayaan RI No. 70 Tahun 2013 tentang Kerangka Dasar dan Struktur Kurikulum Sekolah Menengah Kejuruan/Madrasah Aliyah Kejuruan [Regulation of Minister of Education and Culture No. 70/2013 on Vocational/Islamic Vocational High School Curriculum Basic Framework and Structure]., (2013).

Kementerian Pendidikan dan Kebudayaan. Peraturan Menteri Pendidikan dan Kebudayaan RI No. 20 Tahun 2016 tentang Standar Kompetensi Lulusan Pendidikan Dasar dan Menengah [Regulation of Minister of Education and Culture No. 20/2016 on Standard Competency of Primary and Secondary School Graduates., (2016). 
Kementerian Pendidikan dan Kebudayaan. Peraturan Menteri Pendidikan dan Kebudayaan RI No. 21 Tahun 2016 tentang Standar Isi Pendidikan Dasar dan Menengah [Regulation of Minister of Education and Culture No. 21/2016 on Standard Content of Primary and Secondary Education]., (2016).

Kementerian Pendidikan Nasional. (2010). Pengembangan pendidikan budaya dan karakter bangsa [The development of national culture and character education]. Jakarta, Indonesia: Kementerian Pendidikan Nasional.

Kementerian Pendidikan Nasional. (2011). Pedoman pelaksanaan pendidikan karakter [Guidelines for the implementation of character education]. Jakarta, Indonesia: Kementerian Pendidikan Nasional.

Kirkpatrick, A. (2006). Asian Englishes: implications for English language teaching. Asian Englishes, 9(2), 4-19.

Kirkpatrick, A. (2014). Teaching English in Asia in non-Anglo cultural contexts: principles of the "Lingua Franca Approach." In R. Marlina \& R. Giri (Eds.), The pedagogy of English as an international language: perspectives from scholars, teachers, and students (pp. 23-34). New York: Springer.

Kirkpatrick, A., \& Sussex, R. (2012). Introduction. In A. Kirkpatrick \& R. Sussex (Eds.), English as an International Language in Asia: Implications for Language Education (pp. 1-12). Dordrecht, The Netherlands: Springer.

Kirkpatrick, R., \& Barnawi, O. Z. (2017). Introduction: English language education policy in MENA. In R. Kirkpatrick (Ed.), English language education policy in the Middle East and North Africa (pp. 1-8). Cham, Switzerland: Springer.

Kohler, M. (2015). Teachers as mediators in the foreign language classroom. Bristol, UK: Multilingual Matters.

Kramsch, C. (1993). Context and culture in language teaching. Oxford, UK: Oxford University Press.

Kramsch, C. (1995). The cultural component of language teaching. Language, Culture and Curriculum, 8(2), 83-92.

Kramsch, C. (1998). Language and culture. Oxford, UK: Oxford University Press.

Kramsch, C. (2009). The multilingual subject. Oxford, UK: Oxford University Press.

Kramsch, C. (2013a). Culture in foreign language teaching. Iranian Journal of Language Teaching Research, 1(1), 57-78.

Kramsch, C. (2013b). Language and culture in second language learning. In J. Jackson (Ed.), The Routledge handbook of language and intercultural communication (pp. 403-415). New York: Routledge.

Kramsch, C. (2014a). Language and culture. AILA Review, 27, 30-55.

Kramsch, C. (2014b). Language and culture in second language learning. In F. Sharifian (Ed.), The Routledge handbook of language and culture (1st ed., pp. 403-416). London, UK: Routledge.

Kramsch, C. (2014c). Teaching foreign languages in an era of globalization: introduction. The Modern Language Journal, 98(1), 296-311.

Kramsch, C. (2014d). The challenge of globalization for the teaching of foreign languages and cultures. Electronic Journal of Foreign Language Teaching, 11(2), 249-254.

Kramsch, C., \& Hua, Z. (2016). Language and culture in ELT. In G. Hall (Ed.), The Routledge Handbook of English language teaching (pp. 38-50). New York: Routledge, Taylor \& Francis Group.

Kramsch, C., \& Sullivan, P. (1996). Appropriate pedagogy. ELT Journal, 50(3), 199-212.

Kroeber, A.L. and Kluckhohn, C. (1952). Culture: a critical review of concepts and definitions> Cambridge: The Museum.

Kumaravadivelu, B. (2001). Toward a postmethod pedagogy. TESOL Quarterly, 35(4), 537-560.

Kumaravadivelu, B. (2003). Beyond methods: macrostrategies for language teaching. New Haven: Yale University Press.

Kumaravadivelu, B. (2006). Understanding language teaching: from method to postmethod. Mahwah, NJ: Routledge. 
Kumaravadivelu, B. (2008). Cultural globalization and language education. New Haven: Yale University Press.

Kumaravadivelu, B. (2012). Language teacher education for a global society: a modular model for knowing, analyzing, recognizing, doing, and seeing. New York: Routledge.

Kuswandono, P., Gandana, I., \& Rohani, S. (2015). Towards deimperialization of instructional strategies: cases of task-based learning and reflextive practice implementation in the Indonesian context. In H. Zhang, P. W. K. Chan, \& J. Kenway (Eds.), Asia as method in education studies: a defiant research imagination (pp. 97-110). Oxon, UK: Routledge.

Lamb, K. (2018, May 19). The bombers next door: how an Indonesian family turned into suicide attackers. The Guardian. Retrieved from https://www.theguardian.com/world/2018/may/19/indonesia-blasts-surabaya-family-fromgood-neighbours-suicide-bombers

Lantolf, J. P. (2000). Second language learning as a mediated process. Language Teaching: The International Abstracting Journal for Language Teachers, Educators and Researchers, 33(2), 79-96.

Lauder, A. (2008). The status and function of English in Indonesia. Makara, Sosial Humaniora, 12(1), 9-20.

Leaman, O. (2018). Apostasy. Retrieved September 13, 2018, from The Oxford Encyclopedia of the Islamic World website: http://www.oxfordislamicstudies.com/article/opr/t236/e0066?_hi=3\&_pos=2

Leganger-Krogstad, H. (2011). The religious dimension of intercultural education: contributions to a contextual understanding. Vienna: LIT Verlag.

Liddicoat, A. J. (2002). Static and dynamic views of culture and intercultural language acquisition. Babel, 36(3), 4-11.

Liddicoat, A. J. (2004). Intercultural language teaching: principles for practice. The New Zealand Language Teacher, (30), 17-23.

Liddicoat, A. J. (2007). Modern languages: learning and teaching in an intercultural field by Alison Phipps and Mike Gonzales. Journal of Language, Identity \& Education, 6(3), 250-253.

Liddicoat, A. J. (2011). Language teaching and learning from an intercultural perspective. In E. Hinkel (Ed.), Handbook of research in second language teaching and learning: Vol. II (pp. 837-855). New York: Routledge.

Liddicoat, A. J. (2013). Language-in-education policies: the discursive construction of intercultural relations. Bristol, UK: Multilingual Matters.

Liddicoat, A. J., Crozet, C., \& Bianco, J. L. (1999). Conclusion: striving for the third placeconsequences and implications. In A. J. Liddicoat, J. L. Bianco, \& C. Crozet (Eds.), Striving for the third place: intercultural competence through language education (pp. 181-187). Melbourne: Language Australia.

Liddicoat, A. J., \& Kohler, M. (2012). Teaching Asian languages from an intercultural perspective: building bridges for and with students of Indonesian. In K. Cadman \& X. Song (Eds.), Bridging transcultural divides: Asian languages and cultures in global higher education (pp. 73-100). Adelaide: University of Adelaide Press.

Liddicoat, A. J., Papademetre, L., Scarino, A., \& Kohler, M. (2003). Report on intercultural language learning. Canberra, Australia: Department of Education, Science and Training (DEST).

Liddicoat, A. J., \& Scarino, A. (2013). Intercultural language teaching and learning. West Sussex, UK: Wiley-Blackwell.

Lie, A. (2007). Education policy and EFL curriculum in Indonesia. TEFLIN Journal, 18(1), 1-14.

Lincoln, Y. S., \& Guba, E. G. (1985). Naturalistic inquiry. Beverly Hills: SAGE Publications.

Lincoln, Y. S., Lynham, S. A., \& Guba, E. G. (2011). Paradigmatic controversies, contradictions, and emerging confluences, revisited. In N. K. Denzin \& Y. S. Lincoln (Eds.), The SAGE handbook of qualitative research (4th ed., pp. 97-128). Thousand Oaks: SAGE Publications, Inc.

Lipson, D. (2018, May 14). Surabaya bombings: neighbours say family responsible seemed like "ordinary" people. Retrieved from ABC News website: http://www.abc.net.au/news/201805-14/indonesia-church-attacks-joko-widodo-orders-investigation/9757512 
Littlewood, W., \& Yu, B. (2011). First language and target language in the foreign language classroom. Language Teaching, 44(1), 64-77.

Liu, S., Volčič, Z., \& Gallois, C. (2015). Introducing intercultural communication: global cultures and contexts (2nd ed.). London: SAGE Publications Ltd.

Liu, Y.-F. C. (2016). Cultural collision: the interference of first language cultural identity on pragmatic competence of the target language. GIST Education and Learning Research Journal, (13), 131-147.

Lowe, R. J., \& Pinner, R. (2016). Finding the connections between native-speakerism and authenticity. Applied Linguistics Review, 7(1), 27-52.

Lowenberg, P. H. (1991). English as an additional language in Indonesia. World Englishes, 10(2), $127-138$.

Maarif, A. S. (2015). Islam dalam bingkai keindonesiaan dan kemanusiaan [Islam within the framework of Indonesianness and humanity] (2nd ed.). Bandung, Indonesia: Mizan.

Macaro, E. (2009). Teacher use of codeswitching in the second language classroom: exploring 'optimal' use. In M. Turnbull \& J. Dailey-O'Cain (Eds.), First language use in second and foreign language learning (pp. 35-49). Bristol, UK: Multilingual Matters.

MacDonald, M. N., Badger, R., \& Dasli, M. (2009). Authenticity, culture and language learning. Language and Intercultural Communication, 6(3-4), 250-261.

Mahboob, A. (2009). English as an Islamic language: a case study of Pakistani English. World Englishes, 28(2), 175-189.

Mahboob, A., \& Lin, A. M. Y. (2016). Using local languages in English language classrooms. In W. A. Renandya \& H. P. Widodo (Eds.), English language teaching today: linking theory and practice (pp. 25-40). Switzerland: Springer.

Mahkamah Konstitusi. Putusan Nomor 5/PUU-X/2012. , (2013).

Mambu, J. E. (2014). Negotiating the place of spirituality in English language teaching: a case study in an Indonesian EFL teacher education program (Arizona State University). Retrieved from http://search.proquest.com/docview/1640934446/

Mambu, J. E. (2016). Investigating students' negotiation of religious faiths in ELT contexts: a critical spiritual pedagogy perspective. Critical Inquiry in Language Studies, 13(3), 157182.

Mambu, J. E. (2017). Creatively negotiating the place of spirituality in the ELT classroom. TEFLIN Journal, 28(1), 93-114.

Manara, C. (2014). Intercultural dialogue on English language teaching: multilingual teacher educator's narrative of professional learning. Newcastle upon Tyne, UK: Cambridge Scholars Publishing.

McKay, S. L. (2002). Teaching English as an international language. Oxford: Oxford University Press.

McKay, S. L. (2003). Toward an appropriate EIL pedagogy: re-examining common ELT assumptions. International Journal of Applied Linguistics, 13(1), 1-22.

McKay, S. L. (2004). Teaching English as an international language: the role of culture in Asian contexts. The Journal of AsiaTEFL, 1(1), 1-22.

McKay, S. L. (2006). Researching second language classrooms. Mahwah, NJ: Routledge.

McKay, S. L. (2009). Pragmatics and EIL pedagogy. In F. Sharifian (Ed.), English as an international language: perspectives and pedagogical issues (pp. 227-241). Bristol, UK: Multilingual Matters.

McKay, S. L. (2011). English as an international lingua franca pedagogy. In E. Hinkel (Ed.), Handbook of research in second language teaching and learning: volume 2 (pp. 122-139). Mahwah, N.J.: Routledge.

McKay, S. L. (2012). English as an international language. In J. C. Richards \& A. Burns (Eds.), The Cambridge guide to pedagogy and practice in second language teaching (pp. 15-22). New York: Cambridge University Press.

McKay, S. L. (2018). English as an international language: what it is and what it means for pedagogy. RELC Journal, 1-15.

McKay, S. L., \& Bokhorst-Heng, W. D. (2008). International English in its sociolinguistic contexts: towards a socially sensitive EIL pedagogy. New York: Routledge. 
McKay, S. L., \& Brown, J. D. (2016). Teaching and assessing EIL in local contexts around the world. New York: Routledge.

Medgyes, P. (1992). Native or non-native: who's worth more? ELT Journal, 46(4), 340-349.

Medgyes, P. (1994). The non-native teacher. Hong Kong: Macmillan Publishers Ltd.

Medgyes, P. (2001). When the teacher is a non-native speaker. In M. Celce-Murcia (Ed.), Teaching English as a second or foreign language (3rd ed., pp. 415-428). Boston: Heinle \& Heinle.

Medgyes, P. (2017). The non-native teacher (3rd ed.). Callander, UK: Swan Communication Ltd.

Merriam, S. B. (2009). Qualitative research: a guide to design and implementation (3rd ed.). San Francisco: Jossey-Bass.

Merriam, S. B., \& Tisdell, E. J. (2016). Qualitative research: a guide to design and implementation (4th ed.). San Francisco, CA: Jossey-Bass.

Mertens, D. M. (2009). Research and evaluation in education and psychology: integrating diversity with quantitative, qualitative, and mixed methods (3 rd.). Los Angeles: SAGE Publications, Inc.

Mistar, J. (2005). Teaching English as a foreign language (TEFL) in Indonesia. In G. Braine (Ed.), Teaching English to the world: history, curriculum, and practice (pp. 71-80). Mahwah, NJ: Lawrence Erlbaum.

Mohd-Asraf, R. (2005). English and Islam: a clash of civilizations? Journal of Language, Identity \& Education, 4(2), 103-118.

Moloney, R., \& Harbon, L. (2010). Making intercultural language learning visible and assessible. 1, 281-303. Retrieved from http://cercll.webhost.uits.arizona.edu/_media/development/conferences/2010_icc/moloney harbon.pdf

Moore, P. J. (2013). An emergent perspective on the use of the first language in the English as-aforeign-language classroom. Modern Language Journal, 97(1), 239-253.

Moran, P. (2001). Teaching culture: perspectives in practice. Boston: Heinle ELT.

Moskovsky, C., \& Picard, M. (2019). Introduction. In C. Moskovsky \& M. Picard (Eds.), English as a foreign language in Saudi Arabia: new insights into teaching and learning English (pp. 1-3). Oxon, UK: Routledge.

Murray, G. (2009). Narrative inquiry. In J. Heigham \& R. A. Croker (Eds.), Qualitative research in applied linguistics: a practical introduction (pp. 45-65). Houndmills, UK: Palgrave Macmillan.

Nababan, P. W. J. (1991). Language in education: the case of Indonesia. International Review of Education, 37(1), 115-131.

Nespor, J. (1987). The role of beliefs in the practice of teaching. Journal of Curriculum Studies, 19(4), 317-328.

Newton, J. (2008). Adapting authentic workplace talk for workplace intercultural communication training. In H. Kotthoff, H. Spencer-Oatey, \& K. Knapp (Eds.), Handbook of intercultural communication (pp. 519-535). Berlin, Germany: De Gruyter, Inc.

Newton, J. (2016). Teaching English for intercultural spoken communication. In W. A. Renandya \& H. P. Widodo (Eds.), English language teaching today: linking theory and practice (pp. 161-177). Switzerland: Springer.

Newton, J., Yates, E., Shearn, S., \& Nowitzki, W. (2010). Intercultural communicative language teaching: implications for effective teaching and learning. Report to the Ministry of Education, New Zealand. Retrieved from http://thehub.superu.govt.nz/sites/default/files/42419_iCLT-Full-Report-final-draft_0.doc

Nguyen, L., Harvey, S., \& Grant, L. (2016). What teachers say about addressing culture in their EFL teaching practices: the Vietnamese context. Intercultural Education, 27(2), 165-178.

Nunan, D. (2013). What is this thing called language? (2nd ed.). Houndmills, UK: Palgrave Macmillan.

Osman, H. A. (2015). Investigating English teachers' perceptions of intercultural communicative competence in the Kingdom of Saudi Arabia. University of San Francisco, San Francisco.

Otheguy, R., García, O., \& Reid, W. (2015). Clarifying translanguaging and deconstructing named languages: a perspective from linguistics. Applied Linguistics Review, 6(3), 281-307. 
Otheguy, R., García, O., \& Reid, W. (2018). A translanguaging view of the linguistic system of bilinguals. Applied Linguistics Review. http://dx.doi.org/10.1515/applirev-2018-0020

Pajares, M. F. (1992). Teachers' beliefs and educational research: cleaning up a messy construct. Review of Educational Research, 62(3), 307-332.

Palfreyman, D. (2005). Othering in an English language program. TESOL Quarterly, 39(2), 211233.

Palmer, G., \& Chodidjah, I. (2011). Training the pesantren: intercultural materials for Islamic boarding schools in Indonesia. In T. Muller, S. Herder, J. Adamson, \& P. S. Brown (Eds.), Innovating EFL Teaching in Asia (pp. 35-48). Basingstoke, UK: Palgrave Macmillan.

Parlina, I., \& Aritonang, M. S. S. (2013, January 9). Court rules international-standard schools illegal for unequal access. The Jakarta Post. Retrieved from http://www.thejakartapost.com/news/2013/01/09/court-rules-international-standardschools-illegal-unequal-access.html

Patton, M. Q. (2002). Qualitative research and evaluation methods (3rd ed.). Thousand Oaks: SAGE Publications, Inc.

Pendalungan Regency. (2016). Retrieved October 22, 2016, from Wikipedia website: https://en.wikipedia.org/w/index.php?title=Jember_Regency\&oldid=741884775

Pennycook, A. (1994). The cultural politics of English as an international language. London, UK: Routledge.

Pennycook, A., \& Coutand-Marin, S. (2003). Teaching English as a missionary language. Discourse: Studies in the Cultural Politics of Education, 24(3), 337-353.

Pennycook, A., \& Makoni, S. (2005). The modern mission: the language effects of Christianity. Journal of Language, Identity \& Education, 4(2), 137-155.

Phillipson, R. (1992). Linguistic imperialism. Oxford, UK: Oxford University Press.

Phillipson, R. (2016). NSs in linguistic imperialism. Journal for Critical Education Policy Studies, 14(3), 80-96.

Phipps, S., \& Borg, S. (2007). Exploring the relationship between teachers' beliefs and their classroom practice. The Teacher Trainer, (3), 17-19.

Phipps, S., \& Borg, S. (2009). Exploring tensions between teachers' grammar teaching beliefs and practices. System: An International Journal of Educational Technology and Applied Linguistics, 37(3), 380-390.

Pinner, R. S. (2016a). Reconceptualising authenticity for English as a global language. Bristol: Multilingual Matters.

Pinner, R. S. (2016b). The nature of authenticity in English as a foreign language: a comparison of eight inter-related definitions. NUS CELC 5th Symposium, 78-93. Singapore.

Pluralitas sebagai Sunnatullah [Plurality as the law/way of God]. (2018, September 9). Retrieved September 16, 2018, from http://www.suaramuhammadiyah.id/2018/09/11/pluralitassebagai-sunnatullah/

Poedjosoedarmo, G. (2006). The effect of Bahasa Indonesia as a lingua franca on the Javanese system of speech levels and their functions. International Journal of the Sociology of Language, 2006(177), 111-121.

Poedjosoedarmo, S. (1968). Javanese speech levels. Indonesia, (6), 54-81.

Qoyyimah, U. (2015). EFL teachers professional dilemmas with moral curriculum reform in Indonesia (Queensland University of Technology). Retrieved from https://eprints.qut.edu.au/83676/1/Uswatun_Qoyyimah_Thesis.pdf

Qoyyimah, U. (2016). Inculcating character education through EFL teaching in Indonesian state schools. Pedagogies: An International Journal, 11(2), 109-126.

Quinn, G. (2001). The learner's dictionary of today's Indonesian. NSW, Australia: Allen \& Unwin.

Rallis, S. F., \& Rossman, G. B. (2009). Ethics and trustworthiness. In J. Heigham \& R. A. Croker (Eds.), Qualitative research in applied linguistics: a practical introduction (pp. 263-287). Houndmills, UK: Palgrave Macmillan.

Richards, J. C. (2010). Competence and performance in language teaching. RELC Journal, 41(2), 101-122. 
Richards, J. C. (2012). Competence and performance in language teaching. In J. C. Richards \& A. Burns (Eds.), The Cambridge guide to pedagogy and practice in second language teaching (pp. 46-56). New York: Cambridge University Press.

Richards, J. C., \& Burns, A. (2012). Pedagogy and practice in second language teaching: an overview of the issues. In J. C. Richards \& A. Burns (Eds.), The Cambridge guide to pedagogy and practice in second language teaching (pp. 1-12). New York: Cambridge University Press.

Richards, J. C., \& Schmidt, R. W. (2010). Longman dictionary of language teaching and applied linguistics (4th ed.). Oxon, UK: Routledge.

Richards, K. (2003). Qualitative inquiry in TESOL. New York: Palgrave Macmillan.

Richards, K. (2009). Interviews. In J. Heigham \& R. A. Croker (Eds.), Qualitative research in applied linguistics: a practical introduction (pp. 182-196). Houndmills, UK: Palgrave Macmillan.

Richards, K. (2011). Case study. In E. Hinkel (Ed.), Handbook of research in second language teaching and learning: Vol. II (pp. 207-221). New York: Routledge.

Richardson, V. (1996). The role of attitudes and beliefs in learning to teach. In J. P. Sikula (Ed.), Handbook of research on teacher education (2nd ed., pp. 102-119). New York: Association of Teacher Educators.

Robson, S., \& Wibisono, S. (2002). Javanese English dictionary. Hong Kong: Periplus Editions.

Rochmi, M. N. (2018, October 18). 6 Dari 10 guru punya sikap intoleran [6 of 10 teachers have intolerant attitude]. Retrieved December 29, 2018, from https://beritagar.id/ website: https://beritagar.id/artikel/berita/6-dari-10-guru-punya-sikap-intoleran

Rofiq, M. (2018, May 17). Satu terduga teroris di Probolinggo guru Bahasa Inggris [Terrorist suspect in Probolinggo an English teacher]. Detiknews. Retrieved from https://news.detik.com/read/2018/05/17/131244/4025037/475/satu-terduga-teroris-diprobolinggo-guru-bahasa-inggris

Rokeach, M. (1968). Beliefs, attitudes and values: a theory of organization and change. San Francisco etc.: Jossey-Bass Inc Pub.

Roller, M. R., \& Lavrakas, P. J. (2015). Applied qualitative research design: a total quality framework approach. New York: The Guilford Press.

Ryan, J., \& Gass, S. M. (2012). Stimulated recall. In R. Barnard \& A. Burns (Eds.), Researching language teacher cognition and practice: international case studies (pp. 144-161). Bristol, UK: Multilingual Matters.

Saeed, A. (2018). Apostasy. Retrieved September 13, 2018, from The Oxford Encyclopedia of the Islamic World website: http://www.oxfordislamicstudies.com/article/opr/t342/e0034?_hi=3\&_pos=4

Sagita, D. (2013, January 9). Constitutional court brings end to era of RSBI schools. Jakarta Globe. Retrieved from http://jakartaglobe.beritasatu.com/archive/constitutional-courtbrings-end-to-era-of-rsbi-schools/

Saldaña, J. (2012). The coding manual for qualitative researchers (2nd ed.). Los Angeles: SAGE Publications Ltd.

Samovar, L. A., Porter, R. E., \& McDaniel, E. R. (2009). Communication between cultures (7th ed.). Belmont, CA: Cengage Learning.

Sarangi, S. (2009). Culture. In G. Senft, J.-O. Östman, \& J. Verschueren (Eds.), Culture and language use (pp. 81-104). Amsterdam: John Benjamins.

Scarino, A., \& Liddicoat, A. J. (2009). Teaching and learning languages: a guide. Victoria, Australia: Curriculum Corporation.

Schwandt, T. A. (1994). Constructivist, interpretivist approaches to human inquiry. In N. K. Denzin \& Y. S. Lincoln (Eds.), Handbook of qualitative research (pp. 118-137). Thousand Oaks: SAGE Publications, Inc.

Sercu, L. (2004). Assessing intercultural competence: a framework for systematic test development in foreign language education and beyond. Intercultural Education, 15(1), 73-89.

Shohamy, E. G. (2006). Language policy: hidden agendas and new approaches. Abingdon: Routledge. 
Simons, G. F., \& Fennig, C. D. (Eds.). (2018). Ethnologue: languages of the world. Retrieved from https://www.ethnologue.com/country/ID

Siregar, F. L. (2016). In pursuit of intercultural communicative competence: an investigation into English language policy and practices at a private university in Indonesia (Victoria University of Wellington). Retrieved from http://researcharchive.vuw.ac.nz/handle/10063/5258

Sitepu, M. (2018, October 18). Enam dari sepuluh guru Muslim "intoleran", kemajemukan harus masuk penilaian akreditasi [Six of ten Muslim teachers intolerant, diversity to be part of accreditation]. Retrieved from https://www.bbc.com/indonesia/indonesia-45887762

Skutnabb-Kangas, T. (1981). Bilingualism or not: the education of minorities (L. Malmberg \& D. Crane; Trans.). Clevedon: Multilingual Matters.

Smith, L. E. (1976). English as an international auxiliary language. RELC Journal, 7(2), 38-42.

Song, S. Y. (2014). Teacher's beliefs about language learning and teaching. In M. Bigelow \& J. Ennser-Kananen (Eds.), The Routledge Handbook of Educational Linguistics (1st ed., pp. 263-275). New York: Routledge.

Spolsky, B. (2004). Language policy. Cambridge: Cambridge University Press.

Spolsky, B. (2012). What is language policy? In B. Spolsky (Ed.), The Cambridge handbook of language policy (pp. 3-25). Cambridge: Cambridge University Press.

Stake, R. E. (1994). Case studies. In N. K. Denzin \& Y. S. Lincoln (Eds.), Handbook of qualitative research (pp. 236-247). Thousand Oaks: SAGE Publications, Inc.

Stake, R. E. (1995). The art of case study research. Thousand Oaks: Sage Publications.

Stake, R. E. (2005). Qualitative case studies. In N. K. Denzin \& Y. S. Lincoln (Eds.), The SAGE handbook of qualitative research (3rd ed., pp. 443-466). Thousand Oaks: Sage Publications, Inc.

Stake, R. E. (2010). Qualitative research: studying how things work. New York: The Guilford Press.

Stritikus, T. T. (2003). The interrelationship of beliefs, context, and learning: the case of a teacher reacting to language policy. Journal of Language, Identity \& Education, 2(1), 29-52.

Sugiharto, S. (2014). Disentangling linguistic imperialism in English language education: The Indonesian context. In M. Bigelow \& J. Ennser-Kananen (Eds.), The Routledge Handbook of Educational Linguistics (pp. 224-236). Florence: Taylor and Francis.

Sukyadi, D. (2015). The teaching of English at secondary schools in Indonesia. In B. Spolsky \& K. Sung (Eds.), Secondary school English education in Asia: from policy to practice (pp. 123147). New York: Routledge.

Suryahadi, A., \& Sambodho, P. (2013). An assessment of policies to improve teacher quality and reduce teacher absenteeism. In D. Suryadarma \& G. W. Jones (Eds.), Education in Indonesia (pp. 139-159). Institute of Southeast Asian Studies.

Sussex, R. (2012). Switching in international English. In A. Kirkpatrick \& R. Sussex (Eds.), English as an international language in Asia: implications for language education (pp. 175-187). Dordrecht, The Netherlands: Springer.

Theodorou, A. E. (2015, December 23). Americans are in the middle of the pack globally when it comes to importance of religion. Retrieved September 7, 2017, from Pew Research Center website: http://www.pewresearch.org/fact-tank/2015/12/23/americans-are-in-the-middleof-the-pack-globally-when-it-comes-to-importance-of-religion/

Tian, J. (2013). Beliefs and practices regarding intercultural competence among Chinese teachers of English at a Chinese university (Doctoral dissertation, George Mason University). Retrieved from http://ebot.gmu.edu/bitstream/handle/1920/8205/Tian_gmu_0883E_10311.pdf?sequence=1 \&isAllowed=y

Tomlinson, B., \& Masuhara, H. (2004). Developing cultural awareness: integrating culture into a language course. Modern English Teacher, 13(1), 1-7.

Turnbull, M., \& Dailey-O'Cain, J. (2009). Introduction. In M. Turnbull \& J. Dailey-O'Cain (Eds.), First language use in second and foreign language learning (pp. 1-14). Bristol, UK: Multilingual Matters. 
Undang-Undang Republik Indonesia No. 14 Tahun 2005 tentang Guru dan Dosen [Law No. 14/2005 on Teacher and Lecturer]. , (2005).

Undang-Undang Republik Indonesia No. 20 Tahun 2003 tentang Sistem Pendidikan Nasional. , (2003).

Undang-Undang Republik Indonesia No. 20 Tahun 2003 tentang Sistem Pendidikan Nasional [Law No. 20/2003 on National Education System]. , (2003).

Undang-Undang Republik Indonesia No. 24 Tahun 2009 tentang Bendera, Bahasa, dan Lambang Negara, serta Lagu Kebangsaan [Law No. 24/2009 on the National Flag, Language, Symbol, and Anthem]. , (2009).

Velasco, P., \& García, O. (2014). Translanguaging and the writing of bilingual learners. Bilingual Research Journal, 37(1), 6-23.

Verschueren, J. (2012). Ideology in language use: pragmatic guidelines for empirical research. Cambridge: Cambridge University Press.

Viet, N. G., \& Bygate, M. (2012). Narrative frames. In R. Barnard \& A. Burns (Eds.), Researching language teacher cognition and practice: international case studies (pp. 48-67). Bristol, UK: Multilingual Matters.

Vo, Q. P. (2017). Rethinking intercultural communication competence in English language teaching: a gap between lecturers' perspectives and practices in a Southeast Asian tertiary context. Journal on English Language Teaching, 7(1), 20-29.

Vogel, S., \& García, O. (2017). Translanguaging. Oxford Research Encyclopedia of Education. Retrieved from http://education.oxfordre.com/view/10.1093/acrefore/9780190264093.001.0001/acrefore9780190264093-e-181

Walden, M. (2017, February 20). Democracy in Indonesia: a cause for celebration. Retrieved July 17, 2017, from https://www.lowyinstitute.org/the-interpreter/democracy-indonesia-causecelebration

Widdowson, H. G. (1994). The ownership of English. TESOL Quarterly, 28(2), 377-389.

Widdowson, H. G. (1996). Comment: authenticity and autonomy in ELT. ELT Journal, 50(1), 6768.

Widodo, H. P. (2016). Language policy in practice: reframing the English language curriculum in the Indonesian secondary education sector. In R. Kirkpatrick (Ed.), English language education policy in Asia (pp. 127-151). New York: Springer International Publishing.

Widodo, H. P., Wood, A., \& Gupta, D. (2017). Introduction: re-contextualizing English language teaching in Asia today. In H. P. Widodo, A. Wood, \& D. Gupta (Eds.), Asian English language classrooms: where theory and practice meet (pp. 1-13). London: Routledge.

Woods, D. (1996). Teacher cognition in language teaching: beliefs, decision-making, and classroom practice. New York: Cambridge University Press.

Woodward, M. (2011). Java, Indonesia and Islam. Dordrecht, The Netherlands: Springer.

Yin, R. K. (2011). Qualitative research from start to finish. New York: The Guilford Press.

Yin, R. K. (2014). Case study research: design and methods (5th ed.). Los Angeles: SAGE Publications, Inc.

Yulika, N. C. (2018, May 15). Mengaku home schooling, anak bomber Surabaya hanya terima doktrin orangtua [Disguised as homeschooling, Surabaya bomber's children indoctrinated by parents]. liputan6.com. Retrieved from https://www.liputan6.com/news/read/3525740/mengaku-home-schooling-anak-bombersurabaya-hanya-terima-doktrin-orangtua

Zacharias, N. T. (2003). A survey of tertiary teachers' beliefs about English language teaching in Indonesia with regard to the role of English as a global language. Institute for English Language Education Assumption University of Thailand.

Zacharias, N. T. (2014a). Integrating EIL pedagogy in a pre-service teacher education program. TEFLIN Journal, 25(2), 217-232.

Zacharias, N. T. (2014b). The relocation of culture in the teaching of English as an international language. In R. Marlina \& R. A. Giri (Eds.), The pedagogy of English as an international language: perspectives from scholars, teachers, and students (pp. 129-141). New York: Springer. 
Zentz, L. (2016). English on the rise: access and resources in internationalization. In M. Gazzola \& B.-A. Wickström (Eds.), The economics of language policy (pp. 433-468). London: MIT Press.

Zentz, L. (2017). Statehood, scale and hierarchy: history, language and identity in Indonesia. Bristol, UK: Multilingual Matters.

Zheng, X., \& Gao, Y. (2017). Facilitating transformative learning toward productive bilingualism: innovations in teaching English for intercultural communication in China. In H. Reinders, D. Nunan, \& B. Zou (Eds.), Innovation in language learning and teaching: the case of China (pp. 261-287). London: Palgrave Macmillan. 
Appendix 1 : Victoria University's Ethics Approval

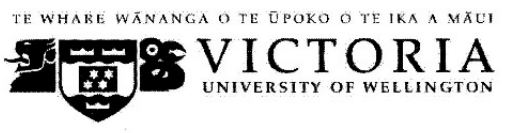

MEMORANDUM
Phone $\quad 0-4-4635205$

Email stephen.marshall $\omega_{\text {vuw.ac.nz }}$

\begin{tabular}{l|l}
\hline TO & Iwan Munandar \\
\hline COPY TO & Jonathan Newton \\
\hline FROM & Dr Stephen Marshall, Acting Convener, Human Ethics Committee \\
\hline & \\
\hline DATE & 25 August 2015 \\
\hline PAGES & 1 \\
\hline
\end{tabular}

\begin{tabular}{l|l}
\hline SUBJECT & $\begin{array}{l}\text { Ethics Approval: } 22192 \\
\text { Nonnative speaker English teachers' beliefs and practices about } \\
\text { culture teaching and learning: a case study of Indonesian high- } \\
\text { school EFL teachers }\end{array}$ \\
\hline
\end{tabular}

Thank you for your application for ethical approval, which has now been considered by the Standing Committee of the Human Ethics Committee.

Your application has been approved from the above date and this approval continues until 25 November 2017. If your data collection is not completed by this date you should apply to the Human Ethics Committee for an extension to this approval.

Best wishes with the research.

Stephen Marshall,

Acting Convener, Victoria University Human Ethics Committee 
Appendix 2 : Application for field-work permission from the Office of National Education (DIKNAS)

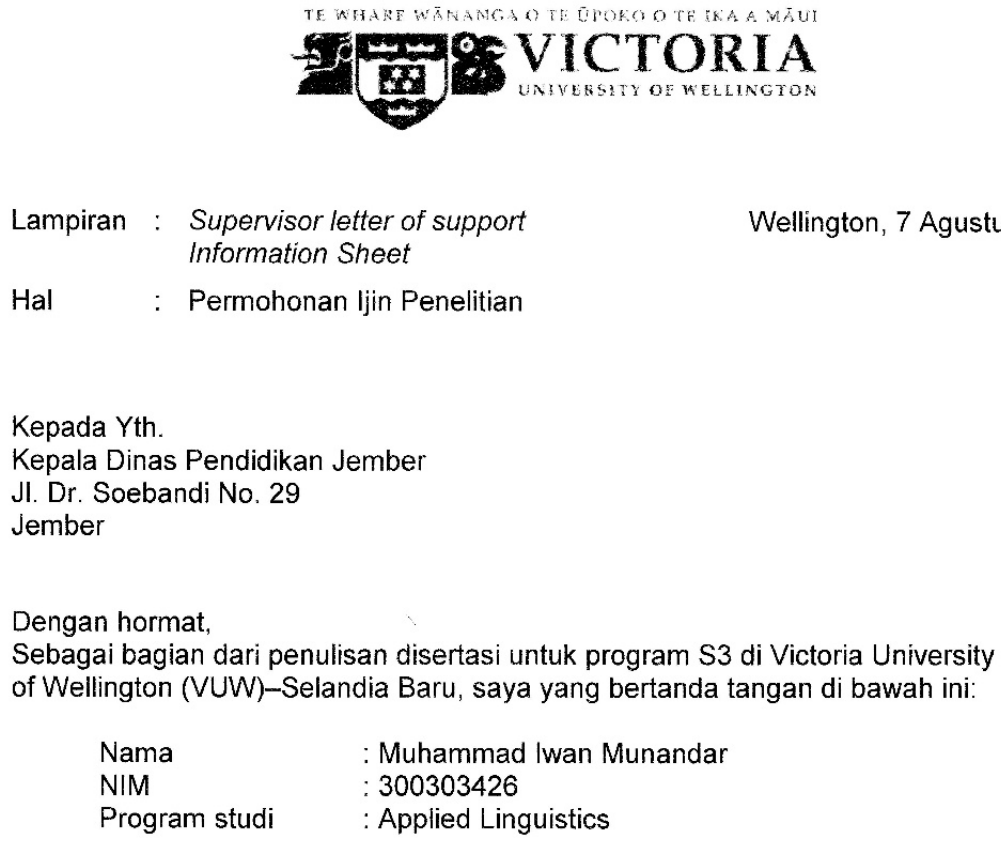

Demikian permohonan saya sampaikan. Atas perhatian dan perkenan yang diberikan, saya ucapkan terima kasih.

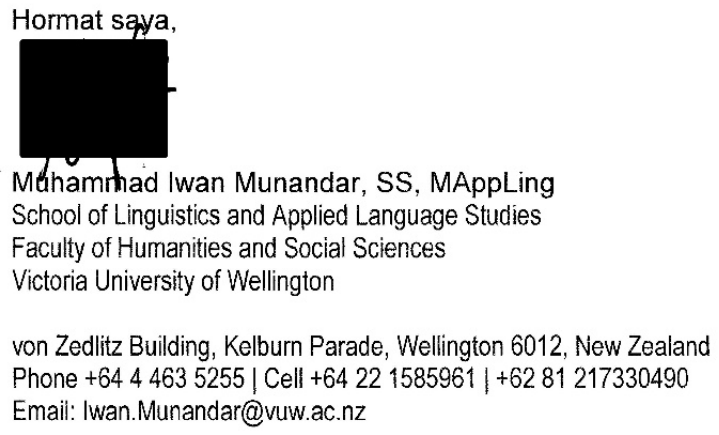




\section{Appendix 3 : Application for field-work permission from the Ministry of Religious Affairs (KEMENAG)}

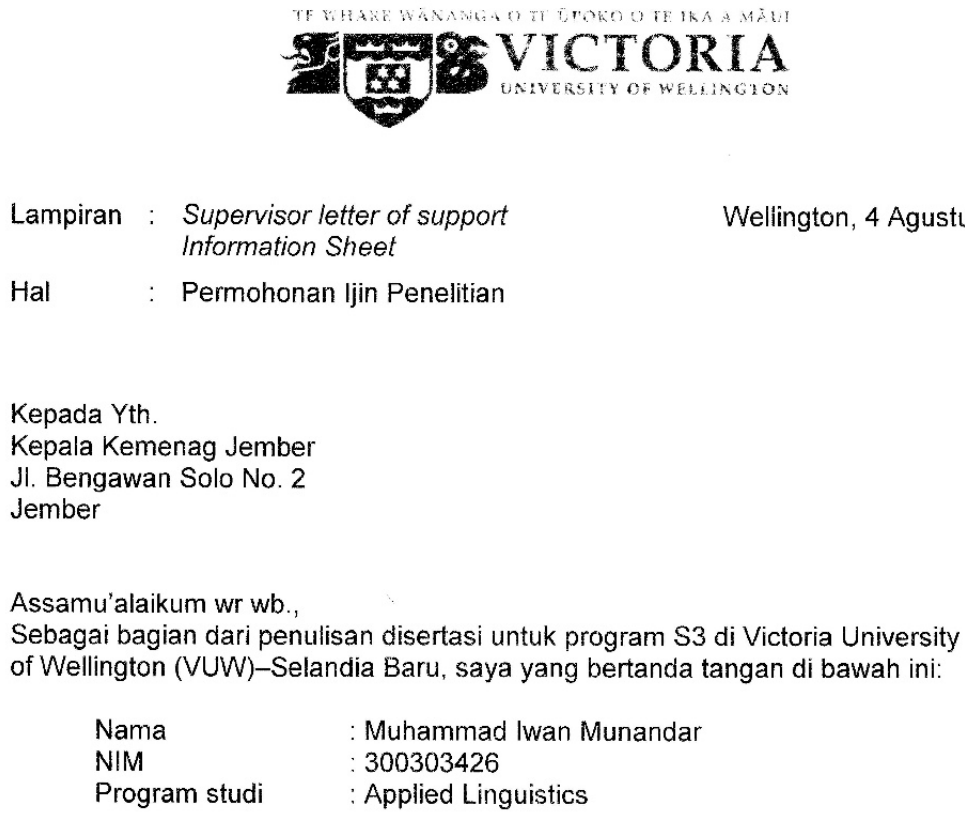

$\begin{array}{ll}\text { Nama } & : \text { Muhammad Iwan Munandar } \\ \text { NIM } & : 300303426 \\ \text { Program studi } & : \text { Applied Linguistics }\end{array}$

bersama ini mengajukan permohonan ijin/rekomendasi untuk mengadakan penelitian yang melibatkan sejumlah guru Bahasa Inggris MA di Jember. Penelitian akan saya lakukan dari bulan September sampai November 2015.

Demikian permohonan saya sampaikan. Atas perhatian dan perkenan yang diberikan, saya ucapkan terima kasih.

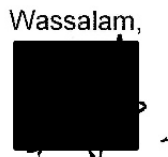

Muhammad Iwan Munandar, SS, MAppLing

School of Linguistics and Applied Language Studies

Faculty of Humanities and Social Sciences

Victoria University of Wellington

von Zedlitz Building, Kelburn Parade, Wellington 6012, New Zealand

Phone +64 44635255 | Cell +64 $221585961 \mid+6281217330490$

Email: Iwan.Munandar@vuw.ac.nz 


\section{Appendix 4 : Application for field-work permission from the principal}

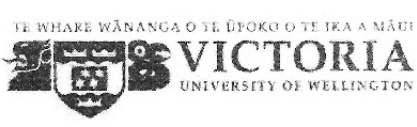

$\begin{array}{ll}\text { Lampiran } & : \begin{array}{l}\text { - ljin DIKNAS Jember } \\ \end{array} \\ & \text { - Supervisor Letter of Support } \\ \text { Hal } & : \text { Permohonan Ijin Penelitian }\end{array}$

Kepada Yth.

Bapak/lbu Kepala Sekolah

Jember

Dengan hormat

Sebagai bagian dari penulisan disertasi untuk program S3 di Victoria University of Wellington (VUW)-Selandia Baru, saya yang bertanda tangan di bawah ini:

$\begin{array}{ll}\text { Nama } & : \text { Muhammad Iwan Munandar } \\ \text { NIM } & : 300303426 \\ \text { Program studi } & : \text { Applied Linguistics }\end{array}$

bersama ini mengajukan permohonan ijin untuk mengadakan penelitian yang melibatkan guru Bahasa Inggris dan siswa di sekolah Bapak/lbu. Penelitian akan saya lakukan dalam jangka waktu bulan September sampai Desember 2015.

Terlampir ljin/Rekomendasi dari Kepala DIKNAS Jember dan Letter of Support dari dosen pembimbing, Dr Jonathan Newton.

Demikian permohonan ijin saya sampaikan. Atas perhatian dan perkenan Bapak/lbu, saya ucapkan terima kasih.

\section{Hormat saya,}

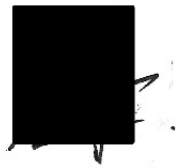

Muhammad Iwan Munandar, SS, MAppLing

School of Linguistics and Applied Language Studies

Faculty of Humanities and Social Sciences

Victoria University of Wellington

von Zedlitz Building, Kelburn Parade, Wellington 6012, New Zealand

Phone +64 44635255 |Cell +64 221585961 | +62 81217330490

Email: Iwan.Munandar@vuw.ac.nz 


\section{Appendix 5 : Primary supervisor's support letter for DIKNAS permission}

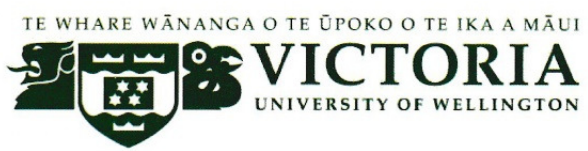

Head of Office of National Education (DIKNAS)

Regency of Jember

Jl. Dr. Soebandi No. 29

Jember

Dear Sir,

I am pleased to write on behalf of Muhammad Iwan Munandar, a current holder of the DIKTI Overseas Graduate Scholarship (BPP-LN). Mr Munandar is applying to the Office of National Education, Regency of Jember for permission to collect data from schools in the region.

I am the primary supervisor for Mr Iwan Munandar, a PhD student at Victoria University of Wellington (VUW), New Zealand. As part of the programme, Mr Iwan Munandar will be undertaking fieldwork to collect data for his thesis research. This will involve English teachers and students in a number of SMA/SMK/MA in Jember as research participants.

Mr Iwan Munandar's research will investigate how culture is represented in the teaching of English as a foreign language (EFL) in Indonesian high schools. For this research, he needs to spend a period of time observing and recording classes as well as interviewing teachers and students to obtain data on their pedagogic beliefs in relation to this topic.

His research proposal was accepted by the Research Committee at the School of Linguistics and Applied Language Studies at Victoria University of Wellington at the end of May and he has since been developing data collection instruments for classroom observation and interviewing participants. I am satisfied therefore that his research methodology will be sufficiently developed to carry out data collection from September until December 2015

I give Mr Iwan Munandar my highest recommendation and very much hope that you consider his application favourably. You are welcome to contact me if you would like any further clarification

Thank you for your time and consideration.

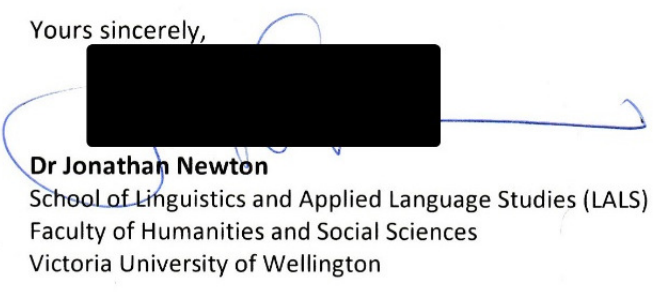

PO Box 600, Wellington 6140, New Zealand Telephone +6444635622 | Cell +64274138302 Email: Jonathan.Newton@vuw.ac.nz 


\section{Appendix 6 : Primary supervisor's support letter for principal permission}

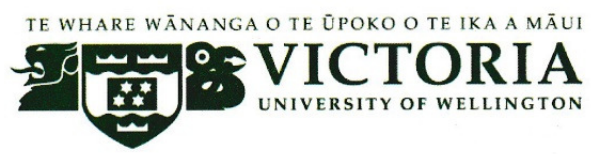

21 August 2015

Headmasters of Islamic High Schools (MA)

Regency of Jember

Jember

Dear Sir,

I am pleased to write on behalf of Muhammad Iwan Munandar, a current holder of the DIKTI Overseas Graduate Scholarship (BPP-LN). Mr Munandar is applying to the Office of National Education, Regency of Jember for permission to collect data from schools in the region.

I am the primary supervisor for Mr Iwan Munandar, a PhD student at Victoria University of Wellington (VUW), New Zealand. As part of the programme, Mr Iwan Munandar will be undertaking fieldwork to collect data for his thesis research. This will involve English teachers and students in a number of SMA/SMK/MA in Jember as research participants.

Mr Iwan Munandar's research will investigate how culture is represented in the teaching of English as a foreign language (EFL) in Indonesian high schools. For this research, he needs to spend a period of time observing and recording classes as well as interviewing teachers and students to obtain data on their pedagogic beliefs in relation to this topic.

His research proposal was accepted by the Research Committee at the School of Linguistics and Applied Language Studies at Victoria University of Wellington at the end of May and he has since been developing data collection instruments for classroom observation and interviewing participants. I am satisfied therefore that his research methodology will be sufficiently developed to carry out data collection from September until December 2015.

I give Mr Iwan Munandar my highest recommendation and very much hope that you consider his application favourably. You are welcome to contact me if you would like any further clarification

Thank you for your time and consideration.

Yours sincerely,

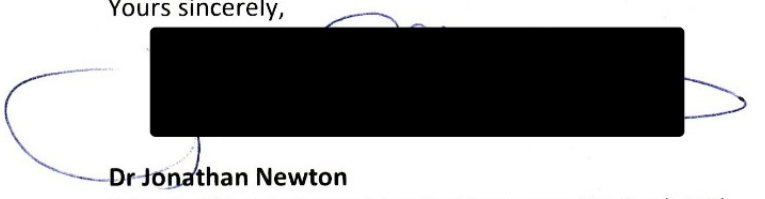

School of Linguistics and Applied Language Studies (LALS)

Faculty of Humanities and Social Sciences

Victoria University of Wellington

PO Box 600, Wellington 6140, New Zealand

Telephone +6444635622 | Cell +64274138302

Email: Jonathan.Newton@vuw.ac.nz 


\section{Appendix 7 : Teacher information sheet (English)}

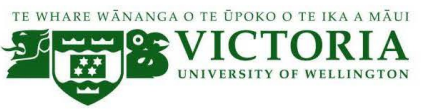

School of Linguisties and Applied Language Studies

Faculty of Humanities and Social Sciences

Victoria University of Wellington

PO Box 600, Wellington, New Zealand

Teacher participation information sheet for a study on the cultural dimension of English education in Indonesian high school

I am a student in the School of Linguistics and Applied Language Studies at the Victoria University. My research is investigating the cultural dimension of English education in Indonesian high school. It has been approved by the Victoria University Human Ethics Committee.

I am inviting you as an Indonesian high school English teacher to participate in this study. Should you agree to participate, I will observe two of your classes, ask you to complete a questionnaire, and arrange two interviews. You will be given a $\$ 30$ (Rp 300.000) top-up mobile voucher and some souvenir as a token of my appreciation.

Please note that your participation in this study is entirely voluntary and will not relate to and/or affect in any way your professional performance or evaluation.

All material collected will be kept strictly confidential. Data from you will be put into a written report. No other person besides me and my supervisors, i.e. Dr Jonathan Newton and Dr John Macalister, will see the data. Your personal and school identity will be disguised by means of pscudonyms and these will not be disclosed to any other party.

The results of the study may be published and will be available in the University Library. Research findings may also be presented at academic conferences and published in scholarly journals without disclosing personal identity, professional affiliation or occupational status of individual participants. Data will be destroyed two (2) years after the end of the study.

You are free to ask any questions about the study at any stage. If you wish to withdraw from the study, please let me know by email no later than two (2) weeks after the final session of the data collection.

If you would like to receive further information, please contact me by email at Iwan.Munandar@vuw.ac.nz. You may also contact my primary supervisor, Dr Jonathan Newton, at Jonathan.Newton@vuw.ac.nz.

If you have any concerns about the ethical conduct of the research, you may contact the Victoria University HEC Convener: Associate Professor Susan Corbett. Email susan.corbett@vuw.ac.nz or telephone +64-4-463 5480. Thank you for your cooperation.

Muhammad Iwan Munandar 


\section{Appendix 8 : Teacher information sheet (Indonesian)}

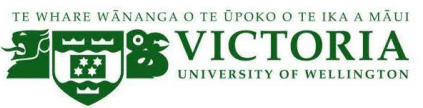

School of Linguisties and Applied Language Studies

Faculty of Humanities and Social Sciences

Victoria University of Wellington

PO Box 600, Wellington, New Zealand

\section{Lembar informasi partisipasi guru dalam riset tentang dimensi budaya dalam pendidikan bahasa Inggris di SMA di Indonesia}

Saya mahasiswa S3 (PhD) di School of Linguistics and Applied Language Studies, Victoria University. Riset/penelitian saya mengkaji dimensi budaya dalam pendidikan bahasa Inggris di SMA/SMK/MA di Indonesia. Riset ini telah disetujui oleh Komite Etik Victoria University.

Saya mengundang Bapak/Ibu sebagai guru Bahasa Inggris di SMA/SMK/MA untuk berpartisipasi dalam riset ini. Jika Anda setuju untuk berpartisipasi, saya akan melakukan dua kali observasi kelas, meminta Anda mengisi kuesioner, dan mengadakan dua kali wawancara. Anda akan mendapatkan kartu isi ulang senilai Rp 300.000 dan suvenir sebagai ungkapan terima kasih.

Penting untuk diingat bahwa partisipasi Anda dalam riset ini sepenuhnya sukarela dan tidak berkaitan dan/atau memengaruhi kinerja atau evaluasi keprofesian dalam bentuk apa pun.

Semua materi yang diperoleh dijaga kerahasianny a secara ketat. Data yang Anda berikan akan saya jadikan bagian dari laporan tertulis. Tidak ada pihak lain yang boleh melihat data kecuali saya dan dosen pembimbing, yaitu Dr Jonathan Newton dan Dr John Macalister. Identitas pribadi dan sekolah Anda akan disamarkan dengan penggunaan nama samaran dan ini tidak akan diberitahukan ke pihak lain manapun.

Hasil riset mungkin dipublikasikan dan bisa diperoleh dari perpustakaan Victoria University. Riset juga mungkin ditampilkan di konferensi dan diterbitkan di jurnal akademik tanpa menampilkan identitas pribadi atau nama sekolah dari partisipan. Data akan dimusnahkan dua (2) tahun setelah studi berakhir.

Anda berhak mengajukan pertanyaan tentang riset ini pada tahap apapun. Jika Anda bermaksud menarik diri dari studi ini, mohon beritahu saya melalui surel/email dalam jangka tidak lebih dari dua (2) minggu setelah sesi pengumpulan data terakhir.

Jika Anda ingin mendapatkan informasi tambahan, silakan mengubungi saya melalui email Iwan.Munandar@vuw.ac.nz, atau pembimbing satu, Dr Jonathan Newton, di Jonathan.Newton@vuw.ac.nz.

Jika Anda mempunyai pertanyaan tentang aspek etis dari riset ini, Anda bisa menghubungi Ketua Komite Etik (HEC) Victoria University: Associate Professor Susan Corbett. Email susan.corbett@vuw.ac.nz atau telepon +64-4-463 5480. Terima kasih atas kerjasama Anda.

Muhammad Iwan Munandar 


\section{Appendix 9 : Teacher consent form}

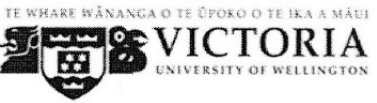
School of Linguistics and Applied Language Studies
Victoria University of Wellington
PO Box 600, Wellington, New Zealand

$\begin{array}{ll}\text { Researcher } & \text { : Muhammad Iwan Munandar (Iwan.Munandar@vuw.ac.nz) } \\ \text { Supervisors } & \text { : Dr Jonathan Newton (Jonathan.Newton@vuw.ac.nz) } \\ & \text { Dr John Macalister (John.Macalister@vuw.ac.nz) }\end{array}$

Topic of the study: The cultural dimension of English education in Indonesian high school

\section{TEACHER CONSENT FORM}

- I have read the Information Sheet and understood what will be required of me if I participate in this study.

- I have been given the opportunity to ask and have had my questions about this study answered to my satisfaction.

- I understand that my participation in this study is entirely voluntary and I may choose to withdraw my participation no longer than two (2) weeks after I attend the final session of the data collections.

- I understand that I have the right to ask further questions at any time.

- I understand that the data collections will be audio- and/or video-taped.

- I understand that any information I give and my identity will be kept under the conditions of strict confidentiality. Initials and pseudonyms will be used.

- I agree to participate in this study and to provide any relevant information needed by the researcher.

$\begin{array}{ll}\text { Teacher's Name } & : \ldots \ldots, \ldots, \ldots \text { Pd } \\ \text { Teacher's Signature } & : \\ \text { Date } & : 01 / 10 / 2015\end{array}$

If you would like to receive a copy of a written summary of this study at the end of this study, please tick here $\square$ and provide me your e-mail address to which this summary can be sent. Otherwise, you may leave it blank.

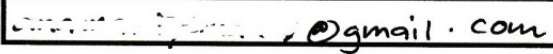

Note: Participant shall retain a completed and signed copy of this form.

Page 1 of 1 


\section{Appendix 10 : Student information sheet (English)}

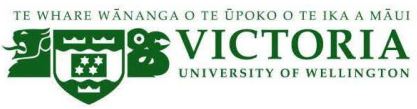

School of Linguistics and Applied Language Studies Faculty of Humanities and Social Sciences

Victoria University of Wellington

PO Box 600, Wellington, New Zealand

\section{Student participation information sheet for a study on the cultural dimension of English education in Indonesian high school}

I am a student in the School of Linguistics and Applied Language Studies at the Victoria University. As part of this degree, I am conducting a study leading to a dissertation. My research is investigating the cultural dimension of English education in Indonesian high school. It has been approved by the Victoria University Human Ethics Committee.

I am inviting you as a high school student to participate in this study. Should you agree to participate and your parent/guardian give consent to your participation, I will ask you to take part in a group discussion. After you have finished the session, you will be given a $\$ 10$ (Rp 100.000 ) top-up voucher and some souvenir as a token of my appreciation. Please note that your participation in this study is entirely voluntary and will not affect your study or grades of any course that you are taking in any way.

All material collected from the discussion will be kept strictly confidential. Data from you and other participants will be used in my study and will be put into a written report. No other person besides me and my supervisors, Dr Jonathan Newton and Dr John Macalister, will see the data. Your personal and school identity will be disguised by means of pseudonyms and these will not be disclosed to any other party.

The results of the study may be published and will be available in the University Library. The research may also be presented at academic conferences and published in scholarly journals without disclosing personal identity or school name of individual participants. Data will be destroyed two (2) years after the end of the study.

You are free to ask any questions about the study at any stage. You may also choose not to contribute while attending the group discussion.

If you would like to receive further information, please contact me by email at Iwan.Munandar@vuw.ac.nz, or my primary supervisor, Dr Jonathan Newton, at Jonathan.Newton@vuw.ac.nz.

If you have any concerns about the ethical conduct of the research, you may contact the Victoria University HEC Convener: Associate Professor Susan Corbett. Email susan.corbett@vuw.ac.nz or telephone +64-4-463 5480. Thank you for your cooperation.

Muhammad Iwan Munandar 


\section{Appendix 11 : Student information sheet (Indonesian)}

- Indonesian version

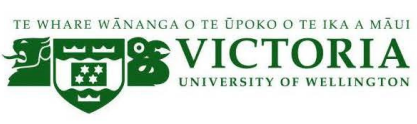

School of Linguistics and Applied Language Studies Faculty of Humanities and Social Sciences

Victoria University of Wellington

PO Box 600, Wellington, New Zealand

\section{Lembar informasi partisipasi siswa dalam riset tentang dimensi budaya dalam pendidikan bahasa Inggris di SMA di Indonesia}

Saya mahasiswa S3 (PhD) di School of Linguistics and Applied Language Studies, Victoria University. Riset /penelitian saya mengkaji dimensi budaya dalam pendidikan bahasa Inggris di SMA/SMK/MA di Indonesia. Riset ini telah disetujui oleh Komite Etik Victoria University.

Saya mengundang Anda sebagai siswa SMA/SMK/MA untuk berpartisipasi dalam riset ini. Jika Anda setuju untuk berpartisipasi, saya akan meminta Anda mengikuti satu sesi diskusi. Setelah selesai, Anda berhak mendapatkan kartu isi ulang senilai Rp 100.000 dan suvenir sebagai ucapan terima kasih. Penting untuk diingat bahwa partisipasi Anda dalam riset ini sepenuhnya sukarela dan tidak akan mempengaruhi studi atau nilai pelajaran apapun yang sedang Anda ikuti.

Semua materi yang diperoleh dari diskusi akan dijaga kerahasiaannya secara ketat. Data yang Anda dan siswa lain berikan akan saya gunakan dalam riset dan jadikan bagian laporan tertulis. Tidak ada pihak lain yang boleh melihat data kecuali saya dan dosen pembimbing, yaitu Dr Jonathan Newton dan Dr John Macalister. Identitas pribadi dan sekolah Anda akan disamarkan dengan penggunaan nama samaran dan ini tidak akan diberitahukan ke pihak lain manapun.

Hasil riset mungkin dipublikasikan dan bisa diperoleh dari perpustakaan Victoria University. Riset juga mungkin ditampilkan di konferensi dan diterbitkan di jurnal akademik tanpa menampilkan identitas pribadi atau nama sekolah dari partisipan. Data akan dimusnahkan dua (2) tahun setelah studi berakhir.

Anda berhak mengajukan pertanyaan tentang riset ini pada tahap apapun. Anda juga berhak untuk tidak berkontribusi saat mengikuti diskusi.

Jika Anda ingin mendapatkan informasi tambahan, silakan mengubungi saya melalui email Iwan.Munandar@vuw.ac.nz, atau pembimbing satu, Dr Jonathan Newton, di Jonathan.Newton@vuw.ac.nz.

Jika Anda mempunyai pertanyaan tentang aspek etis dari riset ini, Anda bisa menghubungi Ketua Komite Etik (HEC) Victoria University: Associate Professor Susan Corbett. Email susan.corbett@ vuw.ac.nz atau telepon +64-4-463 5480. Terima kasih atas kerjasama Anda.

Muhammad Iwan Munandar

Page $\mathbf{2}$ of $\mathbf{2}$ 


\section{Appendix 12 : Student consent form (English)}

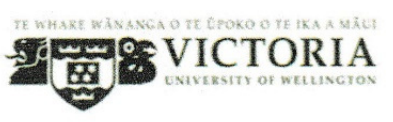

School of Linguistics and Applied Language Studies Victoria University of Wellington PO Box 600, Wellington, New Zealand

$\begin{array}{ll}\text { Researcher } & \text { : Muhammad Iwan Munandar (Iwan.Munandar@vuw.ac.nz) } \\ \text { Supervisors } & \begin{array}{l}\text { :Dr Jonathan Newton (Jonathan.Newton@vuw.ac.nz) } \\ \text { Dr John Macalister (John.Macalister@vuw.ac.nz) }\end{array}\end{array}$

Topic of the study: The cultural dimension of English education in Indonesian high school

\section{STUDENT CONSENT FORM}

- I have read the Information Sheet in both English and Bahasa Indonesia and I have understood what will be required of me if I participate in this study.

- I have been given the opportunity to ask and have had my questions about this study answered to my satisfaction.

- I understand that my participation in this study is entirely voluntary and I may choose to withdraw my participation no longer than two (2) weeks after I attend the final session of the data collections.

- I understand that I have the right to ask further questions at any time.

- I understand that the data collections will be audio- and/or video-taped.

- I understand that any information I give and my identity will be kept under the conditions of strict confidentiality. Initials and pseudonyms will be used.

- I agree to participate in this study and to provide any relevant information needed by the researcher and my parent/guardian has also given consent on his/her consent form.

$\begin{array}{ll}\text { Student's Name } & : \\ \text { Student's Signature } & : \\ \text { Date } & : 11 / 12 / 2015\end{array}$

If you would like to receive a copy of a written summary of this study at the end of this study, please tick here $\square$ and provide me with your e-mail address to which this summary can be sent. Otherwise, you may leave it blank.

$+\sin 1 \cdots+\cdots$

Note: Participant shall retain a completed and signed copy of this form

Page 1 of 2 


\title{
Appendix 13 : Student consent form (Indonesian)
}

- Indonesian version

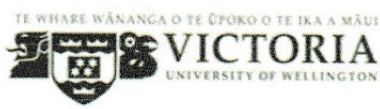

School of Linguistics and Applied Language Studies

Victoria University of Wellington

PO Box 600, Wellington, New Zealand

\author{
Peneliti : Muhammad Iwan Munandar (Iwan.Munandar@vuw.ac.nz) \\ Pembimbing : Dr Jonathan Newton (Jonathan.Newton@vuw.ac.nz) \\ Dr John Macalister (John.Macalister@vuw.ac.nz)
}

Topik riset: The cultural dimension of English education in Indonesian high school

\section{FORMULIR PERSETUJUAN SISWA}

- Saya telah membaca Lembar Informasi baik dalam bahasa Inggris maupun bahasa Indonesia dan saya memahami apa yang perlu saya lakukan jika saya berpartisipasi dalam riset ini.

- Saya telah diberi kesempatan bertanya dan pertanyaan-pertanyaan saya telah dijawab dengan memuaskan.

- Saya memahami bahwa partisipasi dalam riset ini sepenuhnya sukarela dan saya boleh menarik partisipasi saya dalam riset ini dalam jangka tidak lebih dari dua (2) minggu setelah sesi pengumpulan data yang saya ikuti.

- Saya memahami bahwa saya berhak untuk mengajukan pertanyaan pada tahap apapun.

- Saya memahami bahwa pengumpulan data ini akan direkam secara audio dan/atau visual.

- Saya memahami bahwa informasi apapun yang saya sampaikan dan identitas saya akan dijamin kerahasiaannya. Inisial dan nama samaran akan digunakan.

- Saya bersedia untuk berpartisipasi dalam riset ini dan memberikan informasi apapun yang sesuai dan dibutuhkan oleh peneliti dan orang tua/wali saya juga telah memberi persetujuan atas partisipasi saya dalam formulir persetujuan.

$\begin{array}{lll}\text { Nama siswa } & : \frac{1,}{2}, \ldots, \\ \text { Tanda tangan siswa } & : & 11 / 12 / 2015 \\ \text { Tanggal } & : 11, \ldots\end{array}$

Jika Anda berminat menerima salinan ringkasan riset ini setelah riset selesai, silakan contreng kotak berikut ini $\square$ dan tuliskan alamat surel Anda di kotak di bawah ini. Jika tidak, biarkan kosong.

F

Page $\mathbf{2}$ of $\mathbf{2}$ 
Appendix 14 : DIKNAS field-work permission

\section{PEMERINTAH KABUPATEN JEMBER \\ DINAS PENDIDIKAN}

J Dr. Subandi No. 29 Kotak Pos 181 Telp. (0331) 487028 Fax. 421152 Kode Pos 68118

JEMBER

REKOME NDASI

Nomor: $072 / 28 / \pi / 413 / 2015$

TENTANG

IJIN PENELITIAN

Dasar : Surat Rekomendasi dari Badan Kesatuan Bangsa dan Politik Kabupaten Jember nomor : 072/1301/2015, tanggal, 12 Agustus 2015

MENGLINKAN :

$\begin{array}{lll}\text { Nama } & : & \text { MUHAMMAD MWAN MUNANDAR, SS, MAPLING } \\ \text { NIM } & : & 300303426 \\ \text { Alamat } & : \text { Po box 600, Wellington, New Zealand } \\ \text { Fakuttas } & : \begin{array}{l}\text { Prodi Applied Linguistics Fak Of Humanities and Social Scienoes } \\ \text { VUW }\end{array} \\ \text { Kepertuan } & \begin{array}{l}\text { Melakukan Ijin Penelitian yang melibatkan Guru Bahasa } \\ \text { Inggris dan Siswa SMA dan SMK Negeri/Swasta di Kabupaten } \\ \end{array} \\ & \text { Jember. }\end{array}$

Yang akan dilaksanakan pada :

Tanggal : 01 September s.d. 31 Desember 2015

Tempat : SMA dan SMK Negeri / Swasta , di Kab. Jember

\section{Dengan catatan :}

1. Penelitian ini benar-benar untuk kepentingan Pendidikan;

2. Tidak dibenarkan melakukan aktivitas politik;

3. Apabila situasi dan kondisi wilayah tidak memungkinkan akan dikakukan penghentian kegiatan;

4. Tidak mengganggu kegiatan belajar mengajar di sekolah.

Demikian surat ijin ini dibuat untuk dipergunakan sebagaimana mestinya.

\begin{tabular}{ll} 
Ditetapkan di & : Jember \\
Tanggal & $: 13$ Agustus 2015 \\
\hline
\end{tabular}

Tembusan : Yth

1. Kepala Dispendik Kab. Jember sebagai laporan
a.n.Kepala Dinas Pendidikan Kabupaten Jember

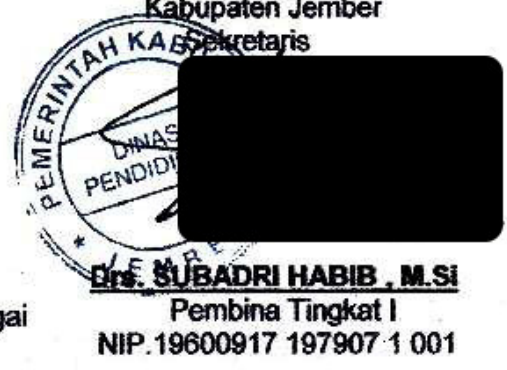


Appendix 15 : KEMENAG field-work permission

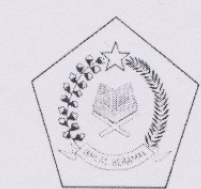

\section{KEMENTERIAN AGAMA KANTOR KABUPATEN JEMBER}

Jl. Bengawan Solo No. 2 囬 337130 JEMBER

$\begin{array}{ll}\text { Nomor } & : \text { Kd. } 15.32 / 2 / \mathrm{PP} .00 / 5238 / 2015 \\ \text { Lampiran } & : 1(\mathrm{satu}) \text { Bendel Prososal }\end{array}$

Jember, 21 Agustus 2015

Perihal : Rekomendasi

Kepada Yth.

1. Kepala MAN 1 Jember

2. Kepala MAN 2 Jember

3. Kepala MA Annuriyah Jember

4. Kepala MA Darus Sholah Jember

Di

Jember

Berdasarkan Surat Sdr. Muhammad Iwan Munandar, SS., MAppLing tanggal 27 Juli 2015 perihal Permohonan Ijin Penelitian, kami merekomendasikan kepada:
Nama
Jabatan
: Muhammad Iwan Munandar, SS., MAppLing
: Mahasiswa Victoria University of Wellington
Program Studi : Applied Sciencess

untuk dapat melakukan penelitian:

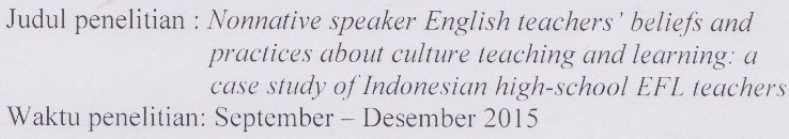

Demikian rekomendasi ini, atas pehatiannya disampaikan terima kasih.

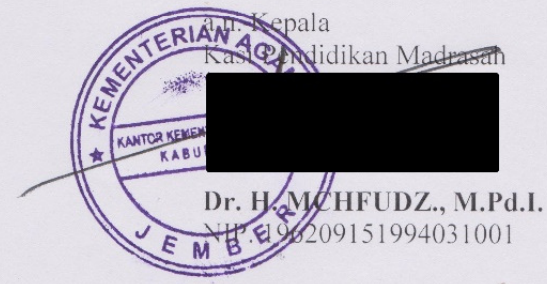

Tembusan:

Kepala Kantor Kemenag Kabupaten Jember 


\section{Appendix 16 : Transcription confidentiality form}

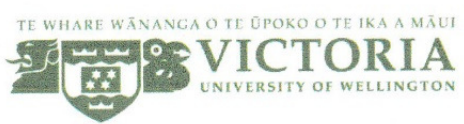

Transcribing Confidentiality Form

Project topic: The cultural dimension of English education in Indonesian high school

Principal investigator: Muhammad Iwan Munandar

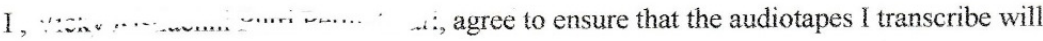
remain confidential to Muhammad Iwan Munandar and myself. I agree to take the following precautions:

1. I will ensure that no person, other than Muhammad Iwan Munandar, hears the recording and reads the transcription.

2. I will ensure that no other person has access to my PC.

3. I will delete the files from my PC once the transcription has been completed.

4. I will not discuss any aspect of the recording and transcription with anyone except

Muhammad Iwan Munandar.

Date : November 30th, 2015

Signature :

Page 1 of 2 


\section{Appendix 17 : Translation confidentiality form}

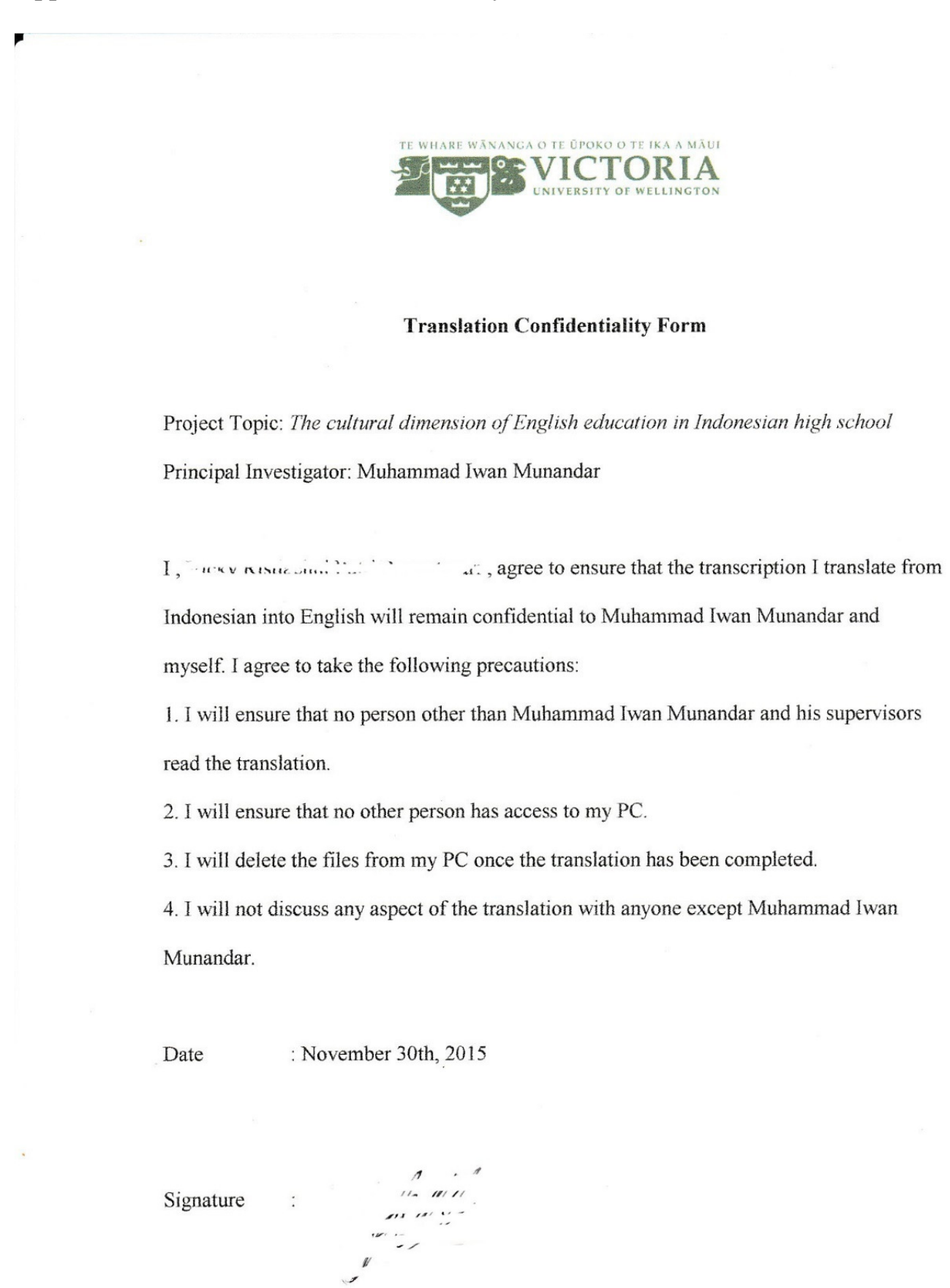

Page 1 of 2 


\section{Appendix 18 : Observation protocol}

\section{Observation protocol}

- Observer's role: non-participant. That is, the observer does not take any active part in the classroom that is being observed. The observer's activities are limited to observing the teachers and students' teaching and learning activities as well as taking notes and making audio-visual recordings of these practices. Nonetheless, due to the focus of this study, a closer attention will be given to teachers' activities rather than to students' activities.

- What to observe: During classroom observations, observed are the teachers' practices of exploring cultural issues, discussing cultural materials and/or providing culture learning opportunities for the students. A particular attention will be given to the way teachers represent cultures, introduce students to the linguistic and cultural diversity of today's English users, familiarize students with the use or role of English in intercultural communication, highlight cultural values of different language expression as well as establish links between target-language, international, and local students' culture.

- What to collect: The dat a to be collected comprise evidence of discussions or explorations of cultural components in teachers' teaching practices, teaching materials used in the observed classes, and classroom interactions in general. These may include evidence of students' learning activities despite less attention being paid.

- What to record: In these classroom observations, the teachers' culture teaching practices are audio-visually recorded. These include teachers' delivery of the lessons and managing class activities. The focus will be on teachers' exploration of cultural issues and provision of culture learning opportunities for the students, particularly the ways teachers deal with cultural input, how they explain cultural components, teachers' set-up and management of tasks and activities that encourage students' culture learning, teachers use of teaching materials or other teaching-learning resources.

- How to record: Recordings of the classroom observations will be in the form of audiovisual or video recordings and field notes. Video recordings and note takings will be conducted in silence and in a manner that is as unobtrusive as possible. These recordings will also be used in Stimulated Recall (SR) interviews.

Page 1 of 1 


\section{Appendix 19 : Interview protocol}

\section{Interview protocol and questions}

\section{Institutions: SMA/SMK/MA}

Interviewee (Title and Name)

Interviewer: Muhammad Iwan Munandar

Survey Section Used:

\section{A: Culture}

B: Language-Culture

C: Culture in EFL/Indonesia's EFL

D: NNS EFL teacher (NNEST)

E: Classroom actions and Learning

Other topics discussed:

Documents obtained:

Post interview comments or leads:

The cultural dimension of English education in Indonesian high school

Introduction

- Thank you for agreeing to participate, signing the consent form

- Voluntary participation

- Purpose of the study

- Purpose of the interview

- In English or Indonesian, or both

- Confidentiality

- Initials/pseudonyms

- Possible topic/theme/subject/issue

- Audio-recorded 
- 90-120 minutes

- One session or two consecutive sessions

- Toilet break

- Question?

Indicative questions

\section{- A: Culture}

- What comes to your mind when you hear the word 'culture'?

- Do you believe that culture can or may change? Why/why not?

- If you happen to meet some people who are culturally different from you, do you think their behaviour is representative of their cultural group? Why/why not?

- If you happen to find some people's action inappropriate, do you think that this is because they belong to a particular culture? Why/why not?

- Do you see that people's behavior as the essence of their culture, and that all people from that culture will behave in that way? Why/why not?

- Do you believe your culture is in some way better than other culture? Why/why not?

\section{- B: Language-Culture}

- Have you ever made direct contact with people from different cultural background? If so, please explain briefly

- Do you think cultural values of the people you meet influence the way they communicate? Why/why not?

- In this case, do you agree that the differences in communication style and language expression between people coming from different cultures result from their different cultural values? Why/why not?

- In general, how do you think culture may relate to language, or language to culture?

\section{- C: Culture in EFL/Indonesia's EFL}

- As an English language teacher, what culture is relevant to English language teaching in Indonesia?

- In your opinion, how important is making your students aware of the linguistic or cultural diversity of today's English speakers? Why/why not?

- How important is local or students' culture in English language education?

- Does it mean that you also want your students to have cultural skills?

- Do you think the existing curriculum facilitates the development of students' cultural awareness or skills? Why/why not?

- Do you think current textbooks and other teaching-learning resources supplied by the Ministry provide relevant cultural information? Why/why not? 


\section{- D: NNS EFL teacher}

- As a local NNS English teacher and in view of your current experience, do you feel confident of introducing target-language culture to your students? Why/why not?

- In this case, do you think being a NNS teacher in ELT is an advantage? Why/why not?

- Do you think your familiarity with students' native culture is also an advantage? Why/why not?

- Do you see yourself as a kind of role model for your students in terms of cultural awareness or skills?

- How important is information and communication technology (ICT) to the development of students' intercultural awareness?

\section{- E: Classroom actions}

- How do you highlight the importance of cultural awareness in English language teaching?

- In what ways do you familiarize students with underlying cultural values implied in different language expressions?

- How do you get students' attention to culture-specific expressions?

- In what ways do you explore the relationship between language and culture?

- How do you introduce your students to the linguistic and/or cultural diversity of today's English users?

- In what ways do you compare target-language, students' culture and/or international culture?

- How do you make students reflect on their native culture, and establish links between target-language or international culture and students' culture? 


\title{
Appendix 20 : Narrative Frame (English)
}

\begin{abstract}
These are your stories about occasions in your classroom teaching when you have addressed topics to do with English speaking people, countries using English, and interacting in English in the real world, that is either between native and non-native speakers of English or between the non-natives ones. Please tell your stories in the blank spaces below. Feel free to use an extra sheet if you wish.
\end{abstract}

Some of these topics that have recently come up in my English classes include interpersonal and transactional materials. The materials are presented in the form of expressions or dialogues. They, of course, deals with actions or attitude how to use the expressions in daily activities. A topic that / found particularly challenging to explain was the transactional topic because the materials involve other people. It means that to practice the expressions, the students must interact with others. It need a well-comprehension about the culture of with whom he, she is speaking. What I realize from this experience is that when the students don't know the cultures of their partner they are speaking with. Their communication would be ineffective then.

Some students have asked me about English speaking people or countries are whether the natives speakers speaks in proper grammars as we do as English learners. I Answer "Yes, Of Course". They think the native speaker don't speaks in proper grammar. Yes I told them that they are the same with us Indonesian as English learners.

Dealing with grammar materials, my students say that it is the most difficult materials. That is because of the different verbs used in different time in English. It is quite different compare with Indonesian language. There is no change of verb in different time. They said that English grammar so complicated. The students often makes errors in expressing sentences involving grammar especially tenses. For instance; They said: I have eaten fried rice this morning instead of $I$ ate fried rice this morning. Of course it is my challenging to explain more about the tenses. I said to them that in expressing idea in English they don't need to think so much about grammar. They just express what they think. As far as their speaking is understandable, it will be ok. They feel happy and well-supported with my encouragement.

Last but not least, I always encourage the students in learning English. Don't be shy or afraid to practice especially the spoken one. By practicing more they will be able to speak fluently with grammatically correct. I said that "Mistake is not always mistake in English. Mistake is learning". That's the end of my story. [Ana] 


\section{Appendix 21 : Narrative Frame (Indonesian)}

Berikut adalah cerita ringkas tentang peristiwa atau kejadian dalam kelas ketika Anda membahas tema yang berkaitan dengan penutur bahasa Inggris (baik penutur asli/native speaker maupun non-penutur asli), negara-negara berpenutur bahasa Inggris, dan interaksi di huar kelas menggunakan bahasa Inggris, baik antara non-penutur asli dengan penuiur asli maupun antara non-penutur asli. Tuliskan cerita Anda di bagian kosong di bawah ini. Silakan gunakan lembar tambahan jika perlu.

Sejumlah topik tentang tema diatas yang akhir-akhir ini muncul dalam kelas bahasa Inggris saya antara lain ketika membicarakan ungkapan/ekspresi dalam bahasa Inggris, mereka mempertanyakan perbedaan antara ungkapan/ekspresi dalam bahasa Indonesia dan bahasa Inggris.

Topik yang paling menantang adalah....ada banyak topik yang menantang... apabila siswa menanyakan ungkapan/ekspresi dalam bahasa Indonesia yang ditanyakan dalam bahasa Inggris karena saya tidak bisa langsung menerjemahkan secara literal ke dalam bahasa Indonesia, karena saya harus tahu dari penutur aslinya dan saya rasa ungkapan atau ekspresi berbeda dengan belajar struktur dan grammar. Contoh, ada pertanyaan dari siswa, $\mathrm{Bu}$, apa bahasa Inggrisnya "Hormat, gerak"

Situasi kelas ketika saya/siswa menelaah topik-topik itu adalah siswa biasanya akan gaduh dan ramai, karena mereka juga akan bertanya yang "nyleneh".

Yang saya pahami dari kejadian tersebut adalah bahwa anak-anak/siswa mempunyai rasa penasaran yang tinggi tentang perbedaan bahasa Indonesia dan bahasa Inggris.

Berkaitan dengan topik-topik tersebut, salah satu yang saya anggap penting adalah saya harus selalu mengajarkan siswa tentang adat ketimuran dan atau budaya Muslim itu berbeda dengan budaya barat karena bagaimanapun juga belajar bahasa Inggris penting untuk menguasai dunia global, tetapi jangan sampai terkontaminasi dengan budaya Barat yang non Muslim.

Namun demikian, hambatan utamanya mungkin adalah apabila saya punya pertanyaan dari siswa yang menanyakan tentang ungkapan dalam bahasa Inggris dan saya tidak tahu ungkapan dalam bahasa Inggrisnya, saya rasa saya membutuhkan penutur asli bahasa Inggris untuk tempat bertanya.

Saya juga pernah mengulas tentang ungkapan "love" (ada di KTSP kelas XI). Di dalam buku paket bahasa Inggris, disebutkan contoh-contoh ungkapan perasaan cinta dengan gamblang sehingga saya harus ekstra keras mengingatkan, menjelaskan dan menasehati anak-anak tentang bagaimana perbedaan sudut pandang "cinta" antara dunia "barat" dan "timur" dan "non-Muslim" dan "Muslim"

Berkaitan dengan topik-topik ini, saya paling suka membicarakan grammar karena belajar grammar sudah pasti sedangkan belajar ekspresi atau pragmatik (ungkapan) butuh pendapat dari penutur asli tentang bahasa ungkapan yang biasa digunakan di negara tersebut. [Yanti] 


\section{Appendix 22 : Interview transcript (Indonesian)}

... [introduction; ice-breaking; truncated] ...

Y : Ya sudah selesai KBM nya. Selesai tanggal 20 Desember.

$\mathrm{X}$ : Ini kan instrument saya sebenarnya ada $4 \mathrm{Bu}$, ini sebenarnya masih yang kedua. Observasi, lalu kalau sudah selesai validasi. Ini kan judulnya stimulated recall. Jadi lebih mengarah ke stimulasi. Ya terstimulasi lah kenapa begini. Selanjutnya kan nanti setelah ini selesai nanti double snap cuma dalam bentuk narasi. Instrument ketiga berdasarkan yang tertulis disitu. Kelas ini saja. Tapi kan kalau narasi, semuanya. Tapi yang istilahnya njenengan ingat dan jalankan, jadi lebih luas di semua pengalaman, sebetulnya. Wawancara kedua mungkin akan lebih panjang termasuk mungkin dari buku-buku itu saya akan coba bandingkan. Saya coba dulu ya Bu. Nanti saya hubungi situasinya disana seperti apa dengan Bu Ira. Saya minta nomor hape...

$\mathrm{Y}$ : Menemui kepala sekolah dulu apa nggak biasanya?

$\mathrm{X}$ : Prosedurnya begitu Bu. Selama ini kan juga begitu sebenarnya. Cuma kan Pak Yuda.... (?). kira-kira begitu $\mathrm{Bu}$. Tapi formalnya ya begitu dari Diknas.

$\mathrm{Y}$ : Biasanya begitu.

$\mathrm{X}$ : Nggih. Ini mungkin cerita yang tadi saya perlu untuk banyak hal, dan fokus saya disini Bu. Nah ini, simulated recall ini lebih ke kelas ini. Cuma juga saya spesifik ya Bu, jadi sesuai topic saya, sesuai apa... Saya sebenarnya off the record, ada beberapa teman ngajak nulis buku tho Bu. Saya bisa mungkin memposisikan dimana itu masih dari sisi content di apa. Juga saya lihat beberapa buku itu kan dari sisi kebahasaan, juga dari sisi lain. Kalimatnya bahasa Inggris, Bu. Tapi sense nya bahasa Indonesia. Jadi banyak hal lah. Yang ini jadi ada 3 kelas. Mungkin yang 1 sama 3 itu lebih banyak Bu, karena 3 itu lebih ke grammar, dan..........tes kemarin ya $\mathrm{Bu}$ ?

$\mathrm{Y}:$ Iya.

$\mathrm{X}$ : Tapi oke kan Bu? Ya memang kondisinya memang sepanjang itu. Nah ini, saya tarik-tarik dan saya seret-seret sesuai topic yang akan saya tanyakan.

$\mathrm{Y}:$ Ngajar apa adanya.

$\mathrm{X}$ : Nggih, nggih. Saya lebih kesana lah Bu. Jadi natural saja.

Y : Tapi nanti saya juga minta masukan kan penting ya. Mungkin ada hal-hal yang salah dari saya ketika saya mengajar, yang tanpa saya sadari sebenarnya itu penting tapi mungkin saya kok tidak memasukkan atau kesulitan memasukkan, nanti Pak Iwan bisa member masukan pada saya.

$\mathrm{X}$ : Sebenarnya bukan hanya Bu Ana, tapi saya lebih ke semuanya. Topik saya mengenai culture teaching. Ya saya coba explore complexitasnya. Ini yang pertama, ini ka nada nyayi terpujilah ya, hymne guru itu. Jadi, kalau kedua yang saya observasi, ini ada apa ya, terpujilah waktu itu, ada rayuan pulau kelapa, ya Bu ya. Kenapa kok harus ada nyanyi Bu? Kelas bahasa Inggris, nyanyi dalam bahasa Indonesia. Itu.

Y [Ana]: Gini, e.... Karena kan saya juga menanggapi apa yang diinformasikan oleh Bapak Anis Baswedan itu kan punya wacanabahwa untuk pembentuk karakterpeserta didik itu salah satunya pada awal pelajaran, 5 sampai 10 menit, memberikan materi-materi kepribadian. Dengan memberikan motivasi, bisa lewat media. Media itu bisa video, bisa lagu, atau anak-anak bisa diberi kesempatan untuk membaca buku non-pelajaran. Tujuannya apa, ya untuk mengawal anak-anak untuk suasana belajar yang menyenangkan, joyful learning, ya. Biar tidak terkesan pada mereka bahwa belajar itu harus membuka buku saja. Atau mengerjakan soal-soal saja. Tetapi harus diawali dengan suasana yang rileks, yang menyenangkan, yang tentunya nanti situasi itu...rentetannya adalah ke materi yang akan kita ajarkan. Berkenaan dengan saya mengapa waktu itu memilih lagu, karena 1 , saya juga ingin meningkatkan, apa ya, menggali kembali rasa-rasa nasionalisme anak. Kita tahu banyak ya, anak-anak itu sudah terkontaminasi dengan lagu-lagu yang tentunya litik-liriknya itu kurang. Untuk situasi seperti 
itu, anak-anak saya ajak untuk kembali ke lirik-lirik yang membuat nasionalisme anak-anak tumbuh, dan ternyata berhasil. Saya sangat merasa berhasil. Karena anak-anak senang, kemudian ketagihan mereka, mesti minta lagu-lagu, dan saya lagunya bervariasi. Itu yang pertama. Yang kedua, saya ingin menggali kemampuan berbicara anak-anak. Meskipun toh nanti materi saya ke grammar atau ke reading, tapi kemampuan berbicara tetap saya gali di awal. Karena saya ingin anak-anak berbicara sesuai apa yang mereka pikirkan saat itu. Jadi kontekstual. Setidaknya memorizing. Kalau dulu kan kita sekolah itu kan gini, hafalan ya. Anak-anak, the book is on the table. Maka dihafalkan, dibaca, terus hafal. Sehingga ketika kita ketemu di real life, kalau dengan turis atau apa, bisanya Cuma what's your name? anak-anak menjawab the book is on the table. Karena yang dihafalkan itu. Nah, yang saya harapkan tidak seperti itu. Anak-anak bisa merespon sesuatu sesuai dengan apa yang terjadi pada saat itu. Spontaneously. Dengan lagu itu sangat penting. Jadi ketika saya memberikan lagu, maka anak-anak kan ndak tahu lagu apa yang akan saya berikan. Dan ketika saya nyanyi, anak-anak kan meresapi lagu itu. Sehingga saya tanya responnya, opininya, terhadap lagu itu gimana. What's your opinion? What's the content of the song? Anak-anak akan bisa dengan sendirinya. Bahkan di kelas atas waktu itu ketika saya awal-awal masuk, saya ajak nyanyi lagu desaku, ya, mereka bisa mengekspresikan perasaannya dengan dengan mencucurkan air mata. Karena dia kangen dengan kampung halamannya. Why? Karena reminds me about my village. Nah, sebenarnya selain saya ingin mengeksplor ideas anak-anak, saya juga ingin mengeksplor speaking mereka. Saya yakin, ketika anak-anak berbicara, dan itu berasal dari dalam hati, maka itu akan lebih lancar daripada mengada-ada. Gitu lho. Ternyata saya merasa terkesan dengan itu. Jadi ada dua hal: yang pertama kita pembelajaran karakter, karakter nasionalisme itu, rasa cinta terhadap lingkungan, kan kita dengan menyanyikan akan membuat ingat akan batin kita.

$\mathrm{X}:$ Lagu Indonesia?

$Y$ : Tidak selalu. Bisa lagu-lagu lain. Tapi saya kalau yang lagu bahasa Inggris saya biasanya pakai video. Sepertu You Raise Me Up, yang anak-anak sudah familiar. Jadi seperti You Raise Me Up, kemudian Mother How Are You Today? Kemudian ada lagu barat juga. Lagu lama, apa tu, Que Sera-sera. Anakanak saya ajak itu kadang-kadang at the end of the study. Dan karaoke biasanya anak-anak bisa menirukan. Tapi di awal 5 menit selalu lagu Indonesia. Karena apa, karena begini Pak Iwan, saya lagu dikelas itu cara berinteraksi dengan anak-anak. Karena kalau di awal itu pakai video, kadang kita masih.... Jadi at the end. Biasanya ketika ada pembelajaran menggunakan LCD. Di akhir pelajaran baru saya memasukkan lagu-lagu yang tentunya selain untuk menghibur anak-anak ketika sudah belajar, juga membuat membuat anak-anak itu senang memutar video di akhir pelajaran. Jadi, say goodbye saya itu, anak-anak pada kondisi senang. Karena habis menyanyi. Habis menyanyikan lagu bersama-sama. Itu lagu-lagu yang familiar, yang simple.

$\mathrm{X}$ : Jadi kalau boleh diringkas ya $\mathrm{Bu}$, jadi ada kaitan dengan character education atau yang lebih spesifik dalam wacana bahasa Inggris yang saya lihat formatnya dari yang $\mathrm{Bu}$ Ana sampaikan harus ada interaksi menyampaikan lirik, do you feel.... Yang ketiga ini yang agak... Saya akan paparkan seperti ini, ada lagu nasionalis patriotic gitu ya. Dan itu dikaitkan dengan nasionalisme. Sedangkan disisi lain, itu di kelas bahasa Inggris. Kira-kira bagaimana Bu Ana melihat hal semacam itu. Kan agakkontradiktif ya. Di satu sisi ada patriotism, disisi lain, itu kelas bahasa Inggris. Itu salah satu aspek yang menarik menurut saya.

Y : Iya, makanya yang saya kira untuk mengimbangi itu, jadi bahasa Inggris juga jalan, juga lagu. Harus dicatat bahwa meskipun kita belajar bahasa asing itu nasionalisme harus tetap dipupuk didalam jiwa anak-anak dengan menyanyikan lagu nasional. Sebenarnya kebijakan pemerintah untuk mengurangi jam bahasa Inggris itu bukan berarti pemerintah tidak memberikan solusi. Pemerintah sudah 
memberikan solusi dengan menyanyi yang wajib, hanya 2 jam. Pemerintah sudah memberi solusi dengan member materi peminatan. Jadi pada akhirnya kelas $X$, ada dua jam wajib, ada 3 jam peminatan. Sehingga malah mereka dapat 5 jam.

$\mathrm{X}$ : Jadi masih mungkin ya, sebelumnya 4 jadi 2 sekarang malah dapat 5.

$\mathrm{Y}:$ Karena peminatan.

$\mathrm{X}$ : Tapi nggak semua ya Bu.

$Y$ : Nggak semua kelas X?

$\mathrm{X}$ : Peminatan disini dibagi ya $\mathrm{Bu}$ ?

$\mathrm{Y}$ : Kan memilih, jadi kita memilih. Untuk semester 2 itu peminatan yang dipilih untuk kelas $\mathrm{X}$, bahasa Inggris. Schingga memungkinkan anak-anak untuk mendapatkan materi bahasa Inggris lebih banyak. Nah kalau sekolah lain saya kurang tahu.

$\mathrm{X}$ : Jadi dikembalikan ke sekolah ya $\mathrm{Bu}$, peminatannnya apa.

Y : Iya, jadi kita mengakomodir. Kan kita dituntut 24 jam. Lamanya 24 itu Pak, untuk berkualifikasi memenuhi syarat sebagai guru SMA itu kan 24 jam. Ketika guru itu berlebih di sekolah, tapi materinya kurang, jamnya itu kurang, maka itu salah satu cara untuk mencari sumber daya. Kalau cara itu sudah tidak bisa mengcover, ya, mau tidak mau guru itu harus mengajar sungguhan 24 jam, seperti PPKN, seperti itu.

$\mathrm{X}$ : Di sekolah lain?

Y : Iya, disini harus. Padahal di sekolah lain, yang namanya semua ingin 24 jam. Ya sebenarnya sih tidak, apa ya istilahnya, itu yang menjadi pertanyaan guru-guru. Sama, bukan hanya Pak Iwan. Tapi rasionalnya itu, ya memang kadang-kadang di kurikulum 2013 itu kan berbunyi bahwa kita harus, standart kelulusannya itu, kita harus menguasai ilmu pengetahuan, keterampilan, dan sikap untuk berinteraksi secara nasional dan internasional. Nah otomatis kalau kita bisa berinteraksi secara internasional itu salah satu modalnya kan dibidang bahasa asing. Nah, kontradiksinya disitu. Kurikulumnya begitu, tapi ada solusi materi sastra.

$\mathrm{X}$ : Saya agak loncat-loncat, gini ya $\mathrm{Bu}$,

$\mathrm{Y}$ : Iya monggo, saya jawab sebisa saya.

$\mathrm{X}$ : Sangat menarik $\mathrm{Bu}$, dari $\mathrm{Bu} \mathrm{Ana}$, dan responden lain. Saya coba dari pattern meneliti, dari penjelasan yang sangat luas dan kaya ini. Ini kan di materi ini ada compliment, ada sympathy atau care. Disini saya lihat menggunakan video. Nah, jadi kan menggunakan educational material itu ya. Jadi sumbernya darimana $\mathrm{Bu}$ ?

$\mathrm{Y}:$ Saya dari...

$\mathrm{X}$ : Dari YouTube, tidak melulu dari YouTube kan $\mathrm{Bu}$ ?

$Y$ : Ya pokoknya saya mengakses dari internet, lalu saya ambil.

$\mathrm{X}$ : Apa saja $\mathrm{Bu}$, yang dipertimbangkan saat memilih materi semacam itu?

Y : Yang saya pertimbangkan pertama tentunya kesesuaian dengan materi yang saya ajarkan. Misalnya compliment, saya cari video tentang compliment. Nah, setelah itu, disitu kan banyak muncul, model conversation, model videonya, tampilannya, macem-macem. Setelah itu saya pilih yang sesuai dengan konsumsi anak-anak. Peserta didik saya SMA, sisi budayanya juga harus ada, sisi entertainment nya. Saya pilih itu kalau saya mau pakai. Ada banyak, tapi saya pilih yang anak-anak masih bisa menangkap dan nanti saya punya kesempatan anak-anak itu bisa menirukan. Ada educationnya disitu. Sehingga saya pilih video yang anak-anak itu nantinya menirukan. Seperti itu pertimbangan saya. Atau sesuai dengan karakter.

$\mathrm{X}$ : Jadi dari sisi kebahasaan, kesesuaian, .... 
Y : Tampilan, layak ndak ini dikonsumsi anak-anak saya SMA.

$\mathrm{X}$ : Kalau tadi sesuai budaya itu apa? Bu Ana menerjemahkan budaya itu seperti apa?

$\mathrm{Y}:$ Budaya ya...

$X$ : Perbedaan dari aspek apa, sisi apa...

Y : Ya kalau saya sih dilihat dari pakaian juga ya, kemudian bahasa juga yang dipakai. Tingkat kesulitan, kan banyak video disitu. Ada tingkat kesulitan yang menurut anak-anak saya terlalu sulit, itu tidak saya ambil. Kalau masalah dari segi budaya ya itu saya kira, yang tampilan pelakunya di video itu sesuai dengan anak-anak sehingga tidak menimbulkan apa ya "pikiran" yang kurang bagus. Pakaian yang dipakai kok seperti ini, tidak sesuai dengan budaya kita, gitu misalnya. Itu yang jadi pertimbangan saya. Kalau yang lain-lain, ga ada saya kira.

$\mathrm{X}$ : Ini kutipan langsung dari (video playing) jadi salah satu instruksi yang Bu Ana sampaikan itu (video playing).

$\mathrm{Y}:$ Oh itu,

$X:$ Iya.

$Y$ : Itu saya ini Pak,

$\mathrm{X}$ : Iya mengisi sesuai situasi gitu ya Bu kalau ga salah

$\mathrm{Y}$ : Iya jadi ini kan menginformasikan kepada anak-anak kalau bentuk tesnya, kalau materinya itu, materi dialognya, tesnya ada 2 anak-anak. Yang pertama itu anda mencari topiknya, judulnya, jadi misalnya Oh, you're very great, itu very great nya di underline itu termasuk apa? Atau dialog tumpang. Dialog tumpang itu misalnya A mengatakan $I$ had an accident last night. Lalu ekspresi apa yang harus disampaikan oleh B? ada opsi B: I'm sorry to hear that, B: I'm happy to hear that, B: Oh, great!, B: Oh very nice, kan gitu ya. Nah, anak-anak kan harus memilih itu. Oh ini kok situasinya tentang kesedihan, berarti saya harus menjawab dengan I'm sorry to hear that. Nah itu yang saya maksud. Tapi saya menginformasikan materi alam ujian nasional yang akan keluar seperti ini. kalau ujian nanti anak-anak akan listening comprehension, jadi anak-anak tahu.

$\mathrm{X}$ : Ini kalau dalam bahasa menyebutnya speech acts, tindak tutur Bu. Kalau di SMA, apa Bu, interpersonal?

$\mathrm{Y}:$ Iya, interpersonal, ketika kita berbicara dengan seseorang.

$\mathrm{X}$ : Nah, di beberapa kesempatan disini, ya itu kan anda juga menyampaikan terjemahan Indonesianya. Nah, kira-kira pernah ndak Bu, dibahas dan dibandingkan baik dari sisi struktur, kadang ka nada beberapa misalnya sisi directness, gitu ya, dari sisi politeness, nah semacam itu.

Y : Untuk materi-materi tertentu, kadang-kadang saya bahas. Tapi kalau untuk complimenting itu kan saya kira tidak ada perbedaan dalam bahasa Indonesia dan Inggris.

$\mathrm{X}$ : Kadang-kadang beda jauh Bu...

$\mathrm{Y}$ : Kalau saya itu mugnkin hanya masalah penggunaan saja. Penggunaan tata bahasa. Itu saya jelaskan. Kalau masalah tingkat kesopanan politenessnya itu ya saya jelaskan. Ketika ingin mengatakan dengan lebih sopan ya gunakan saja I would like to say something to you. Jadi ya kadang-kadang saya serukan. Apa sih, bagaimana sih cara menyampaikan dalam bahasa Inggris itu, ada ndak perbedaan per level atau seperti bahasa daerah. Saya jelaskan dengan bahasa Jawa. Kebetulan anak-anak tahu bahasa Jawa. Ada kromo inggil, dan lain-lain. Tetapi tidak semua materi kan bisa masukkan kesitu. Seperti complimenting kita ga perlu. Tapi kalau misalnya request, itu kita perlu. Shut the door, please, itu mesti saya jelaskan. Dan didalam buku itu ada kok levelnya. Misalnya kalau polite itu mau seperti ini, ada. Itu kan unsur budaya juga ya Pak ya.

$\mathrm{X}$ : Nah, ini yang diobservasikan ini yang menarik, setidaknya menurut saya. Nah, ini kan menggunakan video kreasi anak-anak sendiri 
Y : Iya, itu juga ada tujuannya.

$\mathrm{X}:$ Apa itu Bu?

Y : Ya, supaya mereka melihat, kalau ada yang bisa membuat video seperti ini, maka anak-anak juga harus bisa next time. Jadi semester 2 anak-anak membuat seperti ini. Semester 1 saya suruh buar dialog dan presentasi di depan kelas. Setelah tampil, minggu depannya saya suruh membuat materi complimenting, congratulation, dan presentasi. Next semester 2 saya suruh membuat ini (video).

$\mathrm{X}$ : Berarti ini sudah pada bisa ya $\mathrm{Bu}$, membuat dialog direkam dalam bentuk video.

Y : Iya, sudah biasa. Malah kemarin introductionnya sudah dalam bentuk video Pak, yang introduction anak-anak. Sudah direkam sendiri, dan yang tidak mengumpulkan ya saya beri punishment. Itu yang pengalaman pertama. Nanti yang semester 2 , harapan saya kan anak-anak sudah mulai terlatih bahasa Inggrisnya, pronunciationnya, dan sebagainya. Sehingga nanti kalau direkam kan bagus. Nah, ini salah satu contoh jadi saya ada tujuannya saya milih yang ini, kenapa tidak yang native, kayak gitu ya. Karena anak-anak saya tunjukkan, ini lho mereka bisa, kenapa anda tidak bisa. Kita harus bisa dan kalau ada yang mau mengunggah/posting di YouTube bisa.

$\mathrm{X}$ : Yang sebelumnya itu kan native ya $\mathrm{Bu}$. Yang ini jelas-jelas local dalam arti siswa sini. Biasanya yang sering Ibu dengar kan rujukannya native. Terus apakah misalnya kan kalau British, atau New Zealand, itu kan tidak seberapa terdengar. Pernah ga $\mathrm{Bu}$, siswa mempertanyakan misalnya "Apakah saya harus mendekati kemampuan native speaker?" "Apakah saya harus meniru?" atau dalam dirinya sendiri ada pemikiran bahwa native, non-native itu seperti apa?

$\mathrm{Y}$ : Kalau saya itu kok cenderung kita apa adanya ya Pak ya. Saya menginginkan anak-anak itu...

$\mathrm{X}$ : Seperti apa, apa adanya itu?

Y : Apa adanya itu ya seperti saya. Saya ga punya pikiran saya harus menjadi native. Jadi Javanese, jadi apa adanya saya. Saya hidup di Jember, maka semampu saya seperti ini. Yang penting pronunciationnya betul, mendekati betul, terus lancer, gitu. Nah kan, kalau kita ingin membentuk mereka harus seperti native, saya saja kesulitan, apalagi anak-anak. Ya udah yang penting anda apa adanya, yang penting pronunciationnya usahakan betul. Kalau style of speaking nya ya yourself. Gitu. Accentnya yourself aja. Saya juga sering mengatakan pada anak-anak (38.09-I can't hear it properly). Jadi anda harus paham itu. Jadi berhasa Inggris itu ga harus begini, begitu, dan sebagainya. Itu ga harus. Karena kita ga bisa menjadi orang lain. Kalau saya itu Pak. Makanya saya fokus mencontohkan itu. Bukan anda ketika membuat complimenting harus seperti ini. Saya hanya berkata seperti itu. Biar mereka berfikir sendiri kalau native itu bahasanya begini, pronunciationnya, cara mengucapkannya begini, kalau local itu ya seperti ini, tapi selama masih betul kan gapapa.

$\mathrm{X}$ : Nah, sudah. Ini kan yang saya lihat hamper di semua kelas mungkin lebih dari $95 \%$ itu bahasa Inggris Nah, dalam kaitan antara native dan non-native, masih terkait dengan Bu Ana, setidaknya apakah mereka memandang Ibu sebagai role-model, sebagai acuan, sebagai contoh kurang lebih nanti anda bisa, pada titik tertentu melakukan ini, mungkin tidak secara eksplisit. Adakah pemikiran seperti itu atau?

Y : Kalau saya sih, apa ya, karena saya sendiri merasa ya apa adanya saya. Jadi saya juga tidak meminta anak-anak untuk seperti saya atau seperti siapa, yang penting mereka itu mengenmbangkan kemampuan diri mereka itu berdasarkan kemampuan dia dan gaya dia seperti apa, ya itu dikembangkan. Karena disini banyak juga Pak, anak-anak yang bahasa Inggrisnya bagus sekali menurut pendapat umum sudah seperti native. Ya karena itu kan mungkin bukan awal dia mengenal bahasa Inggris, mungkin sejak dari TK, dan SMP sudah pernah bertemu dengan orang native, sehingga dia bisa seperti itu. Kan bisa jadi Pak. Ketika dia dipaksa sejak SD, SMP, maka akan mempengaruhi gayanya, actionnya, dia akan jadi 
seperti native. Sehingga sekarang SMA dia jadi seperti itu. Banyak seperti itu. Sehingga saya tidak bisa mengajak mereka untuk bisa seperti saya. Tapi saya berusaha semaksimal mungkin untuk menggunakan bahasa Inggris dengan baik dan benar. Pronunciation, benar, meskipun kadang ada slip tongue, ya mungkin nanti lancar. Kan endingnya begitu. Tapi saya selalu fokus untuk berkata as long as your English is understandable, it's okay. Saya gitu. Jadi a mistake isn't a mistake in English. Jadi kesalahan bukan berarti kesalahan dalam bahasa Inggris, tetapi adalah learning, kan begitu. Sehingga anak-anak tidak takut untuk berbicara bahasa Inggris dan tidak harus berkiblat pada native, tidak, yang penting kamu lancar, bisa memproduce kata-kata dengan runtut sesuai dengan kaidah bahasa. Itu sudah bagus, saya gitu.

$\mathrm{X}: \mathrm{Bu}$, ini kan anda setidaknya sudah lingkup ASEAN ya? Sudah ppernah ke Thailand.

Y : Ya. Singapore dan Malaysia.

$\mathrm{X}$ : Malaysia bahkan ya. Nah itu kan kalau dari perspektif EFL, English as Foreign Language, atau yang sekarang lebih sering disebut English as International Language, pernah ga Bu, penggunaan bahasa Inggris sesame non-native dengan latar belakang budaya dan bahasa berbeda dalam konteks internasional ini anda sampaikan pada anak-anak?

$\mathrm{Y}$ : Konteks saya ke luar negeri itu kan yang tugas kedinasan hanya sekali, yang ke Thailand itu saja karena yang guru teladan itu. Itu diberi reward ke luar negeri satu minggu ke Thailand. Saya waktu itu mengunjungi sekolah SD, SMP, SMA terpadu di Thailand. Itu luar biasa. Kalau ga salah 6000 siswanya.

$\mathrm{X}$ : Dalam satu kompleks?

Y : Dalam satu kompleks. Ya kalau disana itu bahasa Inggrisnya saya rasa sama lah ya dengan kita, lebih banyak orang Indonesia dan accentnya juga lebih bagus kalau dibandingkan Thailand, dari yang saya petik.

$\mathrm{X}$ : Lebih sulit dipahami ya $\mathrm{Bu}$, accentnya?

Y : Ya, lebih sulit dipahami. Apalagi yang kayak Malaysia itu kan accentnya Malaysia banget. Kalau Singapore lebih ke Taiwan, ke Mandarin. Kalau Thailand itu mungkin hamper sama dengan Indonesia tapi lebih sulit sana dengan Indonesia. Yang kedua, saya juga punya penngalaman 10 hari bersama orang Vietnam. Saya sebagai Listen Officion.

$\mathrm{X}:$ Dimana?

Y : Disini, di Jember. Itu tahun 2009 itu event volleyball ASEAN. Myanmar, Vietnam, Thailand, pemin volley muda. Kebetulan saya LO nya Vietnam. Kan anak putra-putri. Anak 10 dengan coach nya. Mereka itu bahasa Inggris nya sangat tidak bagus sehingga saya pakai bahasa lisan. Begitu pula dengan coachnya. Coachnya itu pada saya tidak memanggil Miss Ana, tetapi Mit Ana. Kayaknya orang Thailand itu tidak bisa ngomong $\mathrm{S}$ kayaknya.

$\mathrm{X}$ : Vietnam..

Y : Iya, Mit. Ana begitu. Saya mengambil kesimpulan bahwa Indonesia jauh lebih bagus. Kalau yang ke Singapore itu konteksnya saya hanya travelling saja, sehingga secara educational saya tidak masuk Malaysia juga seperti itu. Tidak ada kunjungan-kunjungan secara edukatif. Ya cuma di Thailand. Saya tidak bisa merekam gimana, tapi kesimpulan saya setelah mengikuti seperti kemarin, saya mengikuti presentasi para kepala sekolah se-ASEAN di symposium. Di symposium ka nada lomba to Pak, ada lomba KTI, ada inobel, inovasi pembelajaran, terus ada kepala sekolah berprestasi seluruh ASEAN. Kemarin itu kalau ga salah ada 15 negara. Saya pas mengikuti. Waktu itu ada yang dari Singapore, dari india,....

$\mathrm{X}$ : Sebentar lagi kepala sekolah? 
Y : Saya? Oh. Nggak Pak. Ini aja pulang jam 4 pikirannya sudah dirumah. Kemarin saya ngikuti, kebetulan gini, kemarin itu kita ada acara dengan Pak Anis Baswedan di forum, kan kita dilepas, di Istora itu....

$\mathrm{X}$ : Banyak acara ya Bu?

Y : Iya, disana di sekat-sekat. Di kenanga 1, itu presentasi guru SD, lalu Kimia. Kenanga 2, apa ya, terus SMP, bahasa Inggris. Ketika saya masuk ke ruangan, itu sudah penuh. Terus saya cari ruangan kosong. Ternyata disitu ada space kursi kosong untuk duduk berempat. Nah, ternyata itu ruangan kepala sekolah.

$\mathrm{X}$ : Nggak sengaja lah.

$\mathrm{Y}$ : Nggak sengaja... karena semuanya penuh lalu di lantai 2 kok ada ruang kepala sekolahlalu saya nonton. Kok ternyata yang tampil itu 4 orang, ibu-ibu semua.

$\mathrm{X}$ : Dari mana saja?

$\mathrm{Y}$ : Dari Singapore, yang satunya dari Myanmar, yang satunya...

$\mathrm{X}$ : Setingkat SMP, SMA, campuran?

Y : Kayaknya campuran. Mereka presentasi kiat-kiatnya dia berprestasi. Jadi otomatis English kan begitu. Terus mereka presentasi menggunakan power point, dengan tampilan dan segala macam, membawa kurikulum dan semuanya. Dan ada satu orang Indonesia diantara 4 orang itu. Kemudian ada tanya jawab, tapi karena saya datangnya terakhir jadi mereka sudah presentasi lalu tanya jawab jadi saya ga $100 \%$ mengikuti lah. Kan kalau kita nggak tahu substansinya ya ga berani tanya lah. Terus yang tanya dalam bahasa Inggris. Ada yang mempertanyakan kurikulumnya, dan ternyata mereka hamper semuanya kepala sekolah. Tahunya kenapa, kan pada waktu pembagian konsumsi jam 12 ada pengumuman untuk para participants, silakan keluar dan kepala sekolah silakan didalam. Kebetulan kita makan siangnya didalam bus untuk grup saya.kan kemarin itu orang bahasa itu 500 Pak. Bahasa Perancis, Jepang, Inggris, SMP, SMA. Ya pokoknya yang ada di kurikulum peminatan kan ada bahasa Perancis, Jepang, Mandarin, Arab, dan sebagainya, penulisnya kumpul ada 500 orang. Jadi diundang itu dalam kapasitas sebagai penulis modul. Yang lain diundang dengan kapasitas sebagai peserta KTI, inobel, macam-macam. Jadi kalau masalah bahasa kesimpulan saya setelah melihat yang dari Singapore ya akhirnya cenderung ke Mandarin juga. Bahasanya cenderung ke Mandarin. Yang India juga kayaknya ke native agak jauh juga bahasa Inggrisnya. Yang agak ke native itu Indonesia.

$\mathrm{X}$ : Dari pengalaman ibu tadi...

$\mathrm{Y}$ : Karena kalau kita nggak tanamkan ke anak-anak... Menurut Pak Iwan bagaimana? Sekarang saya tanya Pak Iwan sebagai observer.

$\mathrm{X}$ : Saya juga ditanya?

Y : Iya se. Sebenarnya ga lengkap tanpa (49.56. nama seseorang). Banyuwangi banget dia. Accentnya Javanese banget dia. Ethnic banget sangat medok. Lancar, tapi Javanese banget. Itu seandainya bisa masuk ke Pak Iwan juga, lengkap. Itu Pak Iwan, menurut Pak Iwan gimana kondisi yang seperti itu? Sekarang ganti saya yang nanya Pak Iwan. Pak Iwan kan sudah melanglang buana.

$X$ : Nanti aja setelah ini selesai. Nanti bias. Bukan ga mau.

Y : Saya kan juga perlu belajar dari Pak Iwan.

$X$ : Atau setidaknya setelah report saya selesai. Untuk yang inisaya tunjukkan lagu, terus selesai. Yang ini $\mathrm{Bu}$, video ketiga ini $\mathrm{Bu}$. Yang kedua kan lebih banyak tes nya ya Bu. Jadi saya loneat kesini. Nah, in juga beberapa menarik setidaknya relevan dengan tujuan saya. Nah, ini juga, ini bahasa apa ya, tanpa subtitle, tanpa penerjemahan?

$\mathrm{Y}$ : Kalaupun ada ya mungkin ga ngerti Pak.

$\mathrm{X}$ : Maksud saya subtitle tapi bukan dalam bahasa Indonesia. Ini Thailand apa China $\mathrm{Bu}$ ? 
$\mathrm{Y}$ : Thailand.

$\mathrm{X}$ : Selain berkaitan dengan aspek topic, tema, materi, kira-kira kenapa $\mathrm{Bu}$, kok ini ditampilkan?

Y : Saya ingin menampilkan nilainya saja Pak. Nilai yang ada dalam film itu. Jadi fokus tujuan saya yang pertamaadalah menanamkan kepribadian, sense anak. Kalau dengan lagu mungkin nasionalisme yang saya tanamkan. Kalau yang ini ya rasa cintanya kepada orang tua. Ini kan termasuk character building, juga anak-anak punya karakter yang baik sebagai anak. Kenapa video yang ini, dari Thailand? Karena saya dapatnya itu yang sesuai isinya. Kalau bahasa sudah bisa saya eliminir. Yang penting anak-anak dari tampilan videonya sudah menangkap dan itu terbukti. Dan tujuan kedua, ya itu tadi, saya ingin menggali speaking anak-anak, idea anak-anak tentang itu. Kalau seumpama you're in this situation at that time. Kalau saya turuti, anak-anak itu ngomongnya banyak Pak. Semua ngomong. Bahkan kalau yang pinter itu bahkan bisa mencucurkan air mata saking menghayatinya. Film tersebut touching. Dan anak-anak dapat terhibur. Sebenarnya sih mungkin anak-anak lebih bisa mengakses daripada saya. Saya kan cari waktu untuk mengakses. Itu betul-betul harus saya sempatkan. Kalau anak-anak kan anytime. Tapi kan meskkipun mereka anytime kan jarang sekali anak-anak mau mengambil video-video inspirasional seperti itu. Jarang sekali mereka. Paling yang disentuh ya apa, video Korea, atau video apa. Jadi itu Pak.

$\mathrm{Y}$ : Selain kaitannya nanti... maksudnya nanti ada kaitannya dengan materi yang akan saya sampaikan.

$\mathrm{X}$ : Nah ini kan Bu Ana masih saya kaitkan dengan yang sebelah sini, Thailand. Dalam situasi bahasa Inggris digunakan dengan Vietnam, Philippines, dan sebagainya, setidaknya dalam konteks... Atau yang sekarang disebut persiapan masyarakat uni Asia. Nah, ketika misalnya situasi komunikasi semacam ini, ketika Inggris menjadi bahasa pengantar, bahasa pemersatu. Apakah Bu Ana member aspek latar belakang, tradisi, budaya yang berbeda gitu Bu. Kita Javanese, yang disini Thailand, atau Vietnamese English atau yang semacam itu. Kita asumsikan mereka relatif kemampuannya. Hampir sama lah. Kira-kira unsur apa, budaya, tradisi, kebahasaan, yang agak minim. Dan mereka punya kemampuan yang relative lah.

Y : Ya kurang lebih sama. Karena saya juga termasuk jarang berkomunikasi yang gitu. Kok menurut saya tidak jauh berbeda ya Pak, tentang budaya itu. Tentang tingkat kesopanan dalam komunikasi dengan orang lain. Saya juga tidak terlalu, apa ya istilahnya, menggali kepada anak-anak, karena anak-anak sudah tahu bagaimana etikanya kita berkomunikasi. Terus kan di negara lain juga sama. Seperti orang Vietnam. Seperti saya sudah kumpul dengan orang Vietnam selama sepuluh hari. Mereka juga sopan. Kemudian yang saya ceritakan itu. Ketika kita greeting, salaman itu yang saya ceritakan. Terus bagaimana mereka dengan saya, meskipun saya orang baru, tapi mereka menganggap saya ibu. Ada apa-apa ke saya. Nah itu saya tunjukkan ke mereka. Terus kalau yang lain-lain sih menurut saya hamper sama saya rasa. Ya hanya itu tadi, beberapa dialog yang saya tunjukkan, kalau ingin berkomunikasi dengan teman pakai ini, kalau orang tua dengan guru harus pakai yang seperti ini, lebih sopan seperti ini, mesti saya sampaikan.

$X$ : Ada nilai-nilai perbedaan, apa pemahaman tentang tradisi yang berbeda itu tetap disampaikan?

Y : Tetap saya sampaikan. Nah, seperti yang saya tampilkan di video ini kan, saya ingin menyampaikan kepada anak-anak bahwa di luar negeri itu ya sama bahwa anak itu harus taat kepada orang tua, harus menghormati, respek kepada orang tua. Orang tua juga harus melindungi anak, membuat anak itu sukses. Disitu saya ingin menunjukkan sikap, meskipun bukan dengan bahasa saya, dan mereka menyadari, oh ternyata Thailand itu sama ya dengan kita di Indonesia. Ini salah satu pengajaran budaya seperti itu. Dan kita guru memang harus punya waktu untuk itu. Saya itu tahun 2006 itu ikut seminar kedua sebagai pemakalah. Pada waktu itu saya masih di SMP, saya baru diangkat tahun 2005. Baru 
saya disini. Saya dulu di SMP Glantangan, Tempurejo. Saya memang alumni sana. Setelah lulus, langsung ditarik kesana. Dulu kan kepala sekolah pengangkatannya dari Surabaya diangkat di desa. Kalau sekarang nggak ya. Itu kepala sekolahnya dari SMP 32 Surabaya, diangkat di SMP saya. Terus, beliau dulu benar-benar menginspirasi saya sehinggga saya menjadi seperti ini. saya baru ngajar dan langsung ditampani orang yang sudah expert dibidangnya. Sebagai kepala sekolah, beliau senang dengan bahasa Inggris. Jadi rancangan pembelajaran saya dilihat dan saya benar-benar senang. Saya diangkat disana tahun 2000. Kan dulu gitu ya Pak, ada penataran-penataran gitu. Saya mewakili SMP saya. Dulu waktu itu pakai cawu (caturwulan), pernah dengar bapak? Sehingga ketika pembelajaran itu tiga kali akhirnya. Nah, ketika waktu itu workshop di Malang, tiga kali pertemuan, tiga cawu dengan bahasa Indonesia dan Inggris jadi satu. Nah, ada momen symposium seperti ini akhirnya saya ditelepon "Bu Ana, anda diundang ke symposium sebagai pemakalah". Waduh, saya membuat makalah? Tahun 2006 waktu itu.

$\mathrm{X}$ : Masih guru SMP ya?

$\mathrm{Y}$ : Iya, masih guru SMP. Akhirnya saya membuat makalah temanya permainan. Setelah itu berangkat kita bareng-bareng naik bus. Mungkin kalau sekarang pakai pesawat ya Pak. Dulu kumpul di Jawa Timur dulu, naik bus orang 24, berangkat jam 2 siang. Sampai di Pulogadung jam 6 pagi, terus menuju ke Depok jam 11, saya ingat. Kaki saya sampe bengkak. Pulangnya juga naik bus. Saya presentasi disana, padahal kemarin jadi participant, tahun 2000 jadi penyaji. Tapi beda, kalau kemarin itu di Istora, kalau dulu di (61.13). Nah Alhamdulillah juga waktu itu Jawa Timur punya majalah Gentengkali Pak Majalah edukasi.

$\mathrm{X}$ : Dari Diknas provinsi?

$\mathrm{Y}$ : Iya, makalah saya dimuat disitu. Sampai sekarang saya simpan.

$\mathrm{X}$ : Untuk kenang-kenangan?

Y : Iya. Sampe mana tadi kok nyampe sini. Pak Iwan ini daritadi saya terus yang dikorek-koreki. Pokoknya nanti saya juga harus dapat banyak ilmu dari Pak Iwan. Jadi ini untuk perbaikan saya. Untuk inovasi pembelajaran. Kemarin itu temanya "Guru Mulia Karena Karya", kayaknya. Ya itu, jadi saya pindah tahun 2005, saya disini. Setelah itu ya sudah, saya kan selalu "kecelakaan" terus.

$\mathrm{X}$ : Selalu mengalir ya?

$\mathrm{Y}: \ldots$ [truncated] 